\title{
La tradición surandina del desierto: Etnobotánica del área del Salar de Atacama (Provincia de El Loa, Región de Antofagasta, Chile) ${ }^{1}$
}

\author{
Carolina Villagrán*, Victoria Castro**, Gilberto Sánchez ${ }^{* * *}$, Marcela Romo**, \\ Claudio Latorre** y Luis Felipe Hinojosa**
}

\section{RESUMEN}

El área del Salar de Atacama, Provincia de El Loa, segunda Región de Antofagasta del norte de Chile, es una de las más secas del mundo, correspondiendo al área de máxima penetración del Desierto de Atacama en la costa Pacífica de Sudamérica. En efecto, y en concordancia con la disminución de las lluvias en sentido NW-SE, desde los Andes de Arica $\left(18^{\circ} \mathrm{S}\right)$, hacia los de Antofagasta $\left(24^{\circ} \mathrm{S}\right)$, se observa que la vegetación se retrae paulatinamente hacia mayores altitudes. Así, extensas áreas al interior de la ciudad de Calama, representadas por el Salar de Atacama, Cordillera de Domeyko y sectores bajos de la vertiente occidental andina corresponden a desiertos 'absolutos', con valores de coberturas de plantas vasculares prácticamente nulos. La hiperaridez de la región es interrumpida por oasis, como San Pedro de Atacama y Toconao, y algunas quebradas que cuentan con agua permanente, hábitats que permiten el desarrollo de agricultura en el sector. Así, y a pesar de la extremada aridez y aislamiento, subsisten en la región poblaciones con tradición atacameña que han desarrollado un acabado conocimiento y uso de los precarios recursos bióticos del desierto. El objetivo de este trabajo es acceder al conocimien-

\section{Proyecto FONDECYT 1970908}

Laboratorio de Palinología, Departamento de Biología, Facultad de Ciencias, Universidad de Chile, Casilla 653, Santiago, Chile. E-mail: cvillagr@abello.dic.uchile.cl. Departamento de Antropología, Facultad de Ciencias Sociales, Universidad de Chile, Casilla 10115, Santiago, Chile. E- Mail: vcastro@abello.dic.uchile.cl. Departamento de Lingüística, Facultad de Filosofía, Universidad de Chile, Santiago, Chile. E- Mail : gsanchez@abello.dic.uchile.cl to de las plantas en los territorios de estas culturas y definir sus singularidades etnobotánicas, en correspondencia con su situación tan especial dentro de los Andes del norte de Chile. Con este propósito, se realizó una recolección exhaustiva de la flora del área y un muestreo sistemático de la vegetación, este último siguiendo un transecto altitudinal desde el Salar de Atacama $(2.700 \mathrm{~m})$ hasta el Salar de Aguas Calientes (4.500 m). Posteriormente, se entrevistaron 38 personas provenientes de San Pedro de Atacama, Toconao, Talabre, Camar, Socaire y Peine.

Para las 173 especies de plantas consultadas se registraron 416 nombres vernaculares, correspondiendo la mayor proporción al español (53\%) o una combinación indígena-español (12\%). Entre los nombres indígenas destacan los provenientes de los idiomas atacameño o kunza (8\%), quichua $(5 \%)$, aymara (2\%) o una combinación de estas tres lenguas (16\%). Un rasgo interesante es la existencia de nombres múltiples, y en varias lenguas, para una cierta cantidad de especies, probablemente una expresión del multilingüismo que caracteriza a la región. Se ha registrado también diferenciación de nombres de plantas dentro del área de estudio, existiendo un conjunto de nombres vernaculares de plantas restringidos al sector sur del Salar de Atacama, específicamente a las localidades de Peine, Socaire y Camar. Estos nombres son definidos por algunos informantes como correspondientes a las denominaciones antiguas de las plantas ("nombres que daban los abuelos") y pertenecerían al idioma atacameño o kunza. En lo que se refiere a la etnoclasificación de las plantas, 
y tal como ha sido documentado en otros estudios etnobotánicos andinos, la denominación de las especies, y la distinción de grupos de especies, se basa principalmente en el contraste de características morfo-fisionómicas. Entre las clases de agrupaciones de plantas registradas, categorías etnogenéricas, destacan las construidas sobre la base de formas de crecimiento (agrupaciones de formas de vida); por parecido morfológico general (agrupaciones "taxonómicas"); por comparación con otras plantas importantes o útiles (agrupaciones en torno a un referente); por similitud de algún atributo morfológico, terapéutico, alimenticio, $u$ otros (agrupaciones por similitud en alguna propiedad). En los Andes del norte de Chile, las dos últimas clases de agrupaciones son exclusivas de la región del Salar de Atacama.

De las 173 especies consultadas en Atacama, 165 tenían uno o más usos $(94,8 \%)$, distribuyéndose los distintos tipos de usos en las siguientes 10 clases principales: Forrajero, 35\%; Medicinal, 24\%; Alimenticio, 9\%; Combustible y Leña, 6\%; Construcción y Artesanías, 6\%; Adorno, 5\%; Tintóreo, 4\%; Perjudicial, 3\%; Ritual, 2\%, y Otros usos variados, $6 \%$. Generalmente, las especies tienen de uno a tres usos aunque, para varias especies, se registraron usos múltiples (e.g. la chillka, con siete usos; el algarrobo, con seis). La utilidad de la flora de los distintos pisos de vegetación muestra las siguientes tendencias: El Piso Altoandino es predominantemente forrajero (52\%) y los Pisos Puneño y Prepuneño son principalmente forrajero (Puneño, 31\%; Prepuneño, 44\%) y medicinal (Puneño, 25\%; Prepuneño, 13\%). También, en ambos pisos, las especies de plantas tintóreas y alimenticias son más abundantes que en el resto de la vegetación del área. La flora azonal de las quebradas, riberas de ríos, salares y chacras muestra un uso más diversificado, hecho que corresponde a la heterogeneidad vegetacional que caracteriza estas formaciones.

Se discuten los resultados etnobotánicos en el contexto de la cosmovisión, percepción ambiental, control de recursos naturales y transformaciones, por parte de las comunidades estudiadas.

\section{ABSTRACT}

The Atacama salt flat, or salar, lies in northern Chile's second region of Antofagasta, and is one of the driest areas in the world as it corresponds to the maximum penetration of the Atacama Desert into the interior from the Pacific coast. This is observed as well in the vegetation gradient which retreats to greater altitudes following the precipitation gradient that decreases from the NW towards the SE, from the Andes of Arica $\left(18^{\circ} \mathrm{S}\right)$ to the Andes of Antofagasta $\left(24^{\circ} \mathrm{S}\right)$. Absolute desert, areas with practically no plant vascular plants, occurs near the city of Calama to the interior, such as the Salar de Atacama, the Domeyko cordillera or other low lying piedmont regions of the western slope of the Andes. This hyperaridity is interrupted by only a few oases such as San Pedro de Atacama and Toconao, and a few ravines supplied with flowing water on a permanent basis that allow for agriculture to be sustained on a regular basis. Despite these factors, the few atacameño traditional communities that subsist in the area have developed a thorough knowledge and use of the biotic resources present in the desert. Our objective in this paper was to access the plant knowledge of these cultures as well as defining their ethnobotanical uniqueness, particularly when seen from their special viewpoint within the Andes of northern Chile. With this goal we set out to exhaustively collect the flora of the area as well as working on systematic surveys of the vegetation through an altitudinal transect from the Salar de Atacama (2.700 m) to the Salar de Aguas Calientes $(4.500 \mathrm{~m})$. We also obtained 38 interviews from the inhabitants of San Pedro de Atacama, Toconao, Talabre, Camar, Socaire and Peine.

For the 173 species of plants consulted in these interviews, we registered 416 common names, with the largest proportion of these originating from spanish (53\%) or a native-spanish combination $(12 \%)$. Among those pure native names encountered, these have their origins in atacameño or kunza $(8 \%)$, quichua $(5 \%)$, aymara $(2 \%)$ or a combination of these three languages $(16 \%)$. One interesting feature is the existence of multiple names in several languages for certain species, possibly an expression of the many languages present in the region. Name differentiation within the study area was also observed, with a set of common names restricted to a certain locality, such as Peine, Socaire and Camar. These names were described by a few informants as originating from "ancient" names ("names used by our grandfa- 
thers") and correspond to the atacameño or kunza languages. Regarding plant ethnoclassification, the naming of different species as well as differences between groups of species is based primarily on contrasting morpho-phisionomical traits, as documented in other Andean ethnobotany studies. Among the different classes of groups of plants recorded (ethnogeneric categories), the most prominent are those based on different growth forms (life form groups); morphological similarity ("taxonomic" groups); comparisons to different other important or useful plants (reference groups); or by a common attribute such as morphology, therapeutic value, food, etc. (groups with shared properties). These last two groups are unique to the Salar de Atacama region within northern Chile.

Of the 173 species consulted in Atacama, 165 had one or more uses $(94.8 \%)$, with the different types of uses distributed in 10 main classes: Fodder $35 \%$, Medicinal 24\%, Alimentary 9\%, Fuel and Wood $6 \%$, Building and Crafts 6\%, Decoration 5\%, Dyes $4 \%$, Harmful 3\%, Ceremonial 2\%, Other uses $6 \%$. On average, species had from one to three uses although some species had truly multiple uses (e.g. the chilka, with seven uses and the algarrobo with six). Also, the uses of the flora from different vegetation belts showed certain tendencies. The High Andean belt was predominantly for fodder (52\%) while the Puneño and Prepuneño belts were primarily fodder (Puneño 31\%, Prepuneño 44\%) and medicinal (Puneño 25\%, Prepuneño 13\%) in use. Higher numbers of plants are used as dyes and food in these latter two belts as compared to vegetation from other areas. The azonal flora from ravines, river floodplains, salars, and fields has a more diverse use, observation that coincides with a more heterogeneous vegetation that is present in these areas.

We discuss these ethnobotanical results in the light of the cosmovision, environment perception, control and transformation of natural resources on behalf of the communities studied.

\section{Introducción}

El Desierto de Atacama se extiende desde el norte del Perú $\left(5^{\circ} \mathrm{S}\right)$, a lo largo de la costa Pacífica y vertiente occidental de los Andes, hasta la ciudad de Copiapó en territorio chileno $\left(27^{\circ} \mathrm{S}\right)$, siendo uno de los más secos del mundo (Borgel, 1973; Caviedes, 1973; Mortimer, 1980). La escasez de precipitaciones en la región determina la ausencia total de procesos erosivos significativos y la mantención de uno de los relieves más extraordinarios del mundo: en menos de 300 kilómetros existen casi $15000 \mathrm{~m}$ de desnivel entre la fosa Chileno-Peruana de Atacama (-8066 m) y la cumbre del Volcán Llullaillaco (6723 m), en la Cordillera de los Andes (Abele, 1988).

Dentro del área ocupada por el Desierto de Atacama, la región administrativa de Chile conocida como Región de Antofagasta, entre $22^{\circ}$ y $26^{\circ} \mathrm{S}$, corresponde a la de máxima penetración de la aridez hacia el interior del continente sudamericano, conformando un desierto "absoluto" en gran parte de su superficie, donde los valores de las coberturas de plantas vasculares son prácticamente nulas (Villagrán et al., 1981; Villagrán et al., 1983). La extremada aridez ha permitido la preservación de vastas extensiones de ignimbritas volcánicas, formadas en el Mio-Plioceno, a lo largo de gran parte de la región, interrumpidas por quebradas profundas y por serranías locales de rocas Paleozoicas y Mesozoicas (Cordillera de Domeyko y Serranías frontales con alturas promedio entre 3500 a $4000 \mathrm{~m}$ ) y por grandes cuencas endorreicas intermontanas, como el Salar de Atacama y el Salar de Punta Negra (Abele, 1988; Marinovic \& Lahsen, 1984). Los domos volcánicos y estratovolcanes, cuyas edades van desde el Plioceno hasta el Holoceno, constituyen las cimas más altas de la Cordillera de los Andes, donde gran parte de ellas sobrepasan los $5500 \mathrm{~m}$ en altura (Marinovic \& Lahsen, 1984).

El origen de la aridez en la región de Atacama se remonta al Eoceno, intensificándose a partir del Mioceno medio. Las condiciones desérticas actuales obedecen a dos causas principales: 1) la baja capacidad de aporte de humedad desde el Océano Pacífico, debido a la presencia permanente de la corriente fría de Humboldt y del Anticiclón Subtropical del Pacífico Sur; 2) el efecto de sombra de lluvia que ejerce la Cordillera de los Andes hacia el oeste, bloqueando las masas de aire húmedo que vienen de la Cuenca del Amazonas (Albers \& Brimhall, 1988; Ericksen, 1983; Mortimer, 1973). Esta hiperaridez ha sido inte- 
rrumpida por fases pluviales que tuvieron importantes efectos en los regímenes climáticovegetacionales de las regiones altoandinas durante el Pleistoceno y Holoceno (Grosjean, 1994; Grosjean \& Núñez, 1994; Messerli et al., 1997; Seltzer, 1990).

El clima de los Andes desérticos se caracteriza por precipitaciones escasas, en aumento con la altitud, debido a la predominancia de las tormentas convectivas estivales generadas sobre el Altiplano (entre 4.000 a $5.000 \mathrm{~m}$ ). Este fenómeno es conocido localmente como "invierno boliviano" y capta humedad desde la Cuenca del Amazonas (Caviedes, 1973). En términos altitudinales generales para los Andes desérticos de Chile, entre 2.000-3.000 $\mathrm{m}$ se recibe en promedio entre $<10 \mathrm{a}$ $50 \mathrm{~mm} / \mathrm{año}$ de precipitaciones; entre los 3.000$4.000 \mathrm{~m}$ aumenta a $50-150 \mathrm{~mm} / \mathrm{año}$ y sobre los $4.000 \mathrm{~m}$ las precipitaciones son $200 \mathrm{~mm} / \mathrm{año}$ (Van Husen, 1967; Arroyo et al., 1988; Villagrán et al., $1983)$. Desde Arica ( $\left.18^{\circ} \mathrm{S}\right)$ hacia Antofagasta $\left(24^{\circ} \mathrm{S}\right)$, el desierto absoluto penetra paulatinamente, desde el NW hacia el SE, principalmente en función de la disminución de la precipitación media anual en el mismo sentido $y$, concomitantemente, los pisos de vegetación andina se retraen paulatinamente hacia mayores altitudes (Villagrán et al., 1983; Arroyo et al., 1988). La distribución de la riqueza de la flora y la cobertura vegetal versus la altitud es también característica para los Andes desérticos, con valores mínimos en los extremos inferior/superior y valores máximos en el piso intermedio (Tolar), debido a la conjugación de los dos factores ambientales estresantes para la vegetación: hiperaridez en altitudes bajas y temperaturas frígidas en las altas (Villagrán et al., 1983; Arroyo et al., 1988).

El área de este estudio, la Provincia de El Loa de la Región de Antofagasta, representa así la zona más seca, de más escasa cobertura vegetal y con la biota más pauperizada del Desierto de Atacama chileno-peruano. Geográficamente, esta área corresponde al interior de la ciudad de Calama, cuenca del río Loa y al Salar de Atacama, representando en parte a las vertientes oriental y occidental de la Cordillera de Domeyko y a la vertiente occidental de la Cordillera de los Andes. A pesar de estas dramáticas condiciones de vida, en la Pro- vincia de El Loa viven numerosas comunidades de población originaria, descendientes de los pueblos precolombinos. Sus asentamientos se extienden desde las nacientes del río Loa $\left(21^{\circ} 15^{\prime} \mathrm{S}\right)$, por el norte, hasta el extremo sur del Salar de Atacama $\left(24^{\circ} 15^{\prime} \mathrm{S}\right)$, ocupando una estrecha franja precordillerana y cordillerana entre aproximadamente los 2.500 y $4.400 \mathrm{msnm}$. De norte a sur, en la cuenca superior del río Loa, se ubican los poblados de Amincha, Buenaventura, Puquios, Estación San Pedro y Conchi Viejo, todos situados a partir de los $3.000 \mathrm{~m}$ de altitud, aproximadamente. En el curso medio del Loa están Lasana y Chiuchiu, cercanos a los $2.500 \mathrm{~m}$ de altura. En la cuenca del río Salado, afluente del Loa, se hallan Toconce, Caspana, Cupo y Aiquina, entre los 3.000 y 3.600 m de altitud; al sur del río Loa, en la cuenca del Salar de Atacama, encontramos los pueblos y caseríos de Río Grande, Machuca, San Pedro de Atacama y sus ayllus, Toconao, Camar, Talabre, Socaire y Peine, ubicados entre 2.400 y $3.600 \mathrm{~m}$ de altitud. En los últimos seis poblados se desarrolló este estudio.

El actual patrón de asentamiento es de tipo disperso, articulándose en torno a un núcleo aldeano central del cual dependen varios sectores menores, tanto agrícolas como ganaderos. Para las labores pastoriles se utilizan las estancias, situadas por lo general en pisos ecológicos más altos, distantes a uno o dos días a pie del poblado o entre sí y ocupadas por períodos de tiempo irregulares (desde unos días hasta varios meses), de acuerdo a la abundancia de los pastos o las tareas agrícolas que haya que realizar. Unicamente las aldeas presentan un cierto grado de nucleamiento, en tanto que lo característico de la estancia es su dispersión. Los poblados están vinculados fundamentalmente a actividades sociales y agrícolas, mientras que las estancias lo están al pastoreo y/o la agricultura. Además, hay espacios de ocupación más transitoria, dedicados a la recolección y la integración a la economía de mercado, lo que motiva viajes a los centros urbanos, esencialmente Calama y San Pedro de Atacama, con estadías prolongadas allí cuando la inserción es más fuerte o directa. Todo lo anterior implica la ocupación de un espacio productivo muy disperso y amplio. Esto exige de cada unidad doméstica una alta movilidad y una división sexual y por edades del trabajo. 
Considerando la larga y singular historia de permanencia de poblaciones humanas en el área en torno al Salar de Atacama, su aislamiento y precariedad debido a la extrema rigurosidad climática y paupérrima biota, nos hemos propuesto en este estudio investigar las singularidades del conocimiento etnobotánico de la flora silvestre y la percepción del paisaje, fuentes de las cuales extraen estas comunidades sus modos y recursos de subsistencia y las categorías para producir una significación.

\section{Areas de estudio y metodologías}

\subsection{Flora y vegetación del área de estudio}

En la Figura 1 se muestra el área de estudio abarcada por el estudio etnobotánico, coordenadas geográficas, los grandes sectores geomorfológicos y el transcurso del transecto altitudinal a lo largo del cual se coleccionó la flora y se muestreó la vegetación. Con el propósito de conocer la composición de la flora, la fisionomía y cobertura de la vegetación y las distribuciones de las principales asociaciones florísticas del área andina en torno al Salar de Atacama, se realizó un transecto a lo largo de un trayecto altitudinal desde el Salar de Atacama (2316'30"S; $67^{\circ} 58^{\prime} 24^{\prime \prime} \mathrm{W} ; 2.700 \mathrm{~m}$ ), siguiendo el camino internacional hacia el Paso de Guaitiquina y pasando por Talabre y Laguna Lejía, hasta el Salar de Aguas Calientes $\left(23^{\circ} 29^{\prime} 54^{\prime \prime} \mathrm{S} ; 6^{\circ} 43^{\prime} 06^{\prime \prime} \mathrm{W} ; 4.500 \mathrm{~m}\right)$. En la Figura 1 se muestra el itinerario del transecto y también las localidades en las cuales se realizaron las entrevistas etnobotánicas: el oasis San Pedro de Atacama, Talabre y Socaire, en la Precordillera; Toconao, Camar y Peine, situadas en quebradas junto al margen desértico del Salar de Atacama.

La primera etapa de trabajo de campo consistió en una recolección exhaustiva de la flora zonal y azonal del área y de un muestreo sistemático de la vegetación. Ambas actividades fueron realizadas durante las dos primeras semanas de abril de 1998. Todos los taxa fueron herborizados en triplicado y numerados, a lo largo del transecto altitudinal mencionado (Fig. 1) y de acuerdo con las metodología convencionales en la elaboración de colecciones sistemáticas. La flora azonal fue herborizada en el Salar de Atacama (trayecto San Pedro-Toconao) y en las quebradas, riberas de ríos y chacras de los poblados de Toconao, Talabre, Camar, Socaire, Peine, además del oasis de Tilomonte. Los números de herbario se citan para cada especie en el Anexo 1 y los ejemplares quedan depositados en el Herbario de Carolina Villagrán (Facultad de Ciencias de la Universidad de Chile), con duplicados en el Herbario de la Universidad de Concepción. Las especies fueron determinadas en el Herbario de la Universidad de Concepción, con la colaboración de los Profesores Clodomiro Marticorena y Oscar Matthei. El muestreo de la vegetación se realizó a lo largo del transecto mencionado y sobre la base de 21 parcelas de $16 \mathrm{~m}^{2}$ de superficie, con una réplica cada una (Mueller-Dombois \& Ellenberg, 1974), distribuidas regularmente cada $100 \mathrm{~m}$ de altitud en el gradiente. En cada parcela se consideró la exposición de ladera, pendiente, altitud, tipo de substrato y todos los taxa presentes. Para cada parcela se calculó la cobertura de todos los taxa leñosos y semileñosos, y la cobertura general de la vegetación, sobre la base de mediciones directas de 2 diámetros y la altura de cada individuo. La frecuencia de hierbas fue calculada en las mismas parcelas anteriores, sobre la base de transectos de $4 \mathrm{~m}$ de longitud (con réplica) en los cuales se registró cada $10 \mathrm{~cm}$ la presencia-ausencia de taxa herbáceos. Los resultados se muestran en la Figura 2 [gráfico Tilia] que muestra las tendencias altitudinales de las distribuciones de coberturas de cada taxa a lo largo de la gradiente estudiada, además de las delimitaciones de los pisos de vegetación a través de un análisis de conjuntos (CONISS).

La vegetación zonal de los Andes del norte de Chile ha sido tradicionalmente dividida en cuatro pisos altitudinales de vegetación: el piso Prepuneño o desértico, caracterizado por una vegetación de arbustos de muy escasa cobertura; el piso Puneño o Tolar, semidesierto, caracterizado por la dominancia de arbustos o tolas; el piso Altoandino o Pajonal, con fisionomía esteparia y dominado por Gramíneas en champas y plantas en cojines; y el piso Subnival, con coberturas muy ralas de pequeñas hierbas en rosetas y cojines, que se extiende hasta el límite superior de las plantas (Villagrán et al., 1981; 1983). Esta misma nomenclatura se ha seguido en la definición de los pisos de vegetación del área de estudio, a saber: 
Piso Prepuneño o desértico (Fig. 2), comienza a los $2.600 \mathrm{~m}$ y se extiende hasta los $3.400 \mathrm{~m}$; se caracteriza por coberturas muy bajas $(<10 \%)$ y es el piso con menor diversidad. Las plantas típicas son los arbustos deciduos tikara, monte verde o monte negro (Ambrosia artemisioides, Compuesta) y ojalar, chókel o chókil (Atriplex imbricata, Quenopodiácea); En quebraditas secas, también son frecuentes: la tikara hembra o chakachacka (Krameria lappacea, Krameriácea), la rikarika, kore o kori (Acantholippia deserticola, Verbenácea), la iloka o ilúkar (Adesmia atacamensis, Papilionácea), el tomatillo (Lycopersicon chilense, Solanácea) y la Malvácea primavera o malva blanca (Tarasa operculata), además de diferentes especies suculentas del género Cistanthe (basal, kámen o kámin, Portulacáceas). A partir de los $2.900 \mathrm{~m}$ dominan el paisaje las Cactáceas del género Opuntia, típicamente Opuntia camachoi, el kume.

Piso Puneño o Tolar (Fig. 2), que va desde los 3.400 hasta los 3.800-4.000 m. Es la zona más diversa en especies arbustivas y con mayores coberturas (hasta 30\%). Son importantes los arbustos representantes de las Compuestas como la tolilla o chíjua, la likia o lejía, y (Baccharis boliviensis, Baccharis tola); Solanáceas como el monte negro o tara y la tolilla o tara hembra (Fabiana ramulosa y $F$. denudata.); Fabáceas como la añawa blanca y el konti o konte (Adesmia erinacea y Lupinus oreophilus) y Verbenáceas como la lampaya y la perlilla o roseta (Lampaya medicinalis y Junellia seriphioides). En ciertos sectores el pingopingo, Ephedra breana, es importante, además del tajtará o quebrolla, Chuquiraga atacamensis. El recambio principal de las asociaciones florísticas en esta zona se produce entre los 3.800 y los $4.000 \mathrm{~m}$ de altitud, zona de transición entre el tolar y el pajonal, con las máximas coberturas vegetales y presencia característica y abundante de dos nuevos arbustos, la chacha, chacha hembra o chachakoa (Parastrephia quandrangularis, Compuesta) y la añawa negra (Adesmia spinosissima, Fabácea).

Piso Altoandino o Pajonal (Fig. 2), cuyo comienzo oscila entre los 3.900-4.000 m y termina donde cesa la dominancia de la estepa de Gramíneas, a los 4.350; en laderas y planicies de arena y grava, la vegetación es dominada por cojines (e.g. Mulinum crassifolium, chuchikan; Pycnophyllum bryoides, llaretilla; Urbania pappigera, cuernillo; Nototriche estipulata, altea; Adesmia subterranea, cuerno), hierbas perennes como los maranseles (Perezia atacamensis y Werneria glaberrima) y, sobretodo, por Gramíneas tales como Stipa chrysophylla (paja blanda), Nasella nardoides (chuku o pajita chica), además del iru, iro o paja brava (Festuca chrysophylla). Asociaciones con subarbustos de la familia Compuestas, como las diversas especies del género Senecio (romerillos y chachakomas) y los cojincitos de pupusa (Xenophyllum incisum) abundan en las laderas y quebradas rocosas. Sobre $4.350 \mathrm{~m}$ se extiende el Piso Subnival, con cobertura muy rala de la Gramínea Deyeuxia cabrerae (paja sikuya), cojines de Junellia digitata (altea) y las diminutas hierbas de keúche, (Lenzia chamaepitys y Chaetanthera revoluta). El límite superior de las plantas se sitúa por sobre $4.500 \mathrm{~m}$ de altitud.

Vegetación azonal de salares, quebradas y chacras. Los salares están interrumpidos por fértiles oasis, como San Pedro de Atacama y Toconao, con grandes extensiones de árboles como tamarugos (Prosopis tamarugo), algarrobos (Prosopis alba) y chañares (Geoffroea decorticans); arbustos como el kachiyuyo o kórial (Atriplex madariagae) y una densa cobertura de grama o gramillo en el suelo (especies de Distichlis). A su vez, las quebradas aledañas a los poblados cuentan con agua permanente permitiendo el crecimiendo de numerosas especies de algas verdes acuáticas, llamadas colectivamente lama, lako o loroma (e.g. especies de Oedogonium, Chara, Prasiola); especies palustres, como los unquillos o junquillos (Juncus arcticus) y la cortadera (Cortaderia speciosa), y especies suculentas de halófitas, como la walkawalka (Sarcocornia fruticosa). La humedad también ha permitido el desarrollo de la agricultura en el sector. Tal es el caso de las quebradas de Jérez, Peine y Tilomonte donde, aparte de los cultivos, se encuentra un gran numero de malezas que también son muy útiles como medicina o alimentos; tal es el caso del lokoche (Hypochaeris sp.), la enredadera o correhuela (Convolvulus arvensis) y el llantén (Plantago lanceolata). 


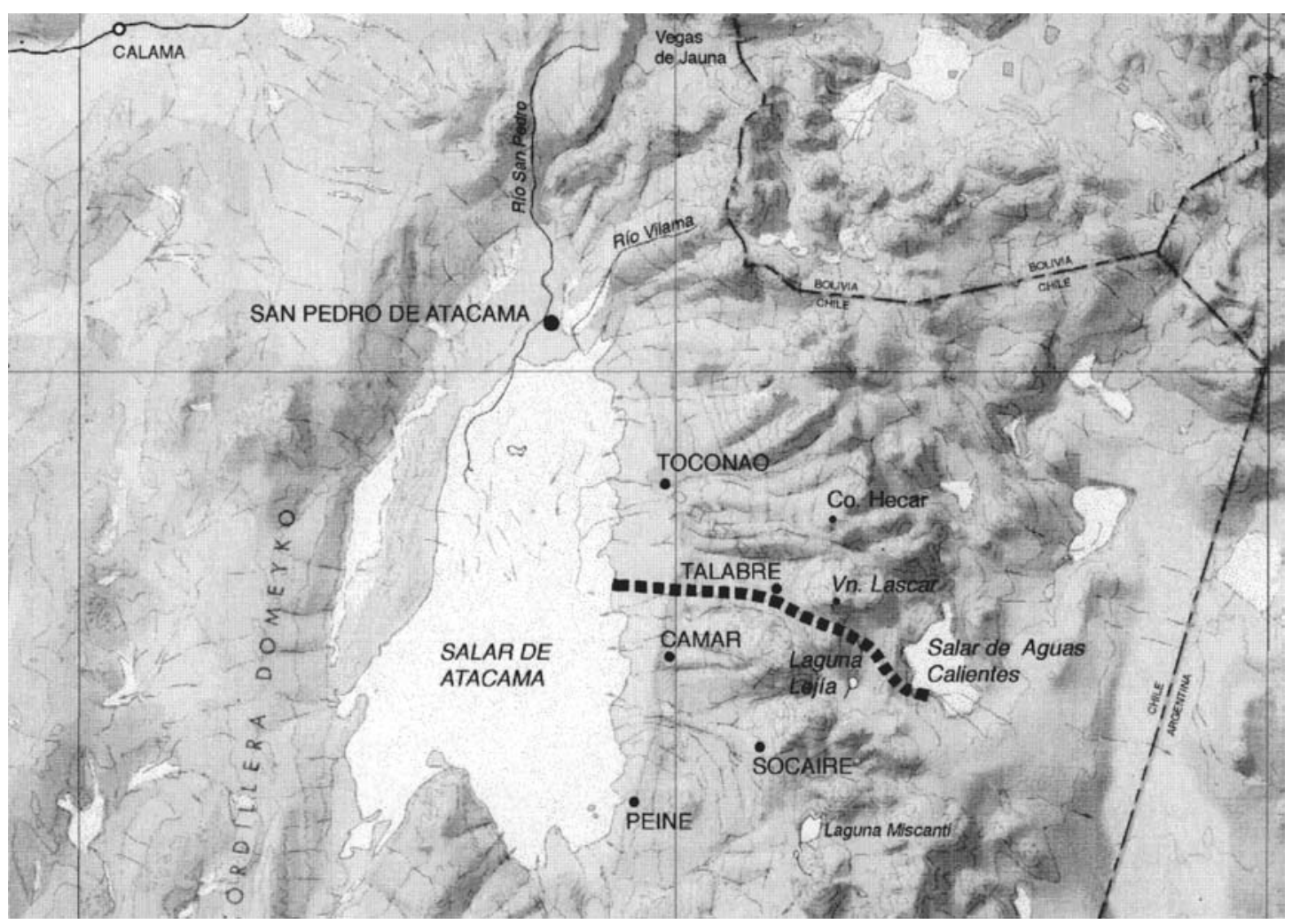

Figura 1: Región de estudio mostrando el Salar de Atacama, la trayectoria del transecto para el muestreo altitudinal de la vegetación y los poblados en que se realizaron las entrevistas etnobotánicas.

\subsection{Las comunidades del área de estudio (Figura 1)}

\section{San Pedro de Atacama}

Es un oasis de pie de puna, situado a una altura de $2.436 \mathrm{~m}$ y cercano a la confluencia de los ríos Atacama y Vilama. Desde tiempos coloniales fue un centro de tráfico y engorde de ganado, con población mayoritariamente indígena, pero también de administración española. A principios del siglo veinte, el poblado ya contaba con servicios públicos, como correo, telégrafo, registro civil, escuelas públicas y aduana. Los problemas sufridos por este pueblo, cabecera del Salar de Atacama, han sido diversos a través de su historia y, en conjunto, han contribuido a un fuerte proceso de cambio que ha sido más acelerado que en ninguna comunidad del área. Hacia mediados de la década de los 60, la mayoría de agricultura se realizaba en planos, variando los terrenos entre $10 \mathrm{~m}^{2}$ a más de una hectárea; ya entonces la gente percibía la paulatina merma del recurso hídrico (Aranda, 1961-
64; Field, 1966; Castro, 1987), problema que se ha acelerado en las últimas décadas. De modo que, si bien en sus ayllus se mantiene un modo de vida de énfasis agropastoril (Gundermann \& González, 1995), el curso de los cambios muestra una fuerte tendencia a constituirla en un área urbana, al servicio del turismo nacional e internacional masivo. Sin embargo, esto no significa la ausencia de ciclos diversos de revitalización, como por ejemplo, la artesanía textil, actividad que abarca una comercialización masiva a nivel local y nacional y la participación de artesanos de otras comunidades del Salar de Atacama.

\section{Toconao}

El poblado de Toconao se sitúa $38 \mathrm{~km}$ al sureste de San Pedro, en el borde oriental del Salar de Atacama. Su particular microclima lo convierte en un vergel en medio del desierto, siendo famoso por sus bosques de algarrobos y chañares, además de la producción frutera de membrillos, paltas, damascos, peras, manzanas, uvas, ciruelas, 


\begin{tabular}{|l|l|l|}
\hline ARBUSTOS, SUBARBUSTOS Y SUCULENTAS & PAJAS & COJINES \\
\hline
\end{tabular}

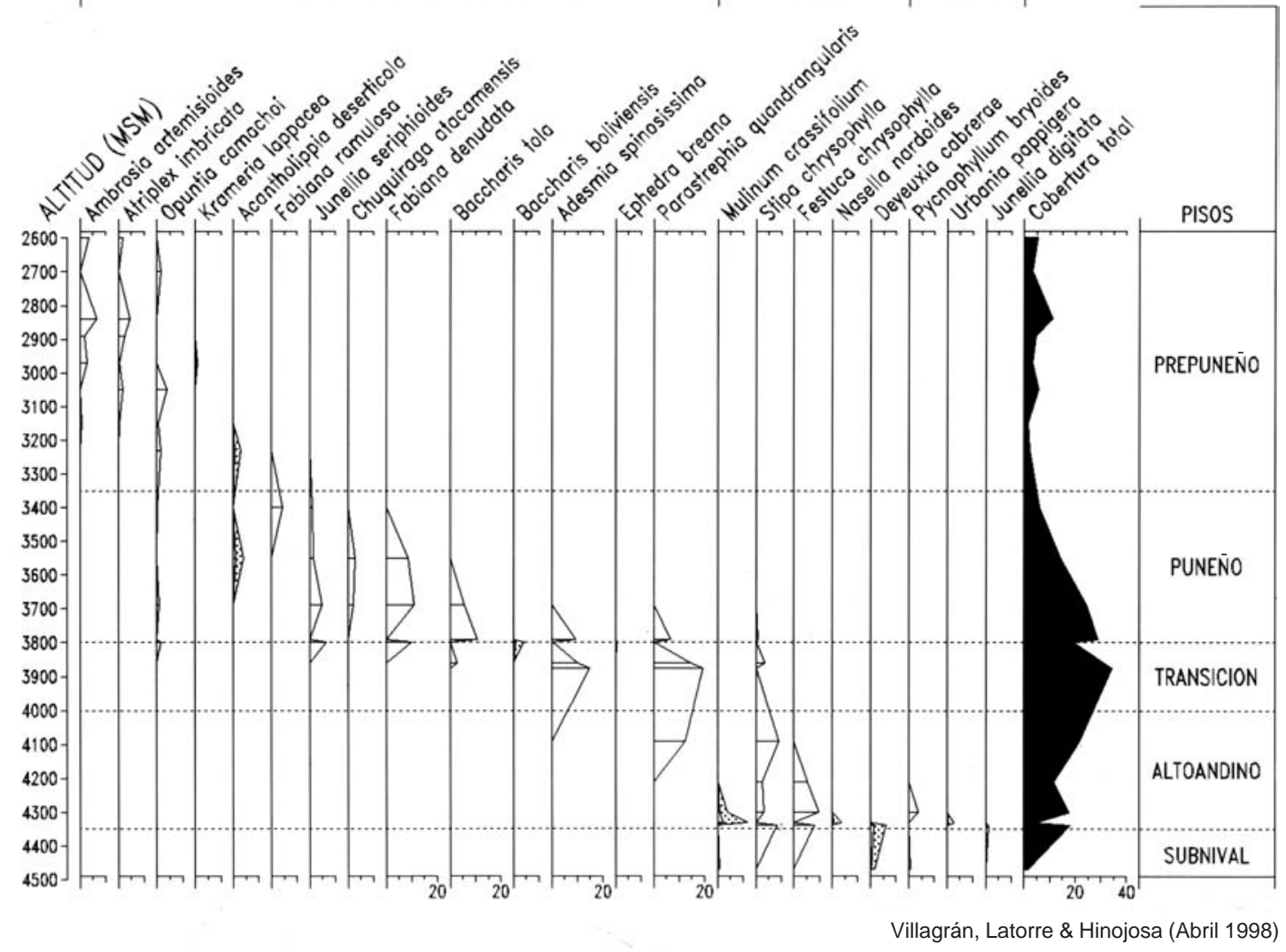

Figura 2: Distribución altitudinal de coberturas vegetales (\%) en un transecto Salar de AtacamaTalabre-Laguna Lejía y Salar Aguas Calientes, Región de Antofagasta, Chile.

granadas, higos y pasas. El área de cultivos se emplaza en las vertientes de las quebradas donde hay agua en abundancia (e.g. Quebrada Jerez); la irrigación es facilitada por la construcción de terrazas en suave pendiente, donde el terreno lo permite. Hay énfasis en el cultivo del maíz, pero también se cultivan papas, zanahorias, ajos, rábanos, perejil y claveles dobles, siendo este último un producto valioso para su comercialización en el mercado urbano (Castro, 1987). La ganadería en Toconao privilegia la masa de ovinos por sobre el $50 \%$, seguido por el ganado de camélido, caprinos, equinos y porcinos en mucho menor proporción; con todo, su masa pecuaria representaría el 14,5\% del total existente en la cuenca del Salar de Atacama (Gundermann \& González, 1995).

\section{Talabre}

Talabre se localiza en el Piso Puneño de Tolar, al este del Salar de Atacama y a unos $3.500 \mathrm{~m}$ de altitud, cercano a la quebrada del mismo nombre; se emplaza a los pies del volcán Lascar, aproximadamente a 80 kilómetros de San Pedro de Atacama. Situado en la hoya hidrográfica del Salar de Atacama, el río Talabre comienza en la vega de Saltar, es afluente del Soncor y conforma una quebrada con dirección E-O. La ubicación actual del poblado, en un sector denominado campo azul por los talabreños, data de 1982. El traslado de la población, desde su ubicación original quebrada arriba, fue una consecuencia de la actividad del volcán Lascar. En tiempos de la colonia esta comunidad dependía administrativamente de Toconao, 
pueblo con el que mantiene relaciones hasta la actualidad. También existen relaciones de intercambio y parentesco con los poblados de Camar, Socaire y Peine y con el noroeste argentino. Talabre tiene una población estimada de 54 habitantes, según el Censo de 1992, agrupados en trece unidades familiares; a éstas se deben agregar cerca de nueve familias que, aunque se encuentran en localidades vecinas como Peine, Toconao, Camar e incluso San Pedro y Calama, mantienen ganado y pastos en mediería, reafirmando fuertes nexos en el ámbito de la herencia. La cantidad actual de viviendas habitadas en el poblado es de 13 , siendo construcciones con un patrón concentrado en forma de villorrio; en sus inmediaciones se encuentran terrazas de cultivos. La principal actividad económica es el pastoreo y la textilería para el comercio, en tanto que la agricultura es de subsistencia (Morales, 1997).

\section{Camar}

Camar se sitúa a $2.770 \mathrm{~m}$ de altitud, 72 kilómetros al sudeste de San Pedro, entre dos quebradas y frente al Salar de Atacama. Junto con Talabre, Camar se visualiza como una sociedad más conservadora, con una actividad agrícola de subsistencia y alta movilidad para el manejo ganadero.

\section{Socaire}

Al sudeste de Talabre, también en el Piso Puneño de Tolar, a unos $3.600 \mathrm{~m}$ de altura y junto al cerro Miscanti y laguna del mismo nombre, se sitúa Socaire. Su población tiene hasta hoy una movilidad mayor que la de los lugareños de los oasis prepuneños, similar a otros pueblos de altura de la subregión de río Salado. Este asentamiento está rodeado por diferentes clases de terrazas, construidas sobre terrenos de variadas topografías. El emplazamiento original del pueblo parece haber estado en relación directa con los antiguos y abundantes cursos de agua, hoy escasos. Actualmente, el agua es traída al pueblo por un canal desde vertientes que tienen su origen en la alta puna. Destaca un conjunto notable de andenerías de origen prehispánico, algunas reutilizadas y otras modernas, siendo una de las técnicas productivas más exitosas empleadas el uso de aterrazamientos escalonados cruzados por canales (Field, 1966). Un estudio pionero sobre la etnobotánica de la flora silvestre de Socaire es el de Munizaga y Gunckel (1958); además, este trabajo registra el conocimiento de los socairinos sobre el maíz, la papa, la quínoa y la alfalfa. La identificación de los maíces fue realizada por el geógrafo Rafael Baraona. De acuerdo a catastros de esta década, la superficie agrícola actualmente en uso sería de 48,51 ha, con predominio del cultivo de alfalfa por sobre un $70 \%$ del área, seguido en menor escala por el trigo, la papa, el maíz, habas, frutales, ajo, quínoa y otras hortalizas. En cuanto a la ganadería, los rubros más productivos de la localidad lo constituyen los ovinos (58\%), seguido por caprinos (27\%) (Gundermann \& González, 1995; Folla, 1989).

\section{Peine}

Al sudoeste de Socaire, en el borde oriental del Salar de Atacama, a unos 105 kilómetros de San Pedro y a $2.600 \mathrm{~m}$ de altura, se encuentra el poblado de Peine. En una explanada rocosa inclinada, que se alza en la ribera norte de la quebrada de Peine, se encuentran dispersas en una amplia extensión, las ruinas de un pueblo precolombino que puede datar desde antes del arribo de los incas a este territorio y que, aparentemente, siguió en funcionamiento durante el Tawantinsuyu y en la época colonial. En esta localidad hay una capilla, hoy en ruinas, estratégicamente situada al borde del camino que conduce hacia el sur del país. En el borde sur de la misma quebrada, y paralela a ella, se construyó el pueblo actual, emplazado en pendiente y articulado por una calle larga y ascendente que culmina en una placita, donde está construida la nueva iglesia, de aspecto colonial. Por la quebrada adyacente al pueblo escurre una delgada corriente de agua que nace en dos puntos diferentes, a pocos metros, al noreste del pueblo; este recurso permite regar los campos de cultivo aunque su pequeño caudal pone límites a los espacios cultivados, los que alcanzan una extensión de 10 a 12 hectáreas. La gente de Peine ocupa también el oasis de Tilomonte, situado unos 16 kilómetros más al sur, en donde cultiva alfalfa, maíz y trigo en unas tres has. Para el pastoreo, las vegas más importantes que aprovechan los habitantes de Peine, son las de Púlar al sur y a medio día de distancia del pueblo, hacia la frontera con Argentina. Las vegas de Tambillo son usadas tanto por la gente de Peine como por socairinos y los pastores de 
Toconao (Castro, 1987). Mostny (1954) entrega una detallada descripción de la utilización de los recursos vegetales silvestres, siendo de mayor importancia en esta localidad, como en toda el área de estudio, el algarrobo y el chañar. Entre las plantas cultivadas son importantes el maíz, la alfalfa, el trigo, las papas, las habas y hortalizas; la ganadería está representada por burros, mulas, ovejas, camélidos y cabras. Se aprovechan bien los cueros de animales en la fabricación de monturas, sogas, cinchas, riendas y sandalias. Sin embargo, es la textilería con lana de oveja, llama o vicuña la que se considera de mayor importancia. Un vasto panorama sobre estas actividades es documentado por Mostny (1954). La dinámica interna y las presiones externas han cambiado, probablemente, los valores cuantitativos de estas actividades en las últimas décadas, pero Peine aún puede ser considerada esencialmente una sociedad agropastoril.

\subsection{Las entrevistas etnobotánicas}

Con un tercer duplicado del herbario de Atacama se confeccionaron 2 muestrarios de referencia para realizar las entrevistas con los pobladores. El primer muestrario (Cuaderno I) contenía 73 taxa, correspondientes a la flora zonal de los pisos Subnival, Altoandino, Puneño y Prepuneño. El segundo muestrario (Cuaderno II) contenía 111 taxa, correspondientes a la flora azonal de las quebradas y las malezas, mayormente introducidas, de las chacras y huertas. Los números de referencia de las especies contenidas en estos dos cuadernos se citan en el Anexo 1.

Los nombres y usos correspondientes a los 73 taxa, contenidos en el cuaderno I, fueron consultados a 18 personas procedentes de: Toconao (cuatro hombres y una mujer); Socaire (dos hombres y una mujer); Peine (un hombre y una mujer); Camar (un hombre y dos mujeres), Talabre (tres hombres) y San Pedro de Atacama (dos mujeres). Los nombres y usos correspondientes a los 111 taxa contenidos en el Cuaderno II fueron consultados a 20 personas procedentes de: Toconao (cuatro mujeres); Socaire (un hombre y dos mujeres); Peine (un hombre y tres mujeres); Camar (un hombre y tres mujeres), Talabre (tres hombres) y San Pedro de Atacama (dos mujeres).
En las entrevistas participaron todos los autores del trabajo. Las respuestas fueron grabadas en triplicado en cintas magnetofónicas, en poder de los investigadores del proyecto. Sobre la base de la transcripción textual de todas las cintas magnetofónicas grabadas, se confrontaron las repuestas sobre nombres y usos de las plantas y en el Anexo 1 se sintetiza la información obtenida, respetando las diferencias regionales en nombres y usos registrados. Muy poca información fue eliminada como dudosa sobre la base de contrastación de respuestas. En el Anexo 2 se presenta el análisis etimológico de los nombres vernaculares recopilados, de acuerdo a la bibliografía indicada en el encabezado del mismo. En ambos Anexos se presenta el análisis lingüístico y la transcripción fonética de los vernáculos. En el Anexo 3 se listan alfabéticamente los vernáculos registrados y se señala, con abreviaciones, la procedencia lingüística de cada nombre.

\section{Resultados etnobotánicos}

\subsection{El origen de los nombres vernaculares atacameños}

Nos ha resultado extraordinariamente estimulante constatar, en este estudio, que la flora de la Región del Atacama es perfectamente conocida por sus habitantes. Para todas las 173 especies de plantas consultadas se obtuvieron 416 nombres vernaculares. En el Anexo 1 se listan las especies consultadas y sus respectivos nombres vernaculares. En el Anexo 2 se proporcionan los significados de los vernáculos. En el Anexo 3 se enumeran alfabéticamente los 416 nombres vernaculares de plantas registrados en el área de estudio y se indican con símbolos las procedencias de los nombres. En la Figura 3 se muestran las proporciones de nombres de plantas correspondientes a las distintas lenguas registradas.

En la Figura 3 se observa que la mayor proporción de nombres son españoles: 219 vernáculos, correspondientes al 53\% del total de nombres registrados, proceden de este idioma. Algunos, por cierto, bastante enigmáticos como, por ejemplo, lejía, léjia, likia. Aparentemente, es el uso medicinal de la ceniza de la planta llamada así (Baccharis tola ssp tola) la que determina el nombre. Otro nombre extraño es lava, lava del agua o 
bávaro, posiblemente una derivación de las palabras lama y baba. Otro nombre aparentemente español es kaudal, aplicado a Carpobrotus nombres indígenas, los más recurrentes son los del idioma kunza, rasgo extremadamente singular de la etnobotánica atacameña, considerando que la

Nombres múltiples de la flora del área del Salar de Atacama, Región de Antofagasta, Chile

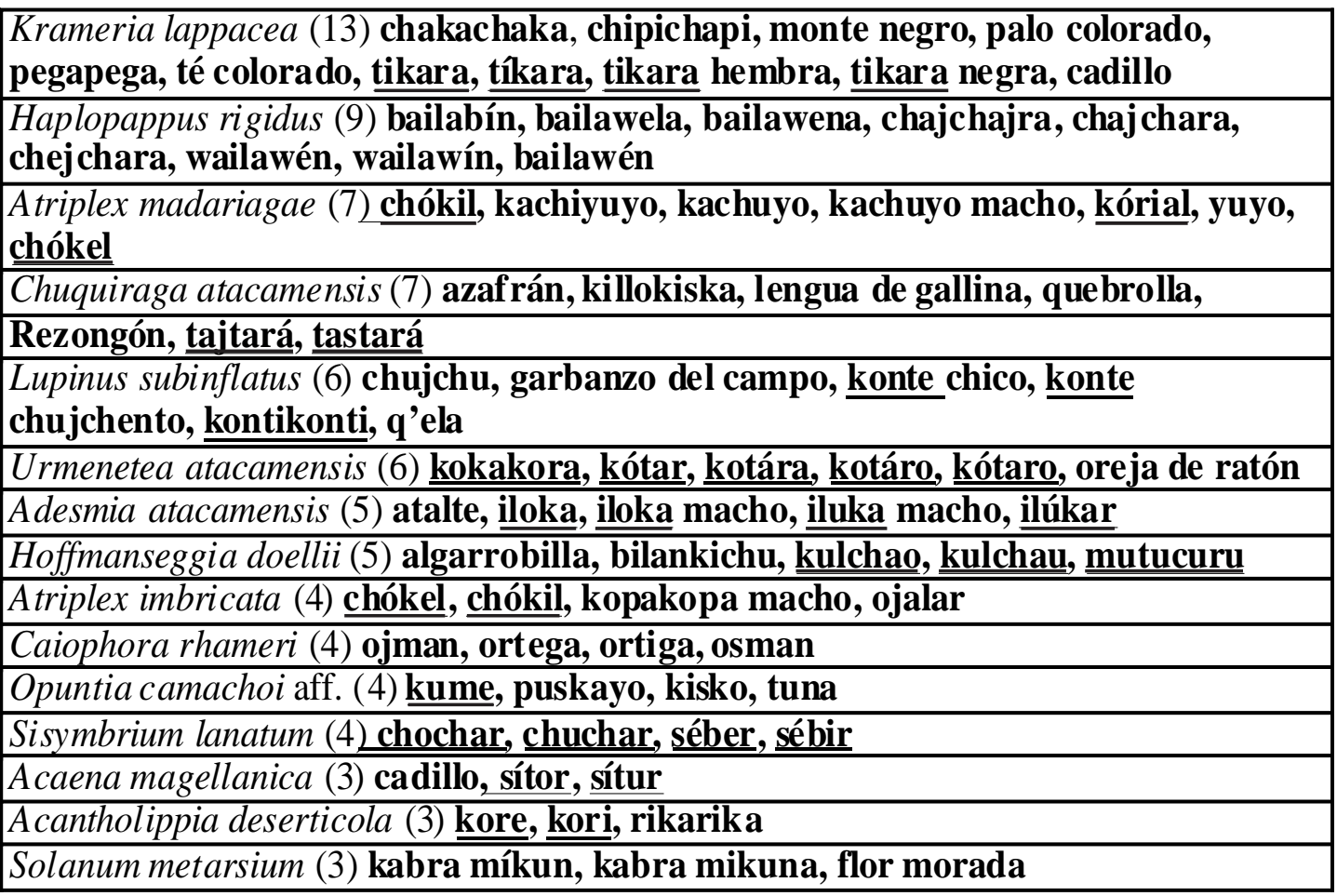

aequilaterus, probablemente refiriéndose a la forma de cola de las hojas carnosas y alargadas. Los nombres esporal, espural, espuro o simbol (Pennisetum chilense), asignados a una Gramínea muy común en las quebradas, es para nosotros totalmente enigmático y no sabemos a qué propiedad de la planta aludiría. Algunos nombres españoles son contracciones o deformaciones de palabras españolas, como, por ejemplo, los nombres alfa o alfilla, derivados de alfalfa. Un préstamo del español sería el nombre ajenko. También existe un buen número de nombres $(49,12 \%)$ que combinan palabras indígenas y españolas.

La proporción de nombres indígenas de plantas corresponde al 34\% del total de nombres registrados, sin consideración de aquellos que mezclan palabras indígenas y españolas (Fig. 3). Entre los mayoría de estos nombres no se conocen ni usan en otras regiones andinas de Chile. Destacan así los alrededor de 35 nombres $(8 \%)$ que ya han sido definidos como provenientes del idioma atacameño o kunza por Munizaga et al. (1958) y Vaïsse $e t$ al. (1896) o bien que, probablemente, también corresponden a este idioma por su uso restringido solamente a esta región (estos últimos se señalan con signo de interrogación en el Anexo 3). Ejemplos de estos nombres kunza son: básal; cháme, chámen o chávil; chochar o chuchar; chókel o chókil; chúkchar; chukula; kafle; kámen o kámin; káuchal; keúche o tieúchi; konte, konti, o kontikonti; kótar, kotára, kotáro, o kótaro; kulchao o kulchau; kume; lokoche; nori o noris; ojalar; ojman u osman; pápur pasto; sáilao o sailáo; sébir o séber; sítur o sítor. 
También destacan entre los nombres indígenas aquéllos provenientes de los idiomas aymara o quechua, rasgo común en la nomenclatura botánica de distintas comunidades altiplánicas, documentadas en la literatura (Fig. 3, Anexo 3). Del idioma quechua destacan 15 nombres (5\%), a saber: bilankichu; kachiyuyo o kachuyo; kallya; killokiska; maransel; molle o muelle; payko; pupusa; kisko; sicha; suncho; tara; viravira; walkawalka; yuyo wacho. Del idioma aymara merecen destacarse los siguientes nueve nombres vernaculares de plantas (2\%): añawa; chacha; chakachaka; chape y chipichapi; chijlla, chijua o chijuachijua; koa; kotakota; waycha; q'ela.

Un gran número de nombres indígenas de plantas de la región de Atacama (67 nombres, 16\%) han sido documentados en distintos idiomas, generalmente aymara, quechua y kunza. Hasta la fecha, no ha sido posible determinar cuál es el idioma original de estos nombres y cuáles son préstamos. Algunos ejemplos de nombres provenientes tanto del idioma quechua como del aymara y kunza son los siguientes: chacha pulika; chullapasa; chachakoma, chachakoma de la vicuña; champa; chillawa; kokakora; mokoraka; mutukuru; tola;michi; arka; chuchikan o chukikan; chañar; kore, kori o kórial; iro o iru; lampaya; pingo o pingopingo; puskayo; totora; waylla o waya; kopa o kopakopa; yuyo; lako; wilka; chukllara; iloka; tajtará o tastará; pasakana. Asimismo, una buena cantidad de nombres (49,
$12 \%$ ) combinan palabras indígenas y españolas. Así por ejemplo, nombres mixtos español-aymara serían: añawa blanca, añawa grande, añawa negra; chacha chica, chacha fina, chacha hembra, chacha macho, chacha pelada; paja sikuya. Serían nombres mixtos español-quechua los siguientes: kabra mikuna; comida de vizcacha; flor de la champa; forraje de vizcacha; pasto de vicuña; leña de tola; kachuyo macho; pupusa del agua, pupusa del campo; iloka hembra, iloka macho; maransel hembra, maransel macho; tara hembra, tara macho; yuyo arka. Serían nombres español-kunza: konte chico, tikara hembra.

Finalmente, merece destacarse que unos pocos nombres indígenas $(3 \%)$ provienen del idioma mapuche, como ñilwe o ñilhue (y sus variantes niebla, ñible, ñiebla, ñiuble); bailawén (y sus variantes bailabín, bailawela, bailawena, wailawén, wailawín); y palke o palki. Un nombre proviene del idioma arahuaco, tuna. La procedencia de tres nombres todavía no ha sido establecida: tamarugo, tolontolón, rikarika.

\subsection{Nombres múltiples}

Un rasgo muy particular de la etnobotánica atacameña es la existencia de nombres múltiples para varias especies. Por ejemplo, para Krameria lappacea se registraron 13 vernáculos; para Haplopappus rigidus, nueve; para Atriplex

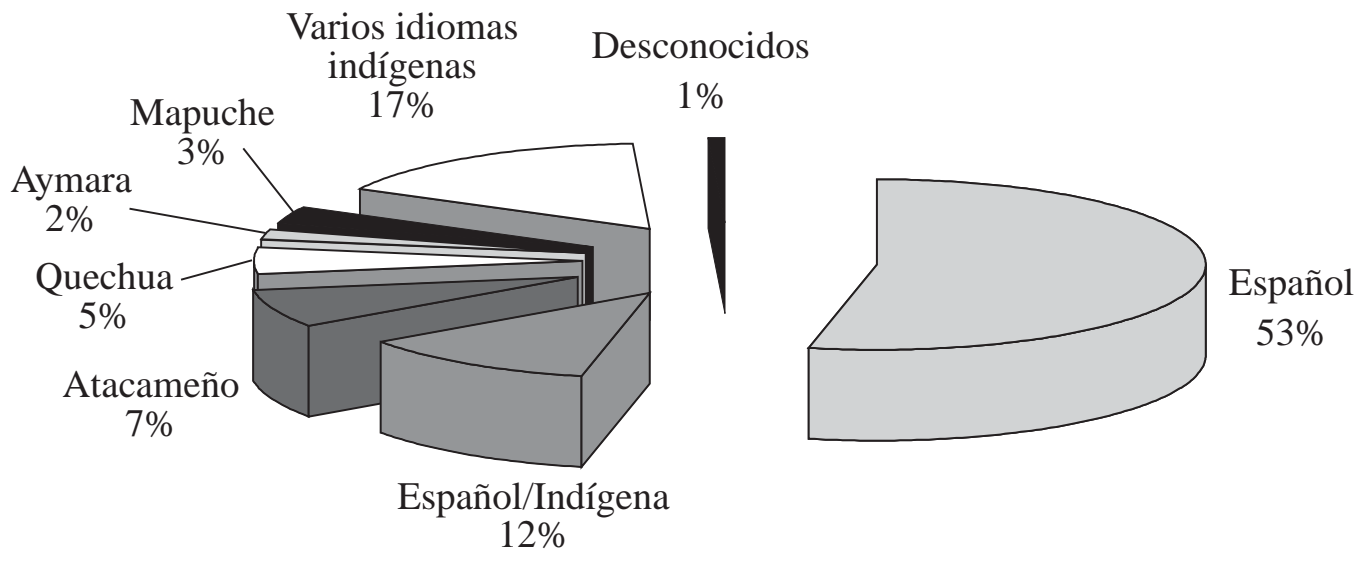

Figura 3: Las distintas lenguas de los nombres vernaculares $(N=416)$ registrados para la flora del Salar de Atacama, Región de Antofagasta, Chile. 
madariagae y Chuquiraga atacamensis, siete; para Lupinus subinflatus y Urmenetea atacamensis, seis. En la Tabla 1 se muestran las especies con más de dos nombres vernaculares y se destacan subrayados los nombres kunza de las especies. Parece ser que la existencia de nombres múltiples obedece al hecho de que se conserven en la zona los nombres antiguos de muchas plantas, en kunza, y además se hayan incorporado los nombres españoles y aymara/quechua de las mismas.

\subsection{Diferenciación local de nombres}

Es también interesante reseñar que se ha registrado diferenciación de nombres de plantas dentro del área del Salar de Atacama. En efecto, existe un conjunto de nombres vernaculares de plantas restringidos al sector sur del Salar de Atacama, específicamente a las comunidades de Peine, Socaire y Camar. Estos nombres son definidos por algunos informantes como correspondientes a las denominaciones antiguas de las plantas, "nombres que daban los abuelos". Estos nombres de uso restringido, no son usados frecuentemente por todos los pobladores, prefiriéndose citar las denominaciones más difundidas actualmente en la región de Atacama.

Para la flora nativa, entre los vernáculos restringidos a Peine, Socaire y Camar se pueden citar: chajchara o chajchajra, para una especie denominada bailawén en una amplia extensión geográfica del territorio chileno (Haplopapus rigidus); kori o kore para una especie conocida regionalmente en los Andes del norte de Chile como rikarika (Acantholippia deserticola); kulchao o kulchau para una hierba conocida como bilankichu o mutukuru (Hoffmanseggia doellii) en otras localidades andinas; y kabran mikun o kabra mikuna (Solanum metarsium) para una especie llamada flor morada en los restantes poblados de Atacama. También se registraron algunos nombres exclusivos de la localidad de Peine, como atalte, para una especie llamada comúnmente iloka o iloka macho en los restantes poblados de Atacama y támor en el Loa superior (Adesmia atacamensis); tolontolón, para una especie llamada tomatillo (Lycopersicon chilense) en los Andes del norte de Chile; y kaudal, para una especie nativa, pero introducida a la zona como planta de jardín, y que en el resto de Atacama, y en el Loa superior, es llamada bálsamo o dedos de ángel (Carpobrotus aequilaterus). De uso solamente restringido a Socaire se pueden citar los casos del cardoncillo, conocido en el resto de la región atacameña como perlilla o roseta y, en el Loa superior, como rosita (Junellia seriphioides); por último, los frecuentes nombres de ortega, ortiga o itapaya de las especies de ortiga en el norte de Chile son reemplazados, en este poblado, por el vernáculo ojman u osman (Caiophora rhameri).

Una mención especial merece el vernáculo lokoche, nombre proporcionado solamente en Peine, para una especie de Hypochaeris que crece como maleza en las huertas del poblado y que no ha sido descrita botánicamente en el país. Esta especie fue solamente observada y coleccionada en Peine, aunque algunas personas de San Pedro y de Talabre reconocieron el nombre y nos aseguraron que esta especie también crecería en Tilomonte y en Coyo.

\subsection{La etnoclasificación}

\subsubsection{Los significados de los nombres de plantas}

Del análisis de los significados de los nombres vernaculares de plantas en Atacama (Anexo 2), se desprende que una de las características más recurrentes para nombrar plantas se refiere a atributos propios de la especie, ya sea el aspecto o forma general (hábito) de la planta o de órganos (raíces, tallos, hojas, espinas, inflorescencias, etc.); también algunas propiedades específicas, como el tamaño, color, olor, producción de latex u otras son consideradas. Los atributos para nombrar pueden ser aludidos directamente en el nombre, o usando analogías con formas de animales o de objetos. Así por ejemplo, el aspecto general de la planta es considerado en nombres como Walkawalka, que alude a los artículos del tallo que asemejan las cuentas de un collar; Cola de lagarto, para la misma especie, es símil de la forma de los tallos cilíndricos y carnosos; Keúche o Tieuchi (liendre en kunza), es tal vez un símil del diminuto tamaño de una plantita altoandina; Acerillo, alude a la forma de cojín o almohadilla de otra especie. Los nombres de Dedos de ángel, 
Káudal y Bálsamo, de otra especie, parecen aludir tanto a la forma de las hojas alargadas y carnosas (a modo de dedos o cola) como al alivio que provoca como medicina; nombres como Oreja de chojchor y Oreja de ratón, son símiles de formas de hojas; nombres como Gato o Michi, son una analogía de la forma del fruto con la cabeza de los felinos; Cola de zorro, es una analogía similar entre este animal y la forma de los hábitos y/o inflorescencias de varios pastos; Pata de perdiz, alude a la ramificación y aspecto de los tallos con cicatrices de hojas, que se asemejan a las escamas de una pata de ave; Zapatilla, a la forma de la corola. El color es también un atributo considerado en muchos nombres, como, por ejemplo, Palo colorado, Espina blanca, Espina negra, Flor amarilla, Flor blanco, Flor morada, Nevadilla, Nevadita o Nieve, Sangría o Sangrinaria, Leche, Lecheleche o Lecherito del campo. El olor es considerado en nombres como Sobaco negro o Sobaquillo.

El hábitat de la planta es otro de los atributos considerado para nombrar especies. Por ejemplo, Flor de la peña, para designar líquenes crustáceos sobre rocas; otros nombres remiten al hábitat acuático o húmedo y las comunidades asociadas, como Flor del agua, Flor de lako, Flor de Champa y, posiblemente, Nori o Noris (mojado o verde, Ver Anexo 2); los nombres Hierba de la sal y Kachiyuyo aluden a hábitats salobres (salares).

La utilidad de la planta también es una característica usada para nombrar especies, ya sea como forraje para la fauna domesticada y silvestre o medicina animal, o para satisfacer necesidades humanas. El valor forrajero de varias especies queda, por ejemplo, consignado en los nombres (ver Anexo 2): Kabra míkun o Kabra mikuna (comida de cabra); Comida de perdiz; Comida de vizcacha; Forraje de vizcacha; Comida del suri; Chujchu (terciana) o Konte chujchento, para plantas que producen tercianas al ganado; Tablilla, aludiendo a su uso para entablillar huesos quebrados de animales. El valor de algunas especies para las personas, ya sea como alimento, remedio u otros usos, se expresa en nombres tales como: Hierba del tapón o Arcilla (contra diarreas); Bálsamo o Bálsamo finito; Pingo o Pingopingo (sano); Té, Hoja de té, Té de burro, Té silvestre, Té verde y Lokoche (achicoria).
Otros usos se expresan en nombres como Brea o Breya, cuya resina se usa como brea; Likia, Lejía o Léjia, cuya ceniza es usada medicinalmente; Quebrolla o Rezongón, por el ruido que hace al ser quemada como combustible.

Desafortunadamente, el significado de muchos nombres propios de plantas de Atacama es totalmente desconocido. Este es el caso de la mayoría de las palabras simples en idioma kunza, que designan especies, principalmente, del desierto como: Chámen o Chávil, Chochar o Chuchar, Chókel o Chókil, Chúkchar, Chukula, Kámen o Kámin, Kótar, Kotára, Kotáro o Kótaro, Kulchao o Kulchau, Séber o Sébir, Sítor o Sítur. También muchos nombres propios y simples de plantas, en idiomas quechua o aymara, tienen significados desconocidos, como, por ejemplo, Atalte, Chakachaka, Ipallapa,Chajchajra, Chajchara o Chejchara, Pupusa, Sicha, etc. Otros nombres de especies silvestres, muy conspicuas y ampliamente utilizadas, son nombradas en toda América con su nombres propios, cuyos significados ya se ha perdido, como Chañar, Molle o Muelle, Palke o Palki, etc. Los nombres propios de plantas en idioma español corresponden, en muchos casos, a especies advenas tanto cultivadas como malezas, que tienen ese nombre en gran parte del mundo de habla hispana. Estos nombres son muy antiguos y con significados ya olvidados. Este es el caso, por ejemplo, de la Alfa o Alfalfa, Apio, Berro, Romero, Espárrago, etc. Otros nombres de especies silvestres, que se parecen a especies cosmopolitas, consignan este parecido en nombres tales como Berrillo, Alfilla, Romerillo, etc. Nombres como Suncho, Rikarika, Esporal, Espural o Espuro, Ojalar, Simbol, Kaudal son absolutamente crípticos en cuanto a su significado y ni siquiera es claro si son españoles o indígenas.

\subsubsection{Las etnocategorías genéricas}

Muchos nombres de las plantas de Atacama están compuestos por dos palabras. Una genérica, usada para un conjunto de plantas que comparten una misma característica, y otra específica. Tal como ha sido documentado en otros estudios etnobotánicos de los Andes de Chile (Aldunate $e t$ al., 1981; Villagrán \& Castro, 1999), las agrupaciones de plantas reconocidas con nombres gené- 
ricos o colectivos (categorías etnogenéricas) se construyen, generalmente, sobre la base del contraste de características morfofisionómicas, ya sea la forma de crecimiento de la planta (agrupaciones por formas de vida) o la morfología total de la planta (agrupaciones "taxonómicas"). Sin embargo, y como rasgo singular de la etnoclasificación andina del norte de Chile, se han registrado en el Salar de Atacama otras clases de agrupaciones. Específicamente, se han registrado agrupaciones construidas sobre la base de la similitud de algún órgano especial u otros atributos, como el uso que se hace de la planta. También se han registrado agrupaciones usando como referente plantas importantes, tanto silvestres como advenas. La distinción de especies dentro de una categoría etnogenérica se realiza sobre la base de los mismos atributos discutidos en el capítulo anterior. Sin embargo es importante destacar que, entre otros atributos usados para la distinción de especies, el más recurrente es el contraste hembramacho. Este contraste se usa para la distinción entre especies más "femeninas" (e.g. pequeñas, gráciles, blandas, con frutos, etc.) y las más "varoniles" (e.g. más altas, robustas, rígidas, sin frutos, con espinas, etc.). Este es un rasgo muy típico de la etnoclasificación andina y ya ha sido destacado en la literatura (Aldunate et al., 1981; Villagrán \& Castro, 1999). Algunos ejemplos atacameños son: pingopingo macho y hembra, tikara macho y hembra, chacha macho y hembra, maransel macho y hembra, iloka macho y hembra, tara macho y hembra. A continuación se describen las principales etnocategorías genéricas registradas en Atacama (ver Fig. 4):

Agrupaciones por formas de vida: Se registraron una serie de nombres vernaculares que agrupan especies distintas que comparten en común una misma forma de crecimiento. Muchos de los nombres usados para distinguir formas de vida ya han sido documentados en la literatura y tienen una amplia difusión en el Altiplano (ver Aldunate et al., 1981; Villagrán \& Castro, 1999). Así, por ejemplo, el nombre de Tola, Tolita o Tolilla, para designar a los arbustos y subarbustos leñosos dominantes en los Tolares. Sin embargo, destaca como rasgo singular de la Región de Atacama el frecuente uso de la palabra española Monte para designar a esta misma forma de vida. Asimismo, el uso del vernáculo Yaretilla, para designar especies con crecimiento en cojines laxos, es de amplio uso en los Andes.

Los nombres colectivos, para designar las distintas formas de vida de los pastos del área de estudio son también usados en una extensa región de los Andes. Así, por ejemplo, el nombre de Paja, Iro o Iru, para nombrar a las Gramíneas perennes de los Pajonales; Pasto o Pastito, para agrupar a las espe-

Tabla 2

El ciclo anual del pastoreo en Talabre

(De acuerdo a Morales, 1997)

\begin{tabular}{|l|l|l|l|l|l|l|l|l|l|l|l|l|}
\hline VEGAS/MES & A & S & O & N & D & E & F & M & A & M & J & J \\
\hline \hline Patos, $5 \mathrm{~km} \mathrm{~S}$ & & & & & & & & & & & $\mathrm{X}$ & \\
\hline Alitar & & & & & & & & & & & $\mathrm{X}$ & $\mathrm{X}$ \\
\hline Tumbre, 15 km E & $\mathrm{X}$ & $\mathrm{X}$ & $\mathrm{X}$ & $\mathrm{X}$ & $\mathrm{X}$ & & & & $\mathrm{X}$ & $\mathrm{X}$ & $\mathrm{X}$ & $\mathrm{X}$ \\
\hline Ojo Ecar, 29 km E & & & & & & $\mathrm{X}$ & $\mathrm{X}$ & $\mathrm{X}$ & $\mathrm{X}$ & & & \\
\hline Pili & & & & $\mathrm{X}$ & $\mathrm{X}$ & $\mathrm{X}$ & $\mathrm{X}$ & $\mathrm{X}$ & & & & \\
\hline Laguna Verde, 70 km E & & & & $\mathrm{X}$ & $\mathrm{X}$ & $\mathrm{X}$ & $\mathrm{X}$ & $\mathrm{X}$ & & & & \\
\hline Tara y Mari-Potor, 100 km E & & & & $\mathrm{X}$ & $\mathrm{X}$ & $\mathrm{X}$ & $\mathrm{X}$ & $\mathrm{X}$ & & & & \\
\hline Toro blanco & & & & $\mathrm{X}$ & $\mathrm{X}$ & $\mathrm{X}$ & $\mathrm{X}$ & $\mathrm{X}$ & & & & \\
\hline Abra & & & & $\mathrm{X}$ & $\mathrm{X}$ & $\mathrm{X}$ & $\mathrm{X}$ & $\mathrm{X}$ & & & & \\
\hline Aguas Calientes & & & & $\mathrm{X}$ & $\mathrm{X}$ & $\mathrm{X}$ & $\mathrm{X}$ & $\mathrm{X}$ & & & & \\
\hline Catarape, 13 km E & $\mathrm{X}$ & $\mathrm{X}$ & $\mathrm{X}$ & $\mathrm{X}$ & $\mathrm{X}$ & $\mathrm{X}$ & $\mathrm{X}$ & $\mathrm{X}$ & $\mathrm{X}$ & $\mathrm{X}$ & $\mathrm{X}$ & $\mathrm{X}$ \\
\hline Soncor, $5 \mathrm{~km} \mathrm{~W}$ & $\mathrm{X}$ & $\mathrm{X}$ & $\mathrm{X}$ & $\mathrm{X}$ & $\mathrm{X}$ & $\mathrm{X}$ & $\mathrm{X}$ & $\mathrm{X}$ & $\mathrm{X}$ & $\mathrm{X}$ & $\mathrm{X}$ & $\mathrm{X}$ \\
\hline Quebrada. Ecar, $30 \mathrm{~km} \mathrm{E}$ & $\mathrm{X}$ & $\mathrm{X}$ & $\mathrm{X}$ & $\mathrm{X}$ & $\mathrm{X}$ & $\mathrm{X}$ & $\mathrm{X}$ & $\mathrm{X}$ & $\mathrm{X}$ & $\mathrm{X}$ & $\mathrm{X}$ & $\mathrm{X}$ \\
\hline
\end{tabular}




\section{ETNOBOTANCA ATACAMEÑA}

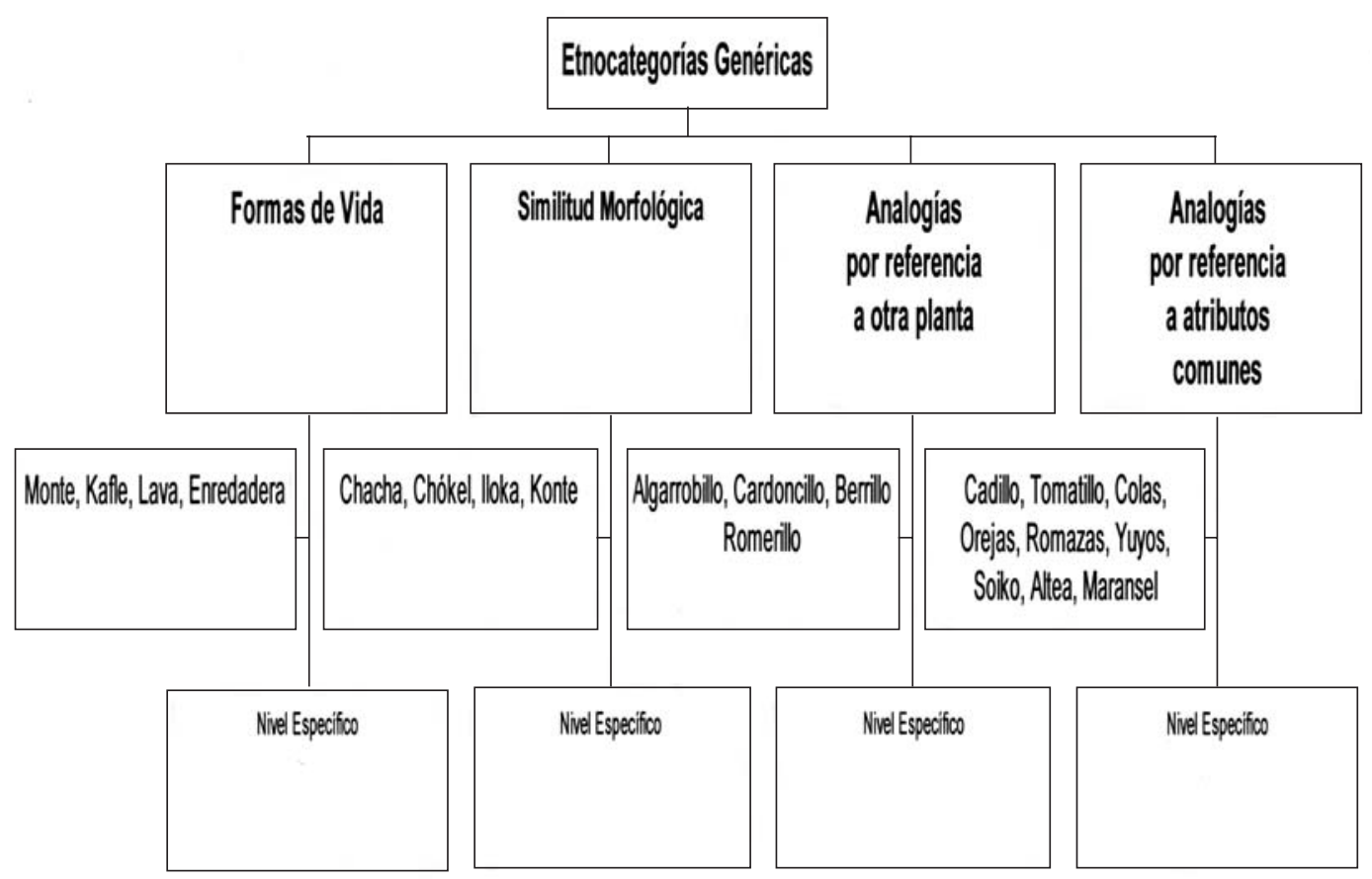

Figura 4: Sistema de clasificación etnobotánica de las plantas del Salar de Atacama, Región de Antofagasta, Chile.

cies de hierbas anuales y perennes, en general (las especies anuales son calificadas frecuentemente como "pastos de lluvia"); Grama, Gramilla o Gramillo, para nombrar a las distintas especies de Gramíneas perennes, pequeñas, rastreras y de hoja dura, que conforman el césped de los fondos de quebradas y riberas; Cebadilla o Cebadillo, para las Gramíneas anuales pequeñas y malezas predominantes en la época de lluvias. Un nombre de forma de vida muy reiterado en la región de Atacama, y que se usa muy poco en otras áreas, es Kafle, el cual agrupa las distintas especies de Gramíneas herbáceas, generalmente de consistencia blanda e introducidas como malezas en las chacras. También estas plantas son llamadas frecuentemente con el vernáculo español Pastos Blandos.

En lo que se refiere a la vegetación palustre y acuática, los nombres registrados tienen igualmente una amplia representatividad en los Andes. Así por ejemplo, el nombre de Champa, Champita o
Vega, para designar a las especies pigmeas que conforman cojines en torno a los cursos de agua; Unquillo, Unquillar, o Junquillo, para las especies palustres de Ciperáceas y Juncáceas de los lugares húmedos de quebradas; Loroma, para las especies acuáticas flotantes de Angiospermas; Lama, Lako o Lava, para las especies de Algas Verdes filamentosas. El último término, Lava, no había sido todavía documentado en la literatura para esta forma de vida.

Una forma de vida singular de la región del Salar de Atacama es la definida con el nombre de Enredadera, que agrupa a las especies herbáceas volubles, ya sean erguidas o postradas.

Agrupaciones por referencia a otra planta (Fig. 4). Un resultado de este estudio, que merece destacarse, es el registro de agrupaciones de plantas hechas por referencia a otra planta importante, ya sea porque es muy conspicua o tiene importancia 
Figura 5: Bosquejo de la percepción del paisaje en Talabre mostrando los sectores de campo, vega y estancias (cerro). De acuerdo al dibujo proporcionado en Abril de 1998 por dos pastores de Talabre, Leonardo Leandro Armella de 19 años y Luis Soza Mamani de 27 años.

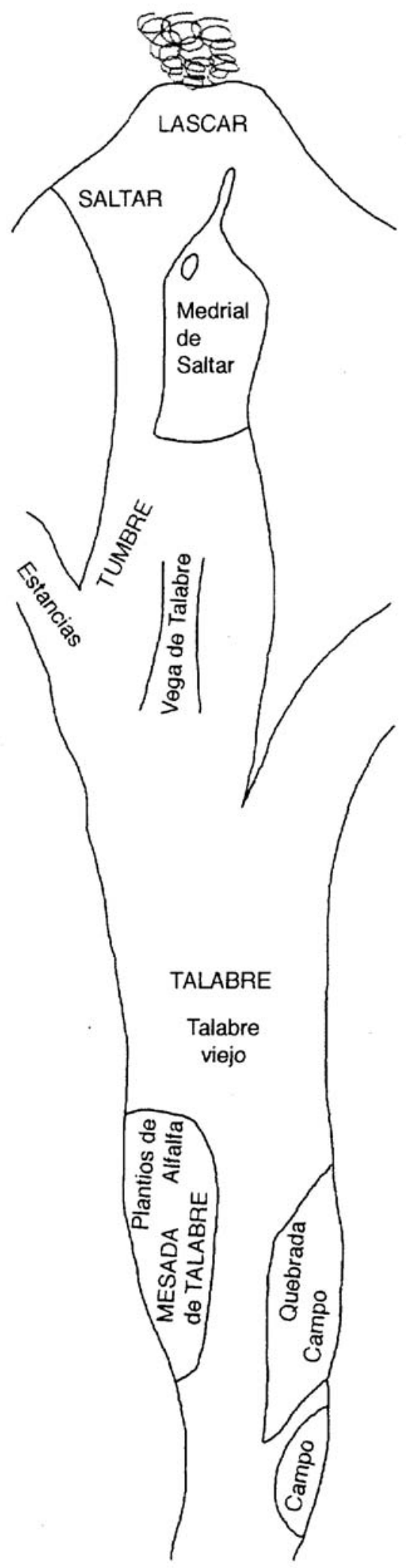


económica. El nombre de las plantas nombradas por referencia a otra, generalmente corresponde a diminutivos de la lengua española, como, por ejemplo, cuernillo, garbancillo, gramilla, sobaquillo. Este es el caso, por ejemplo, de la algarrobilla (Hoffmanseggia doellii) y del algarrobillo (Acacia sp), nombradas así por su similitud con un árbol muy apreciado, el algarrobo (Prosopis alba), semejanza que se refiere al parecido de las hojas, color ceniciento de la planta y forma de las legumbres. Por analogía con el cardón (Echinopsis [=Helianthocereus] atacamensis), el más importante y útil cactus columnar del desierto, es denominado cardón chico otro cactus columnar más pequeño (no determinado) y cardoncillo (Junellia seriphioides), un arbusto del tolar con estípulas espinosas. Otro ejemplo es el berro picante o berrillo (Ranunculus cymbalaria), llamado así por su semejanza, en hábito y hábitat, con una especie comestible, el afamado berro (Mimulus glabratus).

Las referencias a otras plantas no solamente se restringen a especies nativas, sino que también aluden a plantas introducidas e, incluso, malezas. Este es el caso de varias especies de malezas de chacras, con hojas delgadas, tiernas y comestibles, denominadas colectivamente romazas (Amaranthus deflexus, Hypochaeris nov. spec., Plantago major y $P$. lanceolata), por analogía con una maleza comestible ampliamente difundida en el país, la romaza (Rumex aff. crispus). Asimismo, varias especies silvestres de hábito blanquecino, altoandinas y pertenecientes al género Senecio ( $S$. jarae, $S$. xenophyllus, S. scorzonaerifolius), son denominadas romerillo, por analogía con una planta medicinal, comestible y cultivada en las huertas, el romero (Rosmarinus officinalis). Las bayas carnosas de Lycopersicon chilense y Solanum elaegnifolium, parecidas al tomate, explicarían el nombre de tomatillo para estas dos especies. Un caso interesante corresponde a la agrupación de una serie de malezas denominadas yuyo, arka y yuyo arka (Atriplex madariagae, Amaranthus deflexus, Chenopodium album y Ch. ambrosioides), especies asociadas a los cultivos de quinoa (Chenopodium quinua), una de las plantas domésticas andinas más valoradas.

Agrupaciones por similitud de propiedades: También es muy frecuente la elaboración de agru- paciones de plantas sobre la base de propiedades comunes, ya sea la forma de órganos como las raíces, hojas, flores, inflorescencias, frutos, color o algún otro atributo relacionado con el uso (e.g. sabor, olor, efecto terapéutico, etc.). Las especies llamadas orejas de ratón o colas de zorro, por la forma de sus hojas o inflorescencias (Exodeconus integrifolius, Urmenetea atacamensis y varias especies de Gramíneas). Asimismo, los frutos secos y espinosos de Acaena magellanica y Krameria lappacea, que se adhieren al pelaje de animales y a la ropa, explican el nombre de cadillo que se da a estas dos plantas. Este nombre es muy frecuente en Chile para especies con frutos de iguales características.

Por otro lado, propiedades comunes referentes al uso también determinan agrupaciones de plantas. Por ejemplo, los pares de especies llamadas maransel y altea, por la presencia de una raíz engrosada medicinal o comestible, respectivamente (Perezia atacamensis, Werneria glaberrima, Junellia digitata, Nototriche estipulata). El uso como alimento determina los nombres de dos plantas muy parecidas, el soiko (Tagetes minuta), comestible, y el soiko de la cabra (Schkuhria multiflora), no consumido por la gente. El uso medicinal de dos especies altoandinas y aromáticas determina el nombre común de pupusa para ambas (Xenophyllum incisum y Junellia digitata).

Agrupaciones “taxonómicas" (Fig. 4). Finalmente, las especies pueden ser agrupadas por su parecido morfológico general, criterio comúnmente usado en Taxonomía Vegetal. Este tipo de etnocategorías ha sido ampliamente documentado para otras regiones andinas y en la zona de estudio se ha registrado también el uso de etnocategorías ya descritas en la literatura, como el nombre de añawa o espina, para las especies arbustivas y espinosas del género Adesmia; el nombre de malva, malvilla o malvisco para distintas especies de la familia Malváceas; el nombre de tara para especies de Fabiana.

Entre las agrupaciones taxonómicas no documentadas y propias de la región de Atacama se destacan los nombres de chacha, para especies del género Parastrephia; chókel o chókil para especies arbustivas del género Atriplex; iloka o iluka para las especies resinosas y sin espinas del género 
Adesmia; konte, konto o kontikonti para especies del género Lupinus.

\section{Percepción ambiental}

No obstante que cada comunidad tiene su propia micropercepción del paisaje, el estudio que hemos realizado, en los pueblos del Salar de Atacama, nos permite asegurar que estas comunidades comparten el sistema de categorización que hemos dado a conocer para Toconce, en el Loa superior (Aldunate et al., 1981), hace ya cerca de dos décadas, y que ha sido comparado con otras regiones andinas por Villagrán et al. (Villagrán \& Castro, 1999; Villagrán, Castro \& Sánchez, 1999). En el caso de Toconce, poblado situado a $3.400 \mathrm{~m}$ en la cuenca del río Salado, sus habitantes organizan el paisaje en, por lo menos, cuatro ambientes continuos, que se suceden a lo largo del gradiente altitudinal, y tres unidades discontinuas, azonales. Los primeros son, desde el nivel altitudinal inferior, la pampa, término con el que se refieren a las planicies desérticas o con vegetación muy rala; el tolar, ambiente con predominio de arbustos designados con el nombre genérico de tolas; el pajonal, ubicado inmediatamente por sobre el tolar y caracterizado como una zona más fría con predominio de los ichu (pajas); y el panizo, localizado en las cumbres de los cerros y definido por la ausencia de vegetación. Las unidades ecológicas azonales son los médanos o arenales; las hoyadas, lugares fríos con frecuentes heladas; y las vegas, áreas de plantas forrajeras en las cercanías de afloramientos de agua y caracterizadas por la abundancia de champas, pequeños cojines de plantas. De acuerdo a la forma de utilización económico-social del entorno, los toconcinos distinguen tres nuevas unidades: chacra, campo y cerro, incluyendo cada una de ellas varias de las entidades ecológicas mencionadas anteriormente. $\mathrm{La}$ chacra es el espacio agrícola de terrazas y melgas que, por definición, es lo cultural en sí y está directamente asociada a los asentamientos poblacionales. El campo, integra varios pisos ecológicos tales como el tolar, la vega, la pampa y los médanos. Lo que define este concepto es la realización de actividades pastoriles en su ámbito. Se sitúa en la interfaz entre un espacio cultural y otro natural, en cuanto a la percepción del paisaje. El patrón habitacional que le corresponde es la estancia, por definición más transitoria que el poblado en la Provincia de El Loa.
Finalmente, el cerro comprende preferentemente las unidades ecológicas de panizo y pajonal. Es un territorio para la recolección de vegetales, de pastoreo de llamos y de caza; en esta zona, los asentamientos humanos son totalmente transitorios (pascanas, camas de arrieros, etc.). Los sectores de mayor altura de este espacio son concebidos como lugares sagrados.

Debido a la extensión de este trabajo, no nos fue posible estudiar a nivel de detalle la percepción particular del paisaje de cada comunidad del Salar de Atacama. De la información recopilada, se desprende que es en Talabre donde se expresa el más detallado conocimiento y comprensión del paisaje, sus recursos y sus diferentes planos de significación. Es probable que la perduración y mantención de este saber esté fuertemente asociado a la alta movilidad de los talabrinos durante el ciclo anual, dado el énfasis pastoril de esta comunidad, pero sin duda no debe ser ajeno a otras comunidades con actividades pastoriles aún significativas, como por ejemplo Ollagüe, Alto Loa, Socaire. A modo de ejemplo para la región del Salar de Atacama, y gracias al dibujo que nos obsequiaran dos jóvenes pastores talabreños (Fig. 5), ofrecemos un bosquejo de la percepción del paisaje en Talabre. Como se aprecia en el esquema realizado por los pastores de Talabre (Fig. 5), las categorías de Cerro y Campo son explícitas. En la Tabla 2 se muestra la rotación del ganado en los distintos sectores de pastaje usados por los talabrinos, de acuerdo a Morales (1997).

Como se observa en la Tabla 2 (Morales, 1997), las actividades de pastoreo de los talabreños se practican durante casi todo el año, en las vegas más bajas y cercanas del poblado: Tumbre, Quebrada Ecar, Catarape, Soncor y Talabre Viejo. Durante el periodo estival, se prefieren las vegas de altura aledañas a Laguna Lejía, como por ejemplo Laguna Verde, Tara, Pili, Toro Blanco, Abra y Aguas Calientes. En el periodo seco de invierno, además de las vegas bajas se utilizan los pastos de los cerros (Cerros Corona, Tumisa, Lascar, Ecar, Ojos de Ecar, Saltar), además de la alfalfa cultivada como forraje. En las áreas de vegas, tolar y pajonal, los pastores de Talabre tienen estancias o viviendas transitorias. El período de pasteo del ganado camélido, en ellas, es variable y puede cubrir un lapso de dos a tres meses, en compañía 
del pastor; luego, los animales se dejan solos en el lugar, por un período también variable. Los caprinos son conducidos a lugares más bajos y planos de oasis, con algarrobos y chañares, como Tambillo y Soncor, donde también los talabreños tienen sus estancias.

Dentro de la percepción del paisaje de los talabreños juegan un rol fundamental algunos cerros: Tata Liri (Zapaleri), Mama Quimanchu (Quimal), Tata Likanku (Licancabur), Tata Pilancho (Pular) y, particularmente, aquellos que "dan agua" como el Itucuna (Ecar) y Tucusi (Ojos de Ecar) (Cárdenas, 1999). El concepto de Maiko, como deidad tutelar proveedora de agua, de forraje y protector del ganado, si bien genérico y equivalente al concepto Mallku, parece reservado particularmente para mencionar al Volcán Lascar. Para ofrendar (pagar) a este mallku, los talabreños realizan una ceremonia en su cumbre. Como en toda el área andina, existe el culto a la Pachamama y a los antepasados (abuelos). En las cercanías de Talabre hay numerosos paneles con arte rupestre de data prehispánica, en los que destacan motivos antropo-, zoo- y fitomorfos, entre otros, figuras de camélidos, cactus y flores (Morales, 1997). La misma localización de Talabre, aledaña a quebradas y pasos cordilleranos que se entrecruzan, para alcanzar Laguna Lejía, el sector de Patos, Ecar y el Salar, le otorga especial significación a la percepción de los espacios talabreños. Para ellos, estos lugares forman un cordón de gentiles y abuelos, por cuanto cada lugar conserva la huella de los antiguos (antepasados prehispánicos), ya sea grabada en las piedras como arte rupestre, en pequeñas construcciones, o en los mismos espíritus de los antiguos que suelen habitar en Patos y Saltar (Valenzuela et al., 1998).

Por otro lado, el espacio local se integra a una percepción de los espacios regionales y macrorregionales. La mayoría de los pobladores del Salar de Atacama conoce, en el lado boliviano y argentino, los senderos para llegar a las comunidades de Lipez o la puna argentina. Muchos de ellos están igualmente en condiciones de reconocer el sistema de cerros y lugares sagrados existentes en esos lugares, requisito indispensable para transitar por los caminos y manejar las aguadas y nichos que pudieran ser importantes productiva- mente. Estos espacios son esencialmente discontinuos, hecho que plantea el problema de los límites. No nos referimos a las fronteras entre los Estados - Repúblicas de la región ni a los límites político-administrativos nacionales, todos artificialmente impuestos, sino al manejo que hacen las propias comunidades indígenas para definir quienes pueden tener acceso a determinado espacio productivo (Castro \& Martínez, 1996). Este tema, que tiene directa incidencia en el manejo económico de las distintas unidades domésticas, ha sido objeto de escasa atención por parte de los estudiosos en nuestra región y lo retomaremos en la discusión.

\section{Utilización de la flora}

La flora de cada uno de los pisos ecológicos, como asimismo la flora azonal de las vegas, quebradas, salares y las malezas de las chacras de la región son utilizadas, por las comunidades indígenas, para usos que comprenden desde los económicos (agricultura, pastoreo, etc.), alimenticios (recolección) y tecnológicos (construcción, textilería, mueblería, artesanía, etc.), incluyendo los medicinales y rituales (sacrificios, infusiones, vahos, quemas rituales, etc.) y otros de eficacia simbólica. Tras esta utilización opera un elaborado sistema de clasificaciones propias del pensamiento indígena, que ordena y categoriza las distintas especies y sus significados.

Los resultados de nuestro estudio muestran que, de las 173 especies de plantas consultadas en torno al Salar de Atacama, 165 especies tenían uno o más usos (95\%). Solamente para ocho especies no se reconoció uso. En la Fig. 6 se muestra la distribución de los distintos tipos de usos de las plantas, sobre una base de los 328 usos registrados. En la misma se observan los 10 clases de usos principales registrados, en importancia decreciente: Forrajero, 35\%; Medicinal, 24\%; Alimenticio, 9\%; Combustible y Leña, 6\%; Construcción y Artesanías, 6\%; Adorno, 5\%; Tintóreo, 4\%; Perjudicial, $3 \%$; Ritual, $2 \%$ y otros usos variados, $6 \%$. Indudablemente, el recurso vegetal en el área de Atacama es predominantemente de uso forrajero y medicinal. Resulta interesante destacar el porcentaje relativamente alto de especies comestibles y tintóreas, en relación a otras regiones andinas. El resto de los usos se distribuye más o menos 


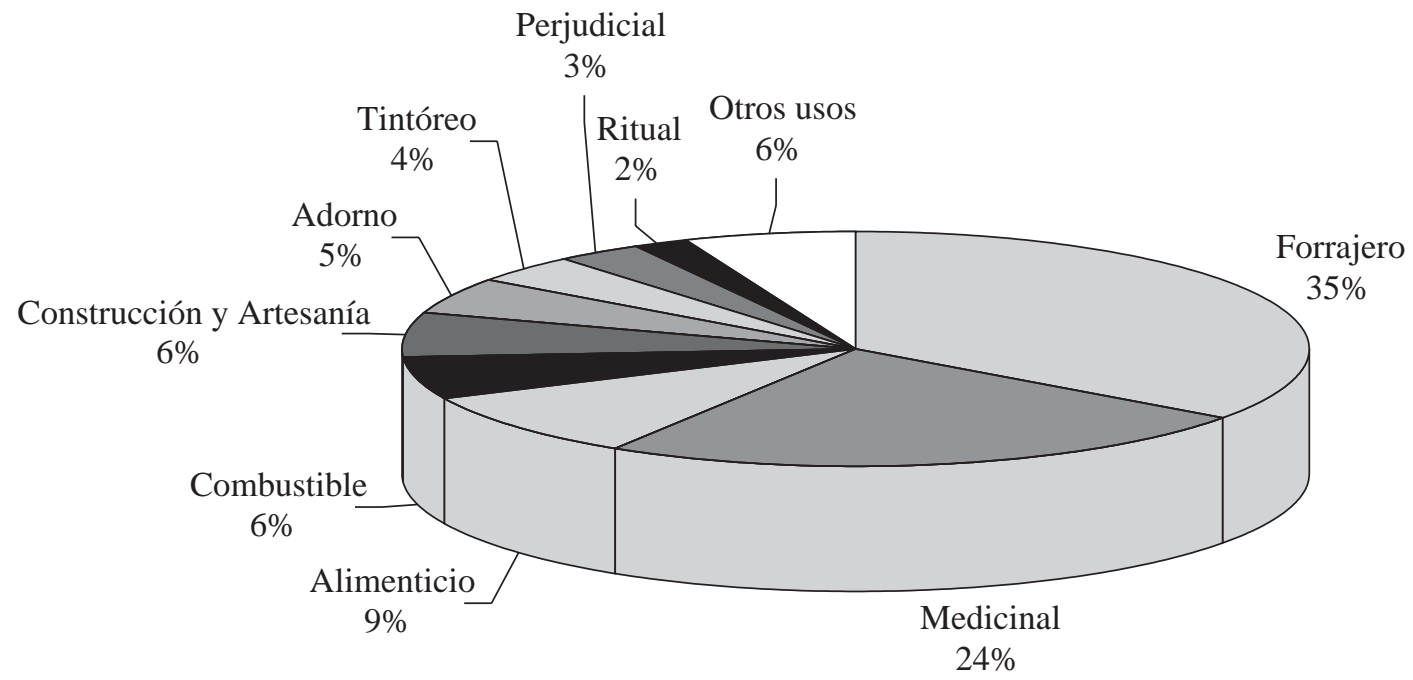

Figura 6: Distribución de los distintos tipos de usos de las plantas (N=328) del Salar de Atacama, Región de Antofagasta, Chile.

equilibradamente, no sobrepasando ninguno de ellos el 6\% del total de usos registrados.

Generalmente, las especies tienen uno, dos o tres usos, aunque, en casos excepcionales, se hace una utilización múltiple de la especie. Este es el caso de la chillka, que tiene siete usos, el algarrobo, que tiene seis usos, y el pingopingo, cachiyuyo, tara, chañar, lejía y cortadera, con cinco usos cada una (ver Anexo 1). Nueve especies fueron calificadas de perjudiciales, especialmente para el ganado y la agricultura, a pesar de que ellas eran valoradas en otros aspectos, tales como el ornamental o medicinal.

En la Figura 7 se muestra la distribución de los usos de la flora de los distintos pisos de vegetación, en el gradiente estudiado. De la comparación de estas distribuciones, se destacan algunas tendencias. Así, por ejemplo, el Piso Altoandino es predominantemente forrajero. De los 63 usos registrados para la flora de este piso, el $52 \%$ corresponde a plantas que alimentan a los animales domésticos y/o silvestres. En este Piso es también importante el uso como leña de los arbustos, especialmente de las raíces y troncos de los arbustos achaparrados y cojines leñosos (16\%). Los Pisos Puneño, o de Tolar, y Prepuneño, o de ma- torral semidesértico (Fig. 7), exhiben una distribución más equilibrada de los distintos tipos de usos de la flora, en comparación con el Altoandino. En ambos pisos predominan los tipos de usos forrajero (Puneño, 31\%; Prepuneño 44\%) y medicinal (Puneño, 25\%; Prepuneño 13\%). También, en ambos pisos las especies de plantas tintóreas son más abundantes que en el resto de la vegetación del área y, en un ámbito regional amplio, extraordinariamente representado (Puneño, 7\%; Prepuneño, 13\%). En particular, se destacan los arbustos del tolar como la principal fuente de combustible y leña de la zona de estudio (Puneño 13\%). Por otro lado, en el Piso semidesértico se destaca la más alta proporción de plantas alimenticias de la zona de estudio (Prepuneño, 14\%). La flora azonal de las Quebradas, riberas de ríos, salares y chacras muestran (Fig. 7), igual que los dos pisos anteriores, un franco predominio de las especies forrajeras $(36 \%)$ y medicinales $(26 \%)$. También son relativamente importantes varios otros tipos de usos tales como comestibles (10\%), adorno (9\%), construcción y artesanías (7\%) y usos varios (7\%). Se desprende del análisis precedente que esta flora es la que tiene la utilización más diversificada, hecho que se corresponde con la heterogeneidad vegetacional que la caracteriza. 
Piso Altoandino

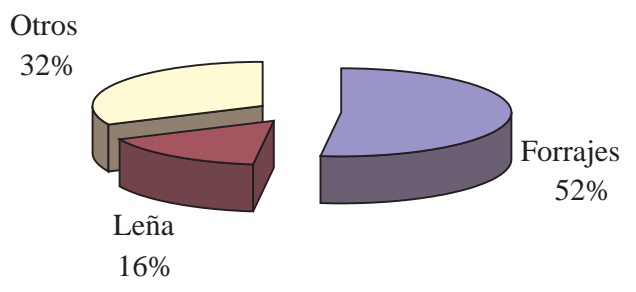

Piso Prepuneño

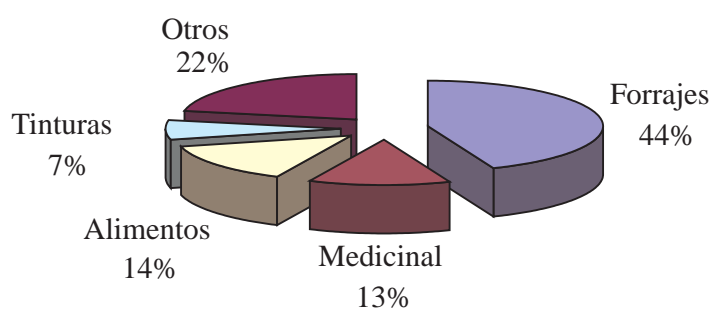

Piso Puneño

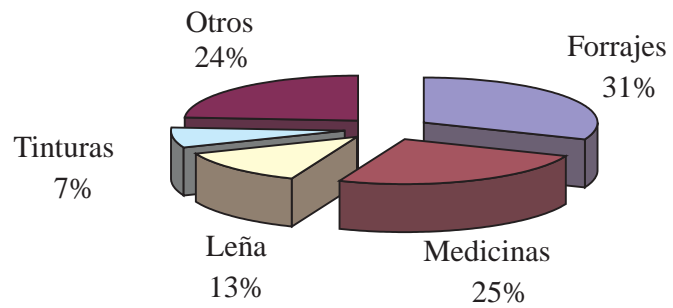

Flora Azonal

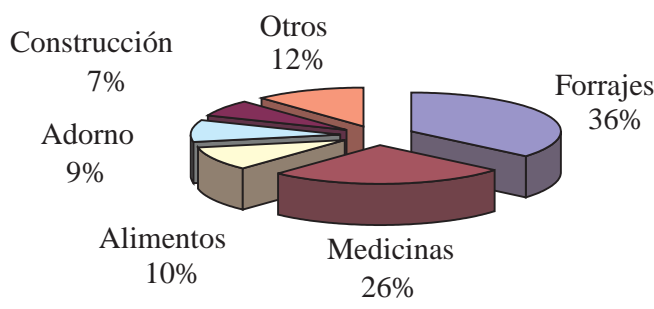

Figura 7: Distribución de los usos de la flora de los distintos pisos de vegetación en el gradiente estudiado.

\section{Discusión}

Definir lo andino y sus posibles límites, tanto culturales como espaciales, es una de las tareas pendientes en el inventario de temas planteados a los estudiosos de los Andes. Más que definir, es necesario conceptualizar, y ser capaces de entender la multiplicidad de manifestaciones diferentes que, a despecho de las disyunciones, seguimos reconociendo como andinas. Los estudios de la última década sobre lo aymara y su especificidad, desarrollados sobre todo en Bolivia y en el área de Quito (Saignes, 1985; Albó \& Mamani, 1980; Bouysse-Cassagne, 1987, entre otros), han permitido ver con una nueva mirada ese manto de aparente homogeneidad que era tan frecuente encontrar en el concepto de lo andino en los trabajos de la década pasada. Esa supuesta continuidad de la tradición andina se extendería desde el nudo de Pasto, por el norte, hasta una frontera sur algo imprecisa, pero que muchos situaban entre el Noroeste Argentino y la región de Copiapó, en Chile (Castro \& Martínez, 1996).

En los Andes del Norte Grande de Chile, a pesar de las improntas de variados procesos sociales y económicos, de diferentes presencias republicanas y de la presencia de distorsionadores enclaves económicos, es posible vislumbrar elementos propios de dos tradiciones culturales distintas. En efecto, entre los rasgos culturales que caracterizan a las comunidades andinas de esta región, se encuentran elementos de una tradición que se ha denominado Tradición Altiplánica, integrando las comunidades genéricamente agrupadas bajo el concepto de "aymara", con elementos de influencia quechua parlantes y de otros grupos que pueblan el Altiplano, sobre cuya etnicidad no nos atrevemos a pronunciarnos. Por otra parte, están pre- 
sentes elementos de otra tradición que, sobre la base de evidencias arqueológicas, Castro, Aldunate y Berenguer (1984) llamaron Tradición del Desierto. Recientemente, esta segunda tradición cultural ha sido redenominada, sobre la base de evidencias etnográficas, Tradición de tierras áridas (Castro \& Martínez, 1996), involucrando tanto los espacios de la franja desértica del Salar de Atacama y Cuenca del río Loa, como también aquellos de la Puna Salada desde el gran Salar de Uyuni hacia el sur, en un espacio que involucra varios territorios étnicos: lípez, atacamas, la puna de Jujuy e, incluso, el borde de la región de Tarapacá. Concordando con los conceptos de estos últimos autores, nos parece adecuado escoger en este trabajo un nombre que consideramos más preciso, Tradición del Desierto y Puna oriental aledaña.

Las particularidades de la tradición cultural del Desierto y Puna oriental fueron advertidas primeramente por los arqueólogos (Núñez y Grosjean, 1994; Núñez \& Dillehay, 1978; Castro, Aldunate \& Berenguer, 1984; Martínez, 1990). De acuerdo a Núñez y Grosjean (1994), las primeras ocupaciones humanas, en el área de Atacama, fueron cazadores trashumantes que vincularon los diversos paleorrecursos de la Alta Puna (camélidos, aves y roedores) con los del pie de monte y quebradas, los cuales, además, contaban con recursos más estables de agua y vegetación correspondientes al Holoceno temprano (arcaico temprano). Posteriormente, durante el arcaico medio (8.500-5.000 A.P.), un lapso bautizado como "silencio arqueológico", ha sido registrado para Atacama, al sur de los $23^{\circ} \mathrm{S}$, donde sólo permanecieron asentamientos en enclaves con recursos más estables asociados a arroyos y vertientes, bajo los $4.000 \mathrm{~m} . \mathrm{snm}$., probablemente bajo condiciones climáticas desfavorables y disminución significativa de los recursos naturales. Esta etapa coincide con el comienzo de la domesticación de camélidos y la agricultura, innovaciones que permitieron lograr una mayor autonomía en relación con los recursos de la caza y la recolección. Estas prácticas, unidas al desarrollo de técnicas de conservación y almacenamiento de alimentos, permitieron, más tarde, el surgimiento de sociedades complejas agroceramistas, adecuadas a las condiciones áridas de la Puna de Atacama.

Dentro de la Tradición del Desierto y Puna oriental, recientemente se viene cuestionando la uni- dad cultural de la categoría atacameño, concepto que cubre con un manto de homogeneidad a los indígenas de Atacama La Alta y La Baja, a partir del siglo XVI, desde que los papeles coloniales identificaron, bajo ese nombre, a toda la población que habitaba el territorio delimitado por la administración española como Atacama. La discusión se ha centrado en la existencia de diferencias, que podrían ser sustanciales, entre las poblaciones prehispánicas que ocuparon la cuenca del río Loa y aquellas asentadas en la hoya del Salar de Atacama; aunque algunos trabajos postulan la existencia de un grupo étnico prehispánico del Salar de Atacama, que podría recibir el nombre de atacameño, faltan estudios que permitan aportar datos suficientes para precisar y definir las características de esta etnia. Por otro lado, ya desde las postrimerías del siglo XIX se viene dando una acelerada desaparición de algunos rasgos y tradiciones culturales propios de este grupo, como la lengua (kunza), lo que denotaría un fuerte proceso de hispanización, pese a lo cual estos grupos han conservado una parte importante de su cultura tradicional.

De acuerdo a los resultados de este estudio etnobotánico, reconoceremos, como perspectiva general, un cierto grado de diferenciación y posible pluralidad cultural en la región de la Tradición del Desierto y Puna oriental aledaña, como lo han sostenido varios autores (Grebe \& Hidalgo, 1988; Martínez, 1990 a,b; Castro \& Martínez, 1996). Esta apreciación se basa en la existencia de una serie de singularidades que caracterizarían el conocimiento de la flora, por parte de las comunidades actuales que integran el sector sur de la tradición del desierto, específicamente de las comunidades que habitan en torno al Salar de Atacama. Estos rasgos característicos se discuten brevemente a continuación, como asimismo sus relaciones con el sector norte, específicamente el área del Loa Superior estudiada etnobotánicamente por varios autores (Aldunate et al. 1981; Villagrán \& Castro 1999; Romo, 1998; Villagrán, Castro \& Sánchez, 1999, este volumen).

Uno de los resultados más interesantes de este trabajo es la constatación de una nomenclatura botánica distintiva en el área de estudio. Como se ha mostrado, una interesante proporción de los nombres indígenas, registrados en este estudio, son 
usados exclusivamente en las comunidades en torno al Salar de Atacama y provienen de un idioma desaparecido, el $\boldsymbol{k u n z a}(8 \%){ }^{2}$ La persistencia aislada de estos nombres de plantas, remanente lingüístico de la cultura atacameña, el grupo étnico prehispánico que pobló el Salar de Atacama, confiere distintividad a la nomenclatura botánica del sector sur de la Tradición del Desierto y Puna Aledaña. Este rasgo también se expresa muy marcadamente en la toponimia de la región. De acuerdo a Munizaga y Gunckel (1958), existen fitotopónimos tales como un grupo de quebradas situadas al SW de Socaire, Sirántur, nombre vernacular kunza de la planta Pennisetum chilense (llamada también esporal, espural, espuro o simbol). Otros fitotopónimos serían: quebrada de Kipsuna, de acuerdo al nombre de una planta llamada kípsur, no determinada botánicamente, y quebrada Chejcheraja, de acuerdo al nombre de Haplopappus rigidus, la chajchajara o chejchara. Tienen también nombre kunza algunas de las comunidades estudiadas, como Socaire, Camar, Puritama.

De la comparación de la nomenclatura botánica, obtenida en las comunidades del Salar de Atacama con otras comunidades de los Andes de Antofagasta, se desprenden relaciones etnobotánicas débiles con el Loa Superior, en lo referente al grupo de nombres de origen kunza. Por ejemplo, entre los 98 nombres vernaculares de plantas compartidos entre Caspana (Villagrán, Castro \& Sánchez, 1999) y los poblados de Atacama, la mayor proporción corresponde a nombres españoles, o mezclas de español e indígena (63\%), nombres quichua/aymara (26\%) y otros. Solamente tres nombres son kunza, sáilao, konte o kontikonto, chukula. Dos nombres son comunes a los idiomas quechua, aymara y kunza y tienen una amplia difusión en los Andes del norte de Chile, lako, kopa o kopakopa. Otros dos nombres pueden ser quechua o kunza, kore o kori y tikara. Estos pocos nombres kunza compartidos entre las dos regiones, tienen un amplio uso en la cuenca del Río Loa (Aldunate et al. 1981; Villagrán

En el Anexo 3 se listan los 35 nombres vernaculares registrados que corresponden, probablemente, al idioma kunza y los 17 que corresponden tanto al kunza, como al aymara y al quechua.
\& Castro 1999), con excepción de dos que solamente se han registrado en la localidad de Caspana, el kore o kori (Acantholippia deserticola), una especie muy abundante en el piso prepuneño y desértico del norte de Chile y conocida en una extensa área geográfica como rikarika, y el konte o kontikonto (Lupinus oreophilus), conocida como flores del campo en Toconce, y garbanzo o q'ela, en otras regiones altiplánicas. El uso exclusivo en Caspana de estos nombres kunza, ampliamente difundidos en el Salar de Atacama, apuntaría a relaciones más estrechas entre estas dos regiones.

Frente a la pregunta ¿dónde se sitúa la transición entre las comunidades del Salar de Atacama y las del Loa Superior?, resulta sugerente destacar que tanto los habitantes de la cuenca del Loa como los del extremo sur del Salar de Atacama visualizan a Toconao como un punto de articulación, más allá del cual ambos sectores ven disminuir sus vínculos y relaciones. Lo interesante es que, precisamente, al sur de Toconao es donde se advierten con mayor fuerza los elementos de la Tradición del Desierto y Puna oriental aledaña, conjuntamente con un aumento de los vínculos hacia la puna de Jujuy y hacia lo que hoy es el Noroeste argentino. De modo concordante, nuestros resultados etnobotánicos han permitido registrar diferenciación local de nombres dentro del área del Salar de Atacama. La región más tradicional, que mantiene hasta la actualidad algunos nombres antiguos y exclusivos, corresponde al territorio situado en el borde sur del Salar de Atacama, específicamente el enclave Camar-Socaire-Peine, donde se conservan nombres tales como chajchara o chajchajra, kori o kore, kulchao o kulchau, atalte. Nombres exclusivos de la localidad de Peine son tolontolón, kaudal, lokoche. De Socaire, ojman u osman. Un caso singular es el de Río Grande, en la cuenca del río Vilama, al norte de San Pedro de Atacama. Un sector de Río Grande, llamado "quebrada abajo", se identifica con San Pedro de Atacama, mientras que los habitantes de Peñaliri y San Juan, igualmente constitutivos de Río Grande, se identifican con Caspana. Se genera así una curiosa situación de "bisagra" o punto de intermediación entre el poblamiento de la cuenca del Salar de Atacama con la del río Loa (Castro \& Martínez, 1996). Los autores del presente trabajo están estudiando actualmente la etnobotánica de 
la región de Río Grande y pueden informar que las relaciones etnobotánicas entre este sector y las comunidades atacameñas son bastante apreciables, a pesar que también evidencian influencia de la nomenclatura usada en el Loa Superior.

Otra de las características de las comunidades, dentro de la región de la Tradición del Desierto, es su diversidad cultural, resultado de la presencia estable de grupos inicialmente externos a la zona, desde, al menos, los períodos Prehispánico tardío y Colonial. Más que en las regiones andinas altiplánicas de Chile, de la primera Región (Castro et al., 1982; Villagrán et al., 1999), la nomenclatura botánica de la Región de Antofagasta expresa la presencia de diversas influencias culturales (Aldunate et al., 1981; Villagrán, Castro \& Sánchez, 1999). Este rasgo se expresa en un notable multilingüismo en el espectro de nombres de plantas, destacando los nombres provenientes del kunza, aymara, quechua, mapuche y, principalmente, del español. Si consideramos solamente los nombres indígenas de plantas, lo distintivo de la región del Salar de Atacama es, como ya se dijo, el predominio del componente kunza, en comparación con los componentes quechua y aymara que predominan en el Loa Superior. Por otra parte, el elevado número de vernáculos registrados (416) en la región del Salar de Atacama, debido a la existencia de nombres múltiples para una misma especie, generalmente en lenguas diferentes, refleja también la múltiple influencia cultural en el área. El mejor ejemplo es Krameria lappacea, una importante planta tintórea de Atacama, con 13 nombres vernaculares registrados, entre los que destacan tikara o tíkara (kunza o quechua), chakachaka y chipichapi (aymara), monte negro, palo colorado, pegapega, té colorado y cadillo (españoles), tikara hembra y tikara negra (kunza/quechua y español).

Por otro lado, desde el período colonial, habría ocurrido un fuerte y prolongado proceso de hispanización en toda la región. Muchas de las comunidades de la Región de Antofagasta chilena tienen una existencia que, documentalmente, puede fijarse desde el siglo XVII y, probablemente, con anterioridad. Es así como, en la segunda mitad del siglo XVII, la administración eclesiástica colonial propugna y logra un aumento significativo del clero secular en el virreinato del Perú, del cual esta área formaba parte. Vitaliza la presencia de santos en los lugares de culto y desarrolla una activa participación en las fiestas patronales. Además, dentro de su actividad evangelizadora, toma a su cargo la educación, la salud de la población y los registros de nacimientos, matrimonios y defunciones; a esta política se suma el apoyo de administradores laicos (Castro, 1997). La fuerte influencia española en el área del Salar de Atacama se expresa en varios rasgos que se desprenden de nuestro estudio etnobotánico. En primer lugar, destaca la elevada proporción de nombres en este idioma (53\%) o de nombres mixtos español-indígena (12\%). Este mismo rasgo se aprecia también en las comunidades del sector norte de la Tradición del Desierto, en el Loa Superior, tanto en Caspana (Villagrán, Castro \& Sánchez, 1999), como en Toconce (Aldunate et al., 1981). La influencia hispánica también se refleja en algunos criterios de etnoclasificación y utilización de la flora advena.

En contraste con los sistemas de clasificación preferentemente morfofisionómicos, característica común de la etnoclasificación en los Andes del norte de Chile (ver Aldunate et al., 1981; Villagrán \& Castro, 1999; Romo, 1998; Villagrán, Castro \& Sánchez, 1999), en las comunidades del Salar de Atacama se ha registrado multiplicidad de criterios en la etnoclasificación. Así, por ejemplo, además de agrupaciones por forma de vida y morfología, hay también reconocimiento de etnocategorías utilitarias y por referencia a plantas importantes, muchas veces introducidas. Estos dos últimos rasgos habían sido registrados en Chile solamente en la etnoclasificación mapuche (Villagrán, 1999; Villagrán et al., 1999). Sin embargo, a diferencia de la cultura mapuche que expresa estas etnocategorías en mapudungun, en la clasificación atacameña es frecuente la definición de etnocategorías genéricas usando como referentes especies importantes con nombre español, ya sean silvestres o introducidas. Las especies subordinadas de una agrupación por referencia se designan, generalmente, con diminutivos (en español) de los nombres de las especies importantes, como por ejemplo, el algarrobo (algarrobillo), alfa (alfilla), cardón (cardoncillo), romero (romerillo), berro (berrillo), garbanzo (garbancillo), grama (gramillo), cuerno (cuernillo), etc. 
Adicionalmente, la influencia hispánica se manifiesta en muchos nombres de especies de plantas de Atacama que corresponden a préstamos de nombres de especies europeas distintas. Obviamente, es el parecido el que lleva a aplicar el mismo nombre español a un taxon diferente. Algunos ejemplos son ajenko, amapola, anís, azafrán, borraja, cedrón, pimiento, etc., todos estos, nombres aplicados a especies diferentes de las europeas que llevan este nombre. En la flora de Chile hay numerosos otros ejemplos de esta característica de los españoles, de nombrar especies desconocidas con el mismo nombre de otras que ellos conocían en Europa. En el caso de la flora arbórea, destacan los préstamos de nombres europeos para designar árboles chilenos sin ninguna relación taxonómica, a pesar de que estos árboles ya tenían sus nombres propios mapuches. Algunos ejemplos de árboles importantes de nuestros bosques, redenominados por los españoles por su parecido a los europeos, son: canelo (foyge, Drimys winteri), ciruelillo (notru, Embothrium coccineum), avellano (ngüfün, Gevuina avellana), avellanillo (piñol, Lomatia dentata), olivillo (tüke, Aextoxicon punctatum), roble (coyam, Nothofagus obliqua), espino (kaven, Acacia caven), ciprés (lawan, Pilgerodendron uviferum), laurel (triwe, Laurelia sempervirens), arrayán (Qütri, Luma apiculata), por citar unos pocos (Moesbach, 1982).

La existencia de una economía básicamente de subsistencia, acoplada a un ecosistema que se caracteriza por la precariedad de sus recursos bióticos, se traduce en una utilización intensiva de la flora, tanto silvestre como advena. Este rasgo se refleja principalmente en el elevado número de usos registrados (328) para la flora de Atacama. Numerosas especies tienen usos múltiples, que es otra característica del uso intensivo de la paupérrima biota del desierto. Por ejemplo, árboles como el chañar y el algarrobo son importantísimos como fuente de alimentos, medicina, forraje, combustible, construcción, artesanías y usos rituales. De acuerdo a Munizaga \& Gunckel (1958), el algarrobo viene siendo usado desde el pasado prehispánico, en forma de harina o aloja, en toda la región del Salar de Atacama. Actualmente, la población de Socaire lo importa por trueque de Peine, mientras que el chañar lo trae de Toconao. El intercambio de estos productos, entre las poblaciones bajas y altas, es muy importante y, al parecer, tiene una larga data (Martínez, 1998). Munizaga \& Gunckel (1958) citan repetidos hallazgos arqueológicos de chañar y algarrobo, en una amplia región geográfica del norte de Chile, y sugieren que, tal vez, muchos artefactos, como morteros, martillos de piedras, etc., estarían relacionados con el aprovechamiento de estas plantas.

Hasta el presente, en la región de Atacama continúa siendo importante la recolección de especies alimenticias. En Anexo 1 se describen cerca de 30 especies consumidas de distintas formas, ya sea frescas, como ensaladas, guisos o en la preparación de productos como harina, licores, bebidas o té. Destacan el algarrobo, el chañar, la sicha, la pasakana, las papas bilankichu, el kachiyuyo, el lokoche, el berro, la altea, el kauchal y el nori, además de otras plantas utilizadas como té, como condimento y para preparar la llikta. Munizaga y Gunckel (1958) citan, además, como especies alimenticias otros dos taxa no determinados botánicamente: la cebolla del campo, con bulbo comestible con gusto a damasco; y el kípsur, una raíz comestible que se obtiene de Peine ${ }^{3}$. Llama también la atención la gran cantidad de especies relacionadas con usos textiles (13), destacando plantas tintóreas como: kopakopa, pingopingo, tikara macho, tikara hembra, chillka, chacha, algarrobo, basal, tomatillo, y la tuna del kume como mordiente. También se fabrican con plantas silvestres los implementos utilizados en la confección de tejidos, como la caña, algarrobo, chañar, azafrán, carda y el cardón chico. Cabe destacar el uso intensivo que se hace de las especies de malezas de las chacras y huertos, de reciente introducción en la zona, reafirmándose así la necesidad de una máxima explotación de todos los medios al alcance. Malezas como las romazas, especies de llantén, el amor seco, cepacaballo, la hierba del tapón, las especies de malvas, sangrinaria, hinojo, verbena e, incluso, una forrajera, la alfalfa, se utilizan en alto grado, tanto en medicina como en alimentación. El uso intensivo de las malezas, de reciente introducción, refleja flexibilidad en la incorporación de nuevos recursos por parte de estas comunidades.

Entre las raíces comestibles del borde del salar de Atacama, destaca Tiquilia atacamensis, el káuchal. ¿Corresponde el káuchal al kípsur? 
Este aprovechamiento máximo de los recursos disponibles, en este ambiente, se mantiene hasta la época actual, destacándose el énfasis en la agricultura de oasis, especialmente en las comunidades de Peine, Camar y Toconao. En términos generales, la producción de las diferentes comunidades del Loa Superior y Salar de Atacama se orienta, en primer lugar, hacia el autoconsumo; en segundo lugar, hacia los mercados locales o regionales; por último, hacia el trueque o el intercambio con gente de otras comunidades vecinas o venidas desde Lípez, en Bolivia, y la puna de Jujuy, en Argentina. El autoconsumo se basa, esencialmente, en la producción agropecuaria y, en algunas circunstancias, en la recolección de especies vegetales o en la caza. Prácticamente, todas las comunidades poseen alguna variedad de maíz apta para su almacenamiento. Por ejemplo, para Socaire (Munizaga y Gunckel, 1958) se han registrado 17 variedades de maíz, algunas con nombres posiblemente kunzas, como aillen (rosado), pokoi y kebir; otros quichua, como pisankalla, chejjecito (chejchisítu, chekkchi), aikenisto, este último procedente de Aiquina y evidenciando, así, relaciones con el Loa Superior. Además, se han citado 13 variedades de papas para Socaire, entre ellas la variedad pauna, vernáculo kunza. El intercambio, aún cuando en los volúmenes involucrados es de importancia variable, tiene gran trascendencia porque posibilita el acceso a recursos que, de otra manera, serían inaccesibles. Además, pone en juego un complejo y extenso sistema de relaciones sociales intercomunitarias e incluso interétnicas, de larga tradición en la región. En efecto, cada caravanero proveniente de otra región se dirige, generalmente, hacia lugares en los cuales ya tiene relaciones preestablecidas con sus moradores y es con ellos con quienes realiza intercambios (Aranda, 19611964).

¿Por qué, y a pesar de las crisis e influencias distorsionadoras sufridas por quinientos años, el conocimiento de la flora y su uso intensivo subsiste en un mundo lleno de transformaciones? Las respuestas a esta pregunta residen en la persistencia de la comunidad. La comunidad está constituida, tanto por la organización comunal como por las unidades familiares, asentadas en un "territorio colectivo" (sensu Plaza y Francke, 1981). Es la posesión de tierras cultivables, con todos los trabajos colectivos de mantención que ellas generan, lo que posibilita la adscripción de un individuo a un núcleo comunitario, el que también proporciona el gentilicio, e.g. talabreño, socairino, etc. Es la comunidad como institución la que articula la red de relaciones sociales, económicas y religiosas que permiten el funcionamiento del patrón de asentamiento (Castro \& Martínez, 1996).

El actual patrón de asentamiento se caracteriza por su dispersión, articulándose en torno a un núcleo aldeano central, del que dependen varios sectores menores, tanto agrícolas como ganaderos. La dispersión de predios y pequeñas extensiones de terrenos cultivables, en un mismo piso ecológico o en varios de ellos es, precisamente, una de las características estructurales más notorias de las estrategias económicas andinas, desde tiempos precolombinos (Murra, 1975; Masuda et al., 1985). Su práctica, con las variaciones y especificidad correspondientes a los distintos períodos y procesos históricos, continúa, hasta ahora, en muchas comunidades andinas. Este sistema de asentamiento, a nivel de la unidad doméstica, podría ser también percibido como una aplicación local del modelo de complementariedad comprimida (Brush, 1974), en tanto es un mecanismo que permite acceder a recursos diversificados sin un control centralizado. La complementariedad, esto es, la posibilidad de tener acceso a recursos distintos, obtenidos en pisos ecológicos diferentes, o de garantizar, mediante la dispersión de los cultivos, una cosecha más segura, sigue siendo hasta hoy un ideal expresado por los campesinos de la Tradición del Desierto y Puna oriental. El sistema de parentesco y transmisión de derechos permite generar situaciones que le den continuidad al sistema. Aparentemente, es la patrilocalidad la práctica de residencia de una nueva unidad doméstica, constituyendo la norma ideal tanto en el Alto Loa como en el Salar de Atacama, aunque también en poblados particulares -Caspana, Peine y Toconce- se han documentado otras modalidades como neolocalidad, matrilocalidad y bilateralidad (Délano, 1982; Mostny, 1954; Gómez, 1981-1982; Castro \& Martínez, 1996).

De acuerdo con el modelo andino de asentamiento que impera también en el Salar de Atacama, especialmente en los poblados precordilleranos de 
Talabre y Socaire, la práctica de obtener recursos de distintos pisos ecológicos se expresa en nuestro estudio etnobotánico en: a) El conocimiento preciso de la flora de todos los pisos altitudinales de vegetación. b) El uso especializado de cada piso de vegetación. c) El énfasis forrajero de todos los tipos vegetacionales, siendo siempre este rubro el más importante. Así, por ejemplo, 114 especies fueron calificadas como consumidas por el ganado doméstico o por la fauna silvestre $(66 \%$ del total de especies consultadas). Estas cifras son concordantes con los datos aportados por Munizaga y Gunckel (1958), quienes documentan para Socaire 66 especies de uso forrajero (56\% del total de especies consultadas). El piso Altoandino es preponderantemente forrajero y, del total de usos registrados para su flora, el porcentaje del rubro forrajero corresponde al 52\%. Una detallada descripción de las especies forrajeras de Talabre, las técnicas de almacenaje, las preferencias del ganado y los circuitos pastoriles de las distintas unidades domésticas son proporcionados por Morales (1997). El segundo tipo de uso importante de la flora del Salar de Atacama corresponde al medicinal. 79 especies consultadas (Anexo 1) se usan como remedios (45\% del total de especies consultadas). En contraposición con el piso Altoandino, eminentemente forrajero, el piso Puneño de tolar y la flora azonal de Quebradas proveen, en mayor grado, las medicinas para las comunidades. De todos los usos registrados para la flora de ambos tipos de vegetación, los porcentajes del rubro medicinal corresponden a un cuarto del total.

¿Qué mecanismos aseguran la coherencia, identidad y permanencia de la comunidad? Uno de los aspectos importantes destacados en la literatura se refiere a las funciones religioso-ideológicas que aseguran la identidad y pertenencia de los miembros de la comunidad. Existe una estrecha asociación entre las actividades productivas y las rituales, vínculo que transforma a las fiestas y ceremonias como extremadamente importantes para la reproducción del sistema comunitario, a la vez que extremadamente frágiles a la presión de los cambios económicos. Los mitos atacameños se centran en tres espíritus de la naturaleza -de la tierra, del cerro y del agua- en los espíritus de los antepasados, y en una serie de espíritus menores asociados a fenómenos naturales y culturales -camino, apacheta, piedra, semilla, siembra, ganado, tejido (Grebe \& Hidalgo, 1988). Como se ha destacado en el capítulo de percepción ambiental, de especial relevancia es el culto a los cerros, los que se asocian a los manantiales y fuentes de agua, personificando entidades sagradas, de carácter local o regional, que pueden aparecer con diversas características ya sea como proveedores de minerales, relacionadas con los fenómenos atmosféricos y el ciclo agrícola, o como una deidad protectora de la vida, la salud y la prosperidad de la gente (Cárdenas, 1999; Castro \&. Martínez, 1996). El conjunto de creencias es reactualizado en un ciclo compuesto de cuatro ritos: el de la semilla o la siembra, de la limpieza de canales de regadío (que incluye la ceremonia de los cantales y el talatur), del carnaval y del enfloramiento (Grebe $\&$ Hidalgo, 1988). En tales ceremonias destaca el simbolismo asociado a ciertas plantas o sustancias de origen vegetal. Así, por ejemplo, en la ceremonia de limpia de difuntos se usa la tara o monte negro para el "separamiento de almas", mezclada con paja sikuya y plumas de parina. En el ceremonial agrícola figuran plantas como el konte $^{4}$, el kafle ${ }^{5}$, la illinkuma ${ }^{6}$, la papa pauna ${ }^{7}$. En diversas fiestas se usa el maíz ${ }^{8}$, las hojas de coca, y se bebe aloja de algarrobo. En el ceremonial ganadero, la especie ritual más importante es la koba para sahumerio (Grebe \& Hidalgo, 1988; Mostny, 1954; Munizaga \& Gunckel, 1958).

De acuerdo a Munizaga \& Gunckel (1958) y a Mostny (1954), en Socaire y en Peine, el cantal se adorna la cabeza con las flores de konte durante en las ceremonias de culto a las montañas durante el rito de limpieza de acequias.

5 En Socaire, "En los cantos regionales aparecería esta planta con la denominación sáflu" (Munizaga \& Gunckel 1958)

6 De acuerdo a Munizaga y Gunckel (1958), en Socaire, esta planta, no identificada botánicamente por los autores, "figuraría en los cantos folclóricos regionales con el nombre de illauca". Es posible que este vernáculo esté relacionado con illakowa, sinónimo de la qoba o koa, término recopilado en Caspana para la principal planta ritual de esta localidad, Fabiana squamata (Villagrán et al., 1999). Probablemente, en el caso de Socaire la especie denominada illauca corresponda a Parastrephia quadrangularis, la chacha o koa, la principal planta ritual del Salar de Atacama. De acuerdo a Mostny (1954), la papa pauna se la nombra en un canto ceremonial del oasis de Peine. corporación del maíz en aspectos ceremoniales de la 
Mediante la ofrenda de estos elementos, y el sacrificio, unidos a ciertos medios de comunicación ritual (tales como el humo de sahumerio y la música del agua) se logra una interacción simbólica entre los atacameños y los espíritus. (Grebe \& Hidalgo, 1988).

Merece una mención aparte la especie ritual más importante de Atacama, Parastrephia quadrangularis (Familia Compuestas), registrada en nuestro estudio con los vernáculos chacha9, chacha hembra, chacha chica, chacha fina, chachakoa, koa y tola. Mezclada con wirakoa ${ }^{10}$, se usa durante los "floramentos" del ganado. El humo se llama koa ('koar al ganado', se dice). Mostny (1954), cita, para Peine, los vernáculos chacha y chachakoma ${ }^{11}$ para esta planta, reseñando que se trata 'de una planta aromática, usada para sahumar y en las ceremonias relacionadas con el agua (limpieza de las acequias)'. Munizaga \& Gunckel (1958) documentan el uso de chacha o koa en el ceremonial agrícola (limpia de canales) y en el ceremonial pastoril (sahumerio de los animales) para que prosperen y se multipliquen. Estos autores sugieren que, de acuerdo a sus informantes, la chacha se "transforma" en koa cuando es quemada con fines ceremoniales. Serracino y colaboradores (1974) citan para Guatín el vernáculo koba para esta especie, agregando que 'se usa para humear las cabras'. De acuerdo a nuestras consultas, otras dos especies de plantas de Atacama también se llaman chacha, Parastrephia teretiuscula ${ }^{12}$, la chacha pelada que se usa para koar el ganado menor, especialmente los burros, cuando no hay chacha koa.

comunidad se verifica en la ceremonia del matrimonio, donde algunos de los presentes ofrecidos a los recién casados consistía, años atrás, en collares en que estaban ensartadas, a maneras de cuentas, mazorcas de maíz de diversos colores, papas, y una clase particular de panes horadados. En un sentido ceremonial además de alimenticio se emplean también actualmente las "flores de máiz" que se confeccionan con el tipo pisangallo.

9 En Perú, las chachas son todas especies de Escallonia (Soukup, 1970).

10 De acuerdo a Cárdenas (1989), en Bolivia la koa más común es llamada huira-koa. Corresponde a una especie de Diplostephium que crece en el norte de Chile o en la frontera con Bolivia. De acuerdo a Castro, Villagrán \& Kalin (1982), la koa en los Andes de Arica es Diplostephium cinereum.
La otra especie de chacha es Fabiana bryoides, llamada también pata de perdíz.

Probablemente, no hay ninguna planta ritual andina más importante que la koa, coba o chacha ni tampoco tanta confusión acerca de su determinación botánica. Efectivamente, con los mismos usos ceremoniales y rituales descritos en el Salar de Atacama para Parastrephia quadrangularis, se han descrito otras especies de plantas andinas, tanto en el Loa Superior como en el altiplano de Tarapacá y países limítrofes. En el Loa superior, dos especies distintas de la Familia Solanáceas, Fabiana. squamata en Caspana, con los nombres de koba, koba Santiago, q'oba, koa, koa Santiago, illakowa, koiye (Villagrán, Castro \& Sánchez, 1999, este volumen) y Fabiana bryoides en Toconce, con los nombres de k'oa Santiago y k'oa (Aldunate et al., 1981). En el Altiplano de Arica, la especie Diplostephium cinereum (Familia Compuestas) ha sido registrada con los nombres de k'oa y coba y con los mismos usos ceremoniales para sahumar el ganado y en las vilanchas (Castro, Villagrán \& Kalin, 1982). El hecho de que todos los pueblos de los Andes del Norte de Chile usen, con exclusivas funciones ceremoniales y con nombres muy parecidos, distintas especies de plantas, es muy significativo acerca del poder que puede tener un nombre. Con respecto a la palabra koba, es interesante que Munizaga \& Gunckel (1958) destaquen que este término no se refiere a una especie de planta sino que es "un término para denominar un ceremonial o un complejo religiosos de rasgos, y no meramente un polvo o una sustancia botánica que constituirían meros rasgos componentes de este

11 El vernáculo chachakoma podría ser una confusión con el nombre que se le da ampliamente en los Andes a distintas especies del género Senecio, o bien, una mala transcripción de chachakoa. Alternativamente, si el registro de Mostny (1954) del nombre chachakoma para $P$. quadrangularis es correcto, es muy interesante este dato ya que, en Perú (Soukup, 1970), a las especies arbóreas del género Escallonia se les llama chachas y chachacomas o chachacumas. En Bolivia, también Escallonia resinosa es llamada chachacoma (Cárdenas, 1989). No hemos visto especies de Escallonia en Atacama, pero sí en las quebradas y oasis de los Andes de Iquique.

12 De acuerdo a Cárdenas (1989), en el sur de Bolivia se le llama koa a la especie Parastrephia teretiuscula. 
complejo ritual andino". Según estos autores, un término similar es por ejemplo coa o cohua (kowa), una planta utilizada en ceremonias del ganado en el NW de Argentina; q'oa (Mentha pulegium $)^{13}$, entre los aymaras del Titicaca, usada en prácticas adivinatorias. De acuerdo a Cárdenas (1989), en Bolivia se llaman koas a una especie de Diplostephium y a Parastrephia teretiuscula. Coa, en la flora peruana, corresponde al nombre de especies de Borreria (Familia Rubiáceas), con poderosas propiedades medicinales (Soukup, 1970). Koa, en las montañas del sur de Perú, es también la denominación para el espíritu sobrenatural de un "gato" ("felino celestial", de acuerdo a Castro, 1997), al que deben hacérsele ofrendas. La explicación sobre la chacha de Munizaga y Gunckel (1958), y su transmutación en koa, es consistente con su sugerencia de una relación entre la palabra koa y manipulaciones mágicas, siendo irrelevante el material botánico utilizado. Esta apreciación concuerda con la comunicación personal de nuestro amigo Jorge Flores Ochoa, según el cual la palabra koa significaría "lo que se transforma en otra cosa".

\section{Conclusión}

Si bien varias de las comunidades de la II Región, integradas en la Tradición del Desierto y Puna Oriental, conservan todavía la capacidad de organizar y controlar los recursos naturales más bási$\cos$, como son la tierra y el agua, la influencia cada vez mayor de la economía de mercado y la creciente presencia de algunas entidades estatales han debilitado o reducido drásticamente sus posibilidades de manejo. Una de las manifestaciones de la tensión a que están sometidas estas comunidades se expresa en la pérdida paulatina de las tec-

Creemos que podría tratarse de una confusión de plantas aromáticas de la Familia Labiadas. El poleo (Mentha pulegium) es una especie de Labiada aromática, introducida en Sudamérica. De acuerdo a García (1991), en Bolivia se llama Koa a tres especies andinas, autóctonas, aromáticas y medicinales, también de la familia Labiadas, Satureja parvifolia, Satureja boliviana y Minthostachys sp. De acuerdo a Cárdenas (1989), estas especies se designarían también en Bolivia, con el nombre colectivo de muñas. Este último nombre es el que se usa en Perú y Chile para especies silvestres de Labiadas aromáticas del género Satureja. nologías tradicionales y su reemplazo por nuevas técnicas productivas, por ejemplo, el abandono de la alternativa multicultivo a favor del monocultivo en algunos poblados. También las prácticas tradicionales de pastoreo han empezado a cambiar con la introducción cada vez más masiva de ganado ovino y la desaparición de los grandes rebaños de camélidos, como consecuencia de la extracción de aguas desde las nacientes de los ríos, hecho que ha producido el abandono paulatino de las estancias situadas en los pisos ecológicos más altos. Por otra parte, el control social se ve cada vez más restringido por la aplicación de una legislación nacional que transforma a las comunidades en Juntas de Vecinos. También el proceso de transformación se manifiesta en la esencialidad y fragilidad de los rituales colectivos, discutiéndose ya, en algunas comunidades, acerca de la conveniencia de mantener la estructura tradicional de algunas ceremonias. Por otro lado, la complejidad de los procesos ocurridos en la región ha generado un reordenamiento demográfico, con desplazamientos hacia aquellos poblados que exhiben un crecimiento económico coyuntural. Este es, por ejemplo, el caso de San Pedro de Atacama, que ha estado recibiendo una importante afluencia de pobladores de más al interior, así como gente de la capital o de otros países, que erigen sus asentamientos en esta localidad y que, sin duda, también coparticipan de este sistema de transformaciones (Castro \& Martínez, 1996).

Nuestro estudio muestra que, a pesar de la evidente contradicción y tensiones entre la estructura tradicional de las comunidades, con una economía de autosubsistencia, y la dinámica impuesta desde afuera, tanto por la hispanidad como por la mercantilizada economía chilena actual, los procesos de transformaciones no se han traducido en pérdida del conocimiento etnobotánico de las comunidades del Salar de Atacama. Por el contrario, nuestros resultados muestran que estas comunidades exhiben un conocimiento extenso y complejo de la flora silvestre y advena, con una serie de rasgos singulares. En efecto, tanto la nomenclatura botánica como la etnoclasificación exhiben rasgos culturales propios al sector sur de la Tradición del Desierto, así como influencias tanto "altiplánicas" como "hispánicas". La forma de utilización de la flora refleja, por una parte, un manejo de larga tradición en Atacama y, por otra, 
un uso intensivo y diverso de la flora advena, de muy reciente introducción. Estas características etnobotánicas permiten inferir que las comunidades del desierto no han recibido pasivamente la influencia y presiones foráneas sino que han respondido con creatividad y flexibilidad al cambio constante al que han estado sometidas, manteniendo y enriqueciendo el conocimiento tradicional de la flora con una constante readecuación de la cultura propia e integración del aporte foráneo. En otros ámbitos culturales, también se han documentado ejemplos de comunidades andinas de Chile que, a pesar de todos los problemas que enfrentan, han desarrollado un proceso de revitalización cultural, de defensa de sus aguas y territorios de forraje, de resignificación de su identidad y de representación ante la sociedad mayor (Villaseca, 1998; Gundermann, 1986).

Sin embargo, toda la fuerza de las comunidades del desierto para poder seguir persistiendo no debe ocultar el enorme riesgo y fragilidad que significa la existencia en uno de los ecosistemas más secos del planeta. En la actualidad ya son muy extensas las áreas afectadas por la desertificación, las cuales difícilmente podrán recuperarse para el hábitat humano y de la biota. Este es un proceso dramático y acelerado que no podemos desconocer y está asociado, básicamente, a la extracción del agua por parte de la gran minería y otras necesidades de la sociedad chilena. A pesar de la subsistencia de una cultura tradicional, readecuada y multiforme, su situación es desigual frente a la economía nacional. Es necesario educar a la sociedad mayor, tremendamente inculta en este sentido, para que comprenda que la riqueza de una nación reside en su heterogeneidad cultural, en la integración con respeto a la diversidad. Esta es una de las tantas tareas urgentes de la sociedad chilena, la cual debe asumir que son las comunidades indígenas las que irán generando su futuro, a partir de su propia historia.

Agradecimientos Se agradece la valiosa ayuda proporcionada por las siguientes personas entrevistadas: José Cruz, Sofía Gavia Cruz, Juan Sosa, María Casimiro, Justo Mondaca, Hilda Vilte, Juana Flores, Jani Cruz Toroco y Osvaldo Flores Sosa, todos de Toconao; Donato Cruz y familia, Luciana Varas, Raimunda Tejerina y familia, Carlos Varas y Silvestre Varas Varas y Sra., de la localidad de Socaire; Idilberta Varas y familia, Dorotea Cruz Carral, Estanislao Ramos, Lino Cruz y Patricia Leiva, Marta Morales y Orlando Torres, de Peine; Lorenza Pachao, Cornelia Tejerina, Wenceslao Flores, Martinina Armella, Rosalía Fabián, Matilde Cruz y Virginia Cruz, de Camar; Sótero Armella, Luciano Sosa y familia y Fabio Sosa, de Talabre; Cecilia Esquivel, Jacinta Puca y Evangelista Sosa de San Pedro de Atacama. Este trabajo fue realizado en el marco del Proyecto FONDECYT 1970908. 


\section{BIBLIOGRAFIA}

\begin{abstract}
ABELE, G.
Geomorphological west - east section 1998 through the north Chilean Andes near Antofagasta. "The Southern Central Andes." (H. Bahlburg, C. Breitkreuz, \& P. Giese, Eds). Lecture Notes in Earth Sciences. Springer-Verlag, Berlin Heidelberg.
\end{abstract}

ALBERS, C. N. y BRIMHALL, G. H. Middle Miocene cli1988 matic change in the Atacama desert, northern Chile: Evidence from supergene mineralization at La Escondida. Geological Society of America Bulletin 100.

ALBO, X y MAMANI, M. Esposos, suegros y padrinos entre 1980 los aymaras. MAYER, E. y R. BOLTON (Eds.): Parentesco y matrimonio en los Andes. Universidad Católica del Perú, Lima.

ALDUNATE, C., ARMESTO J., CASTRO,V. y VILLA1981 GRAN, C. Estudio etnobotánico en una comunidad precordillerana de Antofagasta: Toconce. Boletín del Museo Nacional de Historia Natural 38, Santiago.

\section{ANONIMO Manual Trilingüe de Aymara Que- 1981 chua y castellano. Editorial Mercurio, Lima.}

ARANDA, $X$.

San Pedro de Atacama. Elementos 1961-64 diagnósticos para un plan de desarrollo local. Informaciones Geográficas, Número especial, Universidad de Chile, Santiago.

ARROYO, M. T. K., SQUEO, F.A., ARMESTO, J.J. y C. 1988 VILLAGRAN. Effects of aridity on plant diversity in the northern Chilean Andes: results of a natural experiment. Annals of the Missouri Botanical Garden 75 .

BARTHEL, TH. El agua y el festival de primavera en1986 tre los atacameños. Allpanchis 28, año XVIII, Cusco.

BERTONIO, L. Vocabulario de la lengua Aymara. 1612 Juli, Perú.

1984 (1612) Vocabulario de la lengua Aymara, Ediciones Ceres, Cochabamba, Bolivia.

BÖRGEL, R. The coastal desert of Chile. "Coastal 1973 deserts, Their Natural and Human Environments." (D. H. K. Amiran, Y A. W. Wilson, Eds.) The University of Arizona Press, Tucson, Arizona.
BOUYSSE CASSAGNE, TH. La Identidad Aymara. Edito1987 rial Hisbol, La Paz.

BRUH, S. $\quad$ El lugar del hombre en el ecosistema 1974 andino. Revista del Museo Nacional de Lima 40.

CARDENAS, M. Manual de Plantas Económicas de 1989 Bolivia. Edit. Los Amigos del Libro, La Paz, Cochabamba.

CARDENAS, U. Entre el Tolar y el Pajonal. Percepción 1998 Ambiental y uso de plantas en la comunidad atacameña de Talabre, Segunda Región, Chile. Estudios Atacameños, este volumen.

CASTRO, M., VILLAGRAN, C. y KALIN-ARROYO, M. 1982 Estudio etnobotánico en la Precordillera y Altiplano de los Andes del Norte de Chile $\left(18-19^{\circ} \mathrm{S}\right)$. El Hombre y los Ecosistemas de Montaña, Vol. II. MAB-6, UNESCO, Montevideo.

CASTRO, V. Estudios Antropológicos Informes I, II 1987 y III. Ms in lit. Diagnóstico Agrícola Provincia El Loa. Propuesta CONSECOL Consultores Ecológicos y Ambientales, Santiago.

CASTRO, V. y V. VARELA (eds.) Ceremonias de Tierra y 1994 Agua. Ritos Milenarios Andinos. Fondart-Fundación Andes, Santiago.

CASTRO, V. Huacca Muchay. Evangelización y Re1997 ligión Andina en Charcas. Atacama La Baja. Tesis para optar al grado de Magister en Historia, Mención Etnohistoria. Departamento de Ciencias Históricas, Facultad de Filosofía y Humanidades, Universidad de Chile, Santiago.

CASTRO, V., ALDUNATE, C. y BERENGUER, J. Orígenes 1984 altiplánicos de la fase Toconce. Estudios Atacameños 7. Universidad del Norte, San Pedro de Atacama.

CASTRO, V. y MARTINEZ, J.L. Poblaciones indígenas de 1996 la Provincia de El Loa. Culturas de Chile. Vol. II Etnografía. Edit. Andrés Bello, Santiago

CAVIEDES, C. A climatic profile of the north Chilean 1973 desert at latitude $20^{\circ}$ south. Coastal deserts, Their Natural and Human Environments (D. H. K. Amiran, Y A. W. Wilson, Eds.). The University of Arizona Press, Tucson, Arizona. 
COROMINAS, J. Breve Diccionario Etimológico de la 1973 Lengua Castellana. Ed. Gredos S.A., Madrid.

CUSIHUAMAN, A. Diccionario quechua: Cuzco-Collao. 1976 Ministerio de Educación /Instituto de Estudios Peruanos, Lima.

DELANO, P. Aspectos socioeconómicos de una co1982 munidad del norte grande: Caspana. Tesis para optar al grado de Licenciado en Antropología Social, Facultad de Humanidades, Universidad de Chile, Santiago.

ERICKSEN, G. E. The Chilean nitrate deposits. American 1983 Scientist 71.

FIELD, C. A 1966

FOLLA, J.C. 1989

GARCIA E. 1991

GIRAULT, L. 1987

Kallawaya curanderos itinerantes de los Andes. Imprenta Quipus, La Paz.

GOMEZ, D. 1981-82

Los pueblos andinos de la Segunda Región y su alimentación tradicional. Cuadernos de Filología 15- 16, Antofagasta.

GOMEZ, D. y SIAREZ, E. Alimentación tradicional Ata1995 cameña. Norprint, Antofagasta.

GONZALEZ-HOLGUIN, D. Vocabulario de la lengua ge1952 (1608) neral de todo el Perú llamada lengua qquichua o del Inca. Libro Primero: quechua-castellano:. Libro Segundo: castellano-quechua: Imprenta Santa María, Lima.

GREBE, M.E. y HIDALGO, B. Simbolismo atacameño: un 1988 aporte etnológico a la comprensión de significados culturales. Revista Chilena de Antropología 7. Facultad de Ciencias Sociales, Universidad de Chile.

GROSJEAN, M. Paleohydrology of the Laguna Lejia 1994 (north Chilean Altiplano) and climatic implications for late-glacial times. Palaeogeography, Palaeoclimatology, Palaeoecology 109.

GROSJEAN, M. y NUÑEZ, L. A. Lateglacial, Early and 1994 Middle Holocene environments, human occupation, and resource use in the Atacama (Northern Chile). Geoarchaeology 9.

GUNDERMANN, H. Comunidades ganaderas, mercado y di1986 ferenciación interna en el altiplano chileno. Chungara. 16-17; Actas del X Congreso de Arqueología Chilena, Arica.

GUNDERMANN, H. y H. GONZALEZ. Tierra, Agua y So1995 ciedad Atacameña, un escenario cambiante. Agua, Ocupación del espacio y economía campesina en la región atacameña. Aspectos dinámicos. (Pourrut P. y L. Nuñez, editores científicos). Universidad Católica del Norte, Antofagasta-Institut Francais de recherche scientifique pour le développement en Coopération ORSTOM, Paris.

LEHNERT, R. Diccionario Toponimia Kunza. Nor1994 print, Antofagasta.

LENZ, R. Diccionario etimológico de las voces 1979 (1905-1910) chilenas derivadas de lenguas indígenas americanas. M. Ferreccio (Ed.) Imprenta Universitaria, Santiago.

LIRA, J. Diccionario KKechuwa-Español.Uni1945 versidad Nacional de Tucumán. Publicación 369, Instituto de Historia, Lingüística Y Folklore.

MARINOVIC, N. y LAHSEN, A. Geología de la Hoja Ca1984 lama, Región de Antofagasta. Servicio Nacional de Geología y Minería, Santiago de Chile.

MARTINEZ, J. Asentamientos y acceso a recursos en 1990 a. Atacama (s. XVII). Serie Nuevo mundo: cinco siglos 5. Departamento de Ciencias Históricas, Universidad de Chile, Santiago.

1990 b Interetnicidad y complementariedad en el Altiplano meridional. Andes N.1, Salta.

1998 Pueblos del Chañar y el Algarrobo. Los Atacamas en el siglo XVII. Centro de Investigaciones Diego Barros Arana. Ediciones de la Dirección de Bibliotecas, Archivos y Museos (DIBAM), Santiago. 
MASUDA SH.; I. SHIMADA y C. MORRIS, (eds.). Andean 1985 Ecology and Civilization. An Interdisciplinary perspective on Andean Ecological Complementarity. University of Tokyo Press.

MATTHEI, O.J. Manual de las Malezas que crecen en 1995 Chile. Alfabeta Impresores, Santiago.

MESSERLI, B., GROSJEAN, M. y VUILLE, M. Water avai1997 lability, protected areas, and natural resources in the Andean Desert Altiplano. Moutain Research and Development 17.

MOESBACH, E.W. Botánica Indígena de Chile. (C. Aldu1992 nate y C. Villagrán, eds). Editorial Andrés Bello, Santiago.

MORALES, H. Pastores trashumantes al fin del mundo. 1997 Un enfoque cultural de la tecnología: en una comunidad andina de pastores. Memoria para optar al Título de Antropólogo. Departamento de Antropología, Facultad de Ciencias Sociales, Universidad de Chile.

MORTIMER, C. The Cenozoic history of the southern 1973 Atacama Desert, Chile. Journal of the Geological Society of London 129.

MORTIMER, C. Drainage evolution in the Atacama De1980 sert of northernmost Chile. Revista Geológica de Chile, 3-28.

MOSTnY, G. Peine, un pueblo Atacameño. Publica1954 ción $\mathbf{N}^{\mathbf{0}} \mathbf{4}$ del Instituto de Geografía de la Facultad de Filosofía de la Universidad de Chile.

MUNIZAGA, C. y GUNCKEL, H. Notas Etnobotánicas del 1958 Pueblo Atacameño de Socaire. Publicaciones del Centro de Estudios Antropológicos 5, Universidad de Chile, Santiago.

MURRA, J.

Formaciones económicas y políticas 1975 del mundo andino; I.E.P., Lima.

NUÑEZ, L y DILLEHAY, T. Movilidad giratoria, Armonía 1978 Social y Desarrollo en los Andes Meridionales: Patrones de Tráfico e Interacción Económica. Universidad del Norte, Antofagasta.

PLAZA, O. y FRANCKE, M. Formas de dominio, econo1981 mía y comunidades campesinas; Desco, Lima.

REAL ACADEMIA ESPAÑOLA (eds.) Diccionario de la 1970 Lengua Española. Editorial EspasaCalpe, Madrid.
1971-1992 Diccionario de la Lengua Española. Vigésima Primera Edición, 2 Tomos, Madrid.

RICARDO, A. Vocabulario y phrasis en la Lengua 1951 (1586) General de los Indios del Perú, llamada Quichua. Edición del Instituto de Historia de la Facultad de Letras, Lima.

ROMO, M. biente en un grupo de pastores. Memoria para optar al título de Antropólogo Social. Departamento de Antropología, Facultad de Ciencias Sociales, Universidad de Chile.

SAIGNES, Th. Los Andes orientales: historia de un 1985 olvido. I.F.E.A-CERES, Cochabamba.

SELTZER, G. O. Recent glacial history and paleoclimate 1990 of the Peruvian - Bolivian Andes. Quaternary Science Reviews 9.

SERRACINO, G., STEHBERG, R. y LIBERMANN, G. In1974 forme Etnobotánico de Guatin (San Pedro de Atacama). Antropología Nueva Época 1. Universidad de Chile, Santiago.

SOUKUP, J. 1970

Vocabulario de los nombres vulgares de la flora peruana y catálogo de los géneros. Editorial Salesiana, Lima, Perú.

VAÏSSE, E, HOYOS, F. y ECHEVERRÍA, A. Glosario de la 1896 lengua atacameña. Imprenta Cervantes, Santiago.

VALENZUELA-ROJAS, B. Epítome etnográfico de la cuen1969-70 ca del río Salado. Provincia de Antofagasta, Chile. Boletín de Prehistoria de Chile 2-3, Departamento de Antropología, Universidad de Chile, Santiago.

VALENZUELA, A., VALENZUELA, D. y MORALES, H. 1998 Socaire y Talabre, ritualidad y arte rupestre en dos pueblos atacameños. Informe de Proyecto F.U.D.E. Ms in lit. $28 \mathrm{pp}$.

VAN HUSEN, C. Klimagliederung in Chile auf der Basis 1967 von Häufigkeitverteilungen der Niederschlagssummen. Freiburger Geographische Hefte 4.

VILLAGRAN, C. Etnobotánica indígena de los bosques 1998 de Chile: sistema de clasificación de un recurso de uso múltiple. Revista Chilena de Historia Natural 71.

VILLAGRAN, C.,VILLA, R., HINOJOSA, F., SANCHEZ, 1999 G., ROMO, M., MALDONADO, A., CAVIERES, L., LATORRE, C., CUEVAS, J., CASTRO, S., PAPIC, C. y 
VALENZUELA, A. Etnozoología Mapuche: Un estudio preliminar. Revista Chilena de Historia Natural (en prensa).

VILLAGRAN, C. y CASTRO, V. Etnobotánica y manejo ga1999 nadero de las vegas, bofedales y quebradas en el Loa Superior, Andes de Antofagasta, Segunda región. Revista Chungara (en prensa).

VILLAGRAN, C., CASTRO, V. y SANCHEZ, G. Etnobotá1999 nica y percepción del paisaje en Caspana (Provincia de El Loa, Región de Antofagasta, Chile): ¿Una cuña atacameña en el Loa Superior?. Estudios Atacameños, este volumen.

VILLAGRAN, C., ARMESTO, J. J. y ARROYO, M. T. K. 1981 Vegetation in a high Andean transect between Turi and Cerro León in Northern Chile. Vegetatio 48.
VILLAGRAN, C., ARROYO, M. T. K. y MARTICORENA,

1983 C. Efectos de la desertización en la distribución de la flora andina de Chile. Revista Chilena de Historia Natural 56.

VILLASECA, M. Percepción y Desecación. Estudio Ex1998 ploratorio en una Comunidad del Alto Loa. (Fondecyt 1970908). Informe de Práctica profesional en Antropología Social. Departamento de Antropología, Facultad de Ciencias Sociales, Universidad de Chile.

YACOVLEFF, E. y F.J. HERRERA. El mundo vegetal de los 1935 antiguos peruanos. Revista del Museo Nacional 4 (1), Lima. 


\section{ANEXO 1 \\ CATALOGO SISTEMATICO E INFORMACION ETNOBOTANICA DE LAS ESPECIES VEGETALES COLECTADAS EN ATACAMA, CHILE}

Las especies han sido agrupadas en grandes categorías sistemáticas (Criptógamas, Gimnospermas, Angiospermas-Dicotiledóneas y AngiospermasMonocotiledóneas). Dentro de cada uno de estos grupos, las Familias, Géneros y Especies se ordenaron alfabéticamente. Se destacan con asteriscos (*) las especies introducidas, ya sean cultivadas o malezas. La información de cada especie se ha organizado de la siguiente manera:

1. Número de la especie en las Tablas del texto y en los Anexos 2 y 3. Sigue el nombre científico, autor y familia. A continuación se proporcionan los números de colección correspondientes al Herbario de C. Villagrán (depositado en la Facultad de Ciencias de la Universidad de Chile, con duplicados en el Herbario de la Universidad de Concepción). Entre paréntesis se cita el número de referencia de los muestrarios de plantas (I y II) utilizados en las entrevistas etnobotánicas.

2. Hábitats de la especies: $\mathrm{PP}=\mathrm{Piso}$ Prepuneño o desértico; $\mathrm{P}=\mathrm{Piso}$ Puneño o tolar; $\mathrm{A}=\mathrm{Pisos}$ Altoandino/Subnival o pajonales; $\mathrm{Q}=\mathrm{Quebradas}$; $\mathrm{CH}=$ Chacras y Huertas; R=Riberas y cursos de aguas; $\mathrm{S}=$ Salar desértico de las planicies entre $\mathrm{San}$ Pedro de Atacama y Toconao.

3. Nombres vernaculares con que se conoce a la especie en los distintos poblados de Atacama, de acuerdo a las entrevistas realizadas en este estudio. Cuando se registró más de un nombre, éstos se presentan ordenados comenzando por el nombre que ha sido mencionado por un mayor número de entrevistados.

4. Claves de las clases de usos asignados a la flora de Atacama en este estudio: Co, Comestible; F, Forrajero; M, Medicinal; L, Leña; C, Construcción y Artesanías; $\mathrm{R}$, ritual; T, Tintóreo; A= Adorno; P, Perjudicial; O, Otros usos variados; S, Sin uso reconocido.

5. Información etnobotánica de acuerdo a las entrevistas realizadas en este estudio. Cuando existe información complementaria para las comunida- des en torno al Salar de Atacama y el Loa Superior, obtenida por otros investigadores, se proporciona precedida por las siguientes claves: $\mathrm{M}$, Mostny 1954 (Peine); MG, Munizaga \& Gunckel 1958 (Socaire); SSL, Serracino, Stehberg \& Liberman 1974 (Guatín); GS, Gómez \& Siarez 1995 (Atacama); AACV, Aldunate, Armesto, Castro, Villagrán 1981 (Toconce); VC, Villagrán \& Castro 1999 (Vegas Alto Loa); VCS, Villagrán, Castro \& Sánchez 1999 (Caspana); UC, Cárdenas 1998 (Talabre); VCR, Castro 1997 (Loa Superior).

6. Catálogo de especies adicionales citadas para Atacama por otros autores, y que nosotros no observamos durante el estudio.

7. Transcripción fonética. La transcripción fonética de los nombres da cuenta de la pronunciación de los informantes, pero no en forma exhaustiva; si así fuera, sería necesario emplear muchos diacríticos. No obstante, cuando se trata de diptongos como ai, oi, au, ui (por ejemplo en paiko, soiko $\sim$ suiko, sauce), la semivocal se transcribe con un diacrítico suscrito (['paiko], etc.); $\check{\mathbf{r}}$ representa la pronunciación asibilada del fonema vibrante múltiple /řr/ en Chile. ['] indica que la sílaba siguiente es acentuada.

8. Hemos transcrito un nombre, ya sea indígena o español, sólo la primera vez que ocurre.

9. Los nombres que no presentan alguna particularidad de pronunciación son consignados en forma ortográfica.

\section{CRIPTOGAMAS}

1) Chara ['čare] sp, Charophyta, 9444, II/75

$\mathrm{R}, \mathrm{S}$

loroma [lo'rome]

$\mathrm{F}$

Alga acuática escasa y muy poco conocida. Crece solamente en las lagunas del Salar de Atacama. Una persona la calificó de forraje. El nombre 
loroma es genérico para especies acuáticas y flotantes de hojas estrechas de los géneros Potamogeton, Ruppia, Myriophyllum, Chara, etc. También en el Loa Superior (VCS), las especies de Chara son llamadas loroma. MG cita para Socaire a la especie acuática Myriophyllum proserpinacoides con el nombre loroma.

\section{2) Oedogonium sp, Chlorophyta, 9394, II/2a $\mathrm{R}$}

lama ['lame], lava ['laße], lava del agua, bávaro ['baßaro], laqo ['lako]

S

Alga acuática muy común en quebradas, tanto en ríos como en tranques y canales. Todos los entrevistados coincidieron en clasificar esta planta como inservible. Los nombres de lama y laqo son genéricos para algas verdes filamentosas y flotantes. Lava probablemente sea una modificación de lama.

MG citan para Socaire una planta no identificada llamada lácu que es medicinal y se emplea para cubrir las heridas; sería refrescante. Podría tratarse de alguna especie de alga verde, ya sea de los géneros Oedogonium o Prasiola (ver No3), ambas en Atacama. También en el Loa Superior (VCS) las Algas Verdes filamentosas son llamadas laqulaqu, lakolako, lama, verdelagua. La gente tiene la experiencia de que cuando hay bastante lakolako encima del agua, va a llover. Cuando está la planta asentada, no va a llover.

\section{3) Prasiola sp1, Chlorophyta, 9443 , II/77}

$\mathrm{R}, \mathrm{S}$

chukula [ču'kule], lama, flor del laqo ['flo» del 'lako]

M

Alga acuática muy escasa y poco conocida. Crece solamente en las lagunas del Salar de Atacama. Una persona dijo que de aquí nacía el sapo y otra dijo que era la flor del laqo. Una persona dijo que era un remedio fresco que servía para ponerse como parches en las heridas y cuando se tiene dolor de cabeza. El nombre de chukula parece ser una confusión con algas azules y comestibles de los bofedales del Altiplano (Nostoc spp), consumida en distintos platos.

MG citan para Socaire una especie acuática y comestible no identificada botánicamente y llamada chucula. Creemos que se trata de una confusión con especies de Prasiola, algas verdes muy parecidas pero no comestibles.
4) Prasiola sp2, Chlorophyta, $9429, \mathrm{II} / 2 \mathrm{~b}$

$\mathrm{R}$

lama, pastito [pa ${ }^{\mathrm{h}^{\prime}}$ tito], laqo, loroma $\mathrm{S}$

Alga acuática muy común en quebradas, tanto en ríos como en tranques y canales. Todos los entrevistados coincidieron en clasificar la planta como inservible.

MG citan para Socaire una planta no identificada llamada lácu que es medicinal y se emplea para cubrir las heridas, sería refrescante. Podría tratarse de alguna especie de alga verde, ya sea de los géneros Oedogonium o Prasiola, comunes en Atacama.

5) Líquenes, II/113

PP, P, A

flor de peña

$\mathrm{S}$

No se coleccionaron las especies de líquenes para este estudio. Ellos crecen en todos los pisos de vegetación. Las formas de vida crustáceas, que crecen sobre rocas, son reconocidas colectivamente como flor de peña. Una persona dijo que hay de 12 colores, por ejemplo amarillos, blancos, rojos, naranjas y otros colores. No se mencionaron usos para estas plantas.

MG citan para Socaire el género de Liquen Gyrophora conocido como flor de peña y que sería "medicina para curar el ombligo descompuesto (supuración?) de los niños. Para este fin se muele este liquen y se espolvorea sobre el ombligo". En el Loa Superior, los líquenes conocidos como flor de peña son apreciados por su poder para "quebrar el empacho de las guaguas" (VCR).

6) Musgos, Bryophyta, 9436, II/46

$\mathrm{R}$ champa ['čampe], cuero de sapo, flor del agua F, A

Los cojines de musgos son muy comunes en quebradas, tanto en riberas de ríos como en las orillas de tranques y canales. Grupo de plantas generalmente sin uso reconocido. Una persona dijo que la comía el burro. Otra persona dijo que se queda como adorno.

Los musgos también han sido llamados ch'ampa en el Loa Superior, en Caspana (VCS), y se usan como adorno para el Pesebre Navidad. En el Loa Superior, en Caspana (VCS), es llamada flor del agua el helechito acuático Azolla filiculoides. 
7) Thelypteris argentina (Hieron.) Abbiatti, Thelypteridaceae, 9392, II/3

Q

helecho

A, M

La especie se usa como adorno, ya sea como planta de macetero para la vista, para matizar flores, para hacer ramos o para llevar al cementerio. Solamente una persona dijo que era también remedio, sin especificar propiedades.

Este helecho ha sido llamado Regalís, Regále o Helecho en el Loa Superior, en Caspana (VCS), y se usa como remedio para el estómago.

\section{GIMNOSPERMAS}

8) Ephedra breana Phil., Ephedraceae, 9299, I/15

PP

pingopingo ['pingo'pingo], pingo ['pingo], pingopingo macho

Co, M, T, L, F

Según los informantes, habría tres clases de pingopingo, el macho, la hembra y uno fino más chiquito. Las clases macho y hembra corresponden a las plantas con flores masculinas y femeninas, sexos que se encuentran separados en las especies de Ephedra. Probablemente, la clase finita corresponda a otra especie de Ephedra que no hemos observado. El pingopingo hembra produce frutos rojos, es de menor estatura que el macho y crece más arriba, en el gradiente altitudinal. Los frutos son carnosos como la uva y antiguamente se comían. La raíz, el tronco y la flor constituyen un excelente té que sirve de remedio para las vías urinarias, en general, ya sean los riñones, enfriamientos, la vejiga y el mal de orines. También es medicina para el estómago y purgante. Como planta medicinal es encargada para comercializarla en Calama. La especie es tintórea y tiñe de rojo mezclada con tikara (Krameria lappacea). Además, sirve como leña. El brote tierno lo comen los animales. El fruto carnoso es también consumido por las cabras y los pajaritos.

También los nombres de pingopingo, t'ume y t'umi han sido registrados, para esta especie, en el Loa Superior, en Toconce (AACV) y Caspana (VCS). GM, SSL y MG citan para Peine, Guatín y Socaire a $E$. andina con el nombre pingo-pingo y con los mismos usos medicinales expuestos. MG agregan el vernáculo trasmontana y usos para hacer escobas y carbón. GM agrega que las raíces se hierven y se usan contra la gonorrea, el mal de orines.

\section{ANGIOSPERMAS - DICOTILEDONEAS}

9) Carpobrotus aequilaterus (Haw.) N.E.Br., Aizoaceae, 9407, II/67

\section{$\mathrm{CH}$}

dedos de ángel, bálsamo, caudal ['kau'ðal]

$\mathrm{M}, \mathrm{A}$

La especie es plantada en huertas y jardines como adorno y medicina. El jugo fresco y abundante de las hojas carnosas es considerado muy medicinal para atajar distintos males, como el dolor de oídos, para curar las carachas y los granos, hinchazones, dientes cariados, para aliviar la fiebre, para refrescarse y para bañar a los niños. Como cataplasmas, con barro blanco, se usa para curar heridas y quemaduras. Los nombres probablemente aluden a la forma de dedos o cola que tienen las hojas carnosas y al alivio que provoca, usada como medicina.

En el Loa Superior, en Caspana (VCS), la especie es llamada bálsamo y es medicinal.

10) *Amaranthus deflexus L., Amaranthaceae, 9454, II $/ 85$

\section{$\mathrm{CH}$}

romaza [řo'mase], yuyo arka ['yuyo 'arke] (compañera), arka ['arke]

Co, F, O

Esta especie de maleza es considerada la romaza más exquisita para hacer sopas y guisos. Crece junto con el yuyo arka (arkayuyo, rastrojo de la quinoa), es morada, y se usa para hacer la llikta cuando esta tierna. Cuando la espiga crece se usa como forraje. El nombre romaza es genérico para muchas hojas en roseta, consumidas como ensalada.

MG citan para Socaire una planta no determinada llamada arcayuyo que 'se emplea como sustituto de la yerba mate; es aromática; los informantes expresan que es "mejor que la yerba mate". Puede tratarse de Chenopodium ambrosioides, que es muy aromático y también fue llamado arka en nuestra consulta. También puede ser esta especie llamada compañera del yuyo arka. Por otro lado, yuyo es un nombre genérico para distintas especies de Chenopodium. Para la cocina tradicional atacameña, GS documentan recetas para el "bu- 
dín de yuyo", que se consume en todos los pueblos, especialmente en San Pedro de Atacama.

11) Schinus molle L. var. areira (L.) DC., Anacardiaceae, 9360, II/34

Q

Pimiento [pi'mjento], molle ['moye], muelle ['mweye]

$\mathrm{M}, \mathrm{C}, \mathrm{O}, \mathrm{A}$

La infusión de la hoja, con limón, es un apreciado remedio, principalmente para dolores de estómago, enfriamientos, cólicos y como purgante. La especie es también apreciada, porque proporciona madera, sombra y es hermosa a la vista.

La especie es citada como pimiento o molle para Peine por GM; como molle por MG para Socaire, con los mismos usos. En el Loa Superior, en Caspana (VCS), la especie es llamada muelle, molle o pimiento y es medicinal.

12) Ombrophyton subterraneum (Aspl.) Hansen, Balanophoraceae, II/112

PP, P

sicha ['siče], chullapasa [čuya'pase]

$\mathrm{Co}, \mathrm{R}$

No hemos observado la planta en la región. Los arbustos de la región de Atacama, aparentemente, no forman sichas, tuberosidades radicales que corresponden a la planta parásita Ombrophyton subterraneum. Sin embargo, las personas la mencionaron y señalaron sus usos alimenticio y ritual. La traen de Caspana, Ayquina y Bolivia. Se comercializa en Calama.

También el nombre sicha ha sido registrado, para esta especie, en el Loa Superior (AACV).

\section{3) Cryptantha sp, Boraginaceae, $I / 61$ \\ $\mathrm{PP}, \mathrm{P}$ \\ pápur pasto ['papus 'pa ${ }^{\mathrm{h}}$ to] \\ F}

Hierba anual, pasto de lluvia poco conocido. La encontramos seca. Dos personas dijeron que era forraje para animales.

MG citan para Socaire a Cryptantha dichita como papur pasto.

14) Cryptantha linearis (Colla) Greene, Boraginaceae, 9471, I/62

PP, P

sobaquillo [soßa'kiyo], sobaquilla [soßa'kiye], ipallapa [ipa'yape], pápur pasto
F

Pasto de lluvia que sirve como alimento a los animales.

MG citan para Socaire a Cryptantha dichita como papur pasto. También los nombres itallapa e illapa han sido registrados para Cryptantha aff. hispida en el Loa Superior (AACV).

15) Tiquilia atacamensis (Phil.) A.T. Richardson, Boraginaceae, 9289, I/5

PP

káuchal ['kaǔčal]

Co, M, F

Abundante pasto de lluvias de los arenales desérticos. Todas las personas señalaron que, antiguamente, la gruesa raíz dulce se consumía como alimento. Se come fresca y pelada y es sabrosa como naranjada. Especialmente los niños la buscan para comerla. Una persona agregó que se toma la raíz, hervida con agua, y es buena para la hernia. También la planta es un excelente forraje, especialmente para las cabras.

MG citan para Socaire el nombre de cáuchal para una especie forrajera y alimenticia muy parecida, Coldenia (=Tiquilia) paronychioides. Los nombres catamasa y jatamasa han sido registrados, para esta especie, en el Loa Superior (AACV).

16) Echinopsis atacamensis (Phil.) Friedrich et G.D. Rowley, Cactaceae, I/65

PP

Cardón [kar'ðon], cardón grande [kar'ðon grande], pasakana [pasa'kane],

$\mathrm{Co}, \mathrm{C}$

El fruto, dulce y de muy buen sabor, es comestible y se llama pasakana. La especie proporciona una excelente madera para construcción y, antiguamente, las techumbres, puertas y vigas eran de puro cardón. Hoy en día la planta es muy escasa en la región y se usa principalmente para artesanías como, por ejemplo, confección de bombos, lámparas, etc.

GM cita a la especie con el sinónimo Trichocereus atacamensis y el vernáculo cardón grande, que 'era apreciado por su madera, que se usó en la fabricación de tablas para puertas, techos y ataúdes. Además sus frutos dulces y parecidos a las brevas, se colectaban y comían antiguamente'. También los nombres de cardón y quisco han sido registrados, para esta especie, en el Loa Superior (con el sinónimo Helianthocereus atacamensis), 
en Toconce (AACV) y en Caspana (VCS), con idénticos usos. MG citan para Socaire los nombres de cardón grande y pasacana para una Cactácea no identificada y que puede corresponder a esta especie. Los autores señalan los mismos usos en construcción y alimenticios mencionados. SSL citan también para Guatín el vernáculo cardón, con fruto comestible (para preparar dulce), pero lo adjudican a Puya chilensis, obviamente un error, porque esta conocida planta no crece en el Norte Grande de Chile.

17) Opuntia camachoi Espinosa, aff., Cactaceae, 9327, I/25

PP, P

kume ['kume], tuna ['tune], quisco ['ki ${ }^{\mathrm{x}} \mathrm{ko}$ ], puskayo [pu'kayo]

Co, M, F, T

El fruto, llamado tuna o tunilla, tiene múltiples usos. Es ácido, como limón, y algunas personas lo consumen fresco como fruta. Chupar el jugo es bueno para la puna. Antiguamente, los niños lo consumían mucho. El fruto maduro es también un excelente remedio para resfrío, fiebre, tos y estreñimiento, hervido y mezclado con wailawén (Haplopappaus rigidus). El fruto también le encanta al ganado, sobre todo a las cabras y corderos, y con él se mantienen gordos y la carne resulta bien sabrosa. Los burros prefieren cavar las raíces de la planta para consumirlas. La tuna también se usa en el proceso de teñido de lanas. Se chanca la pulpa y sirve de mordiente. Seguramente, este último uso se debe a lo ácida de la pulpa, ya que GM documenta para Peine el uso de alumbre, limón o vinagre como mordiente.

En el Loa Superior, en Caspana (VCS), la especie es llamada q'ome, q'omer, espina y agujilla y tiene idénticos usos. Probablemente se trata de esta especie la Cactácea citada con el nombre de cume, por MG para Socaire, y no determinada botánicamente. Por lo demás, estos autores citan los mismos usos ya expuestos que tiene la planta, forraje, alimento y mordiente. Además, estos autores citan los vernáculos de puscayo o chujchampu para una planta no determinada botánicamente. El primer vernáculo puede corresponder a esta especie, ya que también lo hemos registrado en nuestra consulta. El nombre chujchampu, para una forrajera de la alta cordillera parece convenir más a una Gramínea (ver $\mathrm{N}^{\circ} \mathrm{s}$ 152, 169). SSL citan para Guatín una especie no determinada con el vernáculo chuchampe, que se usa para teñir y da color amarillo, y que también puede ser la Gramínea mencionada (Deyeuxia curvula).

18) Especie no determinada, Cactaceae, I/66 PP

cardón chico

$\mathrm{C}$

Esta especie no ha sido coleccionada en este estudio. Las personas la describen como creciendo en montones, columnar, compañero del cardón, pero más chico. Una persona dijo que es el mismo cardón grande, en estado de crecimiento. Las espinas son muy largas y usadas como palillos para tejer calcetines.

Con el mismo vernáculo, GM cita para Peine una Cactácea de la cual tampoco pudo conseguir ninguna muestra y que describe como "de tamaño pequeño y apreciada por sus espinas que alcanzan 15 a $30 \mathrm{~cm}$ de largo y que se usan como agujas para gramófono y palillos para tejer medias y otras prendas. Para poder usar los palillos se quema la punta muy punzante y la base de las espinas, produciéndose así puntas romas. Su fruto es ácido y no se presta al consumo". Con este mismo vernáculo, MG citan para Socaire una Cactácea que tampoco ha sido identificada, y cuyas espinas también se usan para tejer medias de lana. Los autores comentan que "las grandes y gruesas espinas de la Cactácea tienen gran semejanza con las encontradas en yacimientos y tumbas costeras de Pisagua, producto de un posible intercambio con el interior, y que no han sido identificadas aún". Para el Loa Superior, Caspana (VCS), es citado el vernáculo chikachika para un cactus columnar bajo, con varias ramas, que no ha sido determinado y cuyas espinas se usan para palillos.

19) Hoffmannseggia doellii Phil. subsp. doellii, Caesalpiniaceae, 9286, 9367, I/2, II/-28

PP, Q

bilankichu [bilan'kiču], kulchau ['kulčau], kulchao ['kulčao], algarrobilla [alyaro'ßiye], mutukuru [mutu'kuru]

Co, F

Esta especie es un frecuente pasto de lluvia de los arenales semidesérticos. Todas las personas coincidieron en señalar que la papa de esta especie es comestible. Generalmente los niños la sacan y lavan y la comen fresca. También se puede consumir cocida. Tiene buen sabor y es un poquito dul- 
ce y lechosa. No todas las papas son buenas; las dulces se extraen solamente de ciertos lugares. La especie es un excelente forraje para el ganado, especialmente los tallitos y las legumbres (vainitas), para las ovejas y los corderos.

MG citan para Socaire dos especies de Hoffmanseggia con el nombre culchao, forrajeras y con bulbos comestibles, $H$. andina y $H$. falcaria. Ninguna de las dos especies figura en la flora chilena y, probablemente, sean sinónimos de $H$. doellii, muy abundante en toda la región de Atacama. También el nombre mutucuru, motokoro o motocoro ha sido registrado para $H$. doellii (Caspana, VCS) y H. eremophila (Toconce, AACV), en el Loa Superior.

20) Moschopsis monocephala (Phil.) Reiche, Calyceraceae, 9310, I/58

A

comida del suri ['suri], botón [bo'ton], pasto de vicuña ['pa ${ }^{\text {hto }}$ ðe Bi'kupe], wajilla [wa'Xiye]

F, M

Especie altoandina en roseta, bastante escasa. La comen las llamas y el suri. Es remedio para los riñones y el corazón.

En el Loa Superior, en Caspana (VCS), la especie es llamada waje o baji y también es forrajera y medicinal.

21) Hypsela reniformis (Kunth) K. Presl, Campanulaceae, 9427, II/48

$\mathrm{R}$

champita [čam'pite], vega ['beye]

$\mathrm{F}$

Abundante plantita que forma cojines en las riberas de cursos de agua. Forraje. El nombre champa o vega es colectivo para varias especies pigmeas que conforman cojines ribereños.

MG citan, para esta especie, el nombre champa, además del vernáculo flor de zapallo, muy apropiado para describir la forma de la flor de esta especie, a pesar de que es diminuta y blanca. También los nombres de champa, vega o pastos de vega han sido registrados, para esta especie, en el Loa Superior (VCS y AACV).

22) Pycnophyllum bryoides (Phil.) Rohrb., Caryophyllaceae, 9313, I/44

A

yaretilla [yare'tiye]

F, M

En general, la especie es considerada inservible.
La comerían las llamas solamente cuando no hay ningún otro forraje disponible. Una persona mencionó su uso medicinal, sin mayores especificaciones.

También el nombre llaretilla ha sido registrado, para esta especie, en el Loa Superior (AACV y VCS).

23) Spergularia fasciculata Phil., Caryophyllaceae, I/63

PP, P

flor blanco

F

Pasto de lluvia con flores blancas, muy poco reconocido. La encontramos seca. Una persona dijo que era forraje para los animales.

También el nombre alucema ha sido registrado, para esta especie, en el Loa Superior (AACV). MG citan para Socaire esta especie con el sinónimo Tissa fasciculata y el vernáculo té blanco.

24) Atriplex imbricata (Moq.) D. Dietr., Chenopodiaceae, 9298, I/14

PP

ojalar [oxa'lau], chókel ['čokel], chókil ['čokil], kopakopa macho ['kope'kope ' mačo]

F

Una persona mencionó el nombre de kopakopa macho para la especie, por analogía de aspecto con la kopakopa hembra (Artemisia copa) que también es plomiza, pero más pequeña y de hoja más fina. La especie es considerada por todas las personas como el mejor y más abundante forraje del desierto.

Probablemente, se trata de un sinónimo de esta especie, la forrajera citada por MG para Socaire (Atriplex microphylla), con los nombres de chókel u ojalar, y también para Guatín por SSL con el mismo nombre científico y el vernáculo ojalar. La especie ha sido citada como ojala y cachiyuyo en el Loa Superior, Caspana (VCS). El nombre pilaya ha sido registrado, para esta especie, en Toconce (AACV), con el sinónimo $A$. microphylla.

25) Atriplex madariagae Phil., Chenopodiaceae, 9396, 9421, II/57, 74

Q, S

kachiyuyo [kači'yuyo], kachuyo [ka'čuyo], kachuyo macho, kórial ['korjal], yuyo ['yuyo], chókel, chókil 


\section{$\mathrm{L}, \mathrm{O}, \mathrm{Co}, \mathrm{M}, \mathrm{F}$}

Los tallos leñosos de este abundante arbusto de los desiertos y salares se usan para leña. Con la ceniza del kachiyuyo se pela el trigo y el maíz. Cuando la gente lleva su trigo a Calama, al comprador le interesa que el producto se haya pelado con esta planta, porque le da un gusto muy sabroso y el grano queda bien amarillito. Las hojas tiernas se consumen, con limón como ensalada y también se preparan en guisos como el charkikan. El agua de las hojas es fresca y alivia la fiebre. La planta es muy utilizada como forraje para los animales, a pesar de su sabor algo salado. En las quebradas, es muy común una forma en cojín de Atriplex madariagae que fue reconocida como kachiyuyo, kachuyo macho, kórial, yuyo, chókel, chókil. Esta forma de crecimiento fue definida como un efecto del ramoneo de los animales. La planta es, obviamente, muy forrajeada. El tronco leñoso de estos cojines constituye una buena leña y también se lo utiliza para obtener ceniza para pelar la pataska.

GM citan para Peine un arbusto cuya madera se usa para leña y cercos, llamado cachiyuyo, sin determinación botánica. MG citan para Socaire el nombre de cachiyuyo para $A$. retusa, un sinónimo de A. madariagae, asignándole las mismas propiedades medicinales registradas por nosotros, $\mathrm{y}$ especificando el tratamiento en forma de baños con que se usa la planta. Para la cocina tradicional atacameña, GS documentan recetas para "ensalada y guiso de cachiyuyo" en que la especie, tierna y cocida, se guisa con carne picada, zanahoria y papas. También el nombre cachiyuyo ha sido registrado, para esta especie, en el Loa Superior (AACV).

\section{6) Atriplex sp, Chenopodiaceae, 9354, II/40}

\section{$\mathrm{Q}$}

kañiwa [ka'niwe] (se parece), yuyo

F, M

Aparentemente esta especie lleva el mismo nombre de otras especies de la familia y pertenecientes generalmente al género Chenopodium, llamadas yuyos, género al cual pertenece la apreciada quinua (Chenopodium quinua). Así por ejemplo, una persona dijo que cuando se siembra quinoa sale el yuyo wacho, no comestible pero de valor forrajero. Otra persona dijo que esta especie tenía los mismos usos de la quinoa, además de forraje.
Solamente una persona dijo que esta especie era medicinal para la sangre.

27) *Chenopodium album L., Chenopodiaceae, 9416, II/59

\section{$\mathrm{CH}$}

yuyo ['yuyo], yuyo wacho ['yuyo 'wačo], yuyo caña colorada, chape ['čape]

F, O

La gente informó que cuando se rearma el sembrado de quinoa (Chenopodium quinua), al otro año sale el yuyo o yuyo wacho. La planta tierna es consumida como forraje por los animales. Antes se hacía llikta con la planta (chile), una especie de cocho para mascar con la coca. Para hacerlo, la hoja se orea, se quema, se sopla, y se amasa un pancito con la ceniza de la planta. El nombre yuyo es genérico para varias especies de Chenopodium.

GM citan para Peine una maleza alta llamada yuyo, sin determinación botánica; MG citan para Socaire la especie Chenopodium frigidum con los nombres de yuyo, chápir o quinoa chica. También los nombres de yuyo, quinoa, ch'api han sido registrados para Ch. hircinum en el Loa Superior (AACV).

28) Chenopodium ambrosioides L., Chenopodiaceae, 9453, 9373, II/22, 86

$\mathrm{Q}, \mathrm{CH}$ paiko ['paiko], arka, toronjil dulce [toron'Xil 'dulse]

M

Excelente remedio para el dolor de estómago y diarreas, tomado como té. Se les da en la mamadera a las guaguas para los empachos, estitiquez y diarreas.

MG citan para Socaire una planta no determinada llamada arcayuyo que "se emplea como sustituto de la yerba mate; es aromática; los informantes expresan que es "mejor que la yerba mate"'. Puede tratarse de Chenopodium ambrosioides, que es muy aromático y también fue llamado arka en nuestra consulta. También puede ser Amaranthus deflexus ( $\left.\mathrm{N}^{\circ} 10\right)$. Por otro lado, yuyo es un nombre genérico para distintas especies de Chenopodium.

29) Nitrophila occidentalis (Moq.) S.Wats ( $=N$. Atacamensis?), Chenopodiaceae, 9485, II/49 
$\mathrm{R}$

champita, sáilao? ['sailao]

$\mathrm{F}$

Forraje. Especie muy escasa en la región y solamente observada en Camar.

El nombre de sáilao probablemente sea una confusión con algún pasto blando.

30) Sarcocornia fruticosa (L.) A.J. Scott, Chenopodiaceae, 9447, II/92

Q

walkawalka ['walke'walke], waycha? ['waičęe], cola de lagarto ['kole ðe la'yarto] $\mathrm{S}$

Especie muy escasa en la región. Solamente la hemos observado en el oasis de Tilomonte. Poco conocida y no usada por la gente. El nombre waycha probablemente sea una confusión con Lycium humile, especie llamada así en Atacama y en el Loa Superior y también de hojas carnosas. El nombre cola de lagarto quizá alude a la forma articulada de los tallos carnosos de la planta.

En el Loa Superior, Caspana (VCS), la especie es llamada walkita, walchawalcha y la come el animal.

31) Ambrosia artemisioides Meyen et Walp., Compositae, 9295, I/11

PP

Tikara [ti'kare], tikara macho, monte verde ['monte 'ßerðe], monte negro ['monte 'neyro], tola negra ['tole 'neyre]

F, T

La consumen los animales, pero no mucho, porque es muy amarga. Cuando no hay otros pastos y está verde la comen las cabras y las ovejas. Habría dos clases de tikara, la macho con potentes espinas en el fruto, y hembra, bajita y con frutitos menos "pegosos" (Krameria lappacea). Igual que su compañera, la tikara hembra, la especie es tintórea. Se utiliza toda la rama y da colores amarillo y verde clarito.

También los nombres de cadillo, pikara y tíkara han sido registrados, para esta especie, en el Loa Superior, en Toconce (AACV) y en Caspana (VCS). GM y MG citan para Peine y Socaire una especie no identificada botánicamente y llamada monte verde, que puede ser esta especie, ya que tiene los mismos usos forrajero y tintóreo. GM describe el procedimiento de tintura: "monte verde da un color verde muy bonito. Cuando está fres- ca, se maja en una pequeña takana (mortero); en seguida se hierve la planta majada en agua durante algún tiempo; este tiempo varía según la intensidad del color deseado. A continuación se sumerge la madeja de lana en el líquido verde y se deja hervir aproximadamente media hora más. Una vez retirada la lana del líquido, se enjuaga la madeja en agua caliente y se pone a secar. No necesita mordiente".

32) Artemisia copa Phil., Compositae, 9409, II/65

$\mathrm{CH}$

kopa ['kope], kopakopa

M, T

La planta crece en la zona de estudio, pero no fue observada por nosotros en la naturaleza. La muestra fue obtenida de una huerta de Socaire. Es cultivada en casa porque es muy apreciada por sus múltiples propiedades medicinales. En infusión bien caliente es remedio para el dolor de estómago y cólicos. Se usa como sahumerio para el dolor de cabeza, para "el aire", para lavarse el cabello y para sahumar la casa. La planta es también tintórea y tiñe verde claro a amarillo, casi exactamente del color que tiene la planta.

GM, MG y SSL citan la especie para Peine, Socaire y Guatín con los vernáculos copa-copa y copa, con los mismos usos medicinales reseñados. GM define la práctica del sahumerio de la siguiente manera: "Una práctica, que ya no se refiere a las dolencias del cuerpo, sino a su purificación y a la expulsión de males espirituales, es el sahumar; se sáhuman las mujeres, cuando hacen su primera salida después de haber dado a luz, y se sáhuman los niños, cuando son más miedosos que de costumbre. En el primer caso, se muele la cáscara de naranja, copal, y otros ingredientes más y se queman en las brasas; el humo que sale es inhalado. Para los niños se usa un nido de pájaro y polvo del rincón de la casa, cerca de la puerta, y se queman sobre las brasas". También los nombres copa, copa copa, copa tola, qopaqopa, kopakopa, qopa y kopa han sido registrados, para esta especie, en el Loa Superior (AACV y VCS).

33) Baccharis boliviensis (Wedd.) Cabrera, Compositae, 9293, I/9

$\mathrm{P}$

Tolilla [to'liye], tolita [to'lite], tola chica, chijlla 
['čixye], chíjua ['čixwe], chíjuachíjua ['čixwe'čixwe]

\section{F, M, O}

Este importante arbusto del tolar es poco utilizado. Generalmente, no la come el ganado, porque es amarga. Solamente cuando no hay más forraje disponible los animales la consumirían. Se usa para entablillar, cuando los animales sufren quebraduras de huesos, mezclada con orines, sal y usando dos tablillas para amarrar. También es remedio para el estómago y, además, la planta hervida sirve para lavarse cuando se sienten los huesos. Una persona agregó que también se usa para barrer el horno cuando se hace pan.

SSL citan también para Guatín el vernáculo chijua-chijua, con los mismos usos medicinales reseñados, y lo adjudican al sinónimo de esta especie Psila boliviensis. También los nombres pesco tola y tola de pájaro han sido registrados, para esta especie, en el Loa Superior, en Toconce (AACV). En Caspana (VCS), la especie es llamada tola, tolilla, tola amarilla y tola de salud.

34) Baccharis juncea (Lehm.) Desf., Compositae, 9340, 9433, I/29, II/51

Q

Suncho ['sunčo], pasto loco, totora [to'tore], chukchuka [čuk'čuke]

$\mathrm{P}, \mathrm{F}, \mathrm{O}$

Cuando la planta está tierna los animales no la consumen, porque su olor es malo. Si la comen mucho, se envenenan, se vuelven locos. Ya madura es consumida por los burros y las cabras. Una persona mencionó que el tallo largo de la planta lo usaban para jugar cuando niños: le sacaban toda la corteza y lo interno blanquillo (médula) quedaba como un gusanillo.

También el nombre chuschuka ha sido registrado, para esta especie, en el Loa Superior (AACV). Probablemente, es esta especie o la siguiente (Baccharis salicifolia) la planta no determinada citada por GM para Peine con el nombre de zuncho, de cerca de un metro de altura, y usada para setos vivos.

35) Baccharis salicifolia (Ruiz et Pavón) Pers., Compositae, II/99

$\mathrm{CH}$ suncho
$\mathrm{O}$

Especie muy rara en la región. Solamente fue observada en una casa en las afueras del pueblo de Socaire. Una sola persona la reconoció con nombre y uso para sombra y para cercos. Probablemente sea esta especie, o la anterior (Baccharis juncea), la planta no determinada citada por GM para Peine con el nombre de zuncho, de cerca de un $\mathrm{m}$ de altura, y usada para setos vivos.

36) Baccharis scandens (Ruiz et Pavón) Pers., Compositae, 9352, 9426, I/18, II/54

Q Chillka ['čilke]

$\mathrm{O}, \mathrm{M}, \mathrm{L}, \mathrm{C}, \mathrm{Co}, \mathrm{T}, \mathrm{F}$

El uso más reiterado de esta abundante planta ribereña es como escobillón, para barrer el horno cuando se hace pan. Entrega un aroma especial y da mejor sabor al pan, al barrer con ella las cenizas que quedan en el horno. Además, es más firme, porque no se quema. También tiene uso medicinal, para los dolores de huesos, los golpes y las quebraduras, como asimismo para vómitos, dolor de cabeza e indigestión. Para ello se calienta la hoja en el brasero y se aplica, mezclada con limón y orines, formando una pasta "pegosa". Igualmente se usa para tomar baños. La especie proporciona leña, cuando está seca. Varios otros usos fueron mencionados por distintas personas como, por ejemplo, para cierres y cortinas de viento, para lo cual hay que podarla. También para hacer ramadas y para sombra. Solamente una persona mencionó que el tronco de la chillka hace chullapacha (sicha), un abultamiento de las raíces producido por la planta parásita Ombrophyton subterraneum, y que su abuelito la traía de Catar con este propósito. Aparentemente, el uso tintóreo de la especie, como lo menciona la literatura, está casi olvidado. Solamente dos personas mencionaron que tiñe verde-amarillo y una sola señaló utilidad forrajera. Otra persona dijo que servía para carbón.

La especie ha sido llamada chilka o suncho, en Caspana (VCS). Probablemente, se trata de esta especie la citada por GM y MG para Peine y Socaire, no identificada botánicamente, llamada chilca y usada como sombra y como tintórea (daría color verde). También los nombres chilca, chilca negra han sido registrados, para esta especie, en Toconce, en el Loa Superior (AACV), citada con el sinónimo B. petiolata. 
37) Baccharis tola Phil. subsp. tola, Compositae, 9324, I/23

$\mathrm{P}$

Likia ['likje], lejía [le'Xie], léjia ['lexje], tola ['tole]

L, F, M, Co, O

Abundante arbusto de los tolares. Los troncos y tallo leñosos de este arbusto proporcionan muy buena leña. Como forraje, la especie no es muy apropiada, porque es dura y amarga y los animales solamente la comen cuando está tierna y no hay otros pastos disponibles. La raíz es blanquecina y, quemada al fuego, queda como harina y es buena para el empacho de los niños. También la raíz proporciona una "miel" (resina) muy blanca y sabrosa. También se usan las ramas para limpiar el horno. Una persona mencionó que produce unos frutitos como manzanitas, posiblemente las agallas tan comunes en las especies del género.

La especie es llamada Loire, Loye, Léjia, Lejía, Tola en Caspana (VCS) y, además de combustible y medicinal, sirve también para la salud del ganado: "Cuando se hace un floramento, se mueven las chullas solamente con loire". La chulla se prepara con la sicha molida del loire o tola amarilla de K'ablor y Ko'iller. Es probable que estas chullas se confeccionen con la harina de la sicha (Ombrophyton subterraneum) que produce el loire. Frente a enfermedades producidas por el rayo, es preciso "chullarla" (acto de purificación) a la persona. También el nombre lejía ha sido registrado, para esta especie, en Toconce (AACV), citada con el sinónimo B. incarum. Probablemente corresponda a esta especie la planta citada por MG para Socaire con el nombre de liquia y adjudicada a Baccharis santelices. No hemos visto esta última especie en la región. Probablemente también sea esta especie la planta citada por SSL para Guatín, no determinada y llamada lejía. Estos autores documentan el mismo uso medicinal reseñado para la especie, con el siguiente procedimiento: "remedio para la disentería en la siguiente forma: se quema el arbusto sin la hoja, hasta que solo queden las cenizas. Luego se mezcla ésta con agua y se bebe".

38) *Bidens laevis (L.) Britton, Sterns et Poggenb., Compositae, 9451, II/88

$\mathrm{CH}$

té de burro, té, té silvestre, té verde, hoja de té
Co, M, F

Maleza cuya hoja produce una bebida con el sabor y el color del té y se toma con canela. Una persona dijo que la planta era remedio para el pulmón; según otra, la comían los animales.

La especie es llamada también té en el Loa Superior, en Caspana (VCS). Probablemente, se trate de esta especie la planta medicinal (para la vejiga), no identificada botánicamente, llamada té negro, y citada por MG para Socaire. Probablemente, sea esta especie la llamada té de burro, adjudicada a Spergularia arbuscula, por MG.

39) *Bidens pseudocosmos Sherff, Compositae, 9374, II/21

Q, CH

amor seco

$\mathrm{M}, \mathrm{A}$

Maleza cuya semilla es remedio para la fiebre. $\mathrm{La}$ flor es adorno, para vista.

40) Chaetanthera revoluta (Phil.) Cabrera, Compositae, 9347, I/55, 57

A

keúche [ke'uče], tieuchi [tje'uči], comida de perdiz

F, M

Esta diminuta planta altoandina es, muchas veces, confundida con la flor de la puna (Chaetanthera sphaeroidalis), y es buena para aliviar esta dolencia. Una persona mencionó que era remedio para el corazón. La comen las llamas y, especialmente, las aves silvestres como el avestruz y la perdiz.

MG citan para Socaire una especie altoandina y forrajera no determinada llamada keúye o keúche. Probablemente se trate de esta especie o de Lenzia chamaepitys, también conocida con estos nombres. En el Loa Superior, en Caspana (VCS), crece también la especie, pero no se registró nombre vernacular para ella aunque se destacó su parecido con la flor de la puna (Ch. sphaeoroidalis), que crece en el piso subnival de los Andes del Norte Grande de Chile.

41) Chuquiraga atacamensis Kuntze, Compositae, 9338, I/28

PP, P

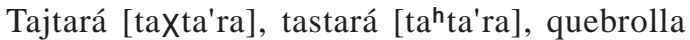
[ке'ßроуе], azafrán [asa'fran], lengua de gallina, rezongón [řeson'gon], killokisca [kiyo'ki ke]

L, F, M 
La especie se llama así (tajtará, quebrolla) porque, al quemarse, "suena como cuete", dijeron varias personas. Otra persona contó que le preguntó a su abuelita por qué le llaman a la planta quebrolla. La respuesta fue: "se llama así porque quiebra las ollas", pero después se corrigió: "esa leña no la usamos porque es muy fuerte, y da un olor a goma". Otra persona dijo que, al quemarla, suena y es medio difícil prenderla, por eso se le llama rezongón. La leña no es buena, porque es humosa y tizna mucho, pero la raíz es muy calurosa y, por eso, se usa específicamente como leña para calentar el horno. Los animales solamente consumen el brote blandito, generalmente solo las cabras. La planta es medicinal y se usa como remedio para el resfrío y tos seca, con flema pegada. Se toma con leche y bien cargada, y eso ayuda a botar la flema. También se usa para baños contra enfriamientos.

MG citan para Socaire una especie no determinada llamada azafrán y quiebra olla, que debe ser esta especie y que es también usada como leña y medicina "contra la descomposición de la sangre". SSL citan para Guatín los vernáculos lengua de gallo y quiere para una planta usada como leña, no determinada, y que, probablemente, sea también esta especie. En el Loa Superior, en Caspana (VCS), la especie es llamada K'iri, K'eri, Candela, Lengua de gallina y se usa como abortivo, mezclado con otras hierbas. También como leña, especialmente para el horno, para hacer pan amasado. Los animales lo comen. El nombre quebraolla o leña quebrolla es usado para Diplostephium meyenii en esta región.

42) Chuquiraga spinosa Less. subsp. rotundifolia (Wedd.) Ezcurra, Compositae, 9479b, I/72

$\mathrm{P}, \mathrm{A}$ azafrán

$\mathrm{M}, \mathrm{C}$

Esta especie no ha sido coleccionada por nosotros en la región. La muestra la proporcionó una persona de Talabre, que la trajo de la cordillera de la región y la plantó en su huerta. Es remedio para la tos y el mal de orines. Es también remedio cuando los abuelos, los gentiles, miran a la guagua y a esta le da diarrea. Los troncos bien trabajados son duros y sirven para confeccionar piezas de telares, como torcedores y husos.

El nombre chana o ch'ana ha sido registrado, para esta especie, en el Loa Superior, en Toconce (AACV) y en Caspana (VCS).

43) Flaveria bidentis (L.) Kuntze, Compositae, 9439, II/42

\section{$\mathrm{CH}$}

monte colorado, flor amarilla, pasto

F, A

Especie poco reconocida por la gente. Según dos informantes, sería pasto para animales, especialmente los conejos. Otras dos personas dijeron que es mala hierba y no sirve para nada. Otra persona dijo que era una florcita para vista.

\section{4) Gnaphalium sp, Compositae, II/115 \\ $\mathrm{P}, \mathrm{A}$ viravira ['bire'Bire] \\ $\mathrm{S}$}

No hemos observado ninguna especie del género en la región. La planta fue mencionada por la gente como creciendo en la zona.

También el nombre wira wira ha sido registrado para G. glandulosum y G. lacteum en el Loa Superior (AACV). MG citan para Socaire una especie no identificada llamada vira-vira, forrajera y medicinal contra la tos.

45) Haplopappus rigidus Phil., Compositae, 9292, $\mathrm{I} / 8$

$\mathrm{P}$

Bailahuén [baila'wen], bailawela [baila'wele], bailawena [baînla'wene], bailavín [baila'ßin], wailawen [waila'wen], wailawin [wailla'win], chajchajra [čax'čaxre], chajchara [čax'čare], chejchara [čex'čare]

M, F

La planta es considerada, unánimemente, como una excelente medicina. Tomada como mate, con rikarika (Acantholippia punensis) y leche de cabra, constituye un cálido remedio para la tos, resfrío, enfriamientos, hielo, riñones y mal de orines. El mate alivia el corazón y los dolores del estómago, cuando está hinchado. Solamente una persona mencionó que la comen las cabras.

Los nombres baylahuina, bailawen, bailabien y baylahuen han sido registrados, para esta especie, en el Loa Superior (AACV y VCS), también con propiedades afrodisíacas. MG citan para Socaire dos nombres asignados a Haplopappus baylahuen, bailahuén y chejchajra. Es muy probable que se trate de $H$. rigidus que es la especie 
que crece abundante en Atacama. Sería, además, "medicina para el reumatismo y para acrecentar la virilidad del hombre". Asimismo, GM y SSL mencionan para Peine y Guatín el bailahuén, con las mismas propiedades medicinales comentadas. GM agrega que el remedio sirve también contra el "aire".

46) Helogyne apaloidea Nutt., Compositae, 9481, $\mathrm{I} / 67$

PP

tola

M?

Especie de arbusto muy rara en la región. Solamente observada en los alrededores de Peine. Una persona dijo que podría ser medicinal por su sabor amargo, aunque no la había visto nunca.

47) Hypochaeris sp. nov.?, Compositae, 9463, II/ 81

$\mathrm{CH}$

Lokoche [lo'koče], romaza

Co, M, A

Especie muy rara en la región, observada solamente en las chacras del pueblo de Peine. Probablemente es nueva para la flora de Chile, ya que no se encuentra registrada en los Herbarios del país. Una persona informó que en Tilomonte también habría lokoche y otra dijo que crecería mucho la especie en el ayllo de Coyo. Se consumen las hojas como ensalada. También es medicinal, hay que bañarse; después se hace un mate con la raíz hervida y se toma. Las flores las usan como adorno. Seguramente corresponde a esta especie la planta medicinal y alimenticia citada para Peine por GM, no identificada botánicamente y llamada locoche. "Una decocción de la raíz de la planta es febrífuga, mientras que sus hojas se comen como ensalada".

48) *Lactuca serriola L., Compositae, 9452, II/87

$\mathrm{CH}$

Maravilla [mara'ßiye], lechuga [le'čuye], cerraja? [se'řaxe] o borraja? [bo'řaxe]

$\mathrm{S}$

Maleza de chacras, perjudicial y asociada a los huertos de lechugas.

49) Parastrephia quadrangularis (Meyen) Cabrera, Compositae, I/26b

$\mathrm{P}, \mathrm{A}$
Chacha ['čače], chacha hembra, chacha chica, chacha fina, chachakoa [čača'koe], koa ['koe], tola

$\mathrm{R}, \mathrm{L}, \mathrm{T}$

Arbusto muy abundante en la transición tolarpajonal y con un importante uso ritual en la región. Mezclada con wirakoa ${ }^{14}$, se usa cuando van a festejar los animales. Durante los "floramentos" del ganado (llamas, corderos) se quema esta aromática planta y el humo se llama koa ('koar al ganado', se dice). En general, se usa para sahumerios, ya sea para la casa, para las siembras, para los "floreos de animales". La planta también es usada como leña. Mezclada con wirakoa también sería tintórea, según un informante.

GM citan para Peine los vernáculos chacha y chachacoma para una planta medicinal-ritual, seguramente correspondientes a esta especie. La autora documenta que se trata "de una planta aromática, usada para sahumar y en las ceremonias relacionadas con el agua (limpieza de las acequias). Dicen que es soberano remedio contra la puna; basta darlas a oler o a mascar a las mulas, cuando se apunan para que se mejoren". La autora agrega que, "mezclada con el molle, copa-copa y malvas se prepara el vaho o pisada de agua, que mejora o sana personas que sufren de reumatismo. Se hierven los ingredientes en agua y se vierte esta decocción en un recipiente grande o balde, poniéndose dos palitos en el borde. Sobre éstos se apoyan los pies y se envuelve bien todo el cuerpo y recipiente con frazadas, para que el vapor suba. El procedimiento es una forma simplificada del baño de cajón". Los mismos usos ceremoniales y rituales de esta especie han sido citados, en el Loa Superior, para dos especies de Fabiana, F. squamata en Caspana y F. bryoides en Toconce. MG citan la especie para Socaire con el sinónimo Lepidophyllum quadrangulare y el vernáculo chacha. La planta sería medicina "contra el reumatismo, mezclada con tolilla, pimiento, bailahuen y pingo-pingo, se hace hervir en un fondo, se colocan unos palitos encima de la boca del fondo $\mathrm{u}$ olla, para pisar encima y recibir el vapor. Este remedio se denomina vaho o pisada del agua". Los autores también citan el mismo uso ritual de la especie que hemos reseñado: "La chacha es también una especie de incienso ritual usado en la ceremonia que celebran actualmente los 
cantales $^{15}$, con motivo de la limpieza de acequias. Importante es que, según la unanimidad de los informantes, la chacha al quemarse en la ceremonia se transforma en $\mathbf{k o a}^{16}$. En la ceremonia de ahumamiento del ganado, que se celebra el 25 de diciembre de cada año, y durante el día de San Juan, se emplea este vegetal como productor de humo, actualmente, en los corrales". SSL citan también para Guatín el vernáculo coba para la especie y agregan que "se usa para humear las cabras". Se quema la coba en las proximidades del corral y bajo el humo desprendido se hacen pasar las cabras'. También los nombres pulika y leña pulika han sido registrados, para esta especie, en el Loa Superior, en Toconce (AACV). En Caspana (VCS), la especie es llamada tola amarilla, tola amarga, tola, tolilla, tola de la cordillera, leña del cerro.

\section{0) Parastrephia teretiuscula (Kuntze) Cabrera, Compositae, 9337, I/26a \\ $\mathrm{P}$}

chacha, chacha pelada, chacha macho, chachakoma [čača'kome], chacha pulika ['čače pu'like]

$\mathrm{R}, \mathrm{M}, \mathrm{L}, \mathrm{T}$

La gente hace la distinción entre tres chachas. Una que crece en los tolares bajos y es alta ramuda, varilluda, erguida y fragante, la chacha pelada $o$ chacha macho. Otra, muy bajita y resinosa que crece arriba en el pajonal, la chacha hembra, fina, chica o chacha koa (Parastrephia quadrangularis). La tercera clase de chacha es la pata de perdiz (Fabiana bryoides), especie muy escasa y cordillerana. Tradicionalmente, es la chachakoa la que se usa como sahumerio para koar animales, durante los floramentos del ganado. Sin embargo, cuando no hay chachakoa se usa la chacha pelada para koar al ganado, especialmente los burros. Esta especie es también medicinal. Se usa para sahumerio y vahos contra malos aires, empacho y dolores de estómago; caliente y en masajes para los calambres; y mezcla-

15 De acuerdo a Barthel (1986), el nombre cantal puede relacionarse con el verbo kunza ckantur. Su significado, 'el que saca algo adelante', expresa la función del sacerdote sacrificial. El cargo y función del cantal es análogo al de puricamani en el Loa Superior (Castro \& Varela 1994).

Koa es un concepto complejo y poco explícito, de connotación ceremonial sagrada. da con otras hierbas se usa para baños. Además se usa como leña. Además, es tintórea y da color amarillo.

El nombre pulika o pulika macho ha sido registrado, para esta especie, en el Loa Superior (AACV). MG citan para Socaire a una especie, no identificada botánicamente, con el vernáculo de chacha mota o pariente de la chacha. Puede tratarse de Parastrephia teretiuscula o Fabiana bryoides (ver $\mathrm{N}^{\mathrm{o}} 122$ ).

51) Perezia atacamensis (Phil.) Reiche, Compositae, 9318, I/52

A

Maransel [maran'sel], maransel hembra, maransel macho?

M, F

Según los entrevistados, hay dos clases de maransel. La consignada sería la hembra porque es herbácea y más chiquita, aunque una persona insistió en que era el macho (ver Werneria glaberrima). Según informaron los entrevistados, la raíz del maransel hembra, muy extensa y profusamente trenzada, es el mejor remedio para las soldaduras de huesos (ver también tolilla, Fabiana denudata). La consumen las ovejas, las cabras y las llamas.

MG citan para Socaire el nombre de maransel, para esta especie, con los mismos usos terapéuticos ya mencionados. También los nombres marancel y marancel hembra han sido registrados para P. purpurata en el Loa Superior, en Toconce (AACV), y para $P$. ciliosa en Caspana (VCS).

52) Pluchea absinthioides (Hook. et Arn.) H. Rob. et Cuatrec., Compositae, 9383, II/13

Q

brea ['bree], breya ['breye]

F, C, M

Especie extraordinariamente abundante en quebradas y salares, y unánimemente reconocida -a pesar de lo amargo de la planta- como de valor forrajero, sobre todo para las ovejas, los conejos y los burros que lo prefieren tierno. Todas las personas coincidieron en señalar que la especie era usada antiguamente para techar las casas. Actualmente, se usa para hacer ramadas para sombra. El tallo consumido como té es remedio para el estómago. 
MG citan esta especie para Socaire (con el sinónimo de Tessaria absinthioides) con el nombre de brea y usada para forraje y techumbres. Los nombres brea, brella y sorona han sido registrados, para esta especie, en el Loa Superior (AACV y VCS).

53) Schkuhria multiflora Hook. et Arn., Compositae, 9401, 9472, II/72, 102

$\mathrm{CH}$

soiko de cabra ['soiko ðe 'kaßre], suiko de cabra ['suiko ðe 'kaßre]

$\mathrm{F}$

Pasto de lluvia. El nombre hace alusión al hecho de que esta planta se parece al soiko comestible (Tagetes minuta), pero no lo comen las personas y sí el ganado.

También los nombres de pasto flor amarilla, pasto del campo y manzanillón han sido registrados, para esta especie, en el Loa Superior (AACV). Probablemente, se trate de la misma especie registrada como compañero del soico por MG, asignado a una planta forrajera de Socaire no identificada botánicamente.

54) Senecio atacamensis Phil., Compositae, 9339, $\mathrm{I} / 27$

$\mathrm{P}$

Mukuraka [muku'rake], mokoraka [moko'rake], mukurakan [muku'rakan]

$\mathrm{F}$

Todas las personas destacaron el valor forrajero de esta especie, especialmente para cabras.

Los nombres chachacoma blanca y chachacoma del burro han sido registrados, para esta especie, en el Loa Superior (AACV). Esta especie puede corresponder al taxon mocaraca o mocoraca, citado para Peine y Socaire por GM y MG, y no identificado botánicamente. GM documentan también uso tintóreo para la especie, que daría un color verde. A pesar de nuestra insistencia, no logramos registrar este uso para esta planta en nuestra consulta.

55) Senecio filaginoides DC. var. lobulatus (Hook. et Arn.) Cabrera, Compositae, 9330, $\mathrm{I} / 39$

A

monte blanco, duraznillo [durah'niyo]

F, M

Forraje para animales. Una persona la calificó de no muy recomendable para el ganado, aunque la comerían las cabras. Otra persona dijo que era remedio.

56) Senecio jarae Phil., Compositae, 9322, I/42

A

Romerillo [řome'riyo]

$\mathrm{F}$

La especie es muy poco conocida. Una persona la calificó de forrajera.

57) Senecio puchii Phil., Compositae, 9345, I/38 A

chachakoma, chachakoma macho, chachakoma de la vicuña [čača'kome de la Bi'kuna], leña de tola ['leja đe 'tole]

$\mathrm{M}, \mathrm{F}, \mathrm{L}$

La planta es considerada, unánimemente, como de valor medicinal y es usada de distintas formas. Como té o como sahumerio es buena para el resfrío, para el estómago y para la puna. Una persona dijo que esta especie no era la medicinal; que la chachakoma hembra, más fina, sí que era buena para todo mal, se van los dolores. Para ello, se calienta en el brasero y se restriega por el cuerpo. Pocas personas mencionaron valor forrajero y combustible para la planta.

SSL citan para Guatín el vernáculo y MG lo nombran para Socaire, adjudicándolo ambos a S. eriophyton, con los mismos usos medicinales expuestos para $S$. puchii. También el nombre chachacoma ha sido registrado para $S$. graveolens en el Loa Superior (AACV).

58) Senecio scorzonerifolius Meyen et Walp., Compositae, 9315, I/40

A romerillo chico [řome'riyo 'čiko]

F, M

La consumen los animales, especialmente las vicuñas. Además, es un remedio igual al romero (Rosmarinus officinalis).

59) Senecio xerophilus Phil., Compositae, 9320, $\mathrm{I} / 37$

A

romerillo, romerillo blanco

F, M

Forraje y remedio para el corazón.

60) *Sonchus asper (L.) Hill, aff., Compositae, 9382, II/14 
Q, CH

Niebla ['njeßle], cerraja, borraja, ñible ['nißle], ñiuble ['njußle], ñiebla ['njeßle], ñilhue ['nilwe] $\mathrm{M}, \mathrm{F}$

Esta maleza es apreciada por ser un excelente remedio, especialmente para los niños y guaguas. Cura la fiebre, los resfríos, la tos, la vesícula y limpia el estómago. Para ello se muele la planta, se vierte en agua caliente y también se toman baños. Una persona mencionó que la comen los animales.

MG citan para Socaire el nombre de cerraja para Sonchus oleraceus, una planta con los mismos usos expuestos. La planta sería comestible. Para la cocina tradicional atacameña, GS documentan una receta para la ensalada de ñible, acompañada de tomate y papas. Los nombres werakucha, wirakucha, verakucha y wirakocha han sido citados, para esta especie, en el Loa Superior, en Caspana (VCS). También el nombre viracocha, wiracocha ha sido registrado para $S$. oleraceus en el Loa Superior, en Toconce (AACV).

\section{1) Tagetes minuta L., Compositae, 9377, II/11 Q, CH \\ suiko, soiko ['soiko], suiko blanco ['suiko'blayko] Co}

Se reconocieron dos clases de soiko, uno consumido por las personas y el otro inservible, soiko de la cabra (Schkuhria multiflora). Todas la personas dijeron que esta especie era la comestible, buena para tomar como té. Los antiguos la echaban a la sopa, la que, con ese aliño -según dicen-, "agarraba un buen olor". Es un condimento aromático como el clavo de olor.

La especie es citada para Caspana (VCS) con el nombre de soiko casero. Probablemente se trate de esta especie la planta no clasificada y citada para Socaire por MG con el nombre de soico, con propiedades medicinales (dolor de estómago) y forrajeras. También el soico citado como Tagetes gracilis por SSL para Guatín, que no aparece en la flora chilena. El nombre soiko o suiko ha sido registrado para T. multiflora en el Loa Superior, en Toconce (AACV).

62) Urmenetea atacamensis Phil., Compositae, $9437, \mathrm{II} / 44$
PP

Kótar ['kotau], kokakora [koka'kore], oreja de ratón [o'rexe ðe řa'ton], kótaro ['kotaro], kotáro [ko'taro], kotára [ko'tare]

F, O

Pasto de lluvias de los desiertos. Especie generalmente reconocida como de valor forrajero, principalmente para las ovejas, aunque una persona dijo que no se usa, porque cría gusanos. Otra persona contó que se usa para mascar como coca, uso también documentado en el Loa Superior para la especie. El nombre oreja de ratón alude al color y a la forma de las hojas.

También el nombre coquilla o coca del suri ha sido registrado, para esta especie, en el Loa Superior $(\mathrm{AACV})$. Probablemente se trate de la misma especie forrajera, no identificada botánicamente, y registrada como cótar por MG, para Socaire.

63) *Verbesina encelioides (Cav.) Benth. et Hook. f. ex A. Gray, Compositae, 9375, II/20

$\mathrm{Q}, \mathrm{CH}$

Maravilla [mara'ßiye], flor amarilla [flod ama'riye], mirasol, mirasol chico

F, A

Especie de maleza generalmente reconocida como de valor forrajero, aunque algunas personas dijeron que era mala hierba. Se ha plantado como adorno en la plaza de Peine.

La especie es citada para Socaire por MG con el nombre maravilla. Puede corresponder a la citada como mirasol por estos autores y no identificada botánicamente.

64) Werneria glaberrima Phil., Compositae, 9344, $\mathrm{I} / 41$

A

maransel, maransel macho, comida de vizcacha? [ko'miða ðe Bi ${ }^{\text {' } k a c ̌ e] ~}$

$\mathrm{M}, \mathrm{O}$

Los entrevistados informaron que hay dos clases de maransel. Esta especie es la macho, porque es de raíz hedionda y leñosa, aunque una persona insistió en que esta sería la hembra. La raíz, mezclada con tolilla (Fabiana denudata), es un excelente remedio para dolores espalda, torceduras, lastimaduras y quebraduras de las personas. Se muele y mezcla con guano de waicho ${ }^{17}$, formando una pomada que se aplica y amarra como 
entablillado. Suelda los huesos como yeso. La raíz es también un remedio de curanderos para dolores de cintura, dolores de rodillas, machucones internos, para lo cual la planta se muele y calienta y se aplica como emplasto, con alcohol. También se puede tomar contra resfriados. La consumiría la vizcacha.

Los nombres marancel y marancel macho han sido registrados, para esta especie, en el Loa Superior (AACV y VCS), con las mismas propiedades terapéuticas. GM cita para Peine una planta medicinal "buena para los pulmones" llamada maransél. Puede tratarse de esta especie o de Perezia atacamensis.

65) *Xanthium spinosum L., Compositae, 9370, II/24

\section{$\mathrm{Q}, \mathrm{CH}$}

cola de caballo ['kola ðe ka'ßayo], cepacaballo [sepaka'ßayo], cepa de caballo ['sepa ðe ka'ßayo] M, O

Tal como el paiko, esta especie de maleza es considerada un buen remedio para la mala sangre, espinillas dolorosas, granos y manchas de la cara, alergias. Se usa la hoja en infusión, como té, la cual debe ser "serenada" e ingerida durante un mes. Como tiene espinas, se usa también como huasca de carnaval. En la chacra es mala hierba y no la comen los animales.

También los nombres cepacaballo, sepa caballo, setacaballo y sepicaballo han sido registrados, para esta especie, en el Loa Superior, tanto en Caspana (VCS) como en Toconce (AACV). MG citan para Socaire con el nombre de cepa caballo a Xanthium ambrosioides. No existe esta especie entre las malezas que crecen en Chile (Matthei 1995) y, probablemente, se trata de un sinónimo de la citada. Los autores registraron los mismos usos medicinales expuestos, aunque varía algo el tratamiento: "se administra la infusión, en ayunas, durante nueve días".

66) Xenophyllum incisum (Phil.) V.A. Funk, Compositae, 9321, I/43

\section{A}

pupusa del agua [pu'puse ðe'lawe], pupusa [pu'puse], pupusa del campo [pu'puse əel 'kampo]

M

La especie es considerada como un excelente remedio para diversos tipos de dolencias. Tomada como té, o en mate, mezclada con la chachakoma, es remedio para el estómago, úlcera y puna. Toda la planta, mezclada con la lampaya (Lampaya medicinalis), sirve para darse baños cuando no se puede caminar, duelen las piernas o se tiene mucho dolor de cabeza.

El taxón llamado pupusa, no identificado botánicamente por MG para Socaire, y con los mismos usos medicinales, puede corresponder a esta especie. En Caspana (VCS), el vernáculo pupusa es adjudicado a Senecio pappii y $S$. rosmarinus.

67) Especie no determinada, Compositae, II/98

\section{$\mathrm{CH}$}

menta koka ['mente 'koke]

$\mathrm{M}$

Especie de arbusto con flores amarillas muy raro en la región. Solamente observada en una casa en las afueras del pueblo de Socaire. Una persona la reconoció con nombre y uso medicinal para el estómago.

68) *Convolvulus arvensis L., Convolvulaceae, 9399, II/73

\section{$\mathrm{CH}$}

enredadera [enřeða'ðere], correhuela [koře'wele], rayito de sol, margarita

$\mathrm{P}, \mathrm{A}$

Todas las personas calificaron esta maleza como perjudicial para la agricultura y mala hierba. Dos personas dijeron que era adorno, por su bonita flor. MG citan esta especie para Socaire con los vernáculos de enredadera y bocina. Para Caspana, VCS citan para la especie los nombres de korriwela, korrewela, korrihuela, korrehuela, korrijuela, korrevuela y Verdelaga.

69) *Lepidium bonariense L., Cruciferae, 9475, II/101

$\mathrm{CH}$

hierba del tapón ['yerße ðel ta'pon], arcilla [ar'siye] F, M

Maleza que sirve como forraje para los animales. El nombre refiere a su uso como remedio cuando se está enfermo de diarrea.

70) *Lobularia maritima (L.) Desv., Cruciferae, 9368, II/27 


\section{Q, $\mathrm{CH}$}

nieve ['njeße], nevadita [neßa'ðite], nevadilla [neßa'ðiye]

A, F

Esta especie de maleza se usa como adorno para matizar flores y para ramos para el cementerio. Los nombres aluden a las profusas inflorescencias blancas. Una persona la reconoció como forraje.

71) Sisymbrium lanatum (Walp.) O.E. Schulz, Cruciferae, 9296, 9415, I/12, II/62

PP, Q

chuchar ['čučau], chochar ['čočau], séber ['seßes], sébir ['seßiı]

\section{F}

Pasto de lluvia considerado forrajero, especialmente para llamas y ovejas. Una persona dijo que reemplazaba a la alfalfa (Medicago sativa).

De acuerdo a nuestra consulta, creemos que se pueden asignar a esta especie dos vernáculos, recopilados por MG para dos plantas de Socaire: una Crucífera forrajera y combustible llamada chuicher y otra forrajera clasificada como Adesmia sp y llamada sébir. Creemos que esta última asignación es errónea, ya que el nombre sébir o séber ha sido asignado, por muchos entrevistados, a S. lanatum.

72) Cuscuta sp, Cuscutaceae, 9386, II/10

\section{$\mathrm{Q}, \mathrm{CH}$}

enredadera, cerda de chancho ['serðe ðe ' čančo], cabello [ka'ßeyo], peludilla [pelu'ðiye]

$\mathrm{P}$

Especie unánimemente reconocida como mala hierba perjudicial para la agricultura.

\section{3) Euphorbia klotzschii Oudejans, Euphorbiaceae, 9422, II/55 \\ $\mathrm{CH}$}

leche ['leče], pasto leche ['pahto 'leče], pasto lechero ['pa ${ }^{\text {h}}$ to le'čero], verdulaga [berðu'laye], lecheleche ['leče'leče], lecherito del campo [leče'rito ðel 'kampo]

$\mathrm{M}, \mathrm{Co}$, F?

Los nombres de esta maleza de chacras aluden al látex (leche) que produce la planta. Esa leche sirve para sanar heridas y para las verrugas. Solamente una persona dijo que la especie se consume como ensalada y en sopa, dato que puede ser erróneo, ya que otras especies del género son venenosas. La información acerca del uso forrajero de la planta, proporcionada por algunos informantes, también se contradice con las observaciones de otras personas según las cuales es mala hierba para los animales porque es amarga y junta gusanos. Una persona dijo que la planta parece "peluca", analogía absolutamente acertada sobre la forma de la planta cuando se saca de la tierra.

MG citan para Socaire a E. minuta con los nombres de leche-leche, lechuga y pasto lechero. También los nombres j'alpa, j'alpa pasto, pasto de la tierra y té del campo han sido registrados para $\boldsymbol{E}$. minuta, en el Loa Superior (AACV). Para la cocina tradicional atacameña, GS documentan recetas para "ensalada de verdolaga", con papas.

74) Geranium core-core Steud., Geraniaceae, 9366, II/29

Q

tipo enredadera

$\mathrm{F}$

Esta especie es poco conocida y muy escasa en la zona. Se le observó solamente en la Quebrada Sira de Toconao. Una persona mencionó que era forraje.

75) Phacelia setigera Phil. var. setigera, Hydrophyllaceae, 9307, I/54

A

sobaco negro [so'ßako 'neyro], sobaquillo [soßa'kiyo]

$\mathrm{F}$

Todos los entrevistados calificaron esta hierba altoandina como buen pasto para los animales, especialmente para las llamas, las cabras y las ovejas.

En Caspana (VCS), esta especie es también llamada sobaco negro. Probablemente se trate de esta especie las plantas forrajeras no identificadas botánicamente, y citadas por MG para Socaire con los vernáculos sobaco negro y sobaquillo. También los nombres sobaco negro o itallapa del cerro han sido registrados para $P$. viscosa en el Loa Superior, en Toconce (AACV).

76) Krameria lappacea (Dombey) Burdet et B.B. Simpson, Krameriaceae, 9353, I/19

$\mathrm{P}$

tikara, tíkara ['tikare], tikara hembra, tikara negra, pegapega ['peya'peye], monte morado, monte colorado, monte negro, té colorado, chakachaka 
['čaka'čake], palo colorado, chipichapi ['čipi'čapi], cadillo [ka'ðiyo]

\section{$\mathrm{T}, \mathrm{M}, \mathrm{F}$}

Llama la atención la gran cantidad de nombres obtenidos para esta especie, sumamente escasa en la región. Observamos solo un ejemplar cerca de Talabre. El nombre de tikara hembra es una comparación, por analogía, con su compañera tintórea, la tikara macho (Ambrosia artemisioides), una planta más grande. Las espinas del fruto de la hembra son también más finitas que las del macho y se pegan a la ropa y pelaje de animales, de ahí los nombres de pegapega y cadillo. Los otros nombres parecen aludir al color y a las propiedades tintóreas de la raíz de la especie. La raíz es colorada y, hervida, es utilizada para tintura y proporciona un color desde café claro hasta verdoso y rosado-cremita muy suave. Mezclada con pingopingo (Ephedra andina) tiñe la lana de rojo, color sangre de toro. La raíz y el tronco también se utiliza en infusión, ingerida como té medicinal con cáscara de naranja, como remedio para tomar, en invierno, para los riñones, la vejiga y el mal de orines. También la especie proporciona forraje para los animales.

GM documenta, para Peine, el uso tintóreo (da un color pardo) de una planta no identificada llamada tícara. MG citan para Socaire a esta especie con el sinónimo Krameria iluca y el vernáculo tícara. Además de los usos medicinales y tintóreos expuestos, los autores agregan que es remedio para la gonorrea. SSL citan para Guatín el vernáculo pega-pega para el sinónimo $K$. iluca. También los nombres chaka chaka y mata ratón han sido registrados para $K$. iluca, en el Loa Superior (AACV).

77) * Marrubium vulgare L., Labiatae, 9419, II/58

$\mathrm{CH}$

toronjil cuyano [toron'Xil ku'yano], toronjil [toron'Xil], yerba buena ['yerße 'ßwene], ajenko [a'Xenko]?

$\mathrm{M}$

La especie es cultivada en las huertas y considerada una medicina de múltiples usos. Así, por ejemplo, se mencionó que es muy buena para todo mal, en especial para los diabéticos, tomada como agua. Otros usos comunes son limpiar el estómago, cuando se la coloca en el caldo, como también para los dolores de espalda, hígado y corazón.
VCS citan, para esta especie, en Caspana, los nombres de toronjil cuyano, paiko cuyano, ajenko.

78)*Rosmarinus officinalis, Labiatae, II/97

$\mathrm{CH}$

romero [ř́o'mero], romero de Castilla [ř́o'mero ðe $\mathrm{ka}^{\mathrm{h}^{\prime}}$ tiye ]

$\mathrm{M}$

La especie es cultivada en las huertas y considerada una medicina de múltiples usos. Cuando la planta está seca, se echa en el brasero para sahumerio contra el aire y "desmandes" (ver Artemisia copa, sahumerios). También se usa para baños y, como infusión, para el dolor de estómago. Se comercializa con estos fines.

79) *Linum usitatissimum L., Linaceae, 9408, II/66

$\mathrm{CH}$

linaza [li'nase], cascabel [kax $\left.{ }^{\mathrm{x} a} ß \mathrm{el}\right]$

$\mathrm{M}$

Esta maleza es cultivada en las huertas y se le llama cascabel, porque, con el viento, suenan las semillas contenidas en las cápsulas. Las semillas, tostadas y hervidas, sirven como remedio para machucones internos, para el corazón, fiebres, para el estómago y estitiquez.

80) Caiophora rahmeri Phil., Loasaceae, 9480, $\mathrm{I} / 71$

$\mathrm{P}$

ortiga [or'tiye], ortega [or'teye], ojman ['oxman], osman ['ohman]

$\mathrm{M}, \mathrm{O}$

La planta tiene uso medicinal. Cuando hay "granujas" o alergias en el cuerpo, hay que tomarlo o bañarse. Como infusión es también un buen remedio infantil, cuando tienen tos, hielo o fiebre. Se la calificó como la borraja silvestre. Cuando los niños son desobedientes con la mamá, se los chicotea con esta planta.

Probablemente, la especie corresponda a los vernáculos ojman, ortega y ortiga, citados por MG para Loasa sp de Socaire. Los autores mencionan que "se emplea para despertar el corazón cuando está dormido; se usa moliéndola, se estruja a través de un lienzo en agua y se bebe. Cuando se está descaecido, aviva". En el Loa Superior, (AACV y VCS) las especies de Caiophora son llamadas ortega y ortiga. 
81) Huidobria fruticosa Phil., Loasaceae, 9484, $\mathrm{I} / 68$

PP

primavera, quebrolla, malva parada ['malve pa'raðe]

$\mathrm{F}$

Especie de subarbusto muy raro en la región. Solamente observado en los alrededores de Peine. Fue llamada quebrolla por los dos informantes de Peine que nos llevaron al lugar donde crecía. Este nombre es también dado a Chuquiraga atacamensis, por un gran número de oriundos de la región. Los nombres de primavera y malva parada generalmente se dan a Tarasa operculata, planta parecida a $H$. fruticosa en el hábito y color plomizo, y pueden tratarse de confusiones con ella.

82) Cristaria dissecta H. et A., Malvaceae, 9466, II/105

$\mathrm{CH}$ malvisco (malvavisco) [mal'ßi ko (malßa'ßi ko)], malva ['malße]

$\mathrm{F}$

Maleza nativa de chacras usada como forraje. El nombre malva es genérico para especies pertenecientes a distintos géneros de la familia Malvaceae (e.g. Cristaria, Tarasa, Malva, Malvastrum, etc.). MG citan para Socaire dos especies de Malváceas llamadas malva y malvilla blanca, Malvastrum pedicularieaefolium y Cristaria andicola, respectivamente.

\section{3) Cristaria sp, Malvaceae, 9294, I/10}

$$
\mathrm{P}
$$

malva, malva del campo, malva rosada ['malße řo'saða]

$\mathrm{F}$

Pasto de lluvia de los desiertos.Todos los entrevistados mencionaron el valor forrajero de esta especie, y una persona la destacó como el mejor pasto para los animales. El nombre malva es genérico para especies pertenecientes a distintos géneros de la familia Malvaceae (e.g. Cristaria, Tarasa, Malva, Malvastrum, etc.)

MG citan para Socaire dos especies de Malváceas llamadas malva y malvilla blanca, Malvastrum pedicularieaefolium y Cristaria andicola, respectivamente.

84) *Malva sp, Malvaceae, II/100

$\mathrm{CH}$

malva rosa ['malße 'řose]
A, M

Especie muy hermosa, con flores de múltiples colores, y cultivada como flor de jardín como adorno para la vista y para llevar al cementerio, para las almas. El agüita de la hoja es usada en baños para la fiebre y para la tos. El nombre malva es genérico para especies pertenecientes a distintos géneros de la familia Malvaceae (e.g. Cristaria, Tarasa, Malva, Malvastrum, etc.)

MG citan, para Socaire, dos especies de Malváceas llamadas malva y malvilla blanca, Malvastrum pedicularieaefolium y Cristaria andicola, respectivamente.

85) * Malva parviflora L., Malvaceae, 9460, II/ 80

$\mathrm{CH}$

malva, malva rosa, amapola

$\mathrm{M}, \mathrm{A}, \mathrm{F}$

Maleza de chacras, usada como medicina para baños cuando las personas se sienten afiebradas; antiguamente, también se bañaba a los niños con la planta. La flor se usa como adorno para la vista o para llevar al cementerio. Una persona dijo que era también forraje para animales. El nombre malva es genérico para especies pertenecientes a distintos géneros de la familia Malvaceae (e.g. Cristaria, Tarasa, Malva, Malvastrum, etc.)

MG citan, para Socaire, dos especies de Malváceas llamadas malva y malvilla blanca, Malvastrum pedicularieaefolium y Cristaria andicola, respectivamente.

86) Nototriche estipulata (Phil.) A.W. Hill ex B.L. Burtt, Malvaceae, 9332, I/49

A

altea [al'tee], kora ['kore]?

$\mathrm{Co}, \mathrm{M}, \mathrm{F}$

Esta especie altoandina tiene las mismas propiedades de otra especie que crece en el mismo hábitat y también llamada altea, Junellia digitata. Por las características de la raíz, blanca y blanda, probablemente $N$. estipulata sea la verdadera altea comestible. Antiguamente, la raíz era alimento y se cultivaba. También es medicina para la tos y dolor de estómago. La raíz es consumida como forraje por las ovejas, las llamas y las cabras.

MG citan, para Socaire, una planta no determinada, y de raíz comestible, llamada kípsur. Puede que se trate de esta especie o de Junellia digitata, cuyas raíces también se comen. Sin embargo, los 
autores reportan que la especie se trae de Peine. A esa altitud hay otra especie con raíz comestible, el kauchal, Tiquilia atacamensis.

87) Tarasa operculata (Cav.) Krapov., Malvaceae, 9300, 9369, I/16, II/26

$\mathrm{P}, \mathrm{Q}$

malva blanca ['malße 'blanke], primavera, malva parada, malva del campo, malvilla [mal'ßiye]

F, M

Especie de desiertos y quebradas, abundante en la época de lluvias. Todos los entrevistados calificaron la planta como forrajera. Solamente una persona agregó que también servía para baños. El nombre malva es genérico para especies pertenecientes a distintos géneros de la familia Malvaceae (e.g. Cristaria, Tarasa, Malva, Malvastrum, etc.) MG citan para Socaire dos plantas, malvilla blanca (Malvastrum pedicularieaefolium) y primavera, no identificada, que pueden corresponder a esta especie. También el vernáculo malva blanca, citado por SSL para Guatín (adjudicado a Cristaria andicola), parece corresponder a esta especie, ya que es el vernáculo más recurrente para nombrarla que hemos obtenido en nuestro estudio. También los nombres ojala, oke lorenzo, k'olis y malva han sido registrados para $T$. operculata en el Loa Superior (AACV).

88)*Tarasa tenella (Cav.) Krapov., aff., Malvaceae, 9417, 9387, II/9, 61

$\mathrm{Q}, \mathrm{CH}$

malva

F, M

Maleza muy abundante en quebradas y chacras, y unánimemente reconocida como de valor forrajero, especialmente para conejos y corderos. En infusión o en baños, es remedio para la fiebre, especialmente para los niños. El nombre malva es genérico para especies pertenecientes a distintos géneros de la familia Malvaceae (e.g. Cristaria, Tarasa, Malva, Malvastrum, etc.)

También el nombre malva ha sido registrado, para esta especie, en el Loa Superior (AACV y VCS). MG citan para Socaire dos especies de Malváceas, llamadas malva y malvilla blanca, Malvastrum pedicularieaefolium y Cristaria andicola, respectivamente.

89) *Acacia visco Lorentz ex Griseb., aff. Mimosaceae, II/93
$\mathrm{CH}$

wilka ['wilke], aromo [a'romo], como algarrobillo [alya'řoßiyo], acacio [a'kasjo]?

A

Especie de árbol plantado en la plaza de Peine para vista y para sombra. Los nombres de acacio y aromo son genéricos para distintas especies arbóreas del género Acacia.

90) Prosopis alba Griseb. var. alba, Mimosaceae, 9358, III/36

Q

algarrobo [alya'řoßo], algarrobillo

Co, M, T, L, F, C

El fruto del algarrobo tiene múltiples usos alimenticios. Antiguamente, los niños comían mucho las vainas crudas. El uso más frecuente es para la elaboración de harina de algarrobo, llamada añapa. Para ello, se muele la vaina y se extrae la pulpa de la misma, sin semillas, mediante colado. Se puede comer con leche y se usa también para preparar postres. La harina más finita es buena para la diarrea, con leche de cabra. Chajna es otro plato mencionado que se prepara con algarrobo, de la siguiente manera: la pulpa molida y remojada se mezcla con harina de maíz, obteniéndose una consistencia de engrudo. Por otro lado, las pepas se dejan remojando, resultando un agua dulce con sabor a algarrobo, y con eso se baña la chajna. También se prepara una chicha de algarrobo, llamada aloja (llamada también ckilampana o kilapana), la cual se toma durante la ceremonia de limpia de canales. Una resina que produce el algarrobo es tintórea, mezclada con otras plantas. Tiñe de color café (marrón). Usando la planta sola se obtiene color granate. Antiguamente, la planta se usaba para hacer un carbón mejor que el de chañar. La planta es también forrajera y las vainas son muy apetecidas por los chanchos y los animales, en general. Finalmente, el algarrobo tiene varios usos en construcción y artesanías. La madera sirve para hacer las puertas y también para confeccionar accesorios del telar, como peines, lizos y tortera o múyena (múina). El huso para hilar se hace con tablas (ver la descripción de estos accesorios de telares en Mostny 1954).

GM cita el algarrobo para Peine (P. chilensis). Además de los usos alimenticios ya descritos, la autora registra el procedimiento de preparación de la chicha de algarrobo o aloja: "se trituran las vainas secas del algarrobo en un mortero de pie- 
dra o madera; después se ponen en un recipiente con agua tibia y de un día al otro se produce la fermentación". También la autora documenta para la planta "su uso en construcciones como postes y en la fabricación de pequeños objetos, tales como torteras para hilar e implementos para tejer, como el tijne y la vinása. Grandes trozos de troncos se ahuecan para servir de morteros, se llaman tacana. Además, se fabrica carbón de leña del algarrobo; su resina y el aserrín se emplean como sustancias tintóreas en el teñido de tejidos, resultando un color pardo claro (color mostaza)". MG citan también este nombre para P. chilensis, en Socaire. "En Socaire se obtiene el fruto del algarrobo por intercambio (trueque) con los oasis más bajos y cercanos de Peine y Toconao. Existen dos variedades: blanco y negro, atendiendo al color de sus frutos". Para la cocina tradicional atacameña, GS documentan las múltiples recetas para el uso de la harina de algarrobo o añapa, por ejemplo, en la preparación de "añapa tostada", "chacna", variedades de chilcán (cocho de añapa y agua hervida), kuidar (postre con líquido de algarrobo con harina de maíz negro, consumido en todos los pueblos atacameños), "helado de añapa" y "postre de añapa".

91) Prosopis tamarugo Phil., Mimosaceae, 9442, II/78

\section{$\mathrm{S}$}

tamarugo [tama'ruyo]

F, L, C

La vaina y las hojas de este árbol del salar de Atacama constituyen un excelente forraje para los animales, especialmente para las ovejas, los corderos y las llamas. Los frutos no son consumidos por las personas, porque son ácidos. También la especie proporciona leña y madera para cierres. Se usa para trabajos manuales en las escuelas y para artesanías que se comercializan en San Pedro, como lámparas y colgados.

92) Allionia incarnata L., Nyctaginaceae, 9461, 9440, II/41, 82

Q

enredadera [enřeða'ðere]

F, M

Especie postrada y escasa, observada solamente en Cámar y en Peine y, generalmente, reconocida como de valor forrajero, principalmente para guar- darla como pasto seco. Una persona dijo que es remedio para la fiebre.

93) Adesmia atacamensis Phil., Papilionaceae, $\mathrm{I} / 60$

PP

iloka [i'loke], iloka macho [i'loke 'mačo], ilúkar [i'lukar], iluka macho [i'luke 'mačo], atalte [a'talte]

F

Esta abundante especie del desierto es considerada el mejor forraje para los animales. Es un arbusto perenne, y solamente en Peine fue denominada atalte. Por analogía con una especie herbácea y más pequeña del género (A. rhameri), es denominada en el resto de la región iloka macho.

SSL citan también, para Guatín, el vernáculo iloca para esta especie forrajera. Probablemente, corresponda a la misma planta forrajera, citada para Socaire, por MG con el nombre ilúcar. Estos autores también citan una especie no determinada de Atriplex llamada atalte. Creemos que es un error, ya que, como se ha dicho, este nombre fue asignado en nuestra consulta a $A$. atacamensis, por los habitantes de Peine. Creemos que también corresponde a esta especie el vernáculo támoro, documentado por SSL para una planta no identificada de Guatín; esto porque los nombres tamor, tamur, t'amur, tamorcillo y tamurquillo fueron registrados, para esta especie, en el Loa Superior, tanto en Toconce (AACV) como en Caspana (VCS).

94) Adesmia caespitosa Phil., aff., Papilionaceae, 9328, I/51

A

añawa [a'nawe], añawa blanca [a' nawe ßlanke], añawa negra [a'nawe neyre], varilla [ba'riye], kallya ['kalye]

L, M, F

Arbusto leñoso escaso y de altura. Una persona dijo que añawa, en quechua, significa "arde", ya que la especie proporciona muy buena leña. Es también medicinal, para baños y para mal de orines. Todas las plantas espinudas servirían contra esta última dolencia. La comen mucho la cabra y también el burro.

Puede ser este taxa el citado por MG para Socaire, no determinado, con el nombre de añagua o varilla y con usos forrajero y como leña. 
95) Adesmia erinacea Phil., Papilionaceae, 9291, $\mathrm{I} / 7$

$\mathrm{P}$

añawa blanca, espina blanca

F, M, L

La planta es consumida por el ganado cuando está tierna, especialmente las hojitas y las flores. La comen las llamas, los burros, las ovejas, los chivatos, las cabras y los corderos. También la aprovecharía la perdiz. La raíz es un remedio para tomarlo cuando se tiene mucha tos, y también es medicina para la mala sangre, la vejiga y el mal de orines. El tronco proporciona leña.

En Caspana (VCS), esta especie ha sido también llamada añawa blanca y espina blanca. Puede tratarse de esta especie la planta, forrajera y sin identificación botánica, citada para Socaire por MG con el nombre de espina blanca. También los nombres añawa blanca, espina blanca, añawilla del burro han sido registrados, para esta especie de Adesmia, la cual ha cido citada como con afinidad a A. gayana, en el Loa Superior, en Toconce (AACV).

96) Adesmia rhameri Phil., Papilionaceae, 9478, $\mathrm{I} / 69$

PP

iluka hembra [i'luke 'embre], iloka hembra [i'loke 'embra]

F

Especie herbácea y pasto de lluvia estacional que crece de semilla. Forraje.

97) Adesmia spinosissima Meyen, Papilionaceae, 9306, I/21

PP, A

añawa, añawa negra, añawa grande [a' nawa yranðe], espina negra,

F, L, M, Co

Todos los entrevistados coincidieron en calificar la planta tierna como forrajera, especialmente para cabras y llamas. Destacaron la abundante hojarasca que genera la planta y que sirve para rastrojar al ganado. El tronquito constituye buena leña, y también es remedio. En infusión da el mismo color que el té. Una persona informó que, en tiempos de mucha necesidad, las personas consumían la florcita que es dulce y la hojita, algo más amarga. También los nombres de añawa, añawilla, añawa verde y añawa colorado han sido registrados, para esta especie, en el Loa Superior (AACV y VCS).
98) Adesmia subterranea Clos, aff., Papilionaceae, 9316, I/46

A

cuerno ['kwerno], cuerno de cabra ['kwerno ðe 'kaßre], cacho de cabra, cuernillo [kwer'niyo], acerillo

L, F, M

Cojín leñoso y plano exclusivo del piso altoandino. Los troncos y la raíz proporcionan una excelente leña, muy calurosa. Lo consumen como forraje las cabras y las llamas. La perdiz come las flores. La raíz, en infusión, adquiere un color igual al té y es medicina para los riñones.

MG citan para Socaire dos especies de Adesmia que pueden ser este taxon. Una especie de Adesmia, no determinada, con el nombre acerillo y que es forrajera. También citan con el nombre de cuerno a Adesmia crassicaule, especie forrajera y combustible.

99) Astragalus cryptobotrys I.M. Johnst., Papilionaceae, 9329, I/50

A

garbancillo [gar'ßansiyo], garbanzo [gar'ßanso]

$\mathrm{P}$

Todos los entrevistados coincidieron en calificar a la planta como perjudicial para los animales, porque los emborracha y vuelve como locos, especialmente a los burros. Sería mucho peor que el konte chico (Lupinus subinflatus).

MG citan para Socaire, con el nombre de garbanzo silvestre, a A. bustillosii. Es altamente improbable que se trate de este taxon, diminuto y de crecimiento restringido exclusivamente a los bofedales altoandinos de la I Región. Por el contrario, A. cryptobotrys es abundante en el piso altoandino de la región de Atacama, y posee las mismas propiedades tóxicas para el ganado documentadas por MG. En el Loa Superior (VCS) se le da el nombre de garbanzo y garbancillo a otra especie de Astragalus tóxica para el ganado, $\boldsymbol{A}$. arequipensis.

100) Geoffroea decorticans (Gillies ex Hook. et Arn.) Burkart, Papilionaceae, 9359, II/35

Q

chañar [ča'nau]

Co, C, L, F, M

El fruto dulce del chañar se puede consumir fresco y, además, tiene múltiples usos culinarios. Así, por ejemplo, el arrope de chañar, cuya receta nos 
la proporcionó una persona de Talabre. Se requieren 10 kilos de chañar para 17 litros de agua, en el primer hervor, para que se deshaga el "cuerito" (la corteza del fruto). Después, se agregan dos litros más de agua hervida, se cuela en una tira; para que no pase nada de "grosso", tiene que caer la pura agüita. Va a salir una gran cantidad, y hay que hacerlo hervir con el fondo destapado, revolviendo con una cucharilla hasta que quede en su punto. El nivel del líquido va bajando y está listo cuando la cuchara queda pegada. Así se obtienen 8 a 10 botellas de arrope. Mientras más se hierve, menos arrope se obtiene, 6-7 botellas. También es muy importante el chañar que se ocupa; hay que buscar el más dulce, ya que no todos los frutos son iguales. Una prueba para seleccionar frutos es tomar muestras de distintos árboles y hervir los frutos cerca de una hora. Si el agua queda dulce sirve para arrope; si queda ácida, no. Algunas personas mencionaron que el arrope es un excelente jarabe para la tos. También se hace postre de chañar. Para ello, se tuesta el fruto y se remoja. Se separan los cuescos colándolo en una malla, sin importar que pase con harina y todo. Después, se le agrega harina de flor y leche de cabra. Queda como un flan, rico y muy sano. También se hace cocho de chañar, plato que antes se comía mucho. Se tuesta y hierve el fruto, se cuela y se mezcla con harina de flor. El chañar tiene varios usos en construcción y artesanías. Proporciona madera para construcción, para cercos y cierres y también para sombra. Con la madera se construyen mangos para herramientas. También accesorios para el telar, como peines, tíjnes, tinaza para poner el hilo; para telares en el suelo, kolmatur, o palos para agarrar el hilo y la única unidad de lizos llamada ilyáwa (ver la descripción de estos accesorios de telares en Mostny 1954). Como combustible el chañar proporciona leña. Antiguamente, se usaba para hacer carbón, aunque el algarrobo es mejor para este propósito. También la especie es un excelente forraje para el ganado. El fruto y la hoja los comen principalmente las ovejas, sobre todo cuando está bajo y tierno. Los chanchos comen mucho el fruto.

GM cita a la especie para Peine con el sinónimo Gourleia chilensis y, además de los usos alimenticios reseñados, menciona su utilización en construcciones, especialmente para vigas de techo; elaboración de pequeños objetos, como husos para hilar (a pesar de que esta madera ha sido reempla- zada en gran parte por las tablas de cajones de embalaje), y fabricación de carbón de leña. MG registran la especie como escasa para Socaire y con el nombre de chañar. Se importaría por trueque con los habitantes de Toconao. Para la cocina tradicional atacameña, GS documentan recetas para la preparación del "arrope de chañar", "cocho de chañar" y "postre o flan de chañar".

101) Lupinus oreophilus Phil., Papilionaceae, 9287, I/3

$\mathrm{P}$

konti ['konti], konte ['konte], kontikonti ['konti'konti]

F, A, P

Todas las personas califican la especie como un pasto de lluvia de hermosos y muy variados colores. Generalmente, las flores son usadas como adorno, ya sea para ornamentar iglesias, para llevar a las almitas al cementerio o para vender. Una persona dijo que, antiguamente, la especie se plantaba con estos fines. Aparentemente, la planta no es buen forraje para los animales cuando está verde, porque los emborracha y, si están muy flacos, los puede matar. Las llamas y las ovejas la consumen seca. Una persona dijo que es un forraje que reemplazaría ocasionalmente a la alfalfa (Medicago sativa).

MG citan para Socaire a esta especie con el nombre de conte. Los autores dicen que el cantal, un personaje ligado a las ceremonias de culto del agua, que se realizan en la actualidad en Socaire, y que puede ser considerado como un sacerdote (de acuerdo a VC, el cantal es nombre kunza del purikamani), se adorna la cabeza con las flores de konte, durante las ceremonias. Las pastoras la estiman muy bella y adornan sus sombreros con las flores. En el Loa Superior, en Caspana (VCS), la especie es llamada kontokonto, kontukontu, konte, kontikonto?, salkarai, salqarai, flor del campo.También el nombre flores del campo ha sido registrado, para esta especie, en Toconce (AACV).

102) Lupinus subinflatus C.P. Sm., Papilionaceae, 9288, 9317, I/4, 53

\section{$\mathrm{P}, \mathrm{A}$}

konte chico ['konte 'čiko], konte chujchento ['konte čux'čento], kontikonti, garbanzo del campo, q'ela [q'ele], chujchu ['čuxču]

$\mathrm{P}, \mathrm{F}, \mathrm{A}$ 
La especie, en general, es considerada perjudicial para el ganado ya que, cuando está madura, lo hincha y le produce chujcho (tercianas), se emborrachan y se caen y si está muy flaco los puede matar. Cuando seca, la consumen las llamas y ovejas. Sirve como adorno, igual que el konte grande.

VCS citan para Caspana el nombre de garbanzo para esta especie. MG mencionan el vernáculo chujchampu para una planta no determinada botánicamente, y que puede también corresponder a esta especie. SSL citan para Guatín una especie no determinada, con el vernáculo chuchampe, que se usa para teñir y da color amarillo, y que también puede ser la especie consignada.

103) *Medicago sativa L., Papilionaceae, 9356, II/38

Q, $\mathrm{CH}$

alfalfa [al'falfe], alfa

$\mathrm{F}, \mathrm{Co}, \mathrm{M}, \mathrm{O}$

Especie unánimemente reconocida como el forraje por excelencia. Cuando la planta está tierna es alimento para las personas. La flor es dulce y un remedio para la tos. La raíz es tónico para afirmar el pelo, cuando se cae mucho.

Citada por MG para Socaire con el nombre de alfa. "Voz de amplio uso regional, derivada de alfalfa. El cultivo de la alfalfa en esta región constituye el trabajo agrícola que alcanza mayor altura, ya que puede llegar hasta más de 3800 m.s.m., junto con algunas variedades de papa y de quinoa". Para la cocina tradicional atacameña, GS documentan recetas para el "guiso de alfalfa", con arroz, zanahoria y papas. Los nombres de alfalfa y alfa, para esta especie, también son usados en el Loa Superior, en Caspana (VCS).

104) *Melilotus indicus (L.) All., Papilionaceae, 9376, II/19

Q, CH

treból [tře'ßol], trigol ['tř̌i ol], trébol ['třeßol], tríbol ['tř́ißol], alfilla [al'fiye]

$\mathrm{F}$

Maleza unánimemente reconocida como de valor forrajero.

MG citan la especie, para Socaire, con el nombre trigol y usos forrajeros y medicinales (la infusión sirve para lavar la piel infectada). En Caspana también la especie es llamada trigól, trébol y treból.
105) *Plantago lanceolata L., Plantaginaceae, 9355, II/39

Q, CH

llantén [yan'ten], pasto, llantel [yan'tel], romaza?

$\mathrm{Co}, \mathrm{F}$

Maleza que se come en ensalada cuando está tiernita. También la comen las ovejas.

106) *Plantago major L., Plantaginaceae, 9378, II/18

Q, $\mathrm{CH}$

llantén, llantel, llantil [yan'til], romaza

M, F

Esta maleza es muy apreciada por sus propiedades medicinales. Para las heridas externas e internas, lastimaduras, hay que cocer la hoja al vapor de las brasitas del fuego. Se adelgaza y queda como papelito blandito. Se aplica como emplasto a la herida. Además, es remedio para toda dolencia, muy bueno y muy respetable, cura el cáncer y la vesícula y el corazón. Le compran mucho en Calama para todos los males. El conejo lo come. También el nombre llantén o lantín ha sido registrado, para esta especie, en el Loa Superior, tanto en Caspana (VCS) como en Toconce (AACV). Probablemente, se trate de esta especie la citada por MG para Socaire con el vernáculo yantil y con el mismo uso medicinal reseñado.

107) *Polygonum aviculare L., Polygonaceae, 9412, II/63

\section{$\mathrm{CH}$}

sangrinaria [sangri'narje], sangría [san'gria] M

Esta maleza es remedio para la mala sangre, la menstruación y para la piel manchada.

108) *Rumex crispus L., aff, Polygonaceae, II/94

$\mathrm{CH}$

romaza

F, Co

Pasto para los animales y comida en ensalada, cuando está tierna.

MG citan para Socaire la planta alimenticia Rumex patientia con el nombre de romasa. Los autores agregan que la especie es también medicinal y tintórea: "en caso de heridas e hinchazones, se asa un poco de la hoja sobre el fuego y se coloca sobre la parte afectada. Servía para teñir de amarillo 
antiguamente". Para la cocina tradicional atacameña, GS documentan recetas para la "ensalada de romasa", cocida y con papas. También el nombre lanteja ha sido registrado para Rumex crispus y Rumex sp. en el Loa Superior, en Caspana (VCS) $\mathrm{y}$ en Toconce (AACV), respectivamente.

109) Cistanthe celosioides (Phil.) Carolin ex Hershk., aff., Portulacaceae, 9424, I/59a PP

básal ['basal], pasto colorado, hierba sal [yerßa'sal], kámin ['kamin]

F, T

Planta de hojas pequeñas y flores de colores variados, generalmente púrpuras-rojizas, y con inflorescencias en glomérulos. Es pasto de lluvia, muy abundante en los márgenes desérticos, y de alto valor forrajero para todo tipo de animales. El nombre más reiterado para la planta es básal. Solamente un informante de Peine insistió en que el nombre era kámin o kámen, nombre dado generalmente a Cistanthe salsoloides, especie no forrajera del género. Dos personas mencionaron uso tintóreo para la especie, para lo cual se hierve, tintando de rojo el hilado de manera más firme que la anilina.

MG citan para Socaire una especie no determinada con nombre basal que sería forraje y, además, "cuando está tierna es un buen alimento en forma de guiso o para espesar los caldos". SSL citan también para Guatín el vernáculo basal, sin determinación botánica, y documentan que es "usado para protegerse de los rayos solares, colocándola en la frente".

110) Cistanthe salsoloides (Barnéoud) Carolin ex Hershk., Portulacaceae, 9448, 9482,

$\mathrm{I} / 59 \mathrm{~b}, \mathrm{II} / 91$

PP

kámin, kámen ['kamen], básal, hierba sal $\mathrm{S}$

Planta con hojas medianas más gruesas, flores moradas e inflorescencias en cimas escorpioídeas. Es muy escasa; solamente se colectó cerca del cementerio de Peine, y en Tilomonte. No la come el ganado. Aparentemente el nombre de la planta es kámen o kámin. Solamente un informante de Peine insistió en que el nombre de esta especie era básal, nombre dado generalmente a Cistanthe celosioides. También hay otras formas de la especie, con hojas grandes y ovales y muy gruesas, llamada hierba sal, de acuerdo a una persona de Camar.

MG citan para Socaire una especie no determinada llamada camen y que puede ser $C$. salsoloides, por el nombre. Sin embargo, no hemos registrado usos forrajero ni alimenticio para esta planta, como lo afirman los autores. También el taxon no identificado y llamado yerba sal puede ser este taxon.

111) Lenzia chamaepitys Phil., Portulacaceae, 9349, I/56

A

keúche, cebadillo [seßa'ðiyo]

F

Diminuta especie altoandina, muy poco conocida. Sólo dos personas la calificaron como forrajera. MG citan para Socaire una especie altoandina y forrajera no determinada, llamada keúye o keúche. Probablemente, se trate de esta especie o de Chaetanthera revoluta, también conocida con estos nombres.

112) Ranunculus cymbalaria Pursh f. cymbalaria, Ranunculaceae, 9431, II/47

$\mathrm{R}$

berro picante ['beřo pi'kante], berrillo [be'řiyo], monte picante ['monte pi'kante], pastito del agua Co

No la consume el ganado, porque es amarga y picante, a excepción del suri. Una persona dijo que la especie era consumida por gente en otras regiones, pero no en Camar.

También los nombres cucharón, cucharoncito o cucharita han sido registrados, para esta especie, en el Loa Superior, tanto en Caspana (VCS) como en Toconce (AACV).

113) Acaena magellanica (Lam.) Vahl, Rosaceae, 9363, II/32

Q

sítor ['sitoı], sítur ['situı], cadillo

F

Especie herbácea de quebradas, generalmente reconocida como de valor forrajero.

MG citan con los nombres de situr, cadillo y pegapega a Acaena laevigata, probablemente un sinónimo de A. magellanica. Los dos primeros vernáculos son unánimes, en Atacama, para esta última especie, pero el nombre de pega-pega lo hemos registrado nosotros para otra especie que también tiene frutitos que se pegan a la ropa, 
Krameria lappacea. Además de forrajera, los autores citados registraron uso medicinal para la planta, "contra afecciones a la vejiga y la descomposición de sangre". SSL citan también para Guatín el vernáculo cadillo para A. laevigata.

114) *Ruta chalepensis L., aff., Rutaceae, II/110 $\mathrm{CH}$ ruda ['řuða]

M

Especie cultivada como medicina en las huertas. Remedio para el mal aire, para el estómago y toda dolencia. Las señoras la usan mucho después del parto. La usan en las comidas, en agüita o como sahumerio. La llevan a Calama para vender.

En Caspana (VCS), la especie $R$. chalepensis es conocida como ruda.

115) Salix humboldtiana Willd., Salicaceae, 9379, II/17

Q

sauce ['sause], pimiento llorón

$\mathrm{C}, \mathrm{A}, \mathrm{F}$

Este árbol proporciona madera derecha para construcciones, como el álamo, para los techos. También se le planta para sombra. Se usa como adorno de los carros alegóricos durante las fiestas y en los pesebre de enero. También se confeccionan artesanías, como los palitos para tocar tamborcitos. La hoja es forraje.

116) Calceolaria stellariifolia Phil., aff, Scrophulariaceae, II/114

$\mathrm{P}, \mathrm{A}$

zapatilla [sapa'tiye]

$\mathrm{M}$

No colectamos la planta en la región, pero los entrevistados la mencionaron como remedio para la tos. MG citan para Socaire la especie con el nombre de zapatilla y uso medicinal contra el dolor de estómago. También el nombre zapatilla ha sido registrado, para esta especie, en el Loa Superior, tanto en Caspana (VCS) como en Toconce (AACV).

117) Mimulus glabratus Kunth, Scrophulariaceae, 9389, II/6

$\mathrm{R}$

berro ['beřo]

Co, M, F

Hierba acuática, unánimemente reconocida como de valor alimenticio, para comer en ensaladas. En infusión y mezclada con la cortadera (Cortaderia speciosa), es remedio para la fiebre y para la vesícula. Una persona dijo que también la come el ganado.

Los nombres berro y berro colorado han sido registrados, para esta especie, en el Loa Superior, tanto en Caspana (VCS) como en Toconce (AACV). MG citan, para Socaire, a una especie acuática y no determinada de Cardamine con este nombre, consumida como ensalada. Creemos que se trata del conocido y abundante Mimulus glabratus, ya que no hemos visto especies de Cardamine en Atacama.

118) Especie no determinada, Scrophulariaceae?, 9470, II/104

$\mathrm{CH}$

toronjil de la pena, toronjil dulce, cedrón [se'ðron]

$\mathrm{M}$

Plantita aromática y de flores blancas, observada solamente en una huerta de Talabre. Es remedio para el corazón, quita las penas y se usa para toda dolencia.

119) Cestrum parqui L'Hérit., Solanaceae, 9450, II/89

$\mathrm{CH}$

palki ['palki], palke ['palke]

M

La especie es usada para baños medicinales, para curar heridas, para el pasmo y para el aire.

El nombre palki también es usado en Caspana (VCS), para esta especie.

120) *Datura stramonium L., Solanaceae, 9418, II $/ 60$

$\mathrm{CH}$

higuerilla [iүe'riye], cardo ['karðo], carda, ['karðe] cardadora [karða'ðore], cardador [karða'ðoג]

$\mathrm{O}$

Maleza observada solamente en Socaire. El fruto, espinoso y seco, sirve para cardar la lana, aunque no es muy firme, porque se le salen los dientes. No lo come el animal. UC cita también el nombre de coco del diablo para esta especie, en Talabre.

121) Exodeconus integrifolius (Phil.) Axelius, Solanaceae, 9474, II/106 


\section{$\mathrm{CH}$}

oreja de ratón, oreja [o'reXe], oreja de chojchor [o'rexe de 'čoXčod]

$\mathrm{F}$

Hierba escasa en la región, y observada solamente en una chacra de Talabre. Forraje. El nombre alude a la forma de las hojas.

122) Fabiana bryoides Phil., Solanaceae, 9479a, $\mathrm{I} / 73$

$\mathrm{P}, \mathrm{A}$

pata de perdiz ['pate ðe per'ði ${ }^{\mathrm{h}}$ ]

$\mathrm{L}, \mathrm{M}$

Esta especie no ha sido coleccionada por nosotros en la región. La muestra la proporcionó una persona de Talabre que la trajo de la cordillera y la guardaba seca en su casa. Nos informó que la usan como leña y, además, como remedio para bañarse, cuando uno tiene granuja. Una persona dijo que esta planta era una clase de chacha, la especie usada ritualmente, en la región de Atacama, para sahumar el ganado durante los floramentos (Parastrephia quadrangularis). Curiosamente, la pata de perdiz es la llamada k'oa Santiago o k'oa en otras regiones de la segunda región (Fabiana bryoides), y usada, precisamente, como planta ritual durante los floramentos de ganado (AACV).

123) Fabiana denudata Miers, Solanaceae, 9326, $\mathrm{I} / 24$

$\mathrm{P}$

tolilla, tablilla [ta'ßliye], tara hembra ['tare 'embre]

M, F, L

El uso más importante de este arbusto es como remedio para las quebraduras de los animales, principalmente corderitos. Para ello, se hace una pasta, moliendo la planta cuando está verde, mezclándola con harina de trigo y aplicándola con vendas a manera de yeso o entablillado (de ahí el nombre de tablilla). También la especie tiene usos medicinales para baños o para pisar, cuando están calientitas las brasas, para curar el frío y el dolor de rodillas. No es buen forraje, porque es dura y no tiene hojas, aunque el burro la consumiría cuando está seca. Además, sirve como leña.

SSL y MG citan para Guatín y Socaire a esta especie, con el vernáculo tolilla y el mismo uso terapéutico. También el nombre tolilla es usado para la especie, en Caspana (VCS). En Toconce (AACV), los nombres alma tola, leña de alma y tara hembra han sido registrados para esta especie.

124) Fabiana ramulosa (Wedd.) Hunz. et Barboza, Solanaceae, 9323, I/22

$\mathrm{P}$

monte negro, monte derecho ['monte ðe'rečo], monte soldao, tara ['tare], tara macho ['tare 'mačo], tola

$\mathrm{R}, \mathrm{M}, \mathrm{L}, \mathrm{O}, \mathrm{F}$

Este es el arbusto más característico del tolar. Hay tara hembra y macho. El macho es llamado también monte soldao y monte derecho, por lo erguido. El uso principal de la especie es en las ceremonias de difuntos. En la limpia de difuntos se usa para el "separamiento de almas", mezclado con la paja sikuya y plumas de parina $\left(\right.$ tokoko $\left.{ }^{18}\right)$. Se usa como incienso o sahumerio para sacar los malos aires, ya que la planta es olorosa. Las personas se hacen una limpia del cuerpo con tara y con la pajita sikuya, despachando así el mal que uno tiene. Esta costumbre es de todos los pueblos atacameños. También la especie es medicinal y se usa para baños, cuando uno tiene "desmandes". La especie proporciona buena leña, muy calurosa, la cual también se usa también para caldear el horno para hacer pan. No la comen mucho los animales, pero sí lo hacen cuando no hay otro pasto.

UC cita el nombre de pecha, para esta especie, en Talabre. Nosotros hemos visto la planta coleccionada por este autor y, por eso, creemos que el nombre pecha de Socaire, citado por MG para una especie no identificada, puede corresponder a F. ramulosa. También los nombres tara, tara macho y tola han sido registrados, para esta especie, en el Loa Superior, tanto en Caspana (VCS) como en Toconce (AACV), citada con el sinónimo F. densa var. ramulosa. La especie puede corresponder a la planta no identificada y del género Fabiana, citada por MG, para Socaire, con los nombres monte derecho y monte negro.

125) Lycium humile Phil., Solanaceae, 9446, II/90

Q

waycha, bálsamo finito

M, F

La especie es escasa en la región y muy poco reconocida por la gente. La hemos visto solamente

$18 \quad$ El ave Phoenicopteris chilensis. 
en Tilomonte. Una persona señaló que el jugo de la hoja carnosa era remedio para sacar males. Otra persona dijo que era forraje.

También el nombre walcha ha sido registrado, para esta especie, en el Loa Superior, en Toconce (AACV). La especie es llamada ch'ampita en Caspana (VCS). Es muy posible que sea esta especie la planta tintórea registrada con el nombre de sacha-uva por GM, en Peine. La autora documenta que su fruto de color oscuro, parecido a la uva, da un color morado. Esta descripción corresponde a la de la baya de la especie. También el vernáculo uvilla, registrado para Guatín por SSL, puede corresponder a este taxon.

126) Lycopersicon chilense Dunal, Solanaceae, 9301, I/17

PP

tomatillo [toma'tiyo], tolontolon [to'lonto'lon]

F, $\mathrm{T}$

Todas las personas destacaron el valor forrajero de la planta, especialmente para la cabra que la come mucho. Una persona informó que antiguamente se usaba como tintura. Para ello se extraían los frutos y se procesaban, obteniendo tintas de varios colores.

Probablemente se trate de esta especie la citada por MG para Socaire con el sinónimo de Solanum chilense y el vernáculo tomate silvestre.

127) Nicotiana acuminata (Graham) Hook., Solanaceae, 9467, II/103

$\mathrm{CH}$

tabaco del burro [ta'ßako ðel 'buřo] $\mathrm{F}$

Hierba escasa en la región y coleccionada solamente en Talabre. No se usa, pero parece que los animales la comen.

Probablemente se trate de la misma especie citada por MG para Socaire con el nombre de Nicotiana brachysolen y el vernáculo tabaco cimarrón. UC cita el nombre tabaco cimarrón para N. acuminata, en Talabre.

128) Solanum elaeagnifolium Cav., Solanaceae, 9362, II/25

Q, CH

tomatillo

$\mathrm{O}, \mathrm{F}$

Todas las personas coincidieron en señalar que la planta servía, antiguamente, para lavar ropa, es- pecialmente la blanca. Se muelen los frutos, cuando están amarillos, se cuelan en un trapo las semillas, se estrujan y se colocan bolsitas para remojar con la ropa igual que jabón. Ahora usan detergentes comprados. La planta es considerada mala hierba, aunque la comen las ovejas.

MG citan para Socaire a esta especie con el mismo nombre vernacular y uso como detergente.

129) Solanum metarsium C.V. Morton, Solanaceae, 9305, I/20

$\mathrm{P}$

flor morada, cabra míkun ['kaßre 'mikun], cabra mikuna ['kaßre mi'kune]

F

Es un pasto de lluvia. Todos los entrevistados destacaron el valor forrajero de la especie, especialmente para ovejas. La planta produce una papa que también es consumida por los animales.

MG citan para Socaire a Trechonaetes floribunda con el nombre de cabra micuna. No hemos visto este taxon en la zona de estudio en Atacama, pero sí cerca, en Machuca. Creemos que la planta de Socaire corresponde a Solanum metarsium, abundante en la región y conocida con este nombre en el sector sur de Atacama (Socaire, Peine y Cámar).

130) *Apium graveolens L., Umbelliferae, 9457, II/ 84

$\mathrm{CH}$

apio ['apjo]

$\mathrm{Co}, \mathrm{M}$

Especie cultivada en las chacras, que se consume en ensaladas y se le agrega a los porotos para que no hagan mal. En infusión, es buen remedio para el dolor de estómago, especialmente para las guaguas.

131) *Foeniculum vulgare Mill., Umbelliferae, II/ 96

$\mathrm{CH}$

hinojo [i'noXo], anís [a'ni' ${ }^{\text {] }}$

$\mathrm{M}, \mathrm{Co}$

Maleza de chacras y huertas. Ingerida como té, en infusión, es remedio para el dolor de estómago, especialmente para las guaguas. También se usa como anís para hacer rosquetes.

Especie citada por MG para Socaire con los mismos usos medicinales y vernáculos. Para la cocina tradicional atacameña, GS documentan rece- 
tas para elaborar rosquetes, dulce típico que se realiza desde muchos años en ceremonias del $1^{\circ}$ de Noviembre. En Caspana esta especie es también citada como hinojo (VCS).

132) Lilaeopsis macloviana (Gand.) A.W. Hill, Umbelliferae, 9428, II/53

$\mathrm{R}$

nori ['nori], noris ['nori' ${ }^{\mathrm{h}}$ ], pastito del agua, veguita [be'yite], champa, vega

Co?

Especie palustre, abundante y muy poco reconocida. Sin usos. Solamente una persona dijo que se come el rizoma tierno, uso también documentado para otras regiones andinas. El nombre nori, restringido a la región de Atacama, parece una etnocategoría genérica para especies acuáticas (ver también Ruppia filifolia, $\mathrm{N}^{\mathrm{o}} 173$ ).

Los nombres champa y chengua han sido registrados, para esta especie, en el Loa Superior (AACV), citada con el sinónimo L. andina. MG cita para Socaire a la especie acuática Potamogeton strictus, con el nombre de nori.

133) Mulinum crassifolium Phil., Umbelliferae, 9311, I/45

A

chuchikan [čuči'kan], chukikan [čuki'kan] M

La especie es considerada una poderosa medicina, y se trae de la cordillera y conserva seca en las casas. El interior blanco de la raíz pelada, tomada en infusión o como mate, con limón, leche, azúcar tostada y una aspirina, es remedio para el resfrío, la tos y dolor de cabeza. Como mate también sirve contra la puna y cuando hacen mal las comidas.

GM cita para Peine una planta medicinal no clasificada llamada chuquicán, con las mismas propiedades reseñadas. Además, agrega la autora, combinada con el maransél, es buena para los pulmones. MG citan la especie para Socaire, con los mismos usos medicinales reseñados y con los vernáculos chuquicán y sulúltur, este último nombre conocido solamente por unos pocos ancianos. También los nombres chukikandi, chukikandia, chuchikandia, chuquicandia o chuquicanya han sido registrados, para esta especie, en el Loa Superior, tanto en Caspana (VCS) como en Toconce (AACV).
134) Acantholippia deserticola (Phil. Ex F. Phil.) Moldenke, Verbenaceae, 9297, I/13

$\mathrm{P}$

rikarika ['řike'řike], kore ['kore], kori ['kori]

M, T, L, F

La especie es muy apreciada por su agradable sabor y aroma y, por esto, se le llamaría rikarika. $\mathrm{Su}$ nombre antiguo es kore o kori. La especie es considerada un muy buen remedio, por todas las personas. Se consume como té aromático con azúcar, a veces con yerba buena, y es muy efectiva contra los dolores del estómago, cuando caen mal las comidas, fiebres y dolores, en general. Mezclada con la kopakopa (Artemisia copa), tiñe amarilla la lana. Además, proporciona leña y forraje para los animales.

MG citan la especie para Socaire con los mismos usos medicinales expuestos, con el sinónimo Verbena origenes y con los nombres de core, cori y rica-rica y costilla. GM y SSL la citan también para Peine y Guatín, con el vernáculo rica-rica. GM agrega que se tuesta la planta y se prepara después una decocción que sirve para los dolores de barriga. También el nombre rica rica es citado para el Loa Superior (AACV), en Toconce. En Caspana la especie es llamada qore, qori y rikarika. En las dos últimas localidades se le conoce, también, con el sinónimo de Acantholippia punensis.

135) Junellia digitata (Phil.) Moldenke, Verbenaceae, 9343, I/47

A

altea, kotakota ['kote'kote], pupusa del campo Co, M, F

Para esta especie se dieron las mismas propiedades de otra clase de altea, Nototriche estipulata: raíz dulce y comestible. La raíz molida y tomada como infusión es remedio para dolores de cabeza y estómago. Una persona dijo que la raíz la consumen las ovejas.

MG citan para Socaire una planta no determinada, y de raíz comestible, llamada kípsur. Probablemente se trate de esta especie o de Nototriche estipulata, cuyas raíces también se comen. Como la planta citada por MG proviene de Peine, es posible también que el kípsur corresponda a Tiquilia atacamensis, con raíz comestible. 
136) Junellia seriphioides (Gillies et Hook.) Moldenke, Verbenaceae, 9290, I/6

$\mathrm{P}$

perlilla [pel-'liye], perdilla [per'ðiye], roseta, cardoncillo [karðon'siyo], tola

$\mathrm{M}, \mathrm{F}$

Se destacó la hermosura de las flores y el aroma de esta especie de arbusto del tolar. Es un buen remedio para los dolores estomacales e indigestión. La flor es buena para el resfrío, tos y vejiga. También se la usa para baños, cuando se tiene dolores de orines. Todas las personas calificaron a la planta como un excelente alimento para las llamas. El nombre cardoncillo alude a las estípulas espinosas del arbusto, análogas a las espinas del cardón.

También el nombre rosa ha sido registrado, para esta especie, en el Loa Superior, tanto en Caspana (VCS) como en Toconce (AACV). En Caspana se le llama, además, comida de llamo, rosas y vinovino. MG citan para Socaire una especie no identificada, con los nombres de cardoncillo y perlilla, también forraje de llamas y medicina. Sin embargo, creemos que ambos vernáculos corresponden a Junellia seriphioides, y no a una Cactácea como afirman los autores.

137) Lampaya medicinalis Phil., Verbenaceae, $\mathrm{I} / 70$

$\mathrm{P}, \mathrm{A}$

lampaya [lam'paye]

$\mathrm{M}$

Esta especie no ha sido coleccionada en la región, durante nuestro estudio. Las personas nos proporcionaron ejemplares coleccionados por ellas y que clasificaron como lampaya chica y fina, ya que habría otras variedades más grandes y gruesas. La planta es muy famosa como medicina para el estómago, cuando caen mal las comidas, resfrío y tos.

La planta es citada como medicinal y con el nombre lampalla, para Peine por GM. También el nombre lampaya ha sido registrado, para esta especie, en el Loa Superior, tanto en Caspana (VCS) como en Toconce (AACV).

138) Pitraea cuneato-ovata (Cav.) Caro, Verbenaceae, 9458, II/83

$\mathrm{CH}$

chámen ['čamen], cháme ['čame], chávil ['čaßil], papa cháme ['pape 'čame]
P, F

Planta muy perjudicial para la agricultura en las chacras. Produce una papita que no se come, porque es amarga. Se dijo que había un profesor en Peine que la comía. La consumen los chanchos. En el Loa Superior, en Caspana (VCS), esta especie es llamada papa blanca y también es perjudicial. Probablemente se trata de esta especie la planta citada por GM, para Peine, y por MG, para Socaire, con el nombre de chamen, y no identificada botánicamente. Ambos autores documentan que las papas son comidas secas y crudas por los niños, por su sabor dulce, hecho que se contradice con la información recopilada por nosotros.

139) Urbania pappigera Phil., Verbenaceae, 9334, $\mathrm{I} / 48$

A

cuerno de lagarto ['kwerno ðe la'yarto], cuernillo F, L

La especie es forraje para los animales. La raíz y tronco sirve como leña.

140) *Verbena bonariensis L., Verbenaceae, 9468 , II/109

$\mathrm{CH}$

verbena [ber'Bene]

$\mathrm{M}$

Maleza de chacras. Remedio para caídas, golpes y machucones internos, ingerida como mate, con sal y un poquito de aguardiente.

Esta especie es también llamada verbena en el Loa Superior, en Caspana (VCS), y tiene los mismos usos medicinales. Esta especie puede ser la que GM cita para Peine como planta medicinal, llamada verbena, sin determinación botánica, cuya decocción es buena para la tos.

141) *Tribulus terrestris L., Zygophyllaceae, 9434, II/50

$\mathrm{CH}$

gato ['gato], michi ['miči], pastito del campo, cabeza de gato

F, M

Maleza observada en Camar. Puede servir como pasto para los animales. Una persona dijo que es remedio para la hernia. La plantita es llamada gato o michi, porque la distribución de las espinas del frutito semeja una cabeza de gato.

Es muy posible que esta especie corresponda a la planta citada por MG para Socaire con los nom- 
bres de caremichi y cabeza de caballo y no identificada botánicamente.

\section{ANGIOSPERMAS - MONOCOTILEDONEAS}

142) Carex gayana E. Desv. o C. maritima Gunnerus, Cyperaceae, 9391, II/4

Q

unquillar [unki'yau], unquillo [un'kiyo], jaboncillo [Xaßon'siyo], césped ['se ${ }^{\text {h }} \mathrm{pe}^{\mathrm{d}}$ ]

$\mathrm{F}$

Hierba palustre unánimemente reconocida como de valor forrajero.

143) Cyperus alternifolius L. o C. laevigatus L., Cyperaceae, 9430, II/45

$\mathrm{Q}, \mathrm{CH}$

unquillo, pastito blando, parecido a la cortadera, unquillar, jaboncillo

$\mathrm{F}$

Hierba palustre generalmente reconocida como de valor forrajero, aunque tres personas dijeron que los animales la comen poco y era solamente mala hierba.

144) Scirpus californicus (C.A. Mey.) Steud., Cyperaceae, 9381, II/15

Q

totora [to'tore]

C, F

Hierba palustre escasa en la región. Observada solamente en Quebrada Jerez de Toconao. Se usa artesanalmente para la confección de esteras, canastos, etc. También forraje, cuando está tierna, para burros y corderos. Madura es muy dura.

145) Scirpus deserticola Phil., Cyperaceae, 9341, $\mathrm{I} / 30$

Q

champa, vega, grama ['yrame]

$\mathrm{F}$

Hierba palustre que conforma cojines en las riberas de los cursos de agua. La planta es forrajera.

También los nombres de champa, vega y pasto de vega han sido registrados, para esta especie, en el Loa Superior, tanto en Caspana (VCS) como en Toconce (AACV).

146) Scirpus sp, Cyperaceae, 9384, II/12

Q

unquillo cuadrado, unquillo, unquillar
F

Hierba palustre, unánimemente reconocida como de valor forrajero.

147) Bromus catharticus Vahl, Gramineae, 9357, II/37

Q

kafle ['kafle], pastito blando, pasto blando

$\mathrm{F}$

Pasto herbáceo, generalmente reconocida como de valor forrajero, principalmente para las ovejas y los conejos. El nombre kafle es genérico para distintas especies de Gramíneas herbáceas que crecen en quebradas y que también se llaman 'pastos blandos'.

Los nombres sailao, pasto blanco, cebadilla, choklla, pasto del diablo han sido registrados, para esta especie, en el Loa Superior, tanto en Caspana (VCS) como en Toconce (AACV); en esta última localidad es citada con el sinónimo B. unioloides. De acuerdo a MG, en los cantos regionales aparecería esta planta con la denominación sáflu, según un informante. Barthel (1986) registra este nombre en Socaire, contenido en la letra del Talantur, canto ceremonial atacameño para la limpia de acequias.

148) Cortaderia speciosa (Nees et Meyen) Stapf, Gramineae, 9285, 9432, I/1, II/52

Q, P

cortadera [korta'ðere], cola de zorro

$\mathrm{M}, \mathrm{C}, \mathrm{F}, \mathrm{A}, \mathrm{P}$

Todos los entrevistados calificaron la especie como un buen remedio. Antiguamente, se hacia un mate de cortadera, con pisco o alcohol, el cual servía para el parto; además, se hacen fricciones con la planta, con chachakoma (Senecio atacamensis) y kopakopa (Artemisia copa): esta mezcla se calienta y muele y se usa como una pasta, en la espalda y caderas. Se transpira y se calienta el cuerpo. El agüita de la hoja de cortadera es además buena para la fiebre, dolores, resfrío. También purgante. La cañita se usa en artesanías, ya sea para hacer canastos o para trabajos manuales de los niños. Antiguamente se la usaba para techado de casas. Además, es forraje para las ovejas. Las espigas, a veces teñidas de colores, se usan como adorno en floreros o para el cementerio. Las hojas y las pelusas de las inflorescencias son muy peligrosas, porque pueden dejar ciega a una persona si entran en los ojos. 
Probablemente se trate de la misma especie de Cortaderia no identificada y citada por MG, para Socaire, como cortadera. Los autores le asignan también valor como febrífugo y forrajero, además para ramadas y, en Toconao, para fabricar sombreros. También los nombres cortadera, cola de zorro y kuchucho han sido registrados para C. speciosa y C. atacamensis en el Loa Superior, en Caspana (VCS) y Toconce (AACV), respectivamente.

149) *Critesium murinum (L.) Löwe, (=Hordeum murinum L.) Gramineae, 9406, II/ 68

\section{$\mathrm{Q}, \mathrm{CH}$}

kafle, cola de zorro, pastito blando, cebadilla [seßa'ðiye]

$\mathrm{F}$

Pasto herbáceo usado como forraje. El nombre kafle es genérico para distintas especies de Gramíneas herbáceas, que crecen en quebradas y que también se llaman "pastos blandos".

Probablemente se trate de esta especie el taxon llamado cola de ratón y citado como Hordeum comosum para el Loa Superior (AACV). De acuerdo a MG, en los cantos regionales aparecería esta planta con la denominación sáflu, según un informante.

150) *Cynodon dactylon (L.) Pers., Gramineae, 9365, II/30

Q

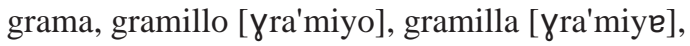
grama chica

$\mathrm{F}$

Pasto herbáceo y cespitoso, unánimemente reconocido como de valor forrajero.

151) Deyeuxia cabrerae (Parodi) Parodi, Gramineae, 9314, I/31

A

paja ['paxe], paja chica ['paxe 'čike], paja sikuya ['paxe si'kuye], ¿paja brava?, paja delgada, paja blanda ['paxe 'blande]

$\mathrm{R}, \mathrm{F}$

Pajita muy abundante en el piso subnival. Todas las personas destacaron el valor forrajero de esta especie, principalmente para las llamas. A pesar de la disparidad de nombres obtenidos, esta especie puede corresponder a la importante paja sikuya, usada ritualmente para las almas, junto con la tara (Fabiana ramulosa).
152) Deyeuxia curvula Wedd., Gramineae, 9404 , II/69

Q

chúkchar ['čukčar], grama, pajita [pa'Xite], paja sukuya

F

Pequeña pajita coleccionada solamente en la quebrada de Socaire. Forraje. Probablemente id. $\mathrm{N}^{\mathrm{o}} 169$.

El nombre chujchampu, recopilado por MG para una forrajera de la alta cordillera de Socaire, parece convenir a esta Gramínea (ver No 169). SSL citan para Guatín una especie no determinada, con el vernáculo chuchampe, que se usa para teñir y da color amarillo, y que también puede ser este taxón.

153) Dielsiochloa floribunda (Pilger) Pilger, Gramineae, I/64

PP, P

cebadilla, cola de zorro, peludilla, grama

F

Diminuto pasto de lluvia con valor como forraje.

Los nombres vernaculares son muy recurrentes para distintas especies de Gramíneas anuales, llamadas también pastitos de lluvia.

MG citan, para Socaire, el nombre de cebadilla para un pasto de lluvia con valor forrajero, Eragrostis deserticola. También el nombre cebadilla ha sido registrado para Eragrostis peruviana, en el Loa Superior (AACV).

154) *Distichlis spicata (L.) Greene, Gramineae, 9385, II/8

Q, $\mathrm{CH}$

grama, gramillo, gramilla

F, M

Pasto cespitoso calificado como de valor forrajero, especialmente para ovejas, aunque varias personas dijeron que los burros la comen muy poco, porque la hoja es muy dura. Una persona dijo que la planta era remedio para el dolor al orinar.

MG citan la especie para Socaire con los nombres de grama o chépica. Reportan que la infusión de la raíz es medicinal como "refrescante". También los nombres de grama y brama han sido registrados, para esta especie, y otras especies de Distichlis en el Loa Superior, tanto en Caspana (VCS) como en Toconce (AACV). 
155) Elymus scabriglumis (Hackel) A. Löve, Gramineae, 9410, II/64

\section{Q}

kafle, kafle (pariente), espural?, como espural?, pasto blando, sáilao, césped

$\mathrm{F}$

Forraje. El nombre kafle es genérico para distintas especies de Gramíneas herbáceas que crecen en quebradas y que también se llaman "pastos blandos".

De acuerdo a MG, en los cantos regionales aparecería esta planta con la denominación sáflu, según un informante.

156) *Eragrostis virescens J. Presl, Gramineae, 9380, II/16

Q

kafle, pastito blando del agua, pasto blando $\mathrm{F}$

Maleza herbácea unánimemente reconocida como de valor forrajero. El nombre kafle es genérico para distintas especies de Gramíneas herbáceas que crecen en quebradas, y que también se llaman "pastos blandos".

De acuerdo a MG, en los cantos regionales aparecería esta planta con la denominación sáflu, según un informante.

157) Festuca chrysophylla Phil., Gramineae, 9312, I/32

A

iru ['iru], iro ['iro], paja, paja brava

F, C

Paja muy característica de los pajonales de altura. Todas las personas destacaron el valor forrajero de esta especie, principalmente para las llamas, agregando que el ganado se mantiene con las espigas. También la consumirían las vizcachas. Solamente una persona mencionó su uso para hacer techumbres de casas.

Probablemente, se trate de esta especie la planta forrajera no determinada llamada iro, citada por MG para Socaire. También los nombres paja iro, iru, paja iru y paja brava han sido registrados, para esta especie, en el Loa Superior, tanto en Caspana (VCS) como en Toconce (AACV).

158) Festuca hypsophila Phil. Gramineae, 9303, 9402, I/35, II/71
P, Q

waya ['waye], paja waya ['paxe 'waye], waylla ['waiye], chillawa [či'yawe], iro, pajita, paja sikuya?

C, F

Antiguamente, y hasta ahora, la planta se usa para techar las casas (wayar casas). Para ello, se le corta raíz, se le machaca, se mezcla con barro y con ese adobe se tapan las casas. El agua no pasa. Además, es forraje para animales.

También los nombres de huailla, guailla, wailla, paja, chillawa, paja chillawa han sido registrados para Calamagrostis ampliflora y Deyeuxia ampliflora en el Loa Superior, tanto en Caspana (VCS) como en Toconce (AACV).

159) Jarava vaginata (Phil.) F. Rojas, Gramineae, 9302, I/34

A

forraje de vizcacha [fo'řaxe ðe $\beta \mathrm{i}^{\mathrm{x}}$ kače], iru, iro, paja crespa, banderilla [bande'riye]

$\mathrm{F}$

Especie de paja altoandina forrajera, cuando verde; la comerían las llamas, a pesar del nombre de vizcachera.

También los nombres sikuya y cebadilla han sido registrados, para esta especie, en el Loa Superior (AACV). Probablemente sea esta especie la planta no identificada citada por MG para Socaire, con el nombre de vizcachera, venenosa para el ganado.

160) * Muhlenbergia asperifolia (Nees et Meyen ex Trin.) Parodi, Gramineae, 9364, II/31

Q grama, grama fina, gramillo $\mathrm{F}$

Maleza perenne y cespitosa, generalmente reconocida como de valor forrajero para burros, aunque varias personas dijeron que no la comen los animales.

También el nombre brama o grama ha sido registrado, para esta especie, en el Loa Superior (AACV).

161) Munroa andina Phil., Gramineae, 9403, II/70

$\mathrm{CH}$

barba de chivo ['barße ðe 'čißo], barba de chivato ['barße де či'ßato], cebadilla, cola de zorro, chacrilla del campo [ča'kriye ðel 'kampo] 
F

Diminuto pasto de lluvia que sirve como forraje.

162) Nasella nardoides (Phil.) Barkworth, Gramineae, 9333, I/36

A

chuku ['čuku], pajita chica, paja

$\mathrm{F}$

Pequeña pajita altoandina, abundante. La comen los animales, especialmente las llamas y las vicuñas.

También los nombres de chuko, paja, pajita y cebadilla han sido citados para esta especie (=Stipa nardoides), en Caspana (VCS).

163) Pennisetum chilense (E. Desv.) B.D. Jackson ex R.E. Fries, Gramineae, 9371, II/23

Q

esporal [e ${ }^{\mathrm{h}}$ po'ral], simbol [sim'bol] (la florcita y tallito), espural [e ${ }^{h}$ pu'ral], espuro [ $\mathrm{e}^{\text {h' }}$ puro]

F, O, C, P

Gramínea abundante que forma grandes bultos en quebradas. Especie forrajera consumida especialmente por los burros. El tallito llamado simbol sirve para hacer tostado. También se usa como relleno para ensillar a los animales, se hacen como cueros llamados llumillejos, para que no sientan la carga. Se usa artesanalmente para hacer canastos, pero no es buen material porque se quiebra ya que es muy débil. Como es una mata alta, proporciona sombra. En la chacra es mala hierba, porque seca la alfalfa.

También los nombres qhaiwa, qhaiba, qaiba, kaiba, paja, esporal, paja blanca, espural, espiral o kaiwa han sido registrados, para esta especie, en el Loa Superior, tanto en Caspana (VCS) como en Toconce (AACV). GM cita para Peine el vernáculo espural para una planta usada como tostador; Seguramente esta especie corresponde al taxon forrajero citado por MG para Socaire con los nombres de espural y espuro. Aparece erróneamente determinado como Cortaderia sp., un género de Gramínea muy distinto y conocido ampliamente como cortadera.

164) *Phragmites australis (Cav.) Trin. ex Steud., Gramineae, 9361, II/33

Q

caña ['kaje], cañaveral [kajaße'ral]

C, F

Esta enorme y abundante Gramínea de las quebradas es muy apreciada por sus múltiples usos en construcción y artesanías. En construcción se usa para techar casas, ramadas para sombra, cierres para el viento, separadores, etc. En artesanía se usa para la confección de esteras, pisos e instrumentos musicales como pitos, quenas, tamborcillo, flautas y clarines. Para el telar se hacen los lizos y peines con la planta. Las hojas sirven de forraje.

GM documenta para Peine el uso de la caña entre los accesorios del telar: "El peine consiste de dos mitades de caña entre las cuales están amarradas, con hilos de lana, muchas delgadas secciones de cañas. Este peine se encuentra embutido en la caja del peine, que es de madera. Los lizos, dos en número, se construyen igualmente de secciones de caña y cordeles delgados".

165) Polypogon interruptus Kunth, Gramineae, 9388, II/7

Q

kafle, pastito blando, pasto blando

$\mathrm{F}$

Gramínea herbácea unánimemente reconocida como de valor forrajero. El nombre kafle es genérico para distintas especies de Gramíneas herbáceas que crecen en quebradas, y que también se llaman "pastos blandos".

También el nombre chojlla ha sido registrado para $P$. linearis, en el Loa Superior (AACV). De acuerdo a MG, en los cantos regionales aparecería esta planta con la denominación sáflu, según un informante.

166) Stipa chrysophylla Desv., Gramineae, 9304, I/33

A

paja blanda, paja, paja chica, paja brava, paja del viento

F, C

Esta paja es extraordinariamente abundante en los pajonales cordilleranos. Todas las personas destacaron su valor forrajero, principalmente para las llamas, agregando que el ganado se mantiene en las alturas cordilleranas con la planta, sobre todo cuando está tierna. También la consumiría la chinchilla. Solamente una persona informó que se usaba para techumbres $\mathrm{y}$, antiguamente, para hacer cestos.

También los nombres de paja blanca, icchu blanco, paja fina, paja vizcachera han sido registrados, para esta especie, en el Loa Superior, tanto 
en Caspana (VCS) como en Toconce (AACV). Los nombres de paja chica, paja del campo, pajonal, citados por MG para Socaire, pueden corresponder a esta especie, la más abundante en el piso altoandino.

167) Stipa speciosa Trin. et Rupr. Especie no determinada, Gramineae, 9423, II/56

Q

paja, pajita, junquillo?, waya?, paja banderilla

F

Paja alta y abundante en el tolar al este de Socaire. Forraje.

168) Especie no determinada, Gramineae, 9476, II/111

$\mathrm{CH}$

césped

$\mathrm{S}$

Gramínea muy alta y conformando un macizo bulto. Muy escasa en la zona. Solamente observada en una chacra, en Talabre. Sin uso.

169) Especie no determinada, (¿Deyeuxia curvula?) Gramineae, 9438, II/43

$\mathrm{CH}$

chukllara [čuk'yare], pastito, como grama, pasto duro, cebadilla, kafle delgado

$\mathrm{F}$

Especie generalmente reconocida como de valor forrajero, principalmente para las vizcachas y las llamas.

El nombre chujchampu recopilado por MG para una forrajera de la alta cordillera de Socaire parece convenir a esta Gramínea. SSL citan para Guatín una especie no determinada con el vernáculo chuchampe, que se usa para teñir y da color amarillo, y que también puede ser este taxón.

170) Juncus arcticus Willd., Juncaceae, 9390, II $/ 5$

Q

unquillo duro, unquillo, junquillo redondo, unquillar redondo, unquillare

F, C, O

Especie unánimemente reconocida como de valor forrajero, especialmente para burros y corderitos. También se usa para amarrar verduras y flores y, artesanalmente, para hacer canastos.

MG citan la especie para Socaire con el sinónimo
J. balticus, el vernáculo unquillo, y los mismos usos expuestos. También los nombres unquillo liso, unquillo duro, junquillo y unquillo han sido registrados, para esta especie, en el Loa Superior, tanto en Caspana (VCS) como en Toconce (AACV); en esta última localidad citada con el sinónimo J. balticus.

171) Lemna valdiviana Phil. (o L. minuta Kunth?), aff., Lemnaceae, 9395, II/1

$\mathrm{R}$

flor de la champa ['floı de la 'čampe], vega $\mathrm{S}$

Diminuta especie acuática flotante. Comida de palomas. El primer vernáculo parece ser genérico para las diminutas especies acuáticas y flotantes. En el Loa Superior, Caspana (VC), esta especie es llamada champa y flor del agua, además del helechito acuático Azolla filiculoides.

172) *Asparagus officinalis L., Liliaceae, 9464 , II/79

$\mathrm{CH}$

espárrago [e $\mathrm{e}^{\mathrm{h}}$ pařayo]

$\mathrm{Co}, \mathrm{A}, \mathrm{M}$

Especie comestible cultivada en las chacras y que se usa para adornar ramos de flores para la casa, iglesia y cementerio. Una persona dijo que la raíz es remedio.

173) Ruppia filifolia (Phil.) Skottsb., Ruppiaceae, 9445, II/ 76

$\mathrm{R}, \mathrm{S}$

loroma, pastito del agua, nori

$\mathrm{F}$

Hierba acuática flotante. Forraje, especialmente para los corderos. El nombre loroma es genérico, y de amplio uso regional, para especies acuáticas y flotantes de hojas estrechas de los géneros Potamogeton, Ruppia, Myriophyllum, etc. El nombre nori, restringido a la región de Atacama, parece también una etnocategoría genérica para esta misma forma de vida.

MG citan para Socaire a la especie acuática Myriophyllum proserpinacoides con el nombre loroma. Con el nombre de nori a Potamogeton strictus. También el nombre loroma ha sido registrado para Myriophyllum quitensis, en el Loa Superior (AACV). En Caspana (VCS), la especie $R$. filifolia es llamada aguasana. 
OTRAS ESPECIES CITADAS PARA EL SALAR DE ATACAMA Y NO REGISTRADAS EN NUESTRO ESTUDIO

( $\mathrm{T}=$ Talabre, de acuerdo a UC; $\mathrm{S}=$ Socaire, de acuerdo a MG; G=Guatín, de acuerdo a SSL; P=Peine, de acuerdo a GM)

1) Airampo [ai'ram'po], Cactaceae, (G), "esta planta nunca ha dado fruta y si uno la mira se esconde".

2) Canchalahua ['kanča'lawe], (S). Forraje y medicina: contra las afecciones cutáneas, en forma de infusión. De acuerdo a Mathei (1995), se denomina cachanlagua o pichana amarga a una especie sudamericana con características de maleza, Schkuhria pinnata (Lam.) Kuntze ex Thell., documentada para las $1^{\mathrm{a}}$ y $4^{\mathrm{a}}$ Regiones.

3) Cebolla del campo [se'ßoye ðel 'kampo], (S). Se come el bulbo que tiene gusto a damasco.

4) Coca ['koke], Erythroxylon coca Lam., Erythroxylaceae, (S). Medicina contra trastornos de altura (puna) y como estimulante. Se obtiene de Bolivia, por comercio.

5) Colan ['kolan], (S). Medicina contra el reumatismo, mezclada con chacha.

6) Corazón [kora'son], (S). Forraje para ovejas y llamas. Crece a más de 3.600 m.sm.

7) Cosmo ['koh mo] o Cosme ['ko $\left.{ }^{\mathrm{h}} \mathrm{me}\right],(\mathrm{S})$, Chrysanthemum anethifolium Brouss. ex Willd. Crece en jardín.

8) Chula ['čule], (S). Rastrojo de la quínoa empleado como forraje.

9) Estrella [e ${ }^{h}$ treye], (G). Pasto para cabras.

10) Flor de la puna ['flod de la 'pune], (T). Hemos visto la especie registrada por UC para Talabre y corresponde a Chaetanthera sphaeroidalis (Reiche) Hicken.

11) Hierba buena ['yerße 'ßwene], (T). Una especie de menta, Mentha piperita L. o $M$. suaveolens Ehrh.
12) Hormiguero [ormi'yero], Encelia canescens Lam. var. tomentosa (Walp.) Ball (sinónimo $E$. tomentosa), Compositae, (S). Forrajera muy visitada por las hormigas.

13) Illincuma [iyin'kume], (S). Forrajera. Figuraría en los cantos folklóricos regionales, con el nombre de illauca [i'yauke]. ¿Se trata de la chacha (Parastrephia quadrangularis) llamada también illakowa, en Caspana (VCS)? Barthel (1986) registra el nombre ilyaukar, dentro del Talantur de Socaire, y señala: "igual que en significado que ilyinkuma, una hierba que crece después de las lluvias en los cerros".

14) Kipsur ['kipsux], (S). Se comía la raíz de esta planta cuando crecía en la Quebrada de Kipsuna; ahora se obtiene en la región de Peine. ¿Tiquilia atacamensis?

15) Mortaga [mor'taye], Brassica rapa L. (sinónimo B. campestris L.), Cruciferae (S). Maleza forrajera. De acuerdo a Mathei (1995), se denomina yuyo o mortaga a la maleza Brassica rapa L., común en todo Chile. También el nombre mostaza ha sido registrado, para esta especie, en el Loa Superior (AACV).

16) Néter ['neter], Artemisia аппиа L, Compositae, (S). Medicina para los nervios que se emplea en forma de infusión. Crece esporádicamente. Esta especie no está registrada ni en la flora nativa ni en la introducida de Chile. En Caspana (VCS), es llamada éter la especie Artemisia abrotanum.

17) Pecalar [peka'lau], (S). Forrajera, pero no de buena calidad.

18) Pecha ['peče], tola Lepidophyllum tola, Compositae, (S), leña. Este taxon puede ser un sinónimo de Parastrephia lepidophylla (Wedd.) Cabr. o P. lucida (Meyen) Cabr. Hemos visto la planta colectada por UC en Talabre, con el nombre de pecha, y es Fabiana ramulosa.

19) Pojnor ['poxnor], (P). Forraje

20) Salvia blanca ['salßje 'blanke], (P). Alimenticia 
21) Tachuela [ta'čwele], Erodium cicutarium (L.) L'Hér. ex Aiton, Geraniaceae, (S). Forrajera. De acuerdo a Mathei (1995), se denomina alfilerillo, relojito o tachuela y es una maleza europea común en todo Chile. Para esta especie, VCS citan, para Caspana, los nombres de agujilla, alfilerillo, alfileres, tachuela.
22) Sacha-uva ['sače'uße], (P). Tintórea. ¿Lycium humile?

23) Uvilla [u'Biye], (G). Pasto para cabras. ¿Lycium humile?

\section{ANEXO 2 \\ NOMBRES ASIGNADOS LOCALMENTE A LAS ESPECIES DE LOS OASIS Y VALLES DEL SALAR DE ATACAMA Y SUS POSIBLES LENGUAS Y SIGNIFICADOS}

( $\mathrm{A}$ = aymara; $\mathrm{E}$ = español; $\mathrm{K}$ = kunza; $\mathrm{M}$ = mapuche; $\mathrm{Q}=$ quechua; $\mathrm{AR}$ = arawak; ? = desconocido. Los números al lado de cada nombre se refieren al orden de las especies en el Anexo 1).

Textos consultados para nombres vernaculares: $\mathrm{A}=$ Aldunate et al. 1981; $\mathrm{B}=$ Bertonio 1612; $\mathrm{Ba}=$ Ballon et al. 1992; JC=J. Corominas 1973; $\mathrm{C}=$ Cusihuaman 1976; DT=Diccionario Trilingüe 1981; G=Girault 1987; GH=González Holguín 1608; L=Lenz 1910; LE=Lehnert 1994; LI=Lira 1945; M=Mösbach 1992; GM= Grete Mostny 1954; Mun= Munizaga y Gunckel 1958; DRAE= Diccionario Real Ac. Española, ed.1970 \& ed.1992; R=Ricardo 1586; SR=San Román 1890; $\mathrm{T}=$ Torero 1992; $\mathrm{V}=$ Vaisse et al $1896 ; \mathrm{VC}=$ Villagrán \& Castro 1999; VCR= Castro V. 1997.

¿Acacio?, 89, E. Nombre genérico para especies del género Acacia. Derivado del latín y castellano "acacia", que refiere a "árbol o arbusto de la familia de las Mimosáceas, a veces con espinas"; también designa a la madera de este árbol y a una "sustancia medicinal concreta y astringente que se extrae del fruto verde de la acacia de Egipto" (DRAE: 16).

Acerillo, 98, E. Concepto morfológico seguramente referido a la forma de cojín de la planta. Sinónimo de acerico, derivado de "hazero", almohada. Almohada pequeña que se pone sobre las otras grandes para mayor comodidad. También es una almohadilla que sirve para clavar en ella alfileres o aguja (DRAE: 23).
Ajenko [a'Xeyko], 77, E. Símil con una planta introducida también aromática y medicinal. Derivado del castellano "ajenjo" y del latín "absinthium". Planta perenne de la familia de las Compuestas de hojas blanquecinas; es medicinal, muy amarga y algo aromática. También se confeccionan con ella algunas bebidas alcohólicas. (DRAE: 74) ]

Alfa, 103, E. Haplología de "alfalfa" en Navarra, Argentina, Bolivia y Chile (DRAE: 94). "Voz de amplio uso regional derivada de alfalfa; esta denominación, para esta planta forrajera, fue anotada ya por R.A. Philippi 1860" (Mun: 14).

Alfalfa [al'falfe], 103, E. Nombre propio de la importante especie forrajera Medicago sativa. Del árabe "al-fasfasa". "Melga común que se cultiva para forraje". Es originaria de Italia y se cultiva como planta de adorno y para forraje" (DRAE: 95).

Alfilla [al'fiye], 104, E. Símil con otra planta, la alfalfa. La palabra es derivada de alfalfa.

Algarrobilla [alyařo'ßiye], 19, E. Símil con otra planta, el importante árbol llamado algarrobo, seguramente por las vainas. En Argentina, Chile, Paraguay y Uruguay es el "nombre de varios ár- 
boles y arbustos leguminosos y de sus frutos". También se denomina así a la planta y semilla de la algarroba (DRAE: 98).

Algarrobillo [alyařo'ßiyo], 89, 19 E. Símil con otra planta, seguramente por las vainas, el importante árbol llamado algarrobo. Ver anterior.

Algarrobo [alya'řoßo], 90, E. Nombre genérico para especies arbóreas de Leguminosas. Derivado del castellano algarroba, árbol de la familia de las Papilionáceas, originario de Oriente, cuyo fruto denominado algarroba es una vaina azucarada y comestible, de color castaño por fuera y amarillento por dentro, con semillas muy duras, y la cual se da como alimento al ganado de labor. En América se da este nombre a varios árboles y plantas, como el curbaril o cenízaro (DRAE: 98).

Altea [al'tee], 86, 135, E. Es enigmático este nombre dado a dos diminutas especies altoandinas. Al menos una, Nototriche stipulata, pertenece a la familia Malváceas y su nombre puede aludir a similitudes de la flor con la altea europea. Del latín "althaea" y este del griego. Malvavisco (DRAE: 115). Malvavisco. "Planta perenne de la familia de las Malváceas, con tallo de un metro de altura, hojas suaves, muy vellosas ovaladas, de lóbulos poco salientes y dentadas por el margen; flores axilares de color blanco rojizo, frutos como el de la malva y raíz gruesa. Abunda en los terrenos húmedos, y la raíz se usa como emoliente" (DRAE: 1300).

Amapola, 85, E. Símil con otra planta introducida, la conocida amapola, Papaver somniferum. Del mozárabe "apapaura". "Planta anual de la familia de las Papaveráceas, con flores rojas por lo común y semilla negruzca. Frecuentemente nace en los sembrados y los infesta. Es sudorífica y algo calmante." A su vez, se da esta denominación a la flor de esta planta. También "se da este nombre a varias plantas americanas semejantes en algún aspecto a la amapola común" (DRAE: 122).

Amor seco, 39, E. Concepto morfológico seguramente referido a frutos secos que se pegan al pelaje de animales. Nombre que designa, en América Meridional y Filipinas, a "diversas especies de plantas herbáceas cuyos frutos espinosos se adhieren al pelo, a la ropa, etc." (DRAE: 130).
Anís [a'ni ${ }^{\mathrm{h}}$ ], 131, E. Símil con otra planta introducida de la misma familia y con el mismo uso comestible de sus semillas. Del latín "anisum" y este del griego. Planta anual de la familia de las Umbelíferas. Sus semillas, que reciben el mismo nombre, son aovadas, verdosas, menudas y aromáticas. Este mismo nombre "se da a otras plantas semejantes al anís, especialmente por su olor" (DRAE: 147).

Añawa [a' nawe], 94, 97, A. Nombre genérico para especies espinosas del género Adesmia. Añahuaya lahua "Mata espinosa". (B (2): 21). Lahua, "leña para quemar" (B: 185,2).

Añawa blanca, 94, 95, A, E. El nombre específico alude al color de la planta.

Añawa grande 97, A, E. El nombre específico alude al tamaño de la planta.

Añawa negra 94, 97, A, E. El nombre específico ¿alude a las plantas verdes por oposición a las blanquecinas?

Apio ['apjo] 130, E. Nombre específico de una importante verdura, el apio. Del latín "apium”. Planta de la familia de las Umbelíferas. Aporcado es comestible (DRAE: 167).

Arcilla 69, E. Enigmático nombre para una planta que es medicina contra diarreas. Del castellano "argilla". "Tierra finamente dividida constituida por agregados de silicatos de aluminio hidratados, que procede de la descomposición de minerales de aluminio, blanca cuando es pura y con coloraciones diversas según las impurezas" (DRAE: 182).

Arka ['arke], 10, 28, Q, A. Arca, aymara, "la obra de servir al tambo" (B: 24,2); compañero del yuyo.

Aromo 89, E. Concepto morfológico seguramente referido a inflorescencias en cabezuelas amarillas y fragantes, parecidas al "aromo" australiano. Del castellano "aroma". Arbol de la familia de las Mimosáceas, con ramas espinosas, y vainas verdes y encorvadas. Su flor, denominada aroma, es dorada vellosa y de olor muy fragante. Por extensión se aplica el nombre aroma a "cualquier goma, bálsamo, leño o hierba de mucha fragan- 
cia" (DRAE: 192). El nombre de aromo o aromo del país se aplica a Azara dentata (R. et P.), A. serrata (R. et P.), y A. integrifolia (R. et P.), de la familia de las Flacourtiáceas, por la fragancia de sus flores (M: 92).

Atalte [a'talte] 93, A?. Enigmático nombre para un arbusto no comestible. Ataco, Bledos, "yerba de comer" (B: 27, 2).

Azafrán [asa'fran] 41, 42, E. Símil con otra planta, el conocido condimento, seguramente por la forma y el color rojizo-anaranjado de los estambres muy largos. Del árabe "az-zafaran". Planta de la familia de las Iridáceas con flores de color rojo anaranjado. Procede de Oriente y se cultiva en varias provincias de España. El estigma de las flores de esta planta se usa como condimento y medicina (DRAE: 242).

Bailahuén [baila'wen] 45, M. Préstamo del mapuche para asignar a una especie parecida. Failahuén, baylahuén, vailahuén, nombre mapuche que significa fermento (Haplopappus baylahuen Remy), subarbusto de la zona marítima del norte. "Contiene una resina medicinal, usada en aplicaciones externas para curación de heridas e ingerida como estimulante, digestivo y sudorífico" (M: 110).

Bailavín [baila'ßin] 45, M. Derivado de bailahuén.

Bailawela [baila'wele] 45, M. Derivado de bailahuén.

Bailawena [baila'wene] 45, M. Derivado de bailahuén.

Bálsamo 9, E . Símil con otras plantas con propiedades medicinales parecidas. Del latín "balsamum" y este del griego. Sustancia aromática que se obtiene de ciertos árboles. Medicamento compuesto de sustancias comúnmente aromáticas que se aplica como remedio en las heridas, llagas y otras enfermedades (DRAE: 256).

Bálsamo finito 125, E. El específico alude a una planta parecida, pero más gracil que el bálsamo.

Banderilla [bande'riye] 159, E. Símil de la paja sacudida por el viento? Derivado de "bandera".
Palo delgado de setenta u ochenta centímetros de largo, armado de una lengüeta de hierro y que, revestido con papel picado y adornado a veces con una banderita, usan los toreros para clavarlo en el cerviguillo de los toros (DRAE: 260).

Barba de chivato ['barba ðe či'ßato] 161, E. Símil del hábito de este diminuto pastito de lluvia.

Barba de chivo ['barba ðe 'čißo], 161, E. Símil del hábito de este diminuto pastito de lluvia. Planta anual de la familia de las Gramíneas, con hojas radicales y muy delgadas, de unos cinco centímetros de largo, que forman un césped, del cual salen unas cañitas lampiñas de unos veinte centímetros, con nudos casi negros y hojas más cortas que sus vainas; las flores forman una panoja cilíndrica, blanca y brillante y las aristas son muy finas en la parte superior" (DRAE: 264).

Básal ['basal] 109, 110, K? El nombre básal, podría estar relacionado con las palabras kunza Balsantur, "Escoba", Baâlsatur, "barrer"(V: 14-15).

Bávaro ['baßaro] 2, E. Podría ser un símil del aspecto de la planta si la palabra derivara de baba. Baba, "saliva espesa y abundante que a veces fluye de la boca del hombre y de algunos mamíferos. Por extensión se aplica al jugo viscoso de algunas plantas" (DRAE: 247).

Berrillo [be'řiyo], 112, E. Símil con otra planta comestible, el berro, por analogía de hábitat y aspecto.

Berro ['beřo] 117, E. Del español, 'Crucífera de lugares aguanosos que se come en ensaladas' (JC: 94). Idem (DRAE: 285) Ibid (M: 80).

Berro picante 112, E. Símil con el berro por analogías de hábitat y aspecto.

Bilankichu [bilan'kiču] 19, Q. El nombre alude al color de tallos y vainas. Del quechua wila, rojo (GH,I: 351).

Borraja [bo'řaxe] 60, E. Símil con otra planta introducida y medicinal, probablemente por las asperezas de la hoja. Del catalán "borratja" y este del latín. "Planta anual de la familia de las 
Borragináceas, de veinte a sesenta centímetros de altura, con tallo grueso y ramoso, hojas grandes y aovadas, flores azules dispuestas en racimos y semillas muy menudas. Está cubierta de pelos ásperos y punzantes, es comestible y la infusión de sus flores se emplea como sudorífico" (DRAE: 314).

Borraja? 48, E. Símil con otra planta introducida y medicinal, probablemente por las asperezas de la hoja. Ver nombre anterior.

Botón 20, E. Símil del hábito de la planta, una roseta de hojas con inflorescencias sésiles como botones. Del castellano "Yema de un vegetal". "Flor cerrada y cubierta de hojas que unidas las defienden hasta que se abren y extienden" (DRAE: 318).

Brea ['bree] 52, E. Alusión al uso de la planta. Del castellano "brear". "Arbusto de Chile, de la familia de las Compuestas, del cual se extraía una resina que se usaba en lugar de brea" (DRAE: 323).

Breya 52, E. Derivado de brea.

Cabello 72, E. Símil del aspecto de la planta. Del latín "capillus". "Cada uno de los pelos que nacen en la cabeza" (DRAE: 342).

Cabeza de gato 141, E. Símil de la forma del fruto.

Cabra míkun ['kaßre 'mikun] 129, E, Q. Ver “cabra mikuna".

Cabra mikuna ['kaßre mi'kune] 129, E, Q. Del quechua micuy (mikhuy=comer; mikhuna=comida) (R (1): 60) (?).

Cacho de cabra 98, E. Símil de la forma de las espinas.

Cadillo [ka'ðiyo] 76,113, E. Concepto morfológico referido a distintas plantas con frutos espinosos que se pegan al pelaje de animales. Del latín "catellus", perrillo. "Planta Umbelífera, muy común en los campos cultivados, que crece hasta unos 30 centímetros de altura; hojas anchas, con dientes profundos; flores de color rojo o purpúreo y fruto elipsoidal erizado de espinas tiesas".
También se denomina así a otra "planta y a su fruto, de la familia de las Compuestas con tallo ahorquillado, de unos 60 centímetros de altura; flores de color verde amarillento y frutos aovados cubiertos de espinas ganchudas. Es muy común entre los escombros y en los campos áridos de toda Europa “ (DRAE: 353). Nombre dado a la planta de la familia de las Rosáceas, Acaena trifida (R. et P.), A. pinnatifida (R. et P.), A. splendens (R. et P.), "tiene una inflorescencia en forma de cabezuelas compactas o de espigas interrumpidas y de frutitos armados de aguijones derechos o glochidios que molestan tanto a los seres humanos como a los animales. Los yerbateros les encuentran a diversas especies propiedades medicinales: refrescantes, astringentes y diuréticas" (M: 83).

Caña ['kape] 164, E. Concepto genérico para Gramíneas altas de tallos huecos. Del latín "canna". "Tallo de las plantas gramíneas, por lo común hueco y nudoso." "Planta gramínea de Europa meridional; tiene tallo leñoso, hueco, flexible y de tres a cuatro metros de altura; hojas anchas un tanto ásperas, y flores en panojas muy ramosas; se cría en parajes húmedos" (DRAE: 393).

Cañaveral [kajeße'ral] 164, E. Del castellano “cañavera”. Sitio poblado de cañas o cañaveras (DRAE: 394).

Carda ['karðe] 120, E. Cabeza terminal del tallo de la cardencha. Sirve para sacar el pelo de los paños y felpas. También es una "especie de cepillo con púas de alambre que de usa en la industria textil para limpiar y separa unas fibras de otras" (DRAE: 410).

\section{Cardador 120, E. Derivado de carda.}

\section{Cardadora 120, E. Derivado de carda.}

Cardo ['karðo], 120, E. Concepto morfológico seguramente referido a especies de Compuestas con espinas. Del latín "cardus". Planta anual, compuesta, que alcanza un metro de altura, hojas grandes y espinosas como las de la alcachofa, flores azules en cabezuela, y pencas que se comen crudas o cocidas, después de aporcada la planta para que resulten más blancas, tiernas y sabrosas (DRAE: 412). 
Cardón 16, E. Nombre propio de la más importante especie de Cactácea de Atacama. Del castellano "cardo". En Argentina especie de cacto gigante que sirve para setos espinosos y como planta forrajera. (DRAE: 412)

Cardón chico 18, E. Símil con el cardón, pero más pequeño.

\section{Cardón grande 16, E. Derivado de cardón.}

Cardoncillo [karðon'siyo] 136, E. Símil con otra planta muy importante, el "cardón", por las estípulas espinosas. "De tallos derechos, hojas abrazadoras, escotadas, espinosas por el margen, y manchadas de blanco y flores purpúreas de cabezuelas terminales" (DRAE: 412).

Cascabel 79, E. Alusión al ruido de las semillas dentro de la cápsula. Del latín "cascabus" por "caccabus", puchero. Bola hueca de metal del tamaño de una avellana, lleva dentro un pedacito de hierro o latón para que suene (DRAE: 430).

Caudal [kau'ðal] 9, E? Símil de los tallos crasos con aspecto de cola. Del latín "capitalis", capital. "Caudaloso, de mucha agua" (DRAE: 442). Del latín "cauda", cola. "Perteneciente o relativo a la cola" (DRAE: 443).

Cebadilla [seßa'ðiye] 149, 153, 161, 169, E. Español, identifica una especie de cebada que crece espontáneamente (DRAE: 383).

Cebadillo [seßa'ðiyo] 111, E. Variante del nombre cebadilla.

Cedrón [se'ðron] 118, E. Símil con otra planta también aromática y medicinal. Planta Verbenácea olorosa y medicinal originaria del Perú, pero que se cría también en Chile, la República Argentina y Uruguay" (DRAE: 449).

Cepa de caballo ['sepe ðe ka'ßayo], 65, E. Derivado de cepacaballo.

Cepacaballo ['sepe'kaßayo], 65, E. Ajonjera (DRAE: 459). Ajonjera: "Planta perenne de la familia de las compuestas, de treinta a cuarenta centímetros de altura, con raíz fusiforme, hojas puntiagudas y espinosas y flores amarillentas" (DRAE: 76).
Cerda de chancho ['serða ðe 'čančo], 72, E. ¿Símil de los gruesos tallos volubles del parásito?

Cerraja [se'řaxe], 48, 60, E. Del latín "serralia". "Hierba de la familia de las Compuestas, de sesenta u ochenta centímetros de altura, con tallo hueco y ramoso, hojas lampiñas, jugosas, oblongas y con dientecillos espinosos en el margen, y flores amarillas en corimbos terminales" (DRAE: 465).

Césped ['se $\left.{ }^{h} e^{d}\right], 142,155,168$, E. Del castellano "césped". "Hierba menuda y tupida que cubre el suelo" (DRAE : 468).

Chacha ['čače], 49, 50, A. Nombre genérico para especies del género Parastrephia. Chacha, aymara, "Varonil"; "varón o marido" (B: 68,2). En la zona de estudio, la chachakoa se alude como el macho de la koa.

Chacha chica ['čače 'čike], 49, A, E. El nombre específico alude al tamaño.

Chacha fina ['čače fine], 49, A, E. El nombre específico alude al aspecto.

Chacha hembra ['čače 'embre], 49, A, E. El nombre específico alude al aspecto más grácil, por analogía con la mujer.

Chacha macho ['čače 'mačo], 50, A, E. El nombre específico alude al aspecto más robusto, por analogía con el hombre.

Chacha pelada ['čače pe'laðe], 50, A, E. El nombre específico alude a que la planta no es koa, es solamente una chacha.

Chacha pulika ['čače pu'like], 50, A/Q? Ver chacha; "Pulicani, andar, volver el rostro a otra parte". "Pulicani, pulicanca, rodela o adarga u otra cosa defensiva" (R (1): 72).

Chachakoa ['čače'koe], 49, A. Koa es también el nombre del felino celestial dentro de la mitología andina (VCR: 221) y, en la cuenca del Salado, el nombre de koa y koa Santiago se aplica exclusivamente a la especie Fabiana bryoides, que se usa sólo con fines ceremoniales $(\mathrm{A}=209)$. 
Chachakoma [čače'kome], 50,57, Q, A. Nombre genérico para especies suculentas y con fuerte olor del género Senecio. Chachakuma, quechua, "Chachacomo: árbol pequeño de altura. Arbusto medicinal" (C: 34); Chachacuma, "árbol de esta tierra” (R, (1): 33). Chachacoma N. vulg. de una planta de la alta cordillera de Coquimbo y Atacama (Senecio eriophyton) usada en la medicina casera, balsámica, excitante, estomacal, contra la "puna", etc. Uso medicinal contra la "puna" [Murillo: 117]. Chachak'uma, quechua [Middendorf: 338]: nombre de un árbol de 20 a 30 pies de alto, de madera muy pesada y de color morado, que tiene muchos usos en la carpintería, $i$ no puede ser la misma planta (L: 237). Chachacoma, en Chile "planta de la cordillera andina, de flores amarillas y de uso en la medicina casera" (DRAE: 632). Chachacoma, voz quechua, según el Dr. Lenz, significa "hombre pobre" (Senecio eriophyton Remy, S. hirtus Cabr.) indicado para el estómago, el mal de puna y la presión alta de la sangre (M: 113). En pukina, Cuma, significa "permanecer" y Coma es "todos"; en kallawaya, kuma es "sentarse" (VCR: 194). En el aymara actual, kuma kuma es la especie "Salvia haenkei, planta silvestre que crece en los valles altos de Bolivia, a los 3.600 m.snm" (esta especie tiene otros nombres muy diferentes en quechua y kallawaya). Kuma también es el nombre de otras dos plantas de crecimiento espontáneo de valles altos; en Charasani (3.600 $\mathrm{m} . \mathrm{snm})$ se trata de Salvia rhombifolia y en Achocalla (3.500 m.snm), de Salvia revoluta. Esta última, mezclada con otra yerba, "la usan las indias estériles para hacerse fecundas". Otra especie que se nombra kuma es Eupatorium percisiflolium, de crecimiento espontáneo. Crece en los valles altos de Irpavi; sus hojas y tallos se usan para preparar la llipta, reactivo alcalino empleado para masticar la coca (G: 375-376 y 437).

Chachakoma de la vicuña [čača'kome de la Bi'kuje], 57, Q, A. Derivado de chachakoma. De acuerdo a Middendorf, en quechua, huik'uña es "cuadrúpedo parecido a la llama, vicuña; de color avellano, cubierta de lana corta y muy fina; vive en manadas en los altos de la cordillera" (L: 776).

Chachakoma macho, 57, Q, A, E. Derivado de chachakoma. Machu, quechua, "viejo común- mente o abuelo" (R: 57). En el idioma castellano de la zona de estudio alude al sexo masculino y se aplica a las plantas de la misma especie que son más robustas y/o no dan fruto.

Chacrilla del campo [ča'kriye ðel 'kampo], 161, Q, E. Del antiguo quechua "chacra", moderno "chajra". En América "alquería o granja" (DRAE: 632). Chakra, quechua, "sementera o terreno de cultivo propio de los Andes" (Ba: 56). Chacra, heredad (R: 33).

Chajchajra [čax'čaxre], 45, Q. Chhakchay, desinflarse, reventarse una pelota (C: 47). Chejcheraja, topónimo Quebrada de Chejcheraja, 3 kilómetros S.E. de Socaire (V: 18).

Chajchara [čax'čare], 45, Q. Derivado de chajachajra.

Chakachaka ['čake'čake], 76, A. Chaaca, aymara, "caña de la quínoa" (B: 67, 2) ; Cchaca, "hueso de los animales"; "gota de algún licor" (B: 73,2). En quechua, Ch'aka, afónico, ronco (C: 41).

Cháme ['čame], 138, K? Tchamma, "fuerza" (V: 33).

Chámen ['čamen], 138, K? Derivado de cháme.

Champa ['čampe], 6,132,145, Q, A. Nombre genérico para la forma de vida de cojín de humedal. Ch'ampa, quechua, "pedazo de césped con la tierra que se pega entre las raíces; especies de plantas que tienen raíces largas, tupidas y ordenadas" (L: 337). 'Terrón moldeado y seco que se usa como adobe' (C: 42). "Terrón, masa de tierra compacta de diversa dimensión"; también "trozo de césped, tierra adherida a la raíz de las plantas cuando se les extrae" (Ba: 93).

Champita [čam'pite], 21, 29, Q, A. Diminutivo castellanizado de Ch'ampa.

Chañar [ča'nau], 100, Q, K? Nombre propio de un árbol importante. En cunza, Tchacknar y Tchaynar es "chañar, árbol" (V: 34). "De origen quechua. América Meridional. Arbol de la familia de las Papilionáceas, espinoso, de corteza amarilla. Sus legumbres son dulces y comestibles. 
También se denomina chañar al fruto de este árbol" (DRAE: 636).

Chape ['čape], 27, A. Cchapi, aymara, "espina, abrojo"; Chappi lahua, "leña espinosa" (B: 77, 2).

Chávil ['čaßil], 138, K? Aparentemente, deformación de la palabra cháme.

Chejchara [čex'čare], 45, Q. Derivado de chajachajra.

Chijlla ['čixye], 33, A, Q? Aparentemente deformación de chijua.

Chíjua ['čixwe], 33, A, Q? Cchihua, aymara, "yerbas de comer cocidas, las crudas". (B (2): 84). En quechua, Chihuan huay, "Una flor colorada y amarilla plumaje" (GH (2): 109).

Chíjuachíjua ['čixwe'čixwe], 33, A, Q? Ver Chijua.

Chillawa [či'yawe], 148, Q, A. Cchillihua, aymara, "hicho gordo y liso como la caña del trigo de que hazen petacas, y otras muchas cosas" (B: 130 y 264, 2).

Chillka ['čilke], 36, Q, A. Nombre genérico para especies arbustivas del género Baccharis. En quechua, "Chillca: Mata de hojas amargas llamada assi". (R; 36). Aymara, "Cchillca, una mata espinosa" (B,II: 85); "Chillquitha brotar, nacer el sembrado, y cualquiera planta" (B, II: 82); Chilca. Del quechua "chillca", arbusto de hojas pegajosas. En Colombia y Guatemala nombre que se da a un "arbusto resinoso de la familia de las Compuestas que crece en las faldas de las montañas de todo el continente americano" (DRAE: 645). Chilca, voz quechua pero de uso corriente entre los mapuches, que reúne ejemplares de hojas delgadas, en su mayoría estrechas y lineares aplicada a diversa especies (Baccharis marginalis DC., B. racemosa (R. et P.) D.C., B. confertifolia Bert. ex. Colla, B. pingDRAEa, B. salicifolia (R. et P.) Pers., Eupatorium salvia Colla, E. glechnophyllum, Pluchea chingoyo) (M: 109-110). De acuerdo a Middendorf, Ch'illca, "plantas de unas hojas de un sabor muy amargo que se em- plean machacadas en cataplasmas sobre articulaciones hinchadas; también se usan para teñir de verde" (L: 278).

Chipichapi ['čipi'čapi], 76, A. En aymara, "Cchapi Espina, abrojo"; Cchapi lahua Leña espinosa; Cchapi cchapi uraque Tierra llena de espinas, de abrojos (B (2): 77) En quechua, "Chhapu chhapu, yerba de la centella" (GH: 97). Chipichape.

Chochar ['čočau], 71, K, ¿Q? Derivado de chuchar.

Chókel ['čokel], 24, 25, ¿K?

Chókil ['čokil], 24, 25, ¿K?

Idem Chókel

Chuchar ['čučas], 71, ¿K?, ¿Q? Tchutchar, kunza, "planta de la cordillera" (V: 35). "Ch'uch'ar, una planta de la cordillera" (Schuller: 34) (Mun: 19). Chuchar, "probablemente quechua, (Sisymbrium amplexicaule Phil.), planta cordillerana de Tarapacá, llamada también "mostacillo"” (M: 80; L: 317)

Chuchikan [čuči'kan], 133; Q, ¿A? Chukikanlla, quechua, planta sudorífica que ostenta espolines ganchudos en el tallo (Li: 138). En quechua, Chuuqui, Lanza (GH (1): 122).

Chujchu ['čuxču],102, A, ¿Q? Chhukhchu, aymara, "Temblor de todo el cuerpo, enfermedad que da en los yungas" (B: (2): 91). Chucchu, quechua, "Frío de calentura" (R: 38). Chuhchu, quechua, tercianas, fiebres intermitentes, malaria (Li: 138).). En quechua, Chucchu: Frío de calentura (R: 38).

Chúkchar ['čukčau], 152, K? Tchotchau, kunza, “arbustito parecido al boj” (V: 34). Ch'och'au, kunza, en Schuller (Mun: 18). Chuchau, quechua, "maguey arbol" (R: 38).

Chukchuka [čuk'čuke], 34, ¿A/ Q?

Chukikan [čuki'kan], 133, Q, A? Variante de chuchikan. 
Chukllara [čuk'yare], 169, Q, ¿A? Chhukhlla, aymara, "pajita" (B: 343,1). Chhokklla, Yerba cebadilla (B (2): 88).

Chuku ['čuku], 162, A, ¿Q? Cchukhu, aymara, "espinoso hablando de la leña" (B: 228,1). Chucu, quechua, "bonetes o sombreros antiguos" (GH: 118,2; R: 38).

Chukula [ču'kule], 3, K. Tchuckula, kunza, "planta acuática que hai en la Cordillera" (V: 34). Tchuckula, kunza, "luche" (LE: 35). Luche, mapuche, de lluche: "yerba del mar que se come" (L: 441), aludiendo obviamente a Porphyra columbina, alga roja marina y comestible (M: 5152).

Chullapasa [čuye'pase], 12, A/ Q? Chullapaasa. Chuya, quechua, "cosa clara como agua, u otro licor" (R: 40). En aymara, chulla "manoxillo de quínua o trigo" (B (2): 92); Cchulla "lo que esta sin su compañero que avía de tener" (B (2): 95). Chuya en quechua (ver. GH (1): 126) tiene el sentido de purificación, tanto del alma como del cuerpo y, en la práctica, esta "limpia" se realiza con varios elementos, entre los que se incluyen harinas, obtenidas de ciertas plantas; la idea es que siempre que se ofrenda, se haga de "a pares" y en la mayoría de los casos, se quemen estas ofrendas (VCR: 215).

Cola de caballo ['kole ðe ka'ßayo], 65, E. ¿Error por alusión a cepacaballo?

Cola de lagarto ['kole ðe la'yarto], 30, E. Alusión a la posición y a la forma de los tallos.

Cola de zorro, 148, 149, 153, 161, E. Símil para el aspecto de las inflorescencias y el hábito de varios pastos. Cola de zorra. "Planta perenne de la familia de las Gramíneas, con raíz articulada, tallo de treinta a ochenta centímetros, hojas planas, lineares y lanceoladas, y flores en tirso cilíndrico con aristas largas y paralelas" (DRAE: 503).

\section{Comida de perdiz, 40, E}

Comida de vizcacha [ko'miða ðe $B i^{x^{\prime}}$ kače], 64, E, Q. En aymara, "Viskacha, ver Hiskachu, Conejo de la tierra silvestre que corre por las peñas"
(B (2): 389. Quechua, Vizcacha, "conejo de la tierra pardo" (R: 87).

Comida del suri, 20, E, A. Suri, en aymara, "avestruz" (B (2): 329); en quechua, "avestruz ave" (R: 81).

Correhuela [koře'wele], 68, E. Nombre propio de la importante especie de maleza muy difundida en Chile. "Mata de la familia de las Convolvuláceas, de tallos largos y rastreros que se enroscan en los objetos que se encuentran; hojas alternas, acorazonadas y con peciolos cortos; flores acampanadas, blancas o rosadas, y raíz con jugo lechoso. Se emplea como vulneraria" (DRAE: 579).

Cortadera [korta'ðere], 148, E. Cortadera, español, de cortar. En Argentina, mata de Gramineae propia de terrenos llanos y húmedos, de hojas angostas de color verde-azulado, y flores en panículas fusiformes, grisácea con reflejos plateados (DRAE: 369).

Cuernillo [kwer'niyo], 98, 139 E. Diminutivo de “cuerno”, pero la planta 139 no tiene espinas (¿?).

Cuerno ['kwerno], 98, E. Alusión a las espinas con forma de cuernos de animal. Del latín "cornu". Prolongación ósea que tienen algunos animales en la región frontal. En sentido figurado se refiere a las "extremidades de alguna cosa que rematan en punta y tienen alguna semejanza con los cuernos" (DRAE: 619).

Cuerno de cabra ['kwerno ðe 'kaßre], 98, E. Ver anterior.

Cuerno de lagarto ['kwerno ðe la' yarto], 139, E. Curioso nombre porque la planta 139 no tiene espinas o cuernos.

Cuero de sapo ['kwero ðe 'sapo], 6, E. Alusión al habitat húmedo del musgo donde habitan los sapos.

Dedos de ángel, 9, E. Alusión a las hojas carnosas, como dedos, y usadas como remedio.

Duraznillo [durah'niyo], 55, E. Del castellano "durazno" por el parecido de sus hojas (DRAE: 
783). Duraznillo, español, nombre dado a Polygonum persicaria y $P$. hydropiperoides porque tiene hojas iguales a las del durazno (M: 75).

Enredadera [enřeða'ðere], 68, 72, 92, 74, E. Concepto colectivo para abarcar especies con forma de vida voluble. "Dícese de las plantas de tallo voluble o trepador, que se enreda en las varas u otros objetos salientes" (DRAE: 842).

Espárrago [e ${ }^{\mathrm{h}}$ pařąo], 172, E. Nombre propio de esta importante especie cultivada. Del latín "asparagus", y este del griego. Planta de la familia de las Liliáceas de tallo herbáceo, muy ramoso, que en la primavera produce abundantes yemas de tallo recto y comestible (DRAE: 891).

Espina blanca, 95, E. Nombre genérico para especies espinosas del género Adesmia. Cardo borriquero (DRAE: 896), cardo de "unos tres metros de altura, con hojas rizadas y espinosas; el tallo con dos bordes membranosos, y flores purpúreas en cabezuelas terminales" (DRAE: 412). Sin duda esta definición es para otra especie.

Espina negra, 97, E. Ver anterior.

Esporal [e ${ }^{\mathrm{h}}$ po'ral], 163, ¿E? ¿Derivado de espo$r a$ ?

Espural [e ${ }^{\mathrm{h}}$ pu'ral], 155,163, ¿E? ¿Derivado de espora?

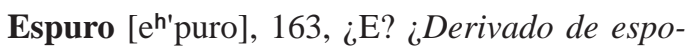
$r a$ ?

Flor amarilla, 43, 63, E. En Colombia, Cuba, México, Panamá, Perú, Río de la Plata y El Salvador, "nombre de distintas plantas americanas caracterizadas por el color amarillo de alguna de sus partes, especialmente la madera" (DRAE: 123).

Flor blanco, 23, E

Flor de la champa ['flod ðe la 'čampe], 172, E, Q

Flor de peña, 5, E. Alusión al hábito de los líquenes crustáceos.

Flor del agua, 6, E. Alusión al habitat acuático.
Flor del laqo ['floı del 'lako], 3, E, Q/A, K. Lako es nombre genérico para la forma de vida de acuáticas flotantes. Lakkho o lakko, quechua, alga de la familia de las Conferváceas, de aspecto filamentoso que se desarrolla en aguas estancadas y en las corrientes. Es reconocida como fresco contra fiebres (LI: 548). Lakho, quechua, correspondería a las algas verdes del género Cladophora (G: 96). Laqhu, quechua, "alga comestible que crece en los lagos" (Ba: 168). En el Lago Titicaca, el repliegue del alga significa año con escasa lluvia. Es señal de sequía o lluvia (Ba: 267). Lako, aymara, "ouas de la Laguna, o yerua verde como estopa, o lana, y suelen comerla en locros" (B: 187, 2). Liki-liki, quechua, "es señal de lluvia o sequía" (BA: 265). Lacko, kunza, 'una planta acuática en las lagunas i ríos de la cordillera' (V: 24; LE: 40).

Flor morada, 129, E.

Forraje de vizcacha [fo'řaXe ðe $B \mathrm{i}^{\mathrm{x}}$ 'kače], 159, E, Q. Forraje, del francés "fourrage". "Hierba que se da al ganado especialmente en primavera". También se denomina así al "pasto seco conservado para alimentación del ganado, y también los cereales destinados a igual uso" (DRAE: 987).

Garbancillo [gar'ßansiyo], 99, E. Diminutivo de garbanzo.

Garbanzo [gar'ßanso], 99, E. Español de origen incierto. "Planta herbácea de la familia de las Papilionáceas, con tallo de cuarenta o cincuenta centímetros de altura, duro y ramosos; hojas compuestas de hojuelas elípticas y aserradas por el margen; flores blancas, axilares y pedunculadas, $\mathrm{y}$ fruto en vaina inflada, pilosa, con una o dos semillas amarillentas, de un centímetro aproximadamente de diámetro, gibosa, y con un ápice encorvado" (DRAE: 1022).

Garbanzo del campo, 102, E. Derivado de garbanzo.

Gato ['gato], 141, E. Alusión a la forma del fruto.

Grama ['yrame], 145, 150, 152, 153, 154, 160, 169, E. Nombre genérico para la forma de vida de Gramíneas cespitosas. Grama, español, del latín Grámen (DRAE: 674).

Grama chica,150, E. Derivado de grama. 
Grama fina,160, E. Derivado de grama.

Gramilla [yra'miye], 150, 154, E. Derivado de grama.

Gramillo [yra'miyo], 150, 154, 160, E. Derivado de grama.

Helecho, 7, E. Español, del latín "filictum". "Planta criptógama, de la clase de las filicíneas, con frondas pecioladas de dos a cinco decímetros de largo, lanceoladas y divididas en segmentos oblongos, alternos y unidos entre sí por la base; cápsulas seminales de dos líneas paralelas al nervio medio de los segmentos, y rizoma carnoso" (DRAE: 770).

Hierba del tapón ['yerße ðel ta'pon], 69, E. Alusión a la acción terapéutica (diarreas) de la planta.

Hierba sal [yerßa'sal], 109, 110, E. Alusión al hábitat salobre de la planta.

Higuerilla [iye'riye], 120, E. Derivado del castellano "higuera". Higuera infernal, planta de ricino (DRAE: 1107).

Hinojo [i'noXo], 131, E. Nombre propio de esta planta introducida. Del bajo latín "fenuculum". Planta herbácea de la familia de las Umbelíferas, toda la planta es aromática, de sabor dulce, y se usa en medicina y como condimento (DRAE: 1110).

Hoja de té, 38, E. Té, del chino "tscha", pronunciado en ciertas provincias te. Arbusto de Extremo Oriente de la familia de las Teáceas, la hoja de este arbusto seca, arrollada se sirve en infusión como bebida estimulante, estomacal y alimenticia (DRAE: 1949).

Iloka [i'loke], 93, ¿Q/A? Iluca (Krameria cistoidea H. Et A., K. iluca Phil.) también llamada pacul, ambos "son nombres indígenas peruanos de dos arbustos de la provincia de Coquimbo" (M: 86); este nombre "debe ser indio; pero no está en los diccionarios" (L: 411)

Iloka hembra [i'loke 'embre], 96, ¿Q/A? E. Derivado de iloka.
Iloka macho [i'loke 'mačo], 93, ¿Q/A? E. Derivado de iloka.

Iluka hembra [i'loke 'embre], 96, ¿Q/A? E. Derivado de iloka.

Iluka macho [i'luke 'mačo], 93, ¿Q/A? E. Derivado de iloka.

Ilúkar [i'lukar], 93, ¿Q/A? Derivado de iloka.

Ipallapa [ipa'yape], 14, A. Ipallapa, podría ser una deformación del aymara "Itapallo, ortiga" (B (2): 183.

Iro ['iro], 157, 158, 159, Q, A. Idem iru.

Iru, 157, 159, Q, A. Iru, aymara "Hicho espinoso" (B (2): 181) y en quechua, "paja brava", maleza de los cultivos que sirve alimento al ganado; también es una "planta medicinal" (Ba: 124).

Jaboncillo [Xaßon'siyo], 142, 143, E. Derivado del castellano "jabón" (DRAE: 1196).

Junquillo [Xun'kiyo]?, 167, E. Nombre genérico para especies del género Juncus. Junquillo. Derivado el castellano "junco". Junquillo, español, nombre dado a varias especies del género Juncus (M: 67).

Junquillo redondo, 170, E. Derivado de junquillo.

Kachiyuyo [kači'yuyo], 25, Q. Cachiyuyo, quechua, hierba de la sal. Varias especies de Chenopodiáceas (M: 76). Kacha yuyu, quechua, "yeruas secadas a mano" (GH: 149,1). Kachi yuyo, aymara, corresponde a Chenopodium murale (G: 174). Del kunza, ckacktchi: "bueno, agradable", yuyo, "variedad de quinoa" (LE: 22); Cachi, quechua, "sal" (R: 19) Q'ächi (quechua), "arista". (Ba: 86). Del kunza, ckacktchi: "bueno, agradable", yuyo, "variedad de quinoa" (LE: 22).

Kachuyo [ka'čuyo], 25, Q. Aparente contracción de kachiyuyo. Khachu, quechua, "crudo", se dice de los tubérculos que permanecen crudos en el proceso de cocción. (Ba: 161). Cachu, quechua, Hierbas. Cachu, cachu, Hierbazal (R: 19). Hachu: Borujo, y particularmente la coca mascada. (R: 40). 
Kachuyo macho [ka'čuyo 'mačo], 25, Q, E. Nombre indígena derivado del anterior. El apelativo "macho", para los lugareños, expresa mayor tamaño o que no da frutos.

Kafle ['kafle], 147, 149, 155, 156, 165, ¿K?. Concepto morfológico referido a pastos blandos.

Kafle delgado, 169, K, E

Kallya ['kalye], 94, Q. En aymara, Caa, "Caui o chuño de ocas" (B (2): 32); Kalla, "entreverado de diverso color, cuarteado como pendines (B (2): 45). En quechua, Caylla, "cerca del lugar"; "extremidad o remate de algo" (R: 24).

Kámen ['kamen], 110, ¿K?

Kámin ['kamin], 109, 110, ¿K? Derivado de kámen.

Kañiwa [ka'niwe] (se parece), 26, Q, A. En aymara, Cañahua, "quinua cenicienta" (B (2): 35). Cañahua aymara, "quínoa cenicienta". Cañihua. Perú. "Especie de mijo que sirve de alimento a los indios, y con el cual, fermentado, se hace chicha" (DRAE: 395).

Káuchal ['kaučal], 15, K. Ckautcha, kunza, "hierba parecida a la malva" (V: 18). Cáuchal “atacameño: k' auch'a: hierba parecida a la malva (Schuller: 33)" (Mun: 16).

Keúche [ke'uče], 40, 111, K. Ckeu-iy, "dientes" (V: 18). Ckei-tchu "liendre" (V: 18).

Killokisca [kiyo'kike], 41, Q. Quisco, derivado del quechua "Quichca, la espina" (GH,I: 307). Middendorf anota para Quisca, "espinas grandes, esp. de las Cactáceas", y quisca, "la espina" (L: 675). Quisca. Del quechua "quichca", espina. Quisco, en Chile, especie de cactos espinosos que crecen en forma de cirio cubierto de espinas, que alcanzan más de treinta centímetros de largo. Kichka, quechua, "broza espinosa, 'quepo', espina"; también "cabello lacio y tieso" (Ba: 124). Quisco, palabra quechua, derivada de "quisca", cualquier cosa provista de espinas o púas; denomina en Chile numerosas especies de género Cereus (M: 94).
Koa ['koe], 49, A, ¿Q? Koa es también el nombre del felino celestial dentro de la mitología andina (VCR: 221) y en la cuenca del Salado, el nombre de koa y koa Santiago se aplica exclusivamente a la especie Fabiana bryoides, que se usa exclusivamente con fines ceremoniales $(A=209)$.

Kokakora, 62, Q, A. Cora aymara, "yerua del campo inútil" (B (2): 52). Del aymara coca, "árbol cualquiera que sea" y "hoja de un árbol así llamado que los indios mascan" (B (2): 49). Qora, quechua, yerba, maleza, mala yerba. (C: 116). Qura, quechua, "broza", mala hierba para los cultivos en general, pero puede ser útil como forraje para el ganado. (Ba: 128-129). En quechua, cora: La mala yerua cizaña. (R: 25). "Cora, en Perú, hierbecilla perjudicial que crece en los plantíos y hay que extirpar con frecuencia" (DRAE: 568). En aymara, Coca, "árbol cualquiera que sea"; hoja de un árbol así llamado que los indios mascan" (B (2): 49). Del aymara "kkoka". Arbusto del Perú, de la familia de las Eritroxiláceas, "esta planta es cultivada y de ella se extrae la cocaína" (DRAE: 494).

Konte ['konte], 101, ¿K? De konti. Ckonnti, ckonte, "Gente" (V: 19). En estas lenguas se intercambia la pronunciación de "e" e "i".

Konte chico ['konte 'čiko], 102, ¿K?, E. De konti.

Konte chujchento ['konte čuX'čento], 102, ¿K?, Q/A, E. De konti. En aymara, Chhuchhu, "Temblor de todo el cuerpo, enfermedad que da en los yungas" (B (2): 91). En quechua, Chucchu: Frío de calentura. (R: 38 ), las personas al describir los efectos de esta planta en los animales aludían a "temblores o tiritones".

Konti ['konti], 101, ¿K? Ckonnti, ckonte "jente (desempeña el papel de on en francés, parece transformación de jente pronunciando guturalmente la letra G.) mui usado" (V: 19).

Kontikonti ['konti'konti], 101, 102, ¿K? Reiteración de konti.

Kopa ['kope], 32, K, Q, A. Ckopa, kunza, "puño, mango - Una planta arborescente de la cordillera, mui abundante es la primera que se encuentra al 
salir del llano de Atacama, después de Peine, vía Antofagasta de la Sierra" (V: 19). K'opa, "una planta arborescente de la cordillera (Schuller: 34)", (Mun: 17). Copa, palabra quechua (Artemisia copa Phil.), arbusto aromático del Norte Grande, envuelto en un tomento blanquizco (M: 113); también en Lenz (L: 209).

Kopakopa ['kope'kope], 32, K, Q, A. Reiteración de kopa.

Kopakopa macho, 24, A, K, Q, E

Kora ['kore]?, 86, Q, A. Cora aymara "yerua del campo inútil" (B (2): 52). Qora, quechua, yerba, maleza, mala yerba. (C: 116). (DRAE: 568). Qura, quechua, "Broza", mala hierba para los cultivos en general, pero puede ser útil como forraje para el ganado. (Ba: 128-129). Cora: La mala yerua, cizaña (R: 25). Cora, en Perú, hierbecilla perjudicial que crece en los plantíos y hay que extirpar con frecuencia (RAE: 568).

\section{Kore ['kore], 134, Q, K? Ver kori.}

Kori ['kori], 134, Q, ¿K? En quechua, Cori, oro, metal (R: 25). En kunza, Ckori "gordo" (V: 20). "Nan: pierna: nanckri: pierna de cori, o rica-rica; dícese como apodo al que tiene la pierna velluda" $(\mathrm{V}: 20)$

\section{Kórial ['korjal], 25, Q, K?}

Kotakota ['kote'kote], 135, A. En aymara, Cota cota es "muchos charcos juntos". Qota es " mar, laguna, charco" (B (2): 53); koota es "amorateado"; (B, (2): 57) y Ccotta "resina como tomillo" (B (2): 55). En kunza, ckota, es "los" y Ckot, "suyos" (V: 20) ; por último, Ycota, en esta misma lengua, significaría "ellos" (SR: 12; GM: 49) ; También se registra el nombre quichua khota, para la yareta de la puna (Azorella sp.) en Bolivia (G: 340).

Kótar ['kotau], 62, ¿K? En kunza, Ckot- es "enfermarse" (V: 20). Una planta forrajera que crece en Socaire se denomina Cotar (Mun: 17).

Kotára [ko'tare], 62, ¿K ? Variante de kótar.

Kotáro [ko'taro], 62, ¿K? Variante de kótar.
Kótaro ['kotaro], 62, ¿K? Variante de kótar.

Kulchao ['kulčao], 19, ¿K? Variante de kulchau.

Kulchau ['kulčau], 19, ¿K? Tchotchau, "arbustito parecido al boj" (V: 30).

Kume ['kume], 17, ¿K? Ckummi, "planta que parece de la familia de las tunas" (V: 21). Ckumi látigo, penca (V: 21). (V: 21).

Lama, 2, 3, 4, E. Nombre genérico para forma de vida de algas filamentosas acuáticas y flotantes. Lama, mapuche moderno, "tejido de lana, generalmente negro, cubierto de flecos largos en toda su extensión" (L: 421-422).). Lama. Del latín "lama". "Cieno blando, suelto y pegajoso, de color oscuro, que se halla en algunos lugares del fondo del mar o de los ríos, y en el de los recipientes o lugares donde hay o ha habido agua por largo tiempo". Otra acepción es: "alga u ova de los lamedales o charcales". En Colombia, Chile y Honduras "capa de plantas criptógamas que se cría en las aguas dulces". En Colombia, Chile, Honduras, México y Puerto Rico "musgo, planta Briófita". En Bolivia, Colombia y México "moho, cardenillo" (DRAE: 1225).

Lampaya [lam'paye], 137, Q, A. Nombre propio de una importante especie medicinal andina. Lampaya, quechua, una Verbenácea medicinal (Li: 550). Lampayo: n. Vulg. De un arbustito medicinal de la cordillera de Atacama, Verbenácea, Lampaya medicinalis Ph. (L: 422). Lampaya, voz aymara (Lampaya medicinalis Phil.), arbusto bajo de gruesas hojas ovales, preconizado como antirreumático, sudorífico e indicado contra los resfriados. Crece en la cordillera de Tarapacá (M: 103).

Laqo ['lako], 2, 4, Q, A, K. Nombre genérico para la forma de vida de especies acuáticas y flotantes. Lakkho o lakko, quechua, alga de la familia Conferváceas, de aspecto filamentoso que se desarrolla en las aguas estancadas y en las corrientes. Es reconocida como fresco contra las fiebres. (Li: 548). Correspondería a las algas verdes del género Cladophora (G: 96). Laqhu, quechua, "alga comestible que crece en los lagos" (Ba: 168). En el Lago Titicaca, el repliegue del alga significa 
año con escasa lluvia. Es señal de sequía o lluvia (Ba: 267). Lako, aymara, "ouas de la Laguna, o yerua verde como estopa, o lana, y suelen comerla en locros" (B: 187, 2). Lacko, kunza, "una planta acuática en las lagunas i ríos de la cordillera" (V: 24; LE: 40).

Lava ['laße], 2, ¿E? Derivado de lama? Derivado de lavar? Aymarización de agua (lagua?, lawa?)

Lava del agua, 2, ¿E? Ver lava.

Leche ['leče], 73, E. Analogía del látex lechoso de la planta. Del latín "lac", "lactis". "Jugo blanco que se extrae de algunas semillas menudas y parduscas, como las de la leche. Su látex, que es abundante y acre, se ha usado en medicina" (DRAE: 1238).

Lecheleche ['leče'leče], 73 E. Duplicación de leche.

Lecherito del campo, 73, E. Derivado de leche.

Lechuga, 48, E. Símil con otra planta cultivada, la conocida hortaliza comestible. Del latín "lactuca". Planta herbácea de la familia de las Compuestas, las hojas son comestibles y del tallo puede extrarse un látex de sabor agradable (DRAE: 1239).

Lejía [le'Xie], 37, E. Símil de color por el blanco ceniciento de las hojas. Del latín "(aqua) lixiva". "Agua en que se han disuelto álcalis o sus carbonatos. La que se obtiene cociendo ceniza sirve para la colada" (DRAE: 1241).

\section{Léjia ['lexje], 37, E. Variante de lejía}

Lengua de gallina, 41, E. ¿Alusión a la forma de las hojas?

Leña de tola ['lepe ðe 'tole], 57, E, Q/A. Nombre genérico para la forma de vida de leñosa (leña). Del latín "ligna". "Parte de los árboles y matas que, cortada y hecha trozos, se emplea como combustible" (DRAE: 1244). Tola, "voz quechua, se refiere según el Dr. Reiche (Geografía Botánica) al hábito, más que a caracteres sistemáticos, de un grupo de arbustos xerófilos del extremo norte"
(M: 105). Ttola, planta sudamericana (JC: 571). Ttola, quechua, "árboles que se llaman tola, que sirven de leña y todo el año está verde". (G: 484). Tola. América Meridional. "Nombre de diferentes especies de arbustos de la familia de las Compuestas, que crecen en las laderas de la cordillera" (DRAE: 1989).

Likia ['likje], 37, ¿E? Variante de lejía. Alternativamente, la palabra original podría ser likia y lejía sería una variante.

Linaza [li'nase], 79, E. Nombre específico del lino. "Simiente del lino en forma de granitos elipsoidales, duros, brillantes y de color gris. Molida proporciona una harina muy usada para cataplasmas emolientes; por presión suelta un aceite secante de gran empleo en la fabricación de pinturas y barnices, y, echada en agua, da un mucílago de mucha aplicación en la industria" (DRAE: 1260)

Llantel [yan'tel], 105, 106, E. Variante de llantén.

Llantén [yan'ten], 105, 106, E. Nombre específico de la planta. Del latín "plantago, -inis". Planta herbácea, de la familia de las Plantagináceas, muy común en los sitios húmedos, y el cocimiento de las hoja se usa en medicina (DRAE: 1280).

Llantil [yan'til], 106, E.Variante de llantén.

Lokoche [lo'koče], 47, K. Símil con otra planta por su uso como hortaliza. Lockotchi, kunza, "achicoria" (V: 25).

Loroma [lo'rome], 1, 4, 173, ¿A? El vocablo loroma puede derivar de larama, aymara, que significa "fino, azul" (B: (1) 242).

Malva ['malße], 82, 83, 85, 88, E. Nombre genérico para especies de la familia Malváceas. Del latín "malva". Planta muy abundante, de la familia de las Malváceas con flores moradas, es usada en medicina por el mucílago que contiene las hojas y las flores (DRAE: 1300).

Malva blanca ['malße 'blanke], 87, E. Especificación de una propiedad de la malva. 
Malva del campo ['malße ðel 'kampo], 83, 87, E. Especificación de una propiedad de la malva.

Malva parada ['malße pa'rade], 81, 87, E. Especificación de una propiedad de la malva.

Malva rosa ['malße 'řose], 84, 85, E. Especificación de una propiedad de la malva.

Malva rosada ['malße řo'saðe], 83, E. Especificación de una propiedad de la malva.

Malvilla [mal'ßiye], 87, E. Diminutivo de malva.

Malvisco [mal'ßiko], 82, E. Reducción de Malvavisco. Del latín "malva" e "hibiscum". Planta perenne de la familia de las Malváceas, de un metro de altura, flores blanco rojizo, fruto como el de la malva, y raíz gruesa. Abunda en los terrenos húmedos y la raíz se usa como emoliente (DRAE: 1300).

Maransel [maran'sel], 51, 64, Q. Símil con otra planta, si derivara de maransera, planta lobelia de la familia de las Campanuláceas, que se usa a manera de especia (Li: 630).

Maransel hembra, 51, Q, E. Especificación de una propiedad de maransel.

Maransel macho, 51, 64, Q, E. Especificación de una propiedad de maransel.

Maravilla [mara'ßiye], 48, 63, E. Símil con otra planta por analogía con la flor de la maravilla o girasol. Del latín "mirabilia", plural de "mirabilis", admirable). "Planta herbácea de la familia de las Compuestas, de treinta a cuarenta centímetros de altura, con hojas abrazadoras y lanceoladas, flores terminales con pedúnculo hinchado, circulares y de color anaranjado. El cocimiento de las flores se ha usado en medicina como antiespasmódico". También se llama maravilla a una "especie de enredadera, originaria de América, que se cultiva en los jardines y tiene flores azules con listas purpúreas". El mismo nombre se da a la planta don Diego de la noche (DRAE: 1321).

Margarita, 68, E. Símil con otra planta por analogía con la flor de la margarita. Del latín "mar- garita" y este del griego. "Planta herbácea de la familia de las Compuestas, de cuarenta a sesenta centímetros de altura, con hojas casi abrazadoras, oblongas, festoneadas, hendidas en la base, y flores terminales de centro amarillo y corola blanca. Es muy común en los sembrados" (DRAE: 1324).

Menta koka ['mente 'koke], 67, E, Q/ A. Ambos nombres son similes con otras plantas que también son medicinales. Menta, del latín "menta", hierbabuena (DRAE: 1356). Koka, del aymara quqa "árbol cualquiera que sea" y "hoja de un arbol así llamado que los indios mascan" (B (2): 49). Coca, del aymara "kkoka". Arbusto del Perú, de la familia de las Eritroxiláceas, esta planta es cultivada y de ella se extrae la cocaína" (DRAE: 494).

Michi ['miči], 141, Q, A, K. Símil de la forma del fruto. Mitchi, kunza, "gato. - León, puma" (V: 26). Mishi, quechua, "gato" (Ba: 169). Michi, mapuche, "el gato... Estoy sin embargo seguro de que esta voz no es mas que una variante del nombre familiar castellano micho o mas bien la voz con que se llama al gato" (L: 497). Micho, cha. De "mizo". Gato, gata (DRAE: 1369).

Mirasol, 63, E. Símil con otra planta, el conocido girasol. De "mirar" y "sol". La planta girasol (DRAE: 1379).

Mirasol chico, 63, E. Especificación de una propiedad del mirasol.

Mokoraka [moko'rake], 54, Q, A. Variante de mukuraka.

Molle ['moye], 11, Q. Nombre propio de una importante especie "de un grande i hermoso árbol del Perú y del norte de Chile, cultivado también en el Centro, donde se denomina "pimiento". Schinus molle. Molli, (Middendorf: 597), quechua, nombre de un árbol de los valles de madera dura; de las pepitas negras de la fruta se prepara una bebida fermentada / (Id: 604) mulli (molli): nombre de un árbol cuya fruta infundida con agua se usa contra los males de la vejiga. (L: 510-511). Molle, del quechua "molli", árbol de mediano tamaño de la familia de las Anacardiáceas, propio de América Central y Meridional, con hojas 
fragantes y frutos rojizos; su corteza y resina se estiman como nervina y antiespasmódicas. El mismo nombre se aplica a otro árbol de la misma familia en Bolivia, Ecuador y Perú cuyos frutos se emplean para fabricar una especie de chicha (DRAE: 1391). Molle, voz quechua y vulgar de un hermoso árbol del Perú de la familia de las Anacardiáceas (Schinus molle L.).

Monte blanco, 55, E. Monte, nombre genérico para la forma de vida de plantas en general, particularmente arbustos. Del latín "mons", "montis", "Tierra inculta cubierta de árboles, arbustos o matas". Monte bajo. Denominación dada tanto al "monte poblado de arbustos, matas o hierbas" como a "estas matas o hierbas" (DRAE: 1398). Blanco, es una especificación de una propiedad de un monte.

Monte colorado, 43, 76, E. Colorado es una especificación de una propiedad (color) de un monte.

Monte derecho, 124, E. Derecho es una especificación de una propiedad (hábito) de un monte.

Monte morado, 76, E. Morado es una especificación de una propiedad (color) de un monte.

Monte negro, 31, 76, 124, E. Negro es una especificación de una propiedad (color) de un monte.

Monte picante, 112, E. Picante es una especificación de una propiedad (sabor) de un monte.

Monte soldao, 124, E. Soldao es una especificación de una propiedad (analogía del hábito erguido) de un monte.

Monte verde ['monte 'ßerðe], 31, E. Verde es una especificación de una propiedad (color) de un monte.

Muelle ['mweye], 11, Q. Variante de molle.

Mukuraka [muku'rake], 54, Q, A. ¿Símil del hábito nudoso de la planta? Moco, quechua, varios significados "coyuntura del cuerpo", "artejos de los dedos", "ñudos de madera o de cañas", "lleno de nudos" (R: 61). Moco, "coyuntura de los hue- sos o nudos de las cañas y palos" (B (2): 224). En cunza, Mucku, "loma” (V: 26).

Mukurakan [muku'rakan], 54, Q, A. Variante de Mukuraka.

Mutukuru [mutu'kuru], 19, A, Q. En aymara, Mutu: "Arbolillo de alcaparras desta tierra". "Buñuelos o tortillas de quinoa a semejanza de un bonete de clérigo" (B (2): 228).

Nevadilla [neßa'ðiye], 70, E. Diminutivo de nieve.

Nevadita, 70, E. Diminutivo de nieve.

Niebla ['njeßle], 60, M. Variante de ñilhue.

Nieve, 70, E. Símil del color blanco de las inflorescencias. Del latín "nix", "nivis". Agua helada que se desprende de las nubes en cristales, los cuales llegan al suelo en copos blancos (DRAE: 1440).

Nori ['nori], 132, 173, ¿K?, ¿A?

Noris ['nori $\left.{ }^{\mathrm{h}}\right], 132, \succsim \mathrm{K}$ ?, ¿A?

Ñible ['nißle], 60, M. Variante de ñilhue.

Ñiebla ['njeßle], 60, M. Variante de ñilhue.

Nilhue ['nilwe], 60, M. Nombre específico de la planta. Denominación mapuche también denominado "ulhui-vaca" (babas de vaca) y "cerraja", planta cosmopolita (Sonchus oleraceus): su infusión es refrescante anticólica y antibiliosa, enfermedades del corazón y fiebre (M: 116).

Ñiuble ['njuble], 60, M. Variante de ñilhue.

Ojalar [o'Xalaı], 24,¿K?, ¿E? Si fuese español, ¿vendría de ojal? El vocablo oja, según Torero, sería voz kallawaya y pukina, que significa "comer" (VCR: 145).

Ojman ['oxman], 80, ¿K?

Oreja [o'rexe], 121, E. Símil de la forma de la hoja. 
Oreja de chojchor [o'rexe ðe 'čoXčod], 121, E, ¿K? Símil de la forma de la hoja.

Oreja de ratón [o'rexe ðe řa'ton], 62, 121, E. Símil de la forma de la hoja.

Ortega [or'teye], 80, E. Variante de ortiga.

Ortiga [or'tiye], 80, E. Símil con otra planta, la conocida ortiga europea, por lo urticante. Del latín "urtica". Planta herbácea de la familia de las Urticáceas, con hojas cubiertas de pelos que segregan un líquido urente, muy común en España (DRAE: 1490).

Osman ['o $\left.{ }^{\text {h }} \operatorname{man}\right], 80, i \mathrm{~K}$ ?

Paiko ['paiko], 28, Q. Nombre propio de la importante especie medicinal. Payco, quechua, "hierba medicinal" (R: 69). Paico, del quechua “payqu”. En América Meridional, "planta herbácea de la familia de las Chenopodiáceas, usada como antihelmíntico en la medicina popular" (DRAE: 1500). Paico, quechua, comprende la sección Ambrina del género Chenopodium (Ch. ambrosioides L., Ch. pinnatisectum, Ch. andicola y Ch. chilense Schrad.), planta muy aromática, su infusión es eficaz para afecciones estomacales y digestivas (M: 75).

Paja ['paxe], 151, 157, 158, 162, 166, 167, E. Nombre genérico para la forma de vida de las Gramineas altoandinas perennes y en champas del pajonal. Paja, del latín "palea". "Caña de trigo, cebada, centeno y otras gramíneas, después de seca y separada del grano" (DRAE: 1501).

Paja brava, 151, 157, 166, E. Brava es una especificación de una propiedad de una paja que pincha. "Hierba de la familia de las Gramíneas, que crece hasta tres o cuatro metros de altura. Es propia de las tierras de gran altitud en América Meridional. Es apreciada como pasto, y como combustible en los hornos de minerales" (DRAE: 1501).

Paja banderilla, 167, E. Banderilla es diminutivo de "bandera" y una especificación de una propiedad de una paja que, probablemente, flamea con el viento como bandera. Bandera, del español, palo delgado de setenta u ochenta centímetros de largo, armado de una lengüeta de hierro y que, revestido con papel picado y adornado a veces con una banderita, usan los toreros para clavarlo en el cerviguillo de los toros (DRAE: 260).

Paja blanda ['paxe 'blande], 151, 166, E. Especificación de una propiedad de una paja.

Paja crespa, 159, E. Especificación de una propiedad de una paja.

Paja chica, 151, 166, E. Especificación de una propiedad de una paja.

Paja del viento, 166, E. Especificación de una propiedad de una paja.

Paja delgada, 151, E. Especificación de una propiedad de una paja.

Paja sikuya ['paxe si'kuye], 151, 158, E, Q, A. En quechua, sikuwa es paja brava (Lira: 910). Según Bertonio, sicuya en aymara es una clase de Hichu (B: 130,2).

Paja sukuya ['paxe su'kuye], 152, E, A. Variante de sikuya.

Paja waya ['paxe 'waye], 158, E, Q, A. Waya es variante de Waylla, quechua, pastizal, prado. (C: 163). Huaylla, aymara, "hicho largo y blando con que cubren las casas" (B: 156, 1; 130,2). Huaylla, quechua, "el prado verde no agostado, o el buen pasto" (GH: 192,2).

Pajita [pa'Xite], 152, 158, 167, E. Diminutivo de paja.

Pajita chica, 162, E. Diminutivo de paja.

Palke ['palke], 119, ¿M?. Variante de palki.

Palki ['palki], 119, M. Nombre propio de la importante especie medicinal. Nombre vulgar de un arbusto o arbolillo mui común i de mal olor; es de mucho uso en la medicina casera como diaforético, excelente sudorífico". Etimología mapuche (L: 547). De origen araucano. Arbusto americano de la familia de las Solanáceas de olor fétido. Su cocimiento se emplea en Chile contra la tiña, y como sudorífico, y la planta para hacer jabón (DRAE: 1512). 
Palo colorado, 76, E. Símil del color del tronco y de la raíz.

Papa cháme ['pape 'čame], 138, Q, ¿K? Papa, del quechua "papa". Tubérculo, patata (DRAE: 1520).

Pápur pasto ['papu^ 'pa ${ }^{\mathrm{h}}$ to], 13, 14, ¿K?, E. Símil con la propiedad adherente de la planta y frutos. Paapur, papur, kunza, "lana" (V: 27). Munizaga señala que esta denominación kunza "debe relacionarse con la particularidad de adherirse a la lana de los animales" (Mun: 22).

Parecido a la cortadera, 143, E. Ver cortadera.

Pasakana [pasa'kane], 16, ¿Q?, ¿A?

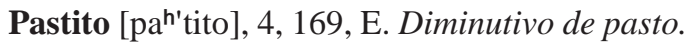

Pastito blando, 143, 147, 149, 165, E. Diminutivo de pasto.

Pastito blando del agua, 156, E. Diminutivo de pasto.

Pastito del agua, 112, 132, 173, E. Diminutivo de pasto.

Pastito del campo, 141, E. Diminutivo de pasto.

Pasto, 43, 105, E. Nombre genérico para la forma de vida herbácea. Del latín "pastus". "Hierba que el ganado pace en el mismo terreno donde se cría" (DRAE: 1545).

Pasto blando, 147, 155, 156, 165, E. Atributo específico de un pasto.

Pasto colorado, 109, E. Atributo específico de un pasto.

Pasto de vicuña, 20, E, Q. Atributo específico de un pasto.

Pasto duro, E, 169. Atributo específico de un pasto.

Pasto leche, E, 73. Atributo específico de un pasto.
Pasto lechero, 73, E. Atributo específico de un pasto.

Pasto loco, 34, E. Atributo específico de un pasto que enloquece a los animales.

Pata de perdiz ['pate ðe per'ði ${ }^{\mathrm{h}}$ ], 122, E. Símil de los tallos áfilos y escamosos de la planta.

Pegapega, 76, E. Concepto morfológico seguramente referido a frutos que se adhieren.

Peludilla [pelu'ðiye], 72, 153, E. Alude a los numerosos y delgados tallos de Cuscuta, llamada también cabello; y al aspecto hirsuto de Dielsiochloa.

Perdilla [per'ðiye], 136, E. Variante de perlilla.

Perlilla [pel-'liye], 136, E. Diminutivo de perla, ¿símil de la belleza de las flores?

Pimiento [pi'mjento], 11, E. Símil con otra planta por el parecido de los frutos. Del latín "pigmentum", color para pintar. Planta herbácea anual de la familia de las Solanáceas, de fruto rojo y amarillo, el fruto es usado como alimento por su sabor, picante en algunas variedades (DRAE: 1803).

Pimiento llorón, 115, E. Ramas péndulas de un sauce (llorón), de la misma manera como el pimiento.

Pingo ['pingo], 8, Q, A. Ver pingopingo.

Pingopingo ['pingo' pingo], 8, Q, A. Pinco pinco (sano sano): aymara "Yerua buena para desecar las flemas" (B (2): 308). De acuerdo a Rosales: "yerba de media vara de alto que ni echa flor, ni hojas ni semilla" (L: 1097). Pingopingo: n. Vulg. De un arbusto sin hojas que crece en las cordilleras de todo el país. Ephedra spec. (L: 600). Pingopingo. Chile. Arbusto de la familia de las Efedráceas con flores pequeñas, y por fruto unas nuececitas que así como sus hojas son diuréticas y depurativas (DRAE: 1604-1605)

Pingopingo macho ['pingo'pingo 'mačo], 8, Q, A, E. Ver pingopingo. 
Primavera, 81, 87, E. ¿Alusión a las lindas flores? Del latín "prima", primera, y "ver" "veris", primavera. "Planta herbácea perenne, de la familia de las Primuláceas, con hojas anchas, largas, arrugadas, ásperas al tacto y tendidas sobre la tierra. De entre ella se elevan varios tallitos desnudos que llevan flores amarillas en figura de quitasol" (DRAE: 1665-1666).

Pupusa [pu'puse], 66, Q. Pupusa, quechua, según Girault (G: 452), corresponde a Werneria poposa. De acuerdo Yacorleff y Herrera (1935), se trataría de W. Digitata.

Pupusa del agua [pu'puse ðe'lawe], 66, Q, E. Ver pupusa.

Pupusa del campo, 66, 135, Q, E. Ver pupusa.

Puskayo [pu'kayo], 17, Q, A.

Q'ela [q'ele], 102, A, ¿K ? Kela, aymara "Una flor morada, como de altramuces” (B (2): 295). Ckeelas, "planta o arbusto llamado también ckatchi-yuyo: - cuyo significado: buena hierba: pero enteramente distinto a la hierba buena de Chile" (V: 18). Kélas, kunza, "cachiyuyo" (SR: 12).

Quebrolla [ke'ßroye], 41, 81, E. Alusión al ruido de la planta al quemarse.

Quisco ['ki'ko], 17, Q. Quisco, derivado del quechua "Quichca, la espina" (GH,I: 307). De acuerdo a Middendorf, Quisca: espinas grandes. espinas de las Cactácea. Quisca, la espina. (L: 675). Quissa yuyu: Ortigas. (G: 76). Quisca ['ki $\left.{ }^{x} k e\right]$. Del quechua "quichca", espina. Quisco, en Chile, especies de cactos espinosos que crecen en forma de cirio cubierto de espinas, que alcanza más de treinta centímetros de largo. Kichka, quechua, "broza espinosa, 'quepo', espina"; también "cabello lacio y tieso" (Ba: 124). Quisco, palabra quechua, derivada de "quisca", cualquier cosa provista de espinas o púas; denomina en Chile numerosas especies de género Cereus (M: 94).

Rayito de sol, 68, E. Alusión a las rayitas moradas de la corola.
Rezongón, 41, E. ¿Alusión al ruido de la planta al quemarse?

Rikarika ['řike'řike], 134, ¿Q?, ¿E? Rica. En Rioja, alholva, planta Papilionácea y su semilla (DRAE: 1797). Ricarica denominación quechua, de una planta Verbenácea del norte de Chile (Acantholippia deserticola) (M: 103).

Romaza [řo'mase], 10, 47, 105, 106, 108, E. Concepto colectivo para varias malezas de hojas comestibles por alusión a la planta introducida, la Romaza. Del latín "rumex, -icis". Hierba perenne de la familia de las Poligonáceas, es común en España, las hojas se comen en potaje, y el cocimiento de la raíz se ha usado como tónico y laxante (DRAE: 1808). Romaza (Rumex romassa Remy, $R$. sanguineus L.), maleza común, la infusión de sus hojas es refrescante y emoliente, la decocción de la raíz limpia y sana tumores y úlceras malignas, además es usada entre los mapuches como tintórea tiñendo de color azul (M: 75).

Romerillo [řome'riyo], 56, 59, E. Símil con otra planta europea alimenticia-medicinal, el romero. En América, "nombre de varias especies de plantas silvestres; la mayor parte de ellas se utilizan en medicina" (DRAE: 1808).

Romerillo blanco 59, E.

Romerillo chico, 58, E.

Romero [řo'mero], 78, E. Del latín "rosmaris". Arbusto de la familia de las Labiadas, es común en España y se utiliza en medicina y perfumería (DRAE 1808).

Romero de Castilla [ř́o'mero ðe ka ${ }^{h}$ tiye], 78, E.

Roseta, 136, E. Derivado de "rosa" (DRAE: 1813).

Ruda ['řuðe], 114, E. Del latín “ruta”. Planta perenne de la familia de las Rutáceas, de olor fuerte y desagradable y se usa en medicina (1816).

Sáilao ['sailao], 29, 155, ¿K?, ¿Q? Sailla, quechua, Festuca dolichophylla (G: 117). En Atacama, sailau fue un nombre usado como apellido indígena en 1612 (V: 29). Sailao se conserva como 
topónimo de un predio agrícola en Calama (LE: 58 ), luego podría ser un vocablo cunza o derivado de otra lengua indígena.

Sangría [san'grie], 107, E. Variante de sangrinaria.

Sangrinaria [sangri'narje], 107, E. Sanguinaria, del latín "sanguinaria". Centinoidia (DRAE: 1842). Centinoidia, "planta pequeña de la familia de las Poligonáceas, con hojas enteras, oblongas y pequeñas, tallos cilíndricos con muchos nudos y tendidos sobre la tierra, y pequeña la semilla que es muy apetecida por las aves; es medicinal" (DRAE: 457).

Sauce ['sause], 115, E. De "salce". Árbol de la familia de las Salicáceas, es común en las orillas de los ríos (DRAE: 1850).

Séber ['seße $]$ ], 71, K. Seber, kunza, "una planta de la cordillera" (V: 29). "Una planta de la cordillera (en Schuller: 34)" (Mun: 23).

Sébir ['seßiı], 71, K. Variante de séber.

Sicha ['siče], 12, Q.

Simbol [sim'bol], 163, ¿E? Simbol, en Argentina, gramínea de tallos largos y flexibles que se usa para hacer cestos (DRAE).

Sítor ['sitod], 113, K. Variante de sítur.

Sítur ['situı], 113, K. Situr "planta llamada tambien cadillo" (V: 30). "Cadillo, (Schuller: 33)" (Mun: 16).

Sobaco negro [so'ßako 'neyro], 75, E. Alusión al fuerte olor de la planta.

Sobaquilla [soßa'kiye], 14, E. Derivado de "sobaco" (DRAE: 1889).

Sobaquillo [soßa'kiyo], 14, 75, E. Derivado de "sobaco" (DRAE: 1889).

Soiko ['soiko], 61, A, ¿Q? Soico, siuica: , aymara, "Yerba, cortadera" (B (2): 321).

Soiko de cabra ['soiko ðe 'kaßre], 53, A, ¿Q?, E. Ver soiko.
Suiko ['suiko], 61, A, ¿Q? Ver soiko.

Suiko blanco, 61, A, ¿Q?, E. Ver soiko.

Suiko de cabra ['suiko ðe 'kaßre], 53, A, ¿Q?, E. Ver soiko.

Suncho ['sunčo], 34, 35, Q. Sunch'u, quechua, "muturu, hongo que se presenta en las hojas de la quínoa en forma de áreas amarillentas onduladas, adquiriendo un aspecto encrespado" (Ba: 135). Suntchir, kunza, "amargo" (V: 30). Suncho. Del latín "cingulum". "Abrazadera, zuncho". En Bolivia, "planta herbácea de la familia de las compuestas, parecida a la margarita, con flores amarillas." En Argentina "chilca, arbolito" (DRAE: 1919).

Tabaco del burro [ta'ßako ðel 'buřo], 127, E. Símil con otra planta de América tropical, el tabaco. De etimología discutida. Planta de la familia de las Solanáceas, originaria de América, toda la planta tiene olor fuerte y es narcótica (DRAE: 1928).

Tablilla [ta'ßliye], 123, E. Alusión al uso de la planta para entablillar miembros quebrados. Derivado de "tabla" (DRAE: 1930).

Tajtará [taxta'ra], 41, ¿Q?, ¿A?

Tamarugo, 91, ¿? Nombre propio de la importante especie. Chile, "árbol de la familia de las Papilionáceas, especie de algarrobo que crece en la pampa" (DRAE: 1937).

Tara ['tare], 124, Q. En aymara, Tara apilla, Occa chata; "como la mano, no redonda"; Tara suto; Ver Chullco; Las hojas de esta manera de ocas o apillas (B (2): 338). Tara. Perú, "arbusto con hojas pinadas, flores amarillas, y legumbres oblongas y esponjosas" (DRAE: 1944). Ttarar, kunza, "blanco: - duro, firme: dícese de un terreno con esflorescencias salitrosas que a la vez que blanco, lo hacen firme i duro" (V: 33) Tara, quechua, psispalla, ispata; "Formación no típica de dos yemas separadas que presentan los tubérculos de papas y ocas; se considera que es el espíritu de las plantas tuberosas" (Ba: 178). Tara (Coulteria tinctoria H.B. Kth.), árbol del norte; usado en medicina por sus propiedades astringentes y en 
tintorería para teñir de negro. En la Araucanía se designa como tara los dos postes largos en cuya horcadura descansa el caballete (parhilera) de la ruca mapuche (M: 84)

Tara hembra, 123, Q, E. Ver tara.

Tara macho, 124, Q, E. Ver tara.

Tastará [tahta'ra], 41, ¿Q?, ¿A?, ¿K? Ttastar, kunza, "apellido de 1612" (V: 33).

Té, 38, E. Símil con otra planta, el Té. Del chino "tscha", pronunciado en ciertas provincias te. Arbusto de Extremo Oriente de la familia de las Teáceas, la hoja de este arbusto seca, arrollada se sirve en infusión como bebida estimulante, estomacal y alimenticia (DRAE: 1949).

Té colorado, 76, E.

Té de burro, 38, E.

Té silvestre, 38, E.

Té verde, 38, E. Té verde. Té que "se ha tostado cuando las hojas están frescas, después de quitado el pecíolo y teñidas después con una mezcla de yeso y añil" (DRAE: 1949).

Tieuchi [tje'uči], 40, ¿K? Ttiu. Arenal en tierra llana que toma un gran trecho", en aymara (B (2): 357). En cunza, Ckeu-iy. "Dientes" (V: 18) Ckeitchu "liendre" (V: 18). En quechua, "Tiu, arena; Tiu tiu, arenal" (R (1): 84). "Chia, liendre" (R (II): 155).

Tikara [ti'kare], 31, 76, Q, ¿K? Tticka, kunza, "señal, flor" (V: 33). Técara, kunza, "nueve" (SR: 9. En quechua, "Tica. Flor o plumaje (R (1): 83). T'ika, "flor" (Ba: 119). T'ikaray, florecer (Ba: 119). En aymara, "Ttica”, escudilla de hicho de que usan en los caminos porque no se quiebra. Es también una caxuela redonda de hicho[paja] en que los hechiceros guardan cosas para sus embustes (B (2): 354). "Tica. Adobe de barro" (B (2): $353)$; la misma grafía y significado en quechua (R (2): 83).

Pikara [pi'kare], posible deformación de la palabra aymara y quechua.
Tikara hembra, 76, ¿K?, Q, E

Tikara macho, 31, ¿K?, Q, E

Tikara negra, 76, ¿K?, Q, E

Tola ['tole], 37, 46, 49, 124,136,46, Q, A. Nombre genérico para la forma de vida arbustos. Ttola, planta sudamericana (JC: 571). Ttola, quechua, "árboles que se llaman tola, que sirven de leña y todo el año está verde". (G: 484). Tola. América Meridional, "Nombre de diferentes especies de arbustos de la familia de las compuestas, que crecen en las laderas de la cordillera" (DRAE: 1989). Ttola, planta sudamericana (JC: 571). Ttola, quechua, "árboles que se llaman tola, que sirven de leña y todo el año está verde". (G: 484). Tola, "voz quechua, se refiere según el Dr. Reiche (Geografía Botánica) al hábito, más que a caracteres sistemáticos, de un grupo de arbustos xerófilos del extremo norte" (M: 105).

Tola chica, 33, Q, A, E.

Tola negra, 31, Q, A, E.

Tolilla [to'liye], 33, 123, Q, A, E. Tolita, diminutivo castellano de tola. Tolilla, de la voz "tola" (quechua), designa a dos especies Fabiana barriosii Phil. y F. denudata Miers (M: 105).

Tolita [to'lite], 33, Q, A, E. Tolita, diminutivo castellano de tola.

Tolontolon [to'lonto'lon], 126, ¿?

Tomatillo [toma'tiyo], 126, 128, E. Tomatillo, de Tomate, nahuatl (L: 521) (Méjico, Mesoamérica), en Chile es un arbusto de las Solanáceas (DRAE: 1274). La palabra nahuatl es tomatl.

Toronjil [toron'xil], 77, E. Del árabe "turunyan", "turunyin", hierba abejera. Planta herbácea anual, de la familia de las Labiadas, sus hojas y flores se usan como remedio tónico y antiespasmódico (DRAE: 1999).

Toronjil cuyano, 77, E. Cuyano, natural de la región de Cuyo, Argentina. En Chile "dícese de los naturales de la República Argentina" (DRAE: 631). 


\section{Toronjil de la pena, 118, E}

Toronjil dulce, 28, 118, E

Totora [to'tore], 34, 144, Q, A. Tutura, quechua, corresponde a Scirpus californicus, S. riparius, Typha angustifolia (M: 60, 65; G: 125). T'otora, "de tallo vacío" (C: 296). Totora, aymara, "junco". "Yerba que dan a las bestias" (B: 274, 1; 359, 2). Totora, del quechua "tutura", "especie de enea o espadaña que se crea en terrenos pantanosos o húmedos" (DRAE: 2002). T'utura "'totorilla', maleza de los cultivos que sirve de alimento al ganado" (Ba: 131).

Treból [tře'ßol], 104, E. Variante de trébol.

Trébol ['třeßol], 104, E. Trébol. Del catalán “trébol" y este del griego. Planta herbácea anual, de la familia de las Papilionáceas, es espontánea en España y se cultiva en como planta forrajera muy estimada (DRAE: 2020).

Tríbol ['třißol], 104, E. Variante de trébol.

Trigol ['třiyol], 104, E. Variante de trébol.

Tuna, 17, AR. De origen arahuaco. "Fruto del candelabro, planta Cactácea" (DRAE: 2038). "Voz caribe que designa en Chile a una Cactácea cultivada (Opuntia vulgaris Hill.), juntamente con su fruto comestible" (M: 94).

Unquillar [unki'yau], 142, 143, 146, E. Derivado de Junquillo, español, de junco (del latín Juncus) (DRAE: 775). Junquillar, español, nombre dado a varias especies del género Juncus (M: 67).

Unquillar redondo, 170, E. Derivado de Junquillo.

Unquillare, 170 E. Derivado de Junquillo.

Unquillo [un'kiyo], 142, 143, 146, 170, E. Derivado de Junquillo.

Unquillo cuadrado, 146, E. Derivado de Junquillo.
Unquillo duro, 170, E. Derivado de Junquillo.

Varilla [ba'riye], 94, E. Derivado de "vara". En Chile, "arbusto, variedad del pelhuén" (DRAE: 2062).

Vega ['beye], 21, 132, 145, 171, E. Concepto morfológico seguramente referido a plantas de humedales. Vega. Del ibérico "vaica". "Parte de tierra, baja, llana y fértil". En Chile, "terreno muy húmedo" (DRAE: 2065).

Veguita [be'yite], 132, E. Diminutivo de vega.

Verbena [ber'ßene], 140, E. Del latín “verbena”. Herbácea anual de la familia de la Verbenáceas, muy común en España (DRAE: 2076).

Verdulaga [berðu'laye], 73, E. Verdolaga, en castellano, del mozárabe "berdolaca". Planta herbácea anual, de la familia de las Portulacáceas, con tallos tendidos, gruesos, jugosos, de tres a cuatro decímetros de largo; hojas sentadas, carnosas, casi redondas, verdes por la haz y blanquecinas por el envés; flores amarillas y fruto capsular con semillas menudas y negras. Es planta hortense y se usa como verdura. Por extensión, cualquier verdura" (DRAE: 2078). Es reconocida, en el aymara colonial, como "verde por madurar" (mori, Llullu, cchokhna) (B: (I): 468). En aymara, Llullu amca, papa pequeñita que aun no ha crecido"; "Llullu tonco, mayz pequeñito que no llega a su crecimiento y se queda asî" (B (2): 208). "Mori, hoco. Mojado o verde" (B (2): 221); "Cchokhna vel Copa: Verde como la yerba o paño desta color" (B (2): 90). En quechua "Verdolaga yerua" [yerba], "llutu llutu" (R (2): 192); "Llutu, mutu". Verdolaga (R (1): 56).

Viravira ['bire'ßire], 44, Q. En quechua "Vira, manteca o cosa gorda" (R (1): 87). Vira vira, "expresión peruana (Gnaphalium viravira Mol.), además llamado "bálsamo del campo" y "yerba de la vida", planta envuelta enteramente en un bello blanquizco-lanudo. Tiene propiedades medicinales curativas de las heridas e interiormente en tisanas expectorantes, sudoríficas y febrífugas (M: 11). Viravira, "nombre vulgar de una yerba lanuda, medicinal (Gnaphalium viravira). Por ser 
famosa vulneraria i febrífuga se llama también "yerba de la vida". Middendorf, anota "huirahuira, Muy gordo; nombre de una planta de la sierra que forma una mata baja de hojas gruesas y cubierta de una pelusa blanca cuya infusión se emplea como remedio contra los catarros pulmonares" (L: 769).

Wailawen [waila'wen], 45, M. Derivado de bailahuén.

Wailawin [waila'win], 45, M. Derivado de bailahuén.

Wajilla [wa'Xiye], 20, ¿A?, ¿Q?, E. Derivado castellanizado de Waje.

Walkawalka ['walke'walke], 30, Q. Huallcca, quechua, "collar o cadena, o sartal de quentas, y todo lo que se pone al cuello hombres y mugeres, o bestias, o animales, etc." (GH: 173,2). Justamente bajo esta forma es descrita por los lugareños ("parece un collarcito") (VC). "Huallka, Kata, poco, o pocos", aymara (B (2): 145).

Waya ['waye], 157, 158, Q, A. Variante de Waylla.

Waycha ['waiče], 30, 125, A. "Huaycha, orégano o poleo de esta tierra", en aymara; "Que es el orégano de esta tierra" (B (2): 154; 185).

Waylla ['waiye], 158, Q, A. Huaylla, aymara, "hicho largo y blando con que cubren las casas" (B (1): 156); "hicho aun mayor que el que llaman orco sucuya, con el que cubren las casas" (B (2): 130). Huaylla, quechua, "el prado verde no agostado, o el buen pasto" (GH: 192,2). Waylla, quechua, Pastizal, prado (C: 163).

Wilka ['wilke], 89, Q, A. "Villca", en aymara, es "el sol como antiguamente decían, y agora dicen Inti"; "adoratorio dedicado al sol, o otros ídolos"; "es también una cosa medicinal, o cosa que se daba a beber como purga para dormir, y en durmiendo dize que acudía el ladrón que había llevado la hazienda del que tomó la purga, y cobraba su haziéda[sic]: era embuste de hechiceros" (B: (2): 386). En quechua, "Un arbol que su fruta como chochos es purga" (GH (I): 352) e "Ydolo" (R: 87). Las semillas de esta planta aún son usadas como remedio por las señoras en la cuenca de río Salado.

Yaretilla [yare'tiye], 22, Q, A, E. Del quechua yarita, variante de yareta (Li: 1184). Derivado de llareta. Yarita y otros yareta, quechua, vegetal punero, que es una hierba forrajera de primera clase para el ganado alpacunero. Se emplea como un excelente combustible en la cocina arequipeña. Es barbarismo decir Llareta. (Li: 1184). Yareta, yaretilla, voces americanas de procedencia discutida (M: 98). Yarita, aymara, "resina de la puna" (B: 412,2). Llareta: $n$. vulg. varias Umbelíferas de la cordillera en cojines (L: 447). Llareta: Barba 160, (citado por Lenz), llama llareta al estiércol de carneros de la tierra (llamas) que se usa para combustible. Boman $(408, I b i d$.) señala que la yareta es un excelente combustible, el único que se usa en la puna de Atacama, lo que puede explicar la definición anterior. (L: 880). Llareta, "planta de Chile de la familia de las Umbelíferas, de hojas sencillas, enteras y oblongas: destila de su tallo una resina transparente de olor agradable, que se usa como estimulante estomacal, y también para curar heridas" (DRAE: 1280).

Yerba buena ['yerßa 'ßwena], 77, E. De "hierba" y "buena". Planta herbácea de la familia de las Labiadas, se cultiva mucho en las huertas y se la utiliza como condimento. El mismo nombre se da a otras plantas Labiadas parecidas a la anterior como el mastrazo, el sándalo y el poleo (DRAE: 1105).

Yuyo ['yuyo], 25, 26, 27, Q, A, K. Yuyu, quechua y aymara, hojas y tallo verdes y tiernos del nabo (C.169), (B: 208). Yuyo, kunza, "variedad de quinoa, llamada tambien sacksaholor" (V: 29); "dícese también de otra planta comestible parecida al bledo español" (V: 36). Llullu, quechua, "tierno, tubérculo no maduro" (Ba: 113). Yuyu, quechua, "bledo, hojas tiernas, comestibles, de la quínoa" (Ba: 121). Yuyo, quechua, denominación dada a Brassica rapa L., maleza comestible (M: 80). Yuyo. Del latín "lolium", cizaña. En Argentina, Chile y Uruguay, “yerbajo, hierba inútil”. En Chile nombre de la planta jaramago. En Perú "hierbas tiernas comestibles (DRAE: 2118). 
Yuyo arka compañera ['yuyo 'arke kompa'nere], 10, Q, A, K. Arca, aymara, "la obra de servir al tambo" (B: 24,2); compañero del yuyo.

Yuyo caña colorada, 27, Q, A, K, E.
Yuyo wacho ['yuyo 'wačo], 27, A- K-Q, Q. Wachu, quechua, "surco, terreno abierto por el arado" y "canal, hendidura" (Ba: 100).

Zapatilla [sapa'tiye], 116, E. Alusión a la forma de la corola. Derivada de "zapata". "Zapato ligero y de suela muy delgada" (DRAE: 2124). 
ANEXO 3

NOMBRES VERNACULARES REGISTRADOS EN ATACAMA ORDENADOS ALFABETICAMENTE E INDICANDO IDIOMAS Y NUMEROS CORRESPONDIENTES A LA ESPECIE EN EL ANEXO 1. (A=AYMARA; E=ESPAÑOL; K, KUNZA; M=MAPUCHE; Q= QUECHUA; AR= ARAWAK; ?= DESCONOCIDO).

\begin{tabular}{|c|c|c|c|}
\hline 1 & ¿acacio? & $E$ & 89 \\
\hline 2 & ¿acerillo? & $E$ & 98 \\
\hline 3 & ¿ajenko? & E & 77 \\
\hline 4 & alfa & $E$ & 103 \\
\hline 5 & alfalfa & $E$ & 103 \\
\hline 6 & alfilla & $E$ & 104 \\
\hline 7 & algarrobilla & $E$ & 19 \\
\hline 8 & algarrobillo & $E$ & 89,19 \\
\hline 9 & algarrobo & $E$ & 90 \\
\hline 10 & altea & $E$ & 86,135 \\
\hline 11 & amapola & $E$ & 85 \\
\hline 12 & amor seco & $E$ & 39 \\
\hline 13 & anís & $E$ & 131 \\
\hline 14 & añawa & $\mathrm{A}$ & 94,97 \\
\hline 15 & añawa blanca & $\mathrm{A}, \mathrm{E}$ & 94,95 \\
\hline 16 & añawa grande & $\mathrm{A}, \mathrm{E}$ & 97 \\
\hline 17 & añawa negra & $\mathrm{A}, \mathrm{E}$ & 94,97 \\
\hline 18 & apio & $E$ & 130 \\
\hline 19 & arcilla & E & 69 \\
\hline 20 & arka & Q, ¿A? & 10,28 \\
\hline 21 & aromo & $E$ & 89 \\
\hline 22 & atalte & ¿A? & 93 \\
\hline 23 & azafrán & $E$ & 41,42 \\
\hline 24 & bailahuén & $\mathrm{M}$ & 45 \\
\hline 25 & bailavín & $\mathrm{M}$ & 45 \\
\hline 26 & bailawela & $\mathrm{M}$ & 45 \\
\hline 27 & bailawena & $\mathrm{M}$ & 45 \\
\hline 28 & bálsamo & $E$ & 9 \\
\hline 29 & bálsamo finito & $E$ & 125 \\
\hline 30 & banderilla & $E$ & 159 \\
\hline 31 & barba de chivato & $E$ & 161 \\
\hline 32 & barba de chivo & $E$ & 161 \\
\hline 33 & básal & ¿K? & 109,11 \\
\hline 34 & bávaro & $E$ & 2 \\
\hline 35 & berrillo & $E$ & 112 \\
\hline 36 & berro & E & 117 \\
\hline 37 & berro picante & $E$ & 112 \\
\hline 38 & bilankichu & Q & 19 \\
\hline 39 & borraja & $\mathrm{E}$ & 60 \\
\hline 40 & ¿borraja? & $E$ & 48 \\
\hline 41 & botón & $E$ & 20 \\
\hline 42 & brea & $E$ & 52 \\
\hline 43 & breya & $\mathrm{E}$ & 52 \\
\hline
\end{tabular}

\begin{tabular}{|c|c|c|c|}
\hline 44 & cabello & $E$ & 72 \\
\hline 45 & cabeza de gato & $\mathrm{E}$ & 141 \\
\hline 46 & cabra míkun & $\mathrm{E}, \mathrm{Q}$ & 129 \\
\hline 47 & cabra mikuna & E,Q & 129 \\
\hline 48 & cacho de cabra & $E$ & 98 \\
\hline 49 & cadillo & $E$ & 76,113 \\
\hline 50 & caña & $E$ & 164 \\
\hline 51 & cañaveral & $E$ & 164 \\
\hline 52 & carda & $E$ & 120 \\
\hline 53 & cardador & $E$ & 120 \\
\hline 54 & cardadora & $E$ & 120 \\
\hline 55 & cardo & $E$ & 120 \\
\hline 56 & cardón & $E$ & 16 \\
\hline 57 & cardón chico & $E$ & 18 \\
\hline 58 & cardón grande & $E$ & 16 \\
\hline 59 & cardoncillo & $\mathrm{E}$ & 136 \\
\hline 60 & cascabel & $\mathrm{E}$ & 79 \\
\hline 61 & caudal & ¿E? & 9 \\
\hline 62 & cebadilla & $E$ & $\begin{array}{l}149,153 \\
161,169\end{array}$ \\
\hline 63 & cebadillo & $\mathrm{E}$ & 111 \\
\hline 64 & cedrón & $\mathrm{E}$ & 118 \\
\hline 65 & cepa de caballo & $\mathrm{E}$ & 65 \\
\hline 66 & cepacaballo & $\mathrm{E}$ & 65 \\
\hline 67 & cerda de chancho & $\mathrm{E}$ & 72 \\
\hline 68 & cerraja & $\mathrm{E}$ & 48,60 \\
\hline 69 & cesped & $\mathrm{E}$ & $\begin{array}{c}142,155 \\
168\end{array}$ \\
\hline 70 & chacha & $\mathrm{A}$ & 49,50 \\
\hline 71 & chacha chica & $\mathrm{A}, \mathrm{E}$ & 49 \\
\hline 72 & chacha fina & $\mathrm{A}, \mathrm{E}$ & 49 \\
\hline 73 & chacha hembra & $\mathrm{A}, \mathrm{E}$ & 49 \\
\hline 74 & chacha macho & $\mathrm{A}, \mathrm{E}$ & 50 \\
\hline 75 & chacha pelada & $\mathrm{A}, \mathrm{E}$ & 50 \\
\hline 76 & chacha pulika & $\mathrm{A},{ }_{\mathrm{A}} \mathrm{A} / \mathrm{Q}$ ? & 50 \\
\hline 77 & chachakoa & $\mathrm{A}$ & 49 \\
\hline 78 & chachakoma & Q,A & 50,57 \\
\hline 79 & chachakoma de la vicuña & Q,A & 57 \\
\hline 80 & chachakoma macho & $\mathrm{Q}, \mathrm{A}, \mathrm{E}$ & 57 \\
\hline 81 & chacrilla del campo & $\mathrm{Q}, \mathrm{E}$ & 161 \\
\hline 82 & chajchajra & Q & 45 \\
\hline 83 & chajchara & Q & 45 \\
\hline 84 & chakachaka & $\mathrm{A}$ & 76 \\
\hline
\end{tabular}




\begin{tabular}{|c|c|c|c|}
\hline 85 & cháme & ¿K? & 138 \\
\hline 86 & chámen & ¿K? & 138 \\
\hline 87 & champa & Q,A & $\begin{array}{c}6,132 \\
145\end{array}$ \\
\hline 88 & champita & Q,A & 21,29 \\
\hline 89 & chañar & Q, K & 100 \\
\hline 90 & chape & A & 27 \\
\hline 91 & chávil & ¿K? & 138 \\
\hline 92 & chejchara & Q & 45 \\
\hline 93 & chijlla & $\mathrm{A}$, ¿Q?? & 33 \\
\hline 94 & chijua & $\mathrm{A}$, ¿Q?? & 33 \\
\hline 95 & chijuachijua & $A, i Q ?$ & 33 \\
\hline 96 & chillawa & Q,A & 158 \\
\hline 97 & chillka & $\mathrm{Q}, \mathrm{A}$ & 36 \\
\hline 98 & chipichapi & A & 76 \\
\hline 99 & chochar & $\mathrm{K}, i \mathrm{Q}$ ? & 71 \\
\hline 100 & chókel & $\mathrm{K}$ ? & 24,25 \\
\hline 101 & chókil & $\mathrm{K}$ ? & 24,25 \\
\hline 102 & chuchar & $\mathrm{K}$, ¿Q? & 71 \\
\hline 103 & chuchikan & Q, ¿A? & 133 \\
\hline 104 & chujchu & $\mathrm{A}, i \mathrm{Q} ?$ & 102 \\
\hline 105 & chúkchar & $\mathrm{K}$ ? & 152 \\
\hline 106 & chukchuka & ¿A/,Q? & 34 \\
\hline 107 & chukikan & ¿Q,A? & 133 \\
\hline 108 & chukllara & ¿Q/A? & 169 \\
\hline 109 & chuku & $\mathrm{A}$, ¿Q?? & 162 \\
\hline 110 & chukula & $\mathrm{K}$ & 3 \\
\hline 111 & chullapasa & ¿A/Q? & 12 \\
\hline 112 & cola de caballo & $\mathrm{E}$ & 65 \\
\hline 113 & cola de lagarto? & $\mathrm{E}$ & 30 \\
\hline 114 & cola de zorro & $\bar{E}$ & $\begin{array}{l}148,149, \\
153,161\end{array}$ \\
\hline 115 & comida de perdiz & $\mathrm{E}$ & 40 \\
\hline 116 & comida de vizcacha? & $\mathrm{E}, \mathrm{Q}$ & 64 \\
\hline 117 & comida del suri & E,A & 20 \\
\hline 118 & correhuela & $\mathrm{E}$ & 68 \\
\hline 119 & cortadera & $\mathrm{E}$ & 148 \\
\hline 120 & cuernillo & $\mathrm{E}$ & 98,139 \\
\hline 121 & cuerno & $\mathrm{E}$ & 98 \\
\hline 122 & cuerno de cabra & $\mathrm{E}$ & 98 \\
\hline 123 & cuerno de lagarto & $\mathrm{E}$ & 139 \\
\hline 124 & cuero de sapo & $\mathrm{E}$ & 6 \\
\hline 125 & dedos de ángel & $\mathrm{E}$ & 9 \\
\hline 126 & duraznillo & $\mathrm{E}$ & 55 \\
\hline 127 & enredadera & $\mathrm{E}$ & $\begin{array}{l}68,72 \\
92,74\end{array}$ \\
\hline 128 & espárrago & $\mathrm{E}$ & 172 \\
\hline 129 & espina blanca & $\mathrm{E}$ & 95 \\
\hline 130 & espina negra & $\mathrm{E}$ & 97 \\
\hline 131 & esporal & ¿E? & 163 \\
\hline 132 & espural & ¿E? & 155,163 \\
\hline
\end{tabular}

\begin{tabular}{|c|c|c|c|}
\hline 133 & espuro & ¿E? & 163 \\
\hline 134 & flor amarilla & $\mathrm{E}$ & 43,63 \\
\hline 135 & flor blanco & $E$ & 23 \\
\hline 136 & flor de la champa & $\mathrm{E}, \mathrm{Q}$ & 171 \\
\hline 137 & flor de peña & $\mathrm{E}$ & 5 \\
\hline 138 & flor del agua & E & 6 \\
\hline 139 & flor del laqo & $\mathrm{E}, \mathrm{Q} / \mathrm{A} / \mathrm{K}$ & 3 \\
\hline 140 & flor morada & $E$ & 129 \\
\hline 141 & forraje de vizcacha & E,Q & 159 \\
\hline 142 & garbancillo & E & 99 \\
\hline 143 & garbanzo & E & 99 \\
\hline 144 & garbanzo del campo & E & 102 \\
\hline 145 & gato & $E$ & 141 \\
\hline 146 & grama & E & $\begin{array}{c}145,150 \\
152,153, \\
54,60,169\end{array}$ \\
\hline 147 & grama chica & $\mathrm{E}$ & 150 \\
\hline 148 & grama fina & $\mathrm{E}$ & 160 \\
\hline 149 & gramilla & $\mathrm{E}$ & 150,154 \\
\hline 150 & gramillo & E & $\begin{array}{c}150,154 \\
160\end{array}$ \\
\hline 151 & helecho & $\mathrm{E}$ & 7 \\
\hline 152 & hierba del tapón & $E$ & 69 \\
\hline 153 & hierba sal & E & 109,110 \\
\hline 154 & higuerilla & E & 120 \\
\hline 155 & hinojo & $E$ & 131 \\
\hline 156 & hoja de té & $E$ & 38 \\
\hline 157 & iloka & ¿Q/A? & 93 \\
\hline 158 & iloka hembra & ¿Q/A?, E & 96 \\
\hline 159 & iloka macho & ¿Q/A?,E & 93 \\
\hline 160 & iluka hembra & ¿Q/A?, E & 96 \\
\hline 161 & iluka macho & ¿Q/A?, E & 93 \\
\hline 162 & ilúkar & ¿Q/A? & 93 \\
\hline 163 & ipallapa & A & 14 \\
\hline 164 & iro & Q,A & $\begin{array}{c}157,158, \\
159\end{array}$ \\
\hline 165 & iru & Q,A & 157,159 \\
\hline 166 & jaboncillo & E & 142,143 \\
\hline 167 & junquillo redondo & $E$ & 170 \\
\hline 168 & junquillo? & E & 167 \\
\hline 169 & kachiyuyo & Q & 25 \\
\hline 170 & kachuyo & Q & 25 \\
\hline 171 & kachuyo macho & Q,E & 25 \\
\hline 172 & kafle & ¿K? & $\begin{array}{c}147,149 \\
155,156 \\
165\end{array}$ \\
\hline 173 & kafle delgado & ¿K?,E & 169 \\
\hline 174 & kallya & Q & 94 \\
\hline 175 & kámen & ¿K? & 110 \\
\hline 176 & kámin & ¿K? & 109,110 \\
\hline 177 & kañiwa (se parece) & Q,A & 26 \\
\hline
\end{tabular}




\begin{tabular}{|c|c|c|c|}
\hline 178 & káuchal & $\bar{K}$ & 15 \\
\hline 179 & keúche & $\mathrm{K}$ & 111 \\
\hline 180 & killokisca & Q & 41 \\
\hline 181 & koa & $A, i Q ?$ & 49 \\
\hline 182 & kokakora & Q,A & 62 \\
\hline 183 & konte & ¿K? & 101 \\
\hline 184 & konte chico & ¿K?,E & 102 \\
\hline 185 & konte chujchento & ¿K?,Q/A,E & 102 \\
\hline 186 & konti & ¿K? & 101 \\
\hline 187 & kontikonti & ¿K? & 101,102 \\
\hline 188 & kopa & $\mathrm{Q}, \mathrm{A}, \mathrm{K}$ & 32 \\
\hline 189 & kopakopa & Q,A, K & 32 \\
\hline 190 & kopakopa macho & Q,A, K, E & 24 \\
\hline 191 & kora? & $\mathrm{Q}, \mathrm{A}$ & 86 \\
\hline 192 & kore & $Q, i K ?$ & 134 \\
\hline 193 & kori & $Q, i K ?$ & 134 \\
\hline 194 & kórial & $Q, i K ?$ & 25 \\
\hline 195 & kotakota & $\mathrm{A}$ & 135 \\
\hline 196 & kótar & ¿K? & 62 \\
\hline 197 & kotára & ¿K? & 62 \\
\hline 198 & kotáro & ¿K? & 62 \\
\hline 199 & kótaro & ¿K? & 62 \\
\hline 200 & kulchao & ¿K? & 19 \\
\hline 201 & kulchau & ¿K? & 19 \\
\hline 202 & kume & ¿K? & 17 \\
\hline 203 & lama & $E$ & $2,3,4$ \\
\hline 204 & lampaya & Q,A & 137 \\
\hline 205 & laqo & Q,A,K & 2,4 \\
\hline 206 & lava & $E$ & 2 \\
\hline 207 & lava del agua & E & 2 \\
\hline 208 & leche & $\mathrm{E}$ & 73 \\
\hline 209 & lecheleche & $E$ & 73 \\
\hline 210 & lecherito del campo & E & 73 \\
\hline 211 & lechuga & E & 48 \\
\hline 212 & lejía & E & 37 \\
\hline 213 & léjia & E & 37 \\
\hline 214 & lengua de gallina & $\mathrm{E}$ & 41 \\
\hline 215 & leña de tola & $\mathrm{E}, \mathrm{Q} / \mathrm{A}$ & 57 \\
\hline 216 & likia & E & 37 \\
\hline 217 & linaza & E & 79 \\
\hline 218 & llantel & E & 105,106 \\
\hline 219 & llantén & $E$ & 105,106 \\
\hline 220 & llantil & $E$ & 106 \\
\hline 221 & lokoche & K & 47 \\
\hline 222 & loroma & ¿A? & $1,4,173$ \\
\hline 223 & malva & E & $\begin{array}{l}82,83 \\
85,88\end{array}$ \\
\hline 224 & malva blanca & $\mathrm{E}$ & 87 \\
\hline 225 & malva del campo & $E$ & 83,87 \\
\hline 226 & malva parada & $\mathrm{E}$ & 81,87 \\
\hline 227 & malva rosa & $E$ & 84,85 \\
\hline
\end{tabular}

\begin{tabular}{|c|c|c|c|}
\hline 228 & malva rosada & $\mathrm{E}$ & 83 \\
\hline 229 & malvilla & $\mathrm{E}$ & 87 \\
\hline 230 & malvisco (malvavisco) & E & 82 \\
\hline 231 & maransel & $Q$ & 51,64 \\
\hline 232 & maransel hembra & Q,E & 51 \\
\hline 233 & maransel macho & Q,E & 51,64 \\
\hline 234 & maravilla & $E$ & 48,63 \\
\hline 235 & margarita & $E$ & 68 \\
\hline 236 & menta koka & $\mathrm{E}, \mathrm{Q} / \mathrm{A}$ & 67 \\
\hline 237 & michi & $\mathrm{Q}, \mathrm{A}, \mathrm{K}$ & 141 \\
\hline 238 & mirasol & $E$ & 63 \\
\hline 239 & mirasol chico & $E$ & 63 \\
\hline 240 & mokoraka & $\mathrm{Q}, \mathrm{A}$ & 54 \\
\hline 241 & molle & Q & 11 \\
\hline 242 & monte blanco & $\mathrm{E}$ & 55 \\
\hline 243 & monte colorado & $E$ & 43,76 \\
\hline 244 & monte derecho & $E$ & 124 \\
\hline 245 & monte morado & $E$ & 76 \\
\hline 246 & monte negro & $\mathrm{E}$ & $\begin{array}{c}31,76 \\
124\end{array}$ \\
\hline 247 & monte picante & $\mathrm{E}$ & 112 \\
\hline 248 & monte soldao & $\mathrm{E}$ & 124 \\
\hline 249 & monte verde & $E$ & 31 \\
\hline 250 & muelle & Q & 11 \\
\hline 251 & mukuraka & Q,A & 54 \\
\hline 252 & mukurakan & Q,A & 54 \\
\hline 253 & mutucuru & Q,A & 19 \\
\hline 254 & nevadilla & $\mathrm{E}$ & 70 \\
\hline 255 & nevadita & $\mathrm{E}$ & 70 \\
\hline 256 & niebla & $\mathrm{M}$ & 60 \\
\hline 257 & nieve & E & 70 \\
\hline 258 & nori & ¿K?, ¿A? & 132,173 \\
\hline 259 & noris & ¿K?, ¿A? & 132 \\
\hline 260 & ñible & $\mathrm{M}$ & 60 \\
\hline 261 & ñiebla & $\mathrm{M}$ & 60 \\
\hline 262 & ñilhue & M & 60 \\
\hline 263 & ñiuble & M & 60 \\
\hline 264 & ojalar & ¿K?, ¿E? & 24 \\
\hline 265 & ojman & ¿K? & 80 \\
\hline 266 & oreja & $E$ & 121 \\
\hline 267 & oreja de chojchor & $\mathrm{E}, i \mathrm{~K}$ ? & 121 \\
\hline 268 & oreja de ratón & E & 62,121 \\
\hline 269 & ortega & E & 80 \\
\hline 270 & ortiga & E & 80 \\
\hline 271 & osman & ¿K? & 80 \\
\hline 272 & paiko & Q & 28 \\
\hline 273 & paja & E & $\begin{array}{l}151,157, \\
158,162, \\
166,167\end{array}$ \\
\hline 274 & paja brava & $E$ & $\begin{array}{c}151,157, \\
166\end{array}$ \\
\hline
\end{tabular}




\begin{tabular}{|c|c|c|c|}
\hline 275 & paja banderilla & $\bar{E}$ & 167 \\
\hline 276 & paja blanda & $\mathrm{E}$ & 151,166 \\
\hline 277 & paja chica & $\mathrm{E}$ & 151,166 \\
\hline 278 & paja crespa & $\mathrm{E}$ & 159 \\
\hline 279 & paja del viento & $\mathrm{E}$ & 166 \\
\hline 280 & paja delgada & $\mathrm{E}$ & 151 \\
\hline 281 & paja sikuya & $\mathrm{E}, \mathrm{A}, \mathrm{Q}$ & 151,158 \\
\hline 282 & paja sukuya & E,A,Q & 152 \\
\hline 283 & paja waya & E,A,Q & 158 \\
\hline 284 & pajita & $E$ & $\begin{array}{c}152,158, \\
167\end{array}$ \\
\hline 285 & pajita chica & $\mathrm{E}$ & 162 \\
\hline 286 & palke & M & 119 \\
\hline 287 & palki & $\mathrm{M}$ & 119 \\
\hline 288 & palo colorado & E & 76 \\
\hline 289 & papa cháme & $Q$, ¿K? & 138 \\
\hline 290 & pápur pasto & $\mathrm{K}, \mathrm{E}$ & 13,14 \\
\hline 291 & parecido a la cortadera & E & 143 \\
\hline 292 & pasakana & ¿Q?, ¿A? & 16 \\
\hline 293 & pastito & $E$ & 4,169 \\
\hline 294 & pastito blando & E & $\begin{array}{l}143,147, \\
149,165\end{array}$ \\
\hline 295 & pastito blando del agua & $E$ & 156 \\
\hline 296 & pastito del agua & $E$ & $\begin{array}{c}112,132 \\
173\end{array}$ \\
\hline 297 & pastito del campo & $\mathrm{E}$ & 141 \\
\hline 298 & pasto & $\mathrm{E}$ & 43,105 \\
\hline 299 & pasto blando & $E$ & $\begin{array}{l}147,155, \\
156,165\end{array}$ \\
\hline 300 & pasto colorado & $E$ & 109 \\
\hline 301 & pasto de vicuña & E,Q & 20 \\
\hline 302 & pasto duro & E & 169 \\
\hline 303 & pasto leche & $E$ & 73 \\
\hline 304 & pasto lechero & E & 73 \\
\hline 305 & pasto loco & E & 34 \\
\hline 306 & pata de perdiz & $E$ & 122 \\
\hline 307 & pegapega & E & 76 \\
\hline 308 & peludilla & E & 72,153 \\
\hline 309 & perdilla & E & 136 \\
\hline 310 & perlilla & $\mathrm{E}$ & 136 \\
\hline 311 & pimiento & E & 11 \\
\hline 312 & pimiento llorón & E & 115 \\
\hline 313 & ping0 & Q,A & 8 \\
\hline 314 & pingopingo & Q,A & 8 \\
\hline 315 & pingopingo macho & Q,A,E & 8 \\
\hline 316 & primavera & E & 81,87 \\
\hline 317 & pupusa & Q & 66 \\
\hline 318 & pupusa del agua & Q,E & 66 \\
\hline 319 & pupusa del campo & Q,E & 66,135 \\
\hline 320 & puskayo & Q,A & 17 \\
\hline 321 & q'ela & $\mathrm{A}$, ¿K? & 102 \\
\hline
\end{tabular}

\begin{tabular}{|c|c|c|c|}
\hline 322 & quebrolla & $\bar{E}$ & 41,81 \\
\hline 323 & quisco & Q & 17 \\
\hline 324 & rayito de sol & E & 68 \\
\hline 325 & rezongón & $\mathrm{E}$ & 41 \\
\hline 326 & rikarika & ¿Q?, ¿E? & 134 \\
\hline 327 & romaza & $\mathrm{E}$ & $\begin{array}{c}10,47, \\
105,106, \\
108\end{array}$ \\
\hline 328 & romerillo & E & 56,59 \\
\hline 329 & romerillo blanco & $E$ & 59 \\
\hline 330 & romerillo chico & $\mathrm{E}$ & 58 \\
\hline 331 & romero & $\mathrm{E}$ & 78 \\
\hline 332 & romero de Castilla & $\mathrm{E}$ & 78 \\
\hline 333 & roseta & E & 136 \\
\hline 334 & ruda & $\mathrm{E}$ & 114 \\
\hline 335 & sáila0 & ¿K? & 29,155 \\
\hline 336 & sangría & $\mathrm{E}$ & 107 \\
\hline 337 & sangrinaria & $E$ & 107 \\
\hline 338 & sauce & $\mathrm{E}$ & 115 \\
\hline 339 & séber & $\mathrm{K}$ & 71 \\
\hline 340 & sébir & $\mathrm{K}$ & 71 \\
\hline 341 & sicha & Q & 12 \\
\hline 342 & simbol & ¿E? & 163 \\
\hline 343 & sítor & $\mathrm{K}$ & 113 \\
\hline 344 & sítur & K & 113 \\
\hline 345 & sobaco negro & $\mathrm{E}$ & 75 \\
\hline 346 & sobaquilla & $\mathrm{E}$ & 14 \\
\hline 347 & sobaquillo & $\mathrm{E}$ & 14,75 \\
\hline 348 & soiko & $\mathrm{A}, i \mathrm{Q} ?$ & 61 \\
\hline 349 & soiko de cabra & $\mathrm{A}$, ¿Q?,E & 53 \\
\hline 350 & suiko & $A, i Q ?$ & 61 \\
\hline 351 & suiko blanco & $\mathrm{A}$, ¿QQ?,E & 61 \\
\hline 352 & suiko de cabra & $\mathrm{A}$, ¿Q?, E & 53 \\
\hline 353 & suncho & Q & 34,35 \\
\hline 354 & tabaco del burro & $\mathrm{E}$ & 127 \\
\hline 355 & tablilla & $\mathrm{E}$ & 123 \\
\hline 356 & tajtará & ¿Q?, ¿A? & 41 \\
\hline 357 & tamarugo & $?$ & 91 \\
\hline 358 & tara & Q & 124 \\
\hline 359 & tara hembra & Q,E & 123 \\
\hline 360 & tara macho & Q,E & 124 \\
\hline 361 & tastará & ¿Q?, ¿A? & 41 \\
\hline 362 & té & $\mathrm{E}$ & 38 \\
\hline 363 & té colorado & $\mathrm{E}$ & 76 \\
\hline 364 & té de burro & $\mathrm{E}$ & 38 \\
\hline 365 & té silvestre & E & 38 \\
\hline 366 & té verde & E & 38 \\
\hline 367 & tieuchi & ¿K? & 40 \\
\hline 368 & tikara & ¿K?, ¿Q? & 31,76 \\
\hline 369 & tíkara & ¿K?, ¿Q? & 76 \\
\hline
\end{tabular}




\begin{tabular}{|c|c|c|c|}
\hline 370 & tikara hembra & $i \mathrm{~K}$ ?, $i \mathrm{Q} ?, \mathrm{E}$ & 76 \\
\hline 371 & tikara macho & ${ }_{\mathrm{iK}} \mathrm{i}, \mathrm{i} \mathrm{Q}, \mathrm{E}$ & 31 \\
\hline 372 & tikara negra & ${ }_{\mathrm{i}} \mathrm{K}, \mathrm{i} \mathrm{Q}, \mathrm{E}$ & 76 \\
\hline 373 & tola & $\mathrm{Q}, \mathrm{A}$ & 37,49, \\
& & & $\begin{array}{c}124,136, \\
46\end{array}$ \\
\hline 374 & tola chica & $\mathrm{Q}, \mathrm{A}, \mathrm{E}$ & 33 \\
\hline 375 & tola negra & $\mathrm{Q}, \mathrm{A}, \mathrm{E}$ & 31 \\
\hline 376 & tolilla & $\mathrm{Q}, \mathrm{A}, \mathrm{E}$ & 33,123 \\
\hline 377 & tolita & $\mathrm{Q}, \mathrm{A}, \mathrm{E}$ & 33 \\
\hline 378 & tolontolon & $?$ & 126 \\
\hline 379 & tomatillo & $\mathrm{E}$ & 126,128 \\
\hline 380 & toronjil & $\mathrm{E}$ & 77 \\
\hline 381 & toronjil cuyano & $\mathrm{E}$ & 77 \\
\hline 382 & toronjil de la pena & $\mathrm{E}$ & 118 \\
\hline 383 & toronjil dulce & $\mathrm{E}$ & 28,118 \\
\hline 384 & totora & $\mathrm{Q}, \mathrm{A}$ & 34,144 \\
\hline 385 & treból & $\mathrm{E}$ & 104 \\
\hline 386 & trébol & $\mathrm{E}$ & 104 \\
\hline 387 & tríbol & $\mathrm{E}$ & 104 \\
\hline 388 & trigol & $\mathrm{E}$ & 104 \\
\hline 389 & tuna & $\mathrm{AR}$ & 17 \\
\hline 390 & unquillar & $\mathrm{E}$ & 142,143, \\
\hline 391 & unquillar redondo & $\mathrm{E}$ & 170 \\
\hline 392 & unquillare & $\mathrm{E}$ & 170 \\
\hline
\end{tabular}

\begin{tabular}{|c|c|c|c|}
\hline 393 & unquillo & $\bar{E}$ & $\begin{array}{l}142,143, \\
146,170\end{array}$ \\
\hline 394 & unquillo cuadrado & E & 146 \\
\hline 395 & unquillo duro & E & 170 \\
\hline 396 & varilla & E & 94 \\
\hline 397 & vega & $\mathrm{E}$ & $\begin{array}{l}21,132 \\
145,171\end{array}$ \\
\hline 398 & veguita & $E$ & 132 \\
\hline 399 & verbena & $\mathrm{E}$ & 140 \\
\hline 400 & verdulaga & $\mathrm{E}$ & 73 \\
\hline 401 & viravira & Q & 44 \\
\hline 402 & wailawen & $\mathrm{M}$ & 45 \\
\hline 403 & wailawin & $\bar{M}$ & 45 \\
\hline 404 & wajilla & ¿A?, ¿Q?, E & 20 \\
\hline 405 & walkawalka & 0 & 30 \\
\hline 406 & waya & $0, \mathrm{~A}$ & 158,157 \\
\hline 407 & waycha & $\mathrm{A}$ & 30,125 \\
\hline 408 & waylla & Q.A & 158 \\
\hline 409 & wilca & $0, i A ?$ & 89 \\
\hline 410 & varetilla & Q,A.E & 22 \\
\hline 411 & yerba buena & $\mathrm{E}$ & 77 \\
\hline 412 & yuyo & Q,A, K & $25,26,27$ \\
\hline 413 & yuyo arka (compañera) & Q,A,K & 10 \\
\hline 414 & yuyo caña colorada & Q,A, K,E & 27 \\
\hline 415 & yuyo wacho & Q & 27 \\
\hline 416 & zapatilla & $\mathrm{E}$ & 116 \\
\hline
\end{tabular}

